\title{
AUSTRALIAN INDIGENOUS KNOWLEDGE AND LIBRARIES
}

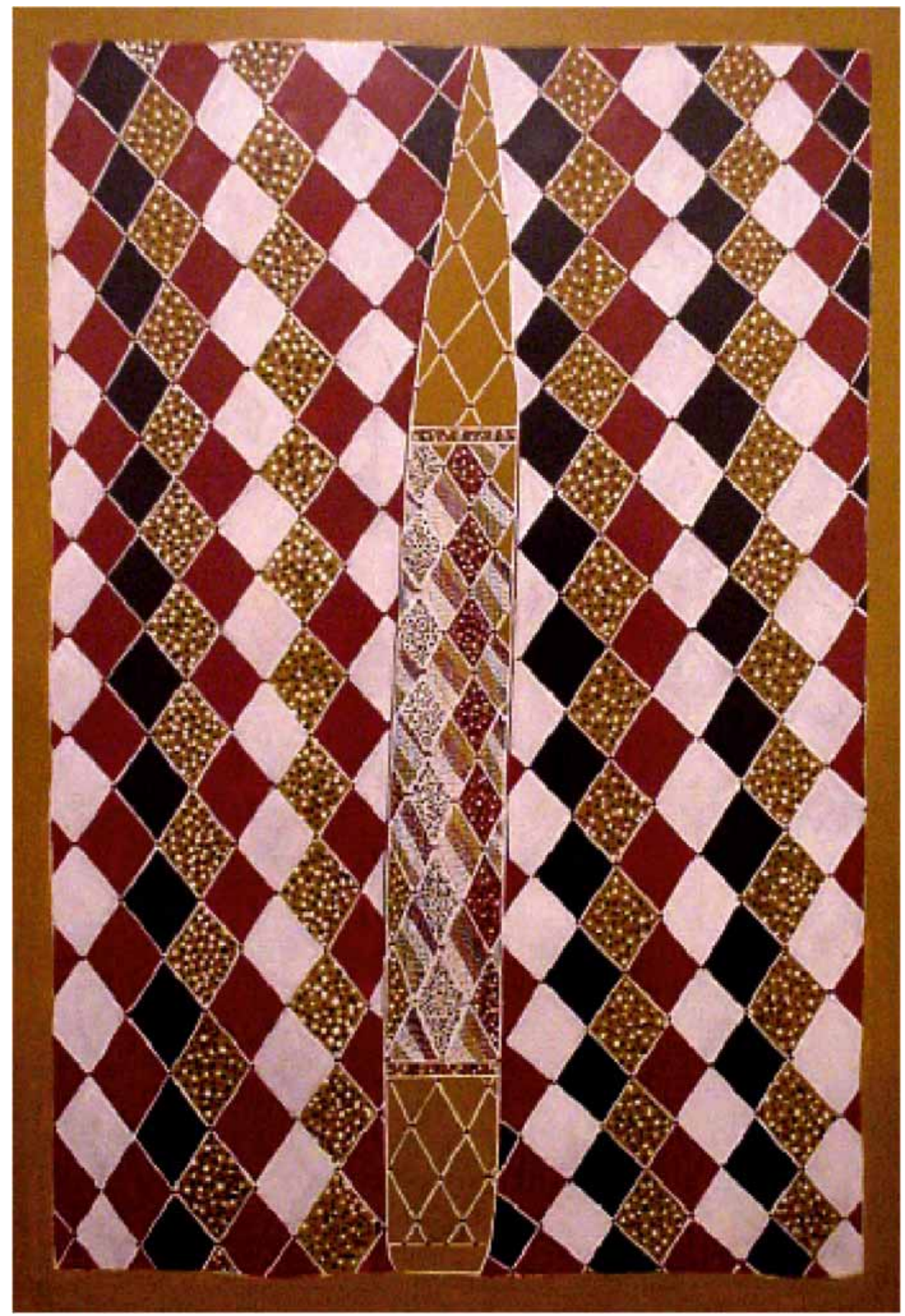




\section{Dedication}

This work is dedicated to Loris Williams who passed away in August 2005 after a short illness. Loris Williams was an inspiration to many archivists and information professionals in Australia. She was strongly connected to the Queensland Aboriginal communities through her father to the Mulinjali people and through her mother to the Birra Gubba people. She was the first qualified Indigenous archivist in Queensland. Through her work in the State Library of Queensland and subsequently in the Community and Personal Histories section of the Queensland Government, Loris saw her role as helping people access government records in order to find their identity and connection to family and land.

Loris worked actively to encourage archivists to make these records more accessible to Indigenous people as a matter of priority, and she saw education of Indigenous people to become archivists as a pathway to the empowerment of her people. Loris was the Convenor of the Australian Society of Archivists Indigenous Issues Special Interest Group. 


\section{AUSTRALIAN INDIGENOUS KNOWLEDGE AND LIBRARIES}

Edited By Martin Nakata and Marcia Langton

Front cover design by Joe Gumbula

UTSePress, Sydney

UNIVERSITY OF

TECHNOLOGY SYDNEY 


\section{Publisher's Note}

A version of this work was originally published in 2005 as a hard copy volume as Australian and Academic Research Libraries vol 36 no 2 June 2005. All chapters were revised or rewritten for this publication and fully refereed, in accordance with Australian Academic and Research Libraries' editorial policy. This publication had as its origin the joint Jumbunna Indigenous House of Learning (University of Technology, Sydney) and State Library of New South Wales colloquium, Libraries and Indigenous Knowledge: A National Forum for Libraries, Archives and Information Services held at the State Library of New South Wales 9-10 December 2004.

\section{Licence Information}

This work is licensed under the Creative Commons 'By Attribution', 'Non Commercial', 'No Derivative Works'. See http://creativecommons.org.au/licences for more details.

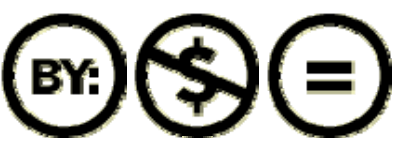

\section{Copyright Information}

This work is copyright. Apart from fair dealing for the purposes of research or study, reproduction in any form by any means for public or commercial use is prohibited without the written permission of the copyright owner. Contributors retain copyright ownership of their individual works and assert their moral right to be identified as authors.

\section{(C) ATSILIRN}

First Published in 2005

Cover design (C) Joe Gumbula

\section{National Library of Australia Cataloguing-in-Publication entry}

Australian Indigenous knowledge and libraries.

ISBN 9780980284010 (web).

1. Libraries and Aboriginal Australians.

2. Libraries and Torres Strait Islanders.

3. Aboriginal Australians - Archives.

4. Torres Strait Islanders - Archives.

5. Aboriginal Australians - Genealogy.

6. Torres Strait Islanders - Genealogy.

I. Nakata, Martin N.

II. Langton, Marcia, 1951- .

III. Title.

IV. Title : Australian academic and research libraries (Online). (Series : Australian academic and research libraries, 0004-8623 ; v.36, no. 2).

\subsection{5}

Published by UTSePress, Sydney 2006

University Library

University of Technology, Sydney

PO Box 123

BROADWAY NSW 2007

AUSTRALIA 


\section{Contents}

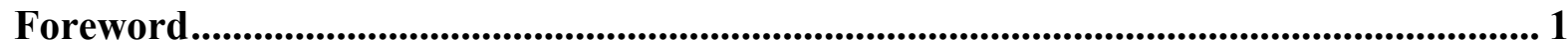

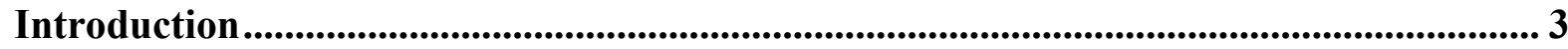

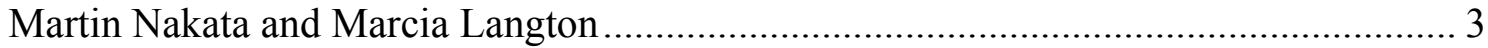

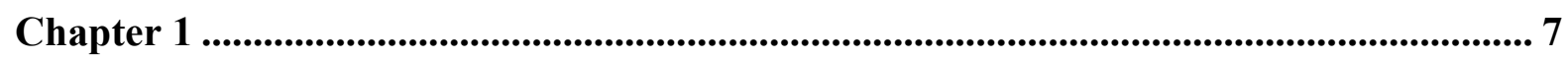

Indigenous Knowledge, the Library and Information Service Sector, and Protocols.. 7

Martin Nakata, Alex Byrne, Vicky Nakata and Gabrielle Gardiner.............................. 7

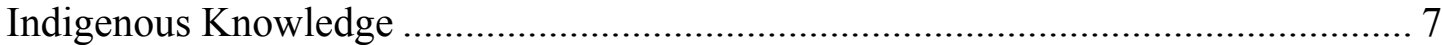

Indigenous Knowledge Documentation in Australia................................................ 10

Indigenous Knowledge - LIS Intersections ............................................................. 12

The Treatment of Materials ............................................................................... 12

Implications for Service Provision..................................................................... 14

Protocols for Practice at IK-LIS Intersections ...................................................... 15

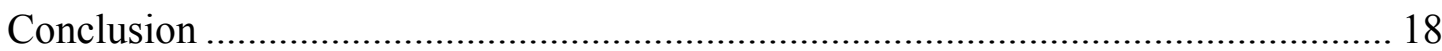

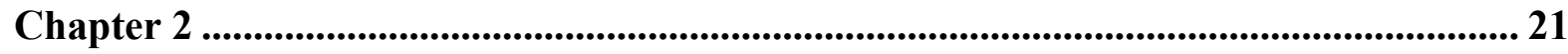

Exploring the Gupapuyya Legacy: Strategies for Developing the Galiwin'ku

Indigenous Knowledge Centre.................................................................................... 21

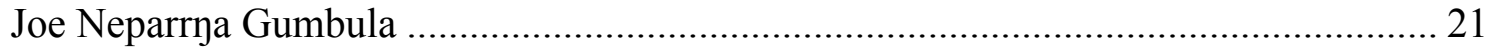

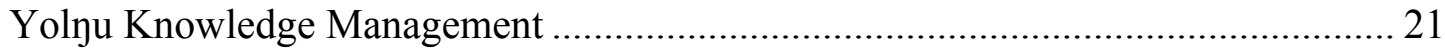

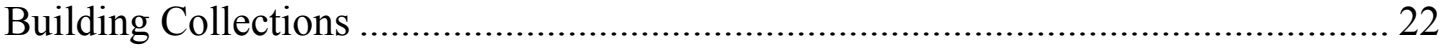

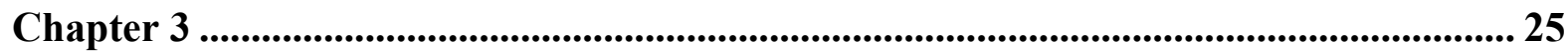

Libraries and Knowledge Centres in the Northern Territory ..................................... 25

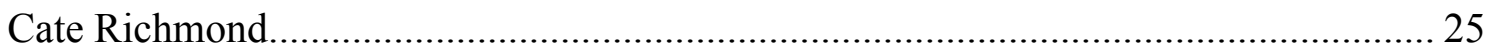

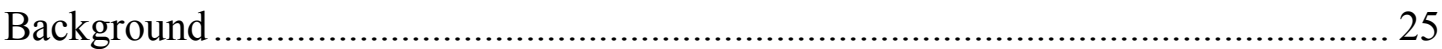

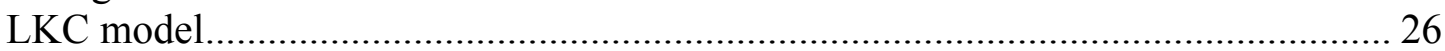

Indigenous Knowledge and Databases ......................................................... 28

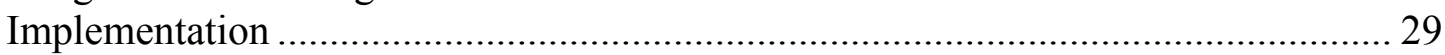

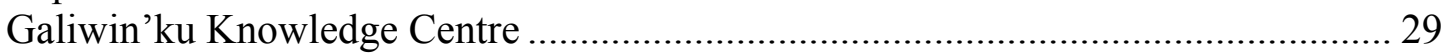

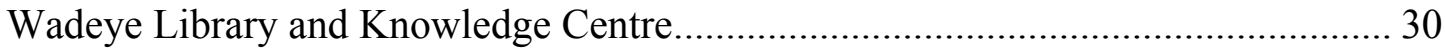

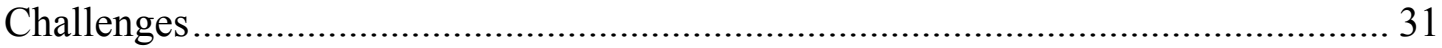

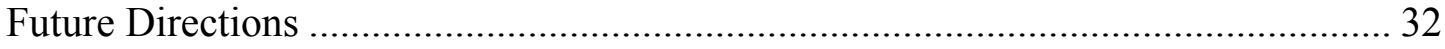

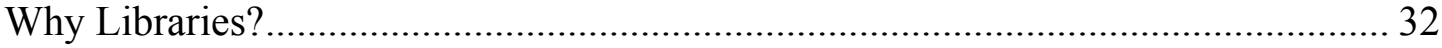

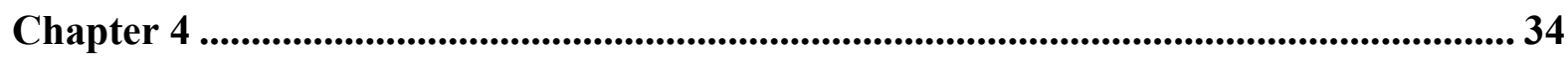

Developing Indigenous Knowledge Centres ...................................................................... 34

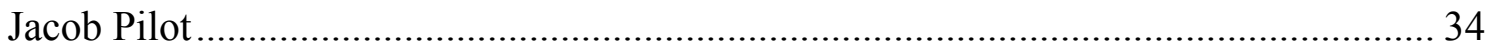

The Indigenous Knowledge Centre (IKC) Model …................................................. 35

Challenges Implementing the IKC Model ............................................................ 35 


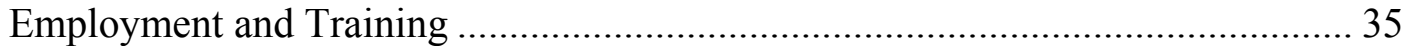

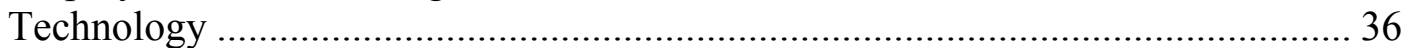

Indigenous Knowledge Centre at the Millennium Library Project............................ 37

Other Queensland State Library Indigenous Services Initiatives .............................. 38

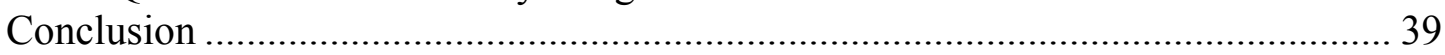

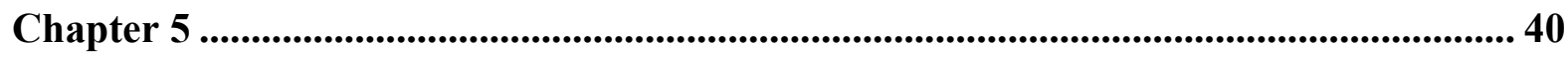

Traditional Indigenous Biodiversity-related Knowledge ................................................. 40

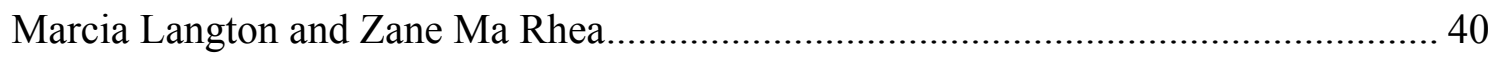

What is Traditional or Indigenous Knowledge and Why is it Important? ................. 41

Threats to Traditional Biodiversity-Related Knowledge ........................................... 43

Language Diversity and the State of Retention of Biodiversity-Related Knowledge 44

The Documentation of Traditional Biodiversity-related Knowledge ........................ 46

Libraries, Databases, Registers and Inventories .................................................. 48

Web Portals and Web Libraries ............................................................................... 50

Indigenous Knowledge and the Fate of Indigenous Peoples in a Globalising World 51

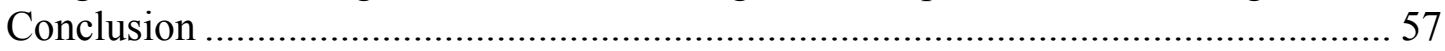

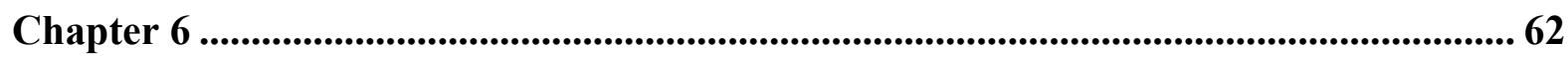

The Politics of Indigenous Knowledge ......................................................................... 62

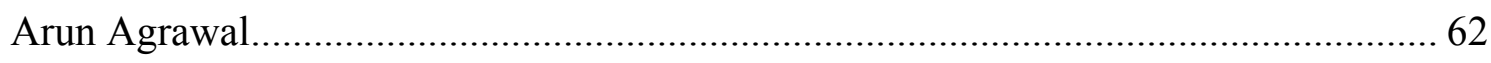

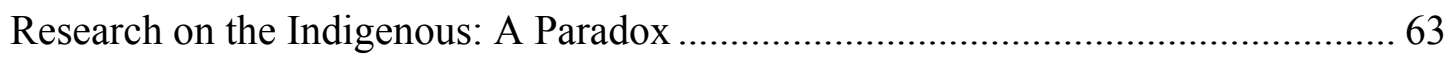

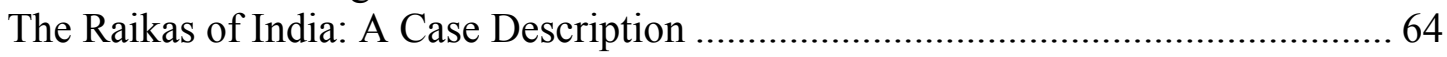

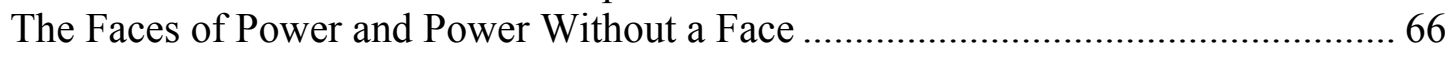

Conclusion: Articulating Power and Indigeneity ................................................... 70

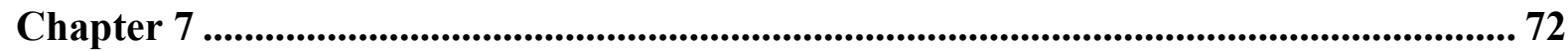

Indigenous Knowledge, Intellectual Property, Libraries and Archives:

Crises of Access, Control and Future Utility .............................................................. 72

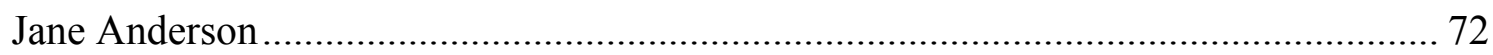

Issues of Access and Ownership: The Importance of Intellectual Property ............... 73

The Role of Archives and Libraries: Some Historical and Philosophical

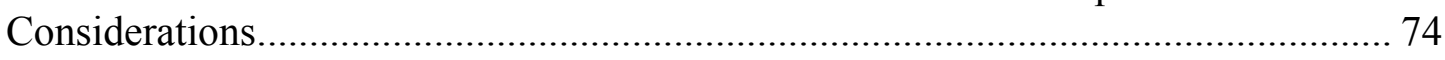

The Liberal Archive ..................................................................................... 75

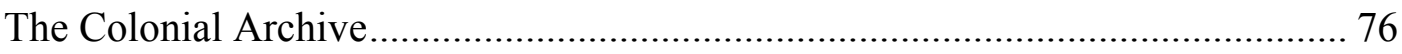

Galiwin'ku Indigenous Knowledge Centre ......................................................... 78

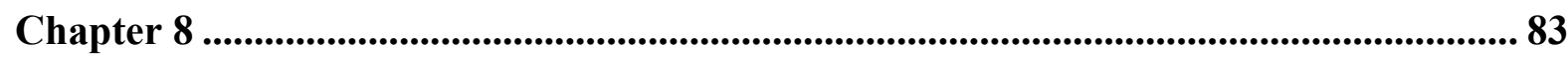

Managing Indigenous Knowledge and Indigenous Cultural and Intellectual

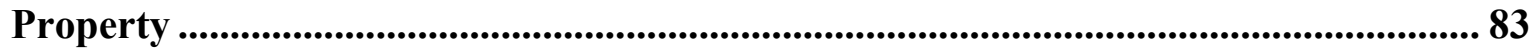

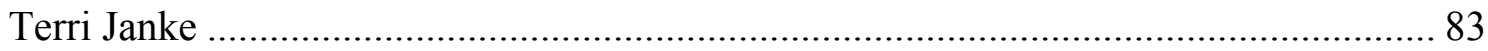

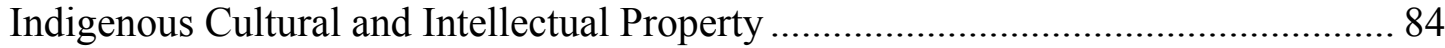

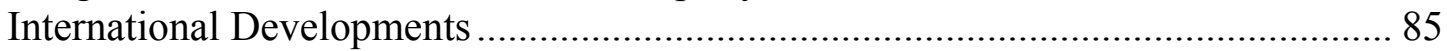




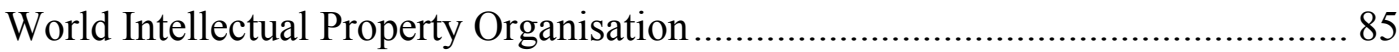

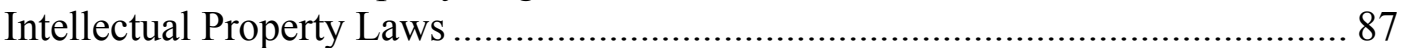

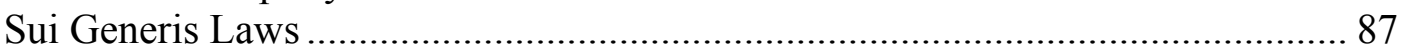

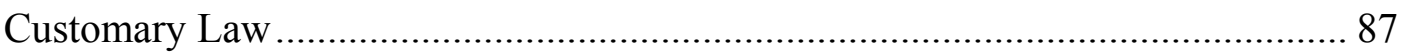

Indigenous Cultural Protocols....................................................................... 88

Principles of the Australia Council Protocols .................................................... 88

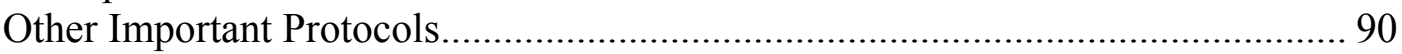

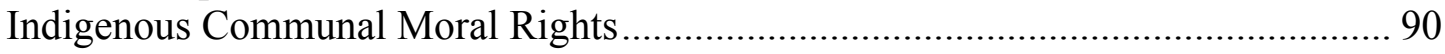

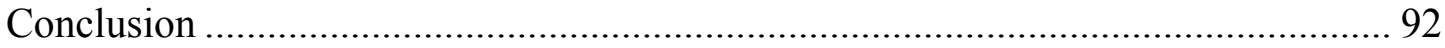

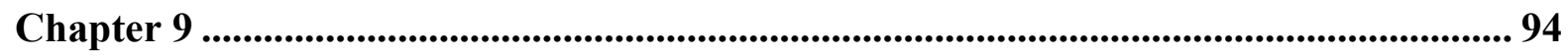

The Role of Information Technologies in Indigenous Knowledge Management ........ 94

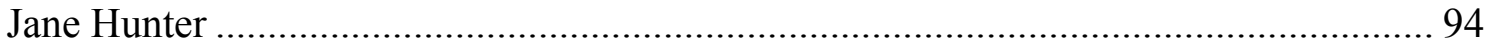

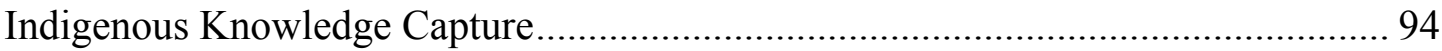

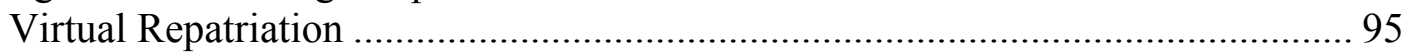

Community Mapping Projects _............................................................................. 99

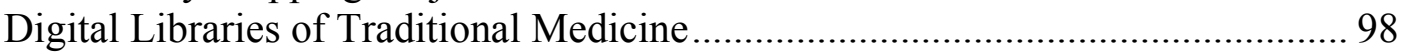

Local Knowledge Bases..................................................................................... 99

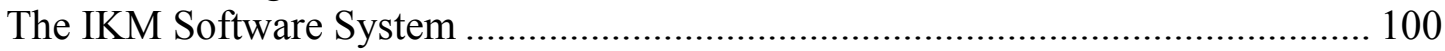

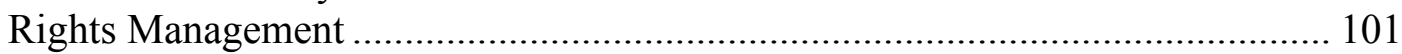

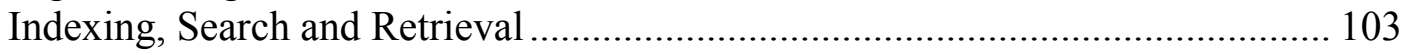

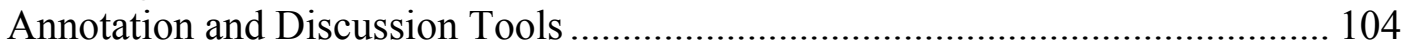

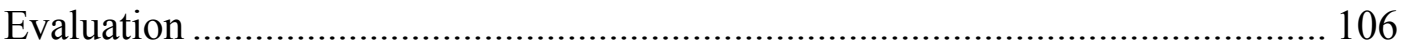

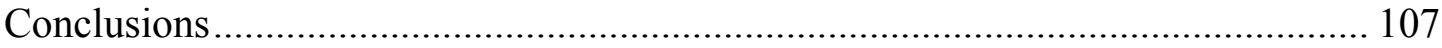

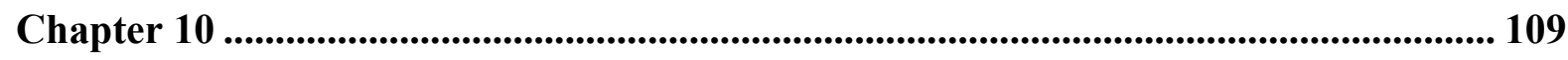

Slouching Towards Australian Public Libraries: The WTO General Agreement on Trade in Services.................................................................................................. 109

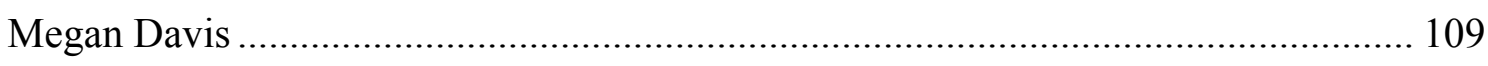

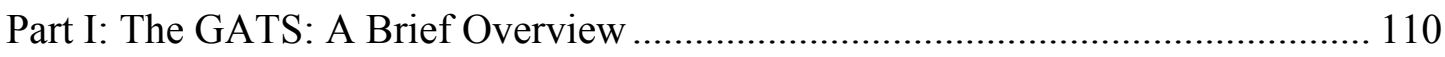

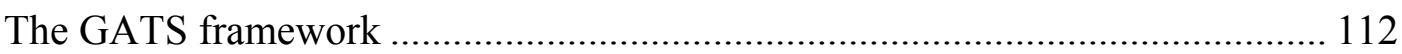

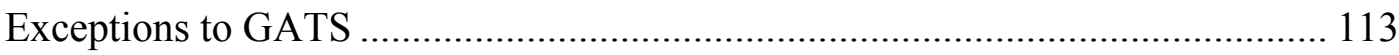

Part II: What Impact upon Public Libraries? ........................................................... 116

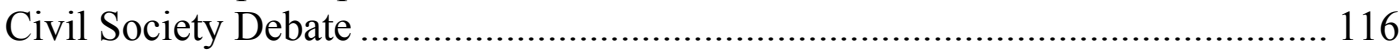

Part III: Human Rights and Liberalisation of Services ......................................... 118

The Principle of Non-Discrimination ............................................................. 118

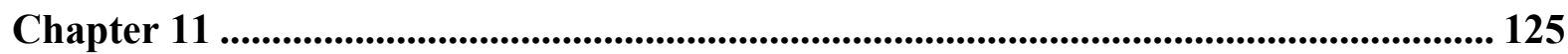

Protocols: Meeting the Challenges of Indigenous Information Needs ......................... 125

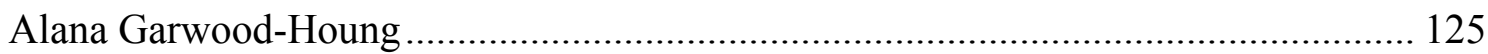

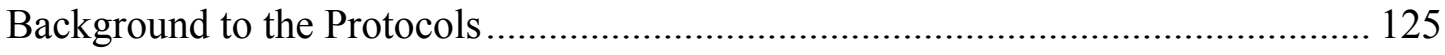

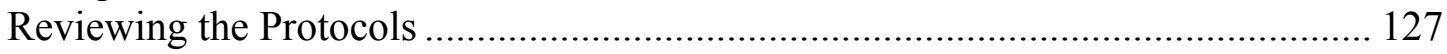

The Ongoing Challenges from an Indigenous Perspective.................................... 127

Governance and management ....................................................................... 128

Professional Preparation and Development on Indigenous Issues ...................... 128 


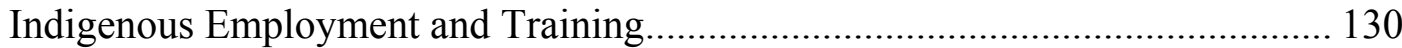

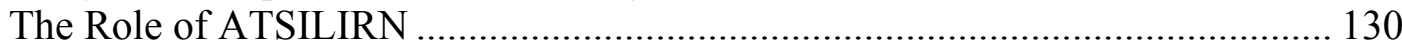

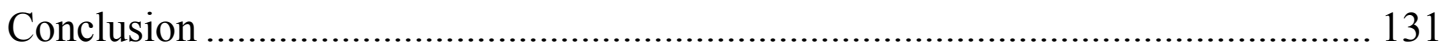

Chapter 12 .................................................................................................................. 133

Indigenous Archival Records at Risk............................................................................... 133

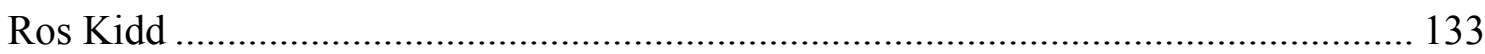

Chapter 13 .................................................................................................................................. 141

Indigenous Knowledge and Archives: Accessing Hidden History and

Understandings ..................................................................................................................... 141

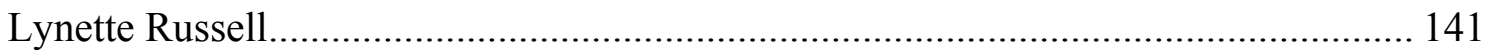

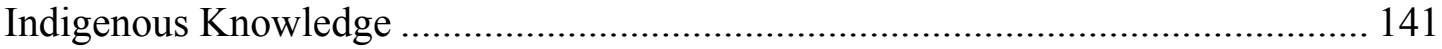

Case Study One: Looking for, Finding and Reclaiming Emily ............................ 142

Accessing Private and Confidential Knowledge................................................ 142

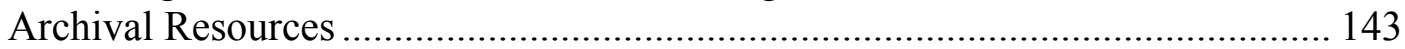

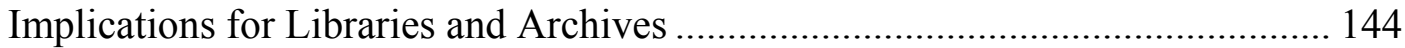

Case Study Two: The Preliminary Indigenous Weather Knowledge Project............ 145

Accessing Ethnographic Knowledge in the Public Domain ................................ 145

Implications for Libraries and Archives ........................................................... 146

Trust and Technology: Building Archival Systems for Indigenous Oral Memory .. 147 The Background to the Project ............................................................................ 147

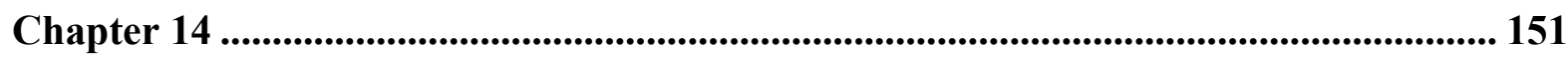

Accessing State Records on Aboriginal People ............................................................ 151

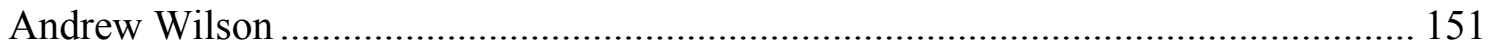

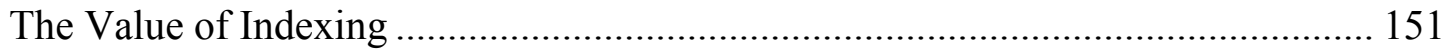

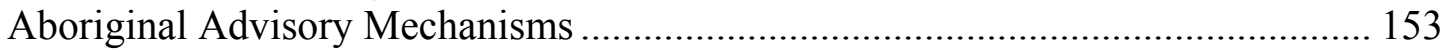

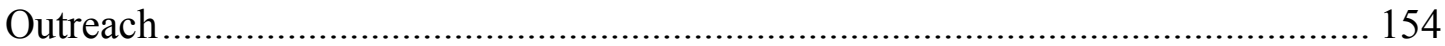

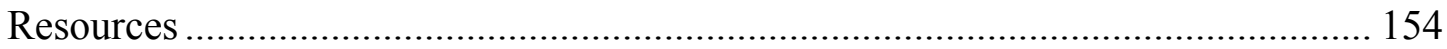

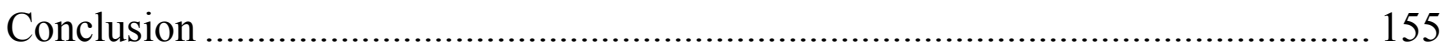

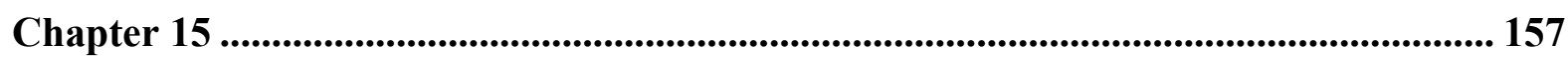

Indigenous Knowledge and Archives ..................................................................... 157

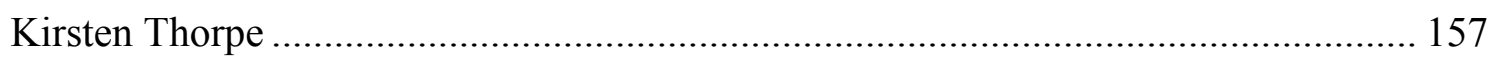

Key Outcomes of the Aboriginal Archivist Cadetship .......................................... 157

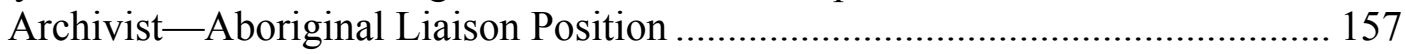

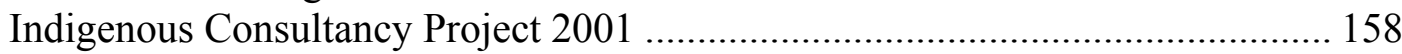

Corporate Goal with Focus on Indigenous Services ........................................ 159

Indigenous Protocols for State Records ......................................................... 159

Exhibition on Photographs of the Aborigines Welfare Board ............................ 160

The Role of the Indigenous Issues Special Interest Group .................................. 160

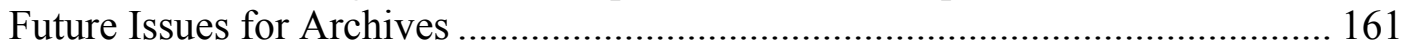


Chapter 16 .......................................................................................................................... 162

Libraries, Indigenous Australians and a Developing Protocols Strategy for the Library and Information Sector.

Martin Nakata, Alex Byrne, Vicky Nakata and Gabrielle Gardiner ........................... 162

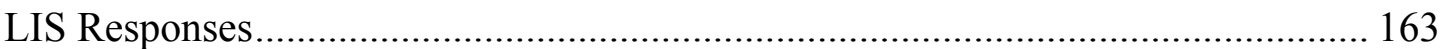

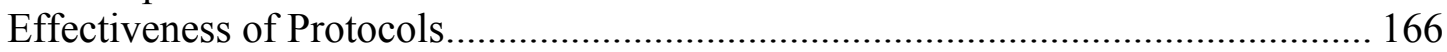

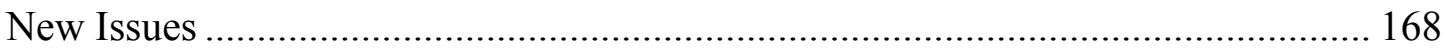

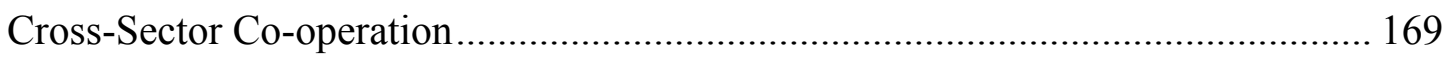

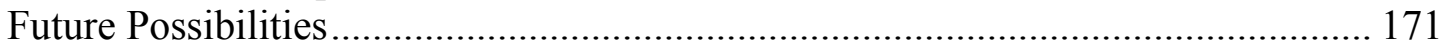

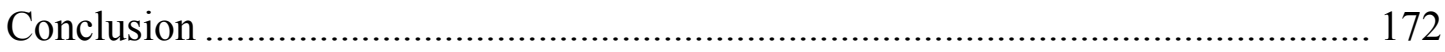

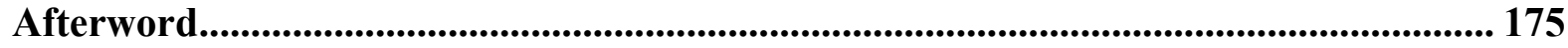

Indigenous Knowledge and Libraries ..................................................................... 175

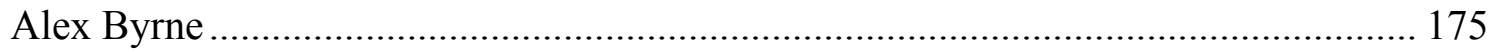




\section{Foreword}

In response to significant changes in the Indigenous information landscape, the State Library of New South Wales and Jumbunna Indigenous House of Learning, University of Technology, Sydney, hosted a Colloquium, Libraries and Indigenous Knowledge, in December 2004. The two-day Colloquium brought together professionals, practitioners and academics to discuss future directions in relation to Indigenous knowledge and library services. An expert and inspiring group of speakers and more than 90 active participants ensured that lively discussions did, indeed, take place.

The library and information profession has much learning to do if we are truly to meet the information needs of Indigenous people and appropriately manage Indigenous knowledge in our organisations. Our learning needs are complex and often require us to move outside our comfort zones. The service development requirements are equally challenging, asking us to exploit new disciplines and new technology and forge new collaborations. Our Indigenous colleagues continue to be generous and patient in sharing their knowledge and skills with us, and we must not disappoint them-the momentum for change generated by the Colloquium and related initiatives in the library and information sector must be maintained.

The Colloquium gave those present an insight into the breadth and depth of Indigenous knowledge issues which impact on libraries and archives. Presentations addressed a range of issues to do with understanding the importance of retaining and valuing Indigenous Knowledge in Australia and internationally, identifying Indigenous knowledge materials in collections, repatriating copies of materials to the relevant groups and communities, determining culturally appropriate access conditions in both collecting institutions and communities, developing, customising and implementing technologies for knowledge management, developing models or strategies for service delivery, understanding and dealing with the legal issues surrounding ownership and access, understanding Indigenous interest in and use of archives and libraries and Indigenous perspectives on professional practice, and appreciating the need for adequate resources to achieve Indigenous goals.

Across all the papers, the importance of knowledge and understanding of the issues emerged as paramount, as did the importance of building good relationships between Indigenous people and communities and collecting institutions. The implications of this for professional preparation and development across the sector, and the need for ongoing effort in addressing Indigenous employment and training issues were also highlighted by many speakers. The importance of protocols, including the development of site-specific sets of protocols, to guide high standards of practice across what are diverse and complex contexts was re-emphasised, along with the need for reinvigoration of the professional activities of the Aboriginal and Torres Strait Islander Library and Information Resource Network to promote the sharing of knowledge and experience. The need for a more concerted effort across the profession to rise to the challenge of these issues has implications at all levels of practice.

As we now embark on the hard work of responding to Indigenous needs and the challenges Indigenous knowledge presents to the sector, we are conscious that many 
members of the library profession were unable to attend the Colloquium. Our hope is that this publication of Colloquium papers and presentations will share our learning and discussions with those who were unable to attend, keep the ideas alive for those who were present and build on our understanding of the issues raised through the inclusion of new papers.

Professor Martin Nakata, Director of Academic Programs, Jumbunna Indigenous House of Learning, University of Technology, Sydney, was actively involved in the Colloquium from the outset. His knowledge, connections, commitment and energy are a powerful combination, and did much to ensure the success of the Colloquium. Professor Marcia Langton, Professor of Australian Indigenous Studies, University of Melbourne is, without doubt, one of Australia's foremost Indigenous intellectuals. Her contribution to Indigenous affairs has been long and wide-ranging and her work in the areas of traditional knowledge, culture and the arts, including library, archive and museum issues, has been significant. By joining forces to jointly edit this compilation of papers, Marcia and Martin have made a further significant contribution to our endeavours. We are most grateful to them for their support in this way

We are also grateful to our sponsors-the Council of Australian State Libraries, the Australian Institute of Aboriginal and Torres Strait Islander Studies and the Faculty of Humanities and Social Sciences at the University of Technology, Sydney-whose support made the Colloquium possible.

The two days of the Colloquium were characterised by vitality and energy and demonstrated much good work and good will, but they were just a beginning. This publication is an important next step in the library and information sector's journey to more effectively respond to the needs of Indigenous people and the issues of Indigenous knowledge, and I am pleased to commend it to you.

Dagmar Schmidmaier AM

State Librarian \& Chief Executive

State Library of New South Wales 


\title{
Introduction
}

\author{
Martin Nakata and Marcia Langton
}

If it is possible to guide the way readers respond to chapters in this book, then perhaps the first thing we would like readers to take away would be an appreciation and understanding of the complexities that library, archives and information professionals must engage with in meeting the needs of Indigenous people and managing Indigenous knowledge within their organisations.

From the Indigenous perspective, we can well understand the profession's desire to have clear prescriptions for practice and practical assistance. However, the path to developing clear and high standards of practice in this area rests on building a strong foundation for understanding what informs the concerns of Indigenous people about the intersection of our knowledge and cultural materials with library and archival systems and practice. This requires a broad sweep across issues of knowledge, culture, history, heritage, law, disciplines, technologies and so forth. It requires consideration of articulations between the local/global, the Indigenous/Western, as well as traditional/contemporary spheres. Most importantly, it requires professional understanding at a level deep enough to generate problem-solving and innovations in practice to overcome the manifold tensions that emerge across all these in a diverse range of situations.

To be even more emphatic on these points, we would suggest that developing understanding of complexities requires the profession to do more than understand Indigenous concerns and perspectives on the issues. It requires, as much, an unsettling of established practice, and the questioning of some of the assumptions on which accepted practice rests. This is not to suggest that professionals should undermine or abandon their codes and standards of practice. Quite the opposite, we would argue. It is important for professionals to be clear on why the tenets of the profession are so important and central to their practice. Then perhaps it can be more fully appreciated just why Indigenous cultural principles are so important when it comes to restoring and continuing the principles of Indigenous knowledge management.

This helps to identify when and which assumptions and principles are misapplied and inappropriate for the management of Indigenous knowledge and cultural materials. It helps to reveal where changes need to be made and to see these as appropriate to Indigenous knowledge rather than as contradictory to established professional practice. It encourages Indigenous people and professionals to make use of aspects of each other's practice in the interest of evolving new and more appropriate practice in changing times.

Why is it so important for the profession to adjust practice and why impose this on libraries and archives when these are clearly Western institutions? If we are dealing with documented forms of Indigenous knowledge, why should these forms not be treated according to the traditions of libraries and archives? Why are Indigenous people asserting changed library and archival practice and not the complete separation 
between the two systems when clearly there are some stark and irreconcilable differences between them?

The answer to these questions lies in a simple assertion of the facts. Indigenous knowledge materials are already contained within library and archive collections and have been and often still are being inappropriately managed, by Indigenous standards. For many Indigenous groups this documented material is a tenuous thread that connects present generations to a traditional heritage. Many groups and individuals do not know what material is held in collections and many libraries and archives are not familiar with the full content of their collections. Under Western principles of access to information, Indigenous people have every right to know and access this material and under international human rights covenants, they have a right to claim, restore and continue their own knowledge and cultural heritage. From the Indigenous standpoint, issues of ownership and authority are increasingly a matter of contestation, not just in Australia but across the globe.

The complicated answer, however, lies in the differences between the two quite different cultural and knowledge traditions and their associated social institutions, a complicated history of Indigenous/coloniser relations, and their contemporary legacies. Complex intersections between knowledge systems, in the context of political and cultural reassertion by Indigenous people, are what professionals now confront and must work through. It must be understandable to all concerned that Indigenous people seek a more just and reasonable balance of interests when it comes to our knowledge, heritage and cultural materials. In this sense, changing professional practice fundamentally involves changing relations between people, changing understandings about Indigenous peoples' knowledge, and recognising the different knowledge traditions that people seek to preserve, store and access.

And so, when we consider the challenges associated with Indigenous knowledge and libraries and archives, we are not talking solely about the liberal project of equality and inclusion. It is patronising to take the view that changing practice is limited to ensuring libraries adjust practice to include Indigenous people so we can access our own materials. More fundamentally it must be about recognition of and respect for continuing but still distinct knowledge traditions. It must be about developing a set of practices that recognise the entanglement of the two traditions as they move forward together in a somewhat problematic tension. It must be about understanding the intentions and purposes of Indigenous information activity and why, when, and which aspects of these remain quite distinct from other types of information activity. It must be about the authority of Indigenous people to determine how and under what conditions they want to manage their knowledge and cultural materials in the new millennium. At every level it must be about developing trust and good working relations between Indigenous people and collecting institutions.

None of this can occur without the requisite levels of knowledge. Tensions cannot be resolved, problems cannot be solved, innovations cannot occur unless there is good communication between those with vested interests and unless the relevant knowledge or understanding is brought to bear to generate quality conversation, discussions and dialogue between stakeholders. This is a circular process. It is not about simple consultation with Indigenous people, although consultation must be part of the process. It is about dialogue, conversation, education, and working through things 
together. It is not just about developing the language to describe what needs to be done, but providing the opportunity and means for Indigenous people to be part of what they determine should be done. It is not about being focused just long enough to fix a problem but is about investment in the issues for the long term and for future generations.

The information profession is uniquely placed to develop models of good practice in relation to Indigenous knowledge. Traditionally, they are custodians of knowledge and materials, not the owners. They are custodians and preservers of Australia's documentary heritage. They are mediators in the sense that they occupy an intermediate space between those who produce and are the legal owners of knowledge and those who require access to knowledge. The profession is practised in adjusting management systems and models of practice in line with changing external circumstances and demands. The profession also has a deep commitment to the ideals of democracy and free and universal access to knowledge and information. Openness and goodwill are the hallmarks of the profession in Australia. This goodwill is evident in the response by the profession to the concerns of Indigenous Australians over the last decade and a half. Increasingly, there is a realisation that there is no quick fix, no easy prescription to address the issues, but only the hard work associated with understanding issues, listening to needs, innovating ideas, and improving regimes for practice.

For those organisations who deal with Indigenous knowledge and materials, there is already recognition of the importance of building relationships with Indigenous people and communities and this is the second thing that we would hope readers will absorb from chapters in this book. Indigenous people are at the heart of this matter. The development of practice in this complex intersection must have legitimacy with Indigenous people and communities. It must be relevant to Indigenous needs and interests and, further, it must maintain currency with the relevant developments in both Indigenous and professional areas of scholarship and standards of practice. This means that although knowledge systems of an ancient oral tradition are under discussion, we must provoke discussion of them in their 21 st century intersections with the technologies of another knowledge tradition and not as a relic of the past. Indigenous interest in the intersection includes a strong futures orientation. The development of practice must engage with the possibilities, the constraints and risks associated with this. Such an engagement must involve Indigenous people and communities or risk leaving us disconnected or sceptical, and by default excluded once again from decision-making over the terms and conditions of the management of our own knowledge and heritage.

Indigenous people are a small minority in Australia. Indigenous knowledge intersections with libraries and archives remain a small part of the materials dealt with by the library and information sector. Our materials tend to be housed in collections in institutions far from the places and people from where they were collected and who shared their knowledge. Material belonging to one group may be dispersed across a number of collections in various states. Many of the descendants of the people from whom the material was collected are also dispersed across the country and often far from their traditional country. This adds to the challenges in the area and emphasises an already identified need for both national leadership and cross-sectoral cooperation to keep a focus on this small but very significant part of collections and services. 
This leads us to our final point for readers of this book. We hope that it becomes clearer that understanding the intersections between Indigenous knowledge and libraries and archives and developing appropriate protocols and practices to manage them, will take the profession beyond its own disciplinary knowledge base. It requires multi-disciplinary and collaborative conversations, scholarship, research, and practice with Indigenous cultural experts, academics in related fields, technology and software developers and providers, legal experts, other vested interests, such as governments and Indigenous organisations, and funding agencies. Rather than viewing this as a daunting prospect, we would encourage the view that broad collaboration on all these fronts will assist and enable the development of processes and standards for practice that reassure and satisfy the interests of Indigenous people and the library and information sector, as long as the process is one of genuine sharing and cooperation and works towards consistently high standards, rather than minimum ones.

It is with pleasure, then, that we present the following chapters as an example of this process: of the breadth and depth of issues that contribute to the complexities; of the importance of scholarly conversation to inform the development of practice; of the need to respond to and incorporate Indigenous experiences and perspectives; of the need to cross cultural, legal, historical, and technological issues beyond the usual professional concerns; of the need for innovation and trail-blazing; and of a need to assess, evaluate and keep a critical eye on developments.

We are particularly proud to present so many chapters authored by Indigenous Australians. We are appreciative of the advocacy and commitment to the issues evident in the chapters of our other contributors. We acknowledge the goodwill and interest of all those who attended the Libraries and Indigenous Knowledge Colloquium last December and others who are interested in the issues and we hope this book stimulates interest across a much wider audience.

Finally, we would like to thank Ms Dagmar Schimdmaier AM, State Librarian and Chief Executive of the State Library of New South Wales, and the former chair of the Council of Australian State Libraries (CASL), and Dr Alex Byrne, Librarian at the University of Technology, Sydney, and president-elect of the International Federation of Library Associations (IFLA) for drawing attention to Indigenous knowledge issues in the profession and across the institutions in both the national and international arenas. 


\title{
Chapter 1
}

\section{Indigenous Knowledge, the Library and Information Service Sector, and Protocols}

\author{
Martin Nakata, Alex Byrne, Vicky Nakata and Gabrielle Gardiner*
}

The increasing global recognition of Indigenous knowledge as distinct, legitimate, valuable and vulnerable systems of knowledge raises a range of issues that pose challenges for the library and information services (LIS) sector. Professionals and organisations are increasingly aware that they deal with aspects of Australian Indigenous knowledge within their collections and services and that these require culturally appropriate management. This chapter discusses Indigenous knowledge and its intersection with the LIS sector in Australia, drawing attention to its significance and relevance to Indigenous Australians. It concludes by emphasising the need for Indigenous involvement in the LIS sector and the importance of protocols to guide practice in this most complex of intersections.

\section{Indigenous Knowledge}

The challenges for LIS professionals begin with the imperative to recognise Indigenous knowledge as a distinct system of knowledge that requires handling and management regimes for its materials that are different from those applied by the Western system of knowledge management.

Indigenous knowledge defies simple definition. Indigenous knowledge is commonly understood as traditional knowledge, although there is debate about whether the term Indigenous knowledge should be used interchangeably with the term traditional knowledge or whether it is more accurately a subset of the traditional knowledge category. ${ }^{1}$ Despite contentious terminology, Indigenous knowledge is understood to be the traditional knowledge of Indigenous peoples. In Australia, a common misunderstanding is that this equates Indigenous knowledge to 'past' knowledge, when in fact Indigenous people view their knowledge as continuing.

Whilst Indigenous knowledge systems are now recognised as dynamic and changing, orally transmitted from generation to generation and produced in the context of Indigenous peoples' close and continuing relationships with their environment,

\footnotetext{
* Dr Martin Nakata is Chair of Australian Indigenous Education, and Director of Jumbunna Indigenous House of Learning, University of Technology Sydney.

Dr Alex Byrne is Pro-Vice Chancellor (Teaching \& Learning) and Vice-President (Alumni \& Development) at the University of Technology Sydney, and President of IFLA.

Vicky Nakata is Research Assistant at Jumbunna Indigenous House of Learning, University of Technology Sydney.

Gabrielle Gardiner is Research and Policy Officer at UTS Library, University of Technology Sydney.
} 
definitions, nevertheless, tend to reflect or include the particular focus of those who define it. The following definition of traditional knowledge from the Working Group on the Implementation of Article 8(j) and Related Provisions for the Secretariat of the Convention on Biological Diversity ${ }^{2}$ outlines some characteristics of this knowledge and underlines its position in relation to global environmental concerns:

\begin{abstract}
Traditional knowledge refers to the knowledge, innovations and practices of indigenous and local communities around the world. Developed from experience gained over centuries and adapted to the local culture and environment, traditional knowledge is transmitted orally from generation to generation. It tends to be collectively owned and takes the form of stories, songs, folklore, proverbs, cultural values, beliefs, rituals, community laws, local language, and agricultural practices, including the development of plant species and animal breeds. Traditional knowledge is mainly of a practical nature, particularly in such fields as agriculture, fisheries, health, horticulture, and forestry... There is a growing appreciation of the value of traditional knowledge... This knowledge is valuable not only to those who depend on it in their daily lives, but to modern industry and agriculture as well. Many widely used products, such as plant based medicines and cosmetics are derived from traditional knowledge.
\end{abstract}

The World Intellectual Property Organization's definition reflects its focus by setting out aspects of knowledge that warrant protection.

'[T]raditional knowledge'... refer[s] to tradition-based literary, artistic or scientific works; performances; inventions; scientific discoveries; designs; marks, names and symbols; undisclosed information; and all other tradition-based innovations and creations resulting from intellectual activity in the industrial, scientific, literary or artistic fields. 'tradition-based' refers to knowledge systems, creations, innovations and cultural expressions which: have generally been transmitted from generation to generation; are generally regarded as pertaining to a particular people or its territory; and, are constantly evolving in response to a changing environment. Categories of traditional knowledge could include: agricultural knowledge; scientific knowledge; technical knowledge; ecological knowledge; medicinal knowledge, including related medicines and remedies; biodiversity-related knowledge; 'expressions of folklore' in the form of music, dance, song, handicrafts, designs, stories and artwork; elements of languages, such as names, geographical indications and symbols; and movable cultural properties. Excluded from this description of TK would be items not resulting from intellectual activity in the industrial, scientific, literary or artistic fields, such as human remains, languages in general and other similar elements of 'heritage' in the broad sense.

Indigenous knowledge, although increasingly recognised and valued for its role in sustaining the livelihoods of millions of people globally, and for its potential for innovation, nevertheless remains devalued when attempts to define it do so by contrasting it with Western knowledge. Many attempts to understand and explain the characteristics of Indigenous knowledge as a system through contrast to the Western knowledge system simplify Indigenous knowledge systems and misrepresent them. ${ }^{4}$ For example, there is a tendency to view Indigenous knowledge as an unevaluated or untested data set for the scientific community to extract, validate and incorporate into scientific frameworks. ${ }^{5}$

Recent interest in Indigenous knowledge across the globe, although linked to Indigenous peoples' political and cultural reassertion, has primarily emerged from humanitarian and scientific activity. It has been driven by research into sustainable development practices in developing countries (supported mainly by UN programs 
and non-government organisations) as well as the scientific community's concern about conservation/loss of biodiversity. ${ }^{6}$

The convergence of global sustainable development, conservation, scientific and capitalist interests has increased interest in activities like bio-prospecting and geneharvesting which harness multinational corporate interest via, for example, the pharmaceutical industry for the purposes of innovation based on the continued and largely unacknowledged use of Indigenous traditional knowledge. Indigenous knowledge, from these sets of interests, is increasingly viewed as a commoditysomething that can be utilised, transferred to other contexts, developed, innovated, integrated, extracted, and patented.

The difficulties in protecting Indigenous people's intellectual property rights are associated with the oral nature of Indigenous knowledge and concepts of communal ownership. Western regimes for management of intellectual property do not provide effective mechanisms for recognising and protecting Indigenous cultural and intellectual property rights. The question of how to give recognition, protect, and recompense what is often communal intellectual property rights is a growing part of the literature and activity at community, national and international levels. Both Indigenous Australians and non-Indigenous colleagues contribute to the international work in this area. ${ }^{7}$

In the light of the historical destruction of Indigenous knowledge, its current fragile existence, and its threatened future, the preservation of Indigenous knowledge and protection of Indigenous intellectual property rights to ensure proper attribution and use of it now requires the documentation of such knowledge. ${ }^{8}$

Documentation of Indigenous knowledge runs contradictory to the conceptual basis through which it is most often described. ${ }^{9}$ In the sustainable development context, strategies of conservation and preservation which involve the collection, documentation, storage and dissemination of knowledge, involve the isolation of segments of knowledge that are useful for development and ex situ storage in regional, national and international databases and networks. ${ }^{10}$ Similarly, attempts to include Indigenous knowledge into education curricula often involve fragmentation across non-Indigenous categories of knowledge. ${ }^{11}$

Through such extraction, documented Indigenous knowledge is abstracted, loses its 'holistic' and oral form, its connection to the social context, its fullest meaning. Documentation thus runs the risk of undermining the integrity of the knowledge it aims to preserve. ${ }^{12}$ Langton and Ma Rhea point out that, as documented Indigenous knowledge is a derivative form of knowledge, those who study and use its documented form require skills to critically evaluate its legitimacy according to Indigenous criteria. ${ }^{13}$ Notwithstanding these concerns, documentation is critical for its retention and for the protection of Indigenous intellectual property.

For the LIS sector, recognition of Indigenous knowledge produces additional issues for consideration - how to develop systems that meet the needs of Indigenous peoples and Indigenous knowledge management. The historical colonial experience, contemporary circumstances, and future aspirations of Indigenous Australians mean that the intersection of Indigenous knowledge in the LIS context is a complex one. Libraries and archives must confront the broader issues associated with the preservation of documented Indigenous heritage, through to quite specific issues 
associated with managing particular items of Indigenous knowledge. As well, libraries and information services are increasingly required to consider documented Indigenous knowledge, not simply as part of the historical archive, but as a contemporary form. That is, Indigenous knowledge is always in a sense contemporary, always changing through its association with an ongoing oral tradition, yet in current times, always in tension with other knowledge systems and transmission technologies. Professionals, therefore, also require an informed understanding of Indigenous concerns as well as the purposes for which Indigenous people, seek access to and appropriate management of their cultural materials and how this impacts on service provision for Indigenous Australians.

\section{Indigenous Knowledge Documentation in Australia}

A Google search on Indigenous knowledge instantaneously gives an indication of the extent of interest and documentation globally. The proliferation of networked electronic technologies over the last decade has lent itself to the creation of websites, gateways, networks, databases, registers, inventories, case studies, and resource indexes of Indigenous knowledges internationally. However, the extent of Indigenous knowledge documentation in Australia, which is a 'developed' economy, and whose Indigenous peoples form a tiny minority (approximately 3\%) of the population, is not so clear nor a matter of great national or international interest or priority. The development sector does not frame the priorities for documentation in this country, as it does in other regions of the world.

In Australia, documentation of traditional cultural knowledge occurred historically through missionary and anthropological activity. Consequently, a significant amount of Indigenous knowledge, some of which is secret and sacred knowledge, is stored in collections across the country. Contemporary documentation efforts depend largely on the convergence of Indigenous interest and academic research interest and are dependent on scarce public or philanthropic funds.

There is increasing acknowledgement of the future utility and value of Indigenous knowledge to contribute to Australian Indigenous wellbeing via cultural maintenance, and to produce social and economic benefits through innovation, and thus a strong Indigenous motivation to restore, maintain, and protect it for cultural, educational and future utility purposes. The fact that a constrained funding environment often means that documentation projects are small, narrowly defined, short-term, or specific to some particular academic research purpose should not signal that Indigenous motivation to document, preserve and protect Indigenous knowledge is similarly constrained.

Rather, Indigenous interest and motivation to document Indigenous knowledge is complex and varied. The particular historical specificities and current capacities of communities and groups impinge on documentation interests and priorities, as does the convergence of these with external interests, for example, with government, academic, research, funding or publishing interests. The Indigenous motivation to document crosses a number of areas and cannot be considered to be finite in intention or scope even though projects generally have to be.

Currently, a number of different sorts of documentation can be identified. One area of activity is driven by urgency on the part of some Indigenous groups to record hitherto 
'undocumented' oral knowledge that is threatened by intergenerational loss. Another is local documentation (often digital) of recovered traditional and cultural knowledge collected from Indigenous groups since the nineteenth century and stored in library, archive and museum collections. As well, there are projects to document knowledge, including knowledge innovation, which emerge from contemporary collaboration with academic and scientific interest. This is currently most often associated with the utilisation of Indigenous knowledge for environmental resource management but also includes a renewed interest in Indigenous knowledge for health, medicinal, dietary and other practices that impinge on Indigenous wellbeing. Indeed, there is potential for ongoing documentation, innovation and integration across a range of areas.

These aspects of documentation are generally separate elements in the 'project' sense but cut across a more broadly envisioned Indigenous documentation project in some areas. This is especially the case in the quest by particular groups to restore traditional knowledge continuity disrupted by colonial intervention. Restoration often involves drawing together threads of knowledge from various sources. Some may be drawn from Indigenous memory and the ongoing oral tradition, and some from materials removed from particular groups and housed in museums, art galleries, libraries and archives. Other knowledge that is still practised may be recorded, for example, contemporary productions of traditional performances, or contemporary uses of traditional knowledge. And as well, contemporary innovations of Indigenous knowledge that result from collaboration with scientists may also be documented to facilitate ongoing continuity and utility of traditional knowledge and practice.

The Yolyu from Arnhem Land are an example of a group involved in all these aspects. The Gupapuyyu legacy project at the Galiwin'ku Indigenous Knowledge Centre pursues the digital recovery of Indigenous knowledge and material collected or removed from the community. Joe Nerparrna Gumbula, in the roles of Community Liaison Officer and Senior Research Fellow at the University of Melbourne, is currently identifying Gupapuyyu clan material housed in various collections and is mapping these into Yolyu systems for knowledge management at the local level. As well, contemporary performances and ceremonies are being recorded and stored locally to preserve extant cultural knowledge for the future. The Yolyu people have also established the Garma Cultural Studies Institute (GCSI). The Institute aims to '[s]ustain and extend Yolyu intellectual traditions and knowledge systems; develop partnerships and collaborative relationships with places of learning, other Indigenous peoples and the wider community; and, expand human knowledge in a spirit of mutual respect and tolerance'. ${ }^{14}$ Yolyu collaborative projects include the University of Melbourne's Department of History and Philosophy of Science and other organisations to research cross-cultural philosophical works to find ways for Yolyu knowledge to work with the environmental sciences. A methodology has been developed to explore the nature of theory in Yolyu knowledge and elaborate Yolnu concepts in ways accessible to ecology. ${ }^{15}$

Research to support native title claims also draws on Indigenous oral accounts, archival records, and anthropological reports, in the process recovering and documenting aspects of Indigenous knowledge lost or fragmented through colonial interventions. Research to uncover Indigenous histories of colonial experience likewise draws on oral, archival, and non-Indigenous accounts. 
A number of research centres address Indigenous knowledge issues within their projects and activities. These centres focus on understanding and managing natural resources and sensitive ecologies in the more remote areas of Australia. The Tropical Savannas Cooperative Research Centre (TS-CRC) includes projects to develop different methodologies for recording ecological knowledge, and collaborative management plans and practices like, for instance, different formats for documentation. The past practice of extraction of knowledge is being replaced by attempts to maintain this knowledge in situ within the relevant cultural groups. Research and practice aims to ensure the biodiversity and habitats for the long-term benefits of the Indigenous people who use them. ${ }^{16}$ The Desert Knowledge Cooperative Research Centre (DK-CRC) aims to develop formal and informal knowledge, Indigenous knowledge and research to increase social, economic and cultural capital in desert communities. This Centre has developed its own Indigenous Intellectual Property Protocol, which is used by at least one other research centre, the Centre for Arid Zone Research (CAZR). ${ }^{17}$

Indigenous knowledge is also being documented and utilised in parks, wildlife, fisheries, tourism, and environment departments to assist with the management of resources. These examples represent an interest in the documentation and/or the integration of Indigenous knowledge and Western knowledge in local contexts by scientific interest. The Australian academic research sector supports the use of Indigenous research ethics protocols but the resolution of claims to ownership and access are an ongoing challenge for those involved.

The documentation of traditional Indigenous knowledge is not confined to remote areas where traditional structures or practice are still evident. In urban and regional areas, there is an increasing trend to document the knowledge of people and place belonging to groups whose traditional connections have been severely disrupted by colonial intervention and government policies and which are now literally overlaid by the urban and regional sprawl of the modern nation.

\section{Indigenous Knowledge-LIS Intersections}

Documented Indigenous knowledge forms part of the documentary heritage of the nation and in this capacity intersects with the library and information sector. Legislation mandates the national and state libraries to preserve the documented heritage of the nation, which includes Indigenous heritage. As well, Indigenous knowledge is of interest and relevance to many Indigenous Australians, and forms an important part of the information context that Indigenous Australians require access to if Indigenous LIS service provision is to be relevant and have currency with the Indigenous community.

\section{The Treatment of Materials}

With regard to the handling of materials containing Indigenous knowledge, the challenges to the LIS sector begin with the recognition of Indigenous knowledge as a distinct system of knowledge with its own management regimes. Traditional Indigenous knowledge systems have their own systems for management and access. ${ }^{18}$ Traditional access rights are located within customary law and kinship systems which authorised Indigenous knowledge custodians understand and regulate in local contexts. These can place age, gender, initiate status, role, and specialisation 
restrictions on access to certain knowledge. For example, there are three levels of restriction that apply to Yolnu systems of knowledge: restricted, peri-restricted and public. Primary intellectual property rights reside in each of 60 groups with secondary rights derived from kinship relationships between groups. ${ }^{19}$ These aspects may vary between groups across the continent.

Although the challenges begin in the distinction between the two systems, the challenges do not arise inherently from any complexity in Indigenous knowledge management systems. The challenges emerge in the intersection of the two systems in the LIS sector and, in particular, from the recent challenges by Indigenous people over ownership, attribution and conditions of access to knowledge collected from them (often without informed consent) but now legally owned by others. ${ }^{20}$ Where traditional systems of knowledge management have disintegrated under the pressures of colonial intervention, which have overseen the destruction of knowledge, language, cultures and peoples, there remains nevertheless a strong Indigenous desire to utilise archives and collections to recover as much traditional knowledge that relates to ancestors and country as possible and to manage it with the respect it is due.

These challenges to the LIS sector are complicated by the retrospective implications of the presence of significant amounts of unidentified Indigenous knowledge materials within historical collections. LIS professionals face challenges in finding time and resources to retrospectively examine collections for the existence of Indigenous knowledge within them and to locate the relevant people to assist with identification, appropriate descriptions and indexing, and with whom to negotiate any altered access conditions.

When non-Indigenous authors who collected and produced accounts of this knowledge hold copyright, the original Indigenous custodians of that knowledge (or their descendants) have no means of control over the way it is represented, attributed and used, unless this has been negotiated at the point of production-a rare occurrence until recent times. ${ }^{21}$ When copyright expires, Indigenous knowledge, including secret and sacred knowledge, sits within the public domain freely available to all. Understandably, Indigenous peoples desire to regain, not just access to their own knowledge, but as well, some recognition of their intellectual property interests as a means to gain some measure of control over the ways these materials are attributed and used by others.

Attempts by the sector to respond to these issues have had to overcome consistent obstacles. In attempting to identify Indigenous knowledge and determine appropriate access conditions, it is not always clear from which Indigenous individual, group or community representative or organisation that consent should be sought. Within some Indigenous groups, and for various reasons, consensus on appropriate access and management of materials can sometimes be difficult to achieve. Indigenous groups are also often a long way from the collecting institution extending the difficulties associated with the working through of issues.

Repatriation of Indigenous knowledge materials also poses challenges for the sector. Such questions arise as: how are materials to be identified, copied, organised, stored and retrieved to meet the specific needs and management regimes of particular communities? How is infrastructure to be maintained in the long term? How are standards of technology and consistency of practice across many local Indigenous 
contexts to be developed? How is training to be delivered for the local community, and who is to bear the costs?

Whilst it is perhaps easier to set conditions for ownership, access and use with respect to the ongoing contemporary collection and documentation of Indigenous knowledge via the academic, scientific and legal research sectors, there are still unresolved and ongoing tensions associated with this. ${ }^{22}$ Establishing the conditions of access for collections held within collecting institutions, either on deposit of new materials or retrospectively, is time-consuming. Despite the potential of digital technologies, the provision of access for local communities to this material, is an ongoing challenge.

Collection managers in libraries across the country are increasingly aware of the need to ensure that contemporary publications based on Indigenous knowledge, including traditional stories, include proper attribution and acknowledgement of the owners of those stories or knowledge if their significance as elements of the Indigenous knowledge system is to be respected. This is particularly the case in school libraries where collections are selective to suit educational purposes. Increasingly, these issues are dealt with at the point of production but in evaluating materials for collections, professionals need to be aware of those publications that continue to misrepresent and misappropriate Indigenous traditional knowledge and be guided by Indigenous protocols for dealing with them.

Thus whilst the distinctions between Indigenous knowledge and Western knowledge systems are increasingly asserted, the boundaries between them are not always clear or tidy in the intersection with LIS systems. As well, issues of ownership and access, that in (Western) intellectual property law are quite clear, are increasingly questionable on moral grounds for LIS professionals.

\section{Implications for Service Provision}

Whilst the complexities at the intersection of Indigenous knowledge and LIS practice for managing these materials is challenging enough, recognition of Indigenous knowledge and its importance and relevance to Indigenous Australians has impacted more generally across the sector in the area of service provision for Indigenous peoples. In recognition of diversity within the Indigenous collective, LIS services for Indigenous Australians must always assume the broadest notion of Indigenous access and use of libraries in ways no different from other Australians. However, it has also to concede that both in the collective sense and in terms of many Indigenous individuals and communities, there are Indigenous needs and interests that are distinct from those of other groups of users. This has become increasingly evident in the last 10 to 15 years since the profession began to respond to Indigenous concerns.

In this period, the profession has undertaken a range of activities to facilitate access to Indigenous records and materials held in archives and historical collections. ${ }^{23}$ Whilst the primary motivation has been to assist the link-up of Indigenous families torn apart by government policies that removed and institutionalised children over generations, the effect has been to stimulate much broader Indigenous interest in recovering and documenting Indigenous knowledge and histories-personal, family, community and cultural. This has impacted on organisations across the LIS sector, which has pursued strategies to respond to this need and interest. 
One strategy that directly responds to the intersection between Indigenous knowledge and LIS services is the concept of Indigenous knowledge centres in the Northern Territory and Queensland. ${ }^{24}$ Another is the strategy to involve Indigenous peoples in library services through projects to document local histories, for example, Moree Public Library. ${ }^{25}$ In these, we see the re-conceptualisation of traditional library services to include aspects of Indigenous local knowledge as a legitimate area of activity that is relevant and important to Indigenous Australians. Such activity recognises that documentation is an important project if Indigenous knowledge is to be restored for access by future generations. Such organisations and projects are recognising that both the goal of preserving Indigenous documentary heritage and the goal of increasing the relevance of libraries for Indigenous peoples is assisted by local documentation of Indigenous knowledge and Indigenous perspectives of historical experience. In some cases, such documentation is no more than identifying or interpreting the content of material and attaching Indigenous annotations to existing historical materials such as photographs of people, places, ceremonies, or nonIndigenous accounts of events involving Indigenous peoples. Nevertheless, these are critical aspects of recovering aspects of Indigenous knowledge, rebuilding Indigenous histories to sit alongside other accounts, and of making LIS services relevant to current Indigenous interests.

These attempts also accept that local Indigenous information and knowledge interests are a central part of the broader global information context to which Indigenous communities also need to be connected. Dislocating one from the other is to perpetuate disjuncture and mutual exclusion rather than an integrated and ultimately meaningful LIS model for Indigenous LIS services that responds to Indigenous information needs and recognises the relevance of purposeful Indigenous information activity.

The scope for building relevant and current services for remote Indigenous Australians, in particular, rests on recognition of the importance of Indigenous knowledge to Indigenous Australians and its value to the documentary heritage of the nation. In this sense then, Indigenous knowledge is a source and site of permanent intersection with the LIS sector, not confined to remote areas but also implicating national, state, metropolitan and regional libraries.

\section{Protocols for Practice at IK-LIS Intersections}

Despite the goodwill in the Australian LIS sector and the professions' desire to do the right thing with respect to Indigenous knowledge and peoples, there is still in some places a perceptible undercurrent of apprehension that Indigenous concepts of knowledge management and intellectual property protection are restrictive in a way that is sometimes contradictory to or incompatible with liberal and democratic notions of free and universal access to information and knowledge.

The demand to include 'special' provisions for Indigenous peoples or their knowledges within LIS practice is likewise sometimes still seen as outside the brief of providing services for the singular category of 'all Australians' - a resort to the oftused argument that equality in services means the same services for all, or its corollary that 'special' services in addition to services shared with other Australians denote a 'privilege' for Indigenous Australians that is not extended to other groups. 
There are also arguments sometimes put by both Indigenous and non-Indigenous people that because Indigenous knowledge systems are distinct systems they should remain outside the purview of Western and LIS systems of knowledge management. Whilst it is true that secret and sacred aspects of Indigenous knowledge have no place in the public domain and should remain outside of LIS systems, the fact is that much Indigenous knowledge, including secret and sacred knowledge, is already contained and managed (inappropriately, according to Indigenous customary principles) within LIS systems. It is also the case, as demonstrated by the Yolyu's establishment of the Garma Cultural Studies Institute and by the collaborative Indigenous knowledge projects currently underway, that many Indigenous Australians desire to use, share and circulate their knowledge, which in turn promotes its intersection with the LIS sector. The two systems intersect in myriad ways; the task is to develop processes for dealing with Indigenous knowledge in these intersections.

It is also the case that Australian Indigenous knowledge shares characteristics with and constitutes part of a global network of Indigenous knowledge and that Australian Indigenous peoples are connected to the global Indigenous community in various ways and for various purposes. Globally, (and with UN support), traditional knowledges are being documented, registered, preserved and protected in order to retain them for future utility, sustainable development and to sustain millions of livelihoods that lie outside of market economies. The Australian Indigenous imperative to preserve this heritage and manage it in culturally sustaining ways is complex; in part about the pragmatics of not losing control of the future utility of this knowledge, in part about honouring and defending the traditions of the original inhabitants of this continent and in part about utilising it to overcome the socially destructive legacies of colonial intervention. In many countries, sui generis systems (laws within national legal systems) are being developed to protect these knowledges. Australian Indigenous knowledge enjoys no such culturally appropriate legal protection under Australian law.

To allay concerns of those who have difficulty reconciling the right of Indigenous knowledge to be accorded special treatment within Australian LIS systems, it is useful to consider sections from the preliminary report ${ }^{26}$ of the UN special rapporteur, Mrs Erica-Irene Daes, on the Protection of the Heritage of Indigenous People, in which she noted that:

6. Their own conception of the nature of their heritage and their own ideas for ensuring the protection of their heritage are central to the 'new partnership' with indigenous peoples symbolized by the International Year of the World's Indigenous People in 1993.

7. The Special Rapporteur wishes to underscore the fact... that indigenous [sic] peoples have repeatedly expressed their willingness to share their useful knowledge with all humanity, provided that their fundamental rights to define and control this knowledge are protected by the international community. Greater protection of the indigenous peoples' control over their own heritage will not... decrease the sharing of traditional cultural knowledge, arts and sciences with other people. On the contrary, indigenous peoples' willingness to share, teach, and interpret their heritage will increase.

8. The heritage of an indigenous people is not merely a collection of objects, stories, and ceremonies, but a complete knowledge system with its own concepts of epistemology, philosophy, and scientific and logical validity. The diverse elements of an indigenous peoples heritage can only be fully learned or understood by means 
of the pedagogy traditionally employed by these peoples themselves, including apprenticeship, ceremonies and practice. Simply recording words or images fails to capture the whole context and meaning of songs, rituals, arts or scientific and medical wisdom. This underscores the central role of indigenous peoples' own languages, through which each people's heritage has traditionally been recorded and transmitted from generation to generation.

These statements affirm that Indigenous heritage is linked not just to Indigenous knowledge systems but as well to specific Indigenous cultural contexts. Further, these statements assert that documentation assists circulation and access. It is also useful to consider these statements when thinking about the importance of developing practice that can deal with the intersections between Australian Indigenous peoples' knowledge and LIS systems in culturally appropriate and sensitive ways.

These statements assert a critical principle also contained within the Aboriginal and Torres Strait Islander Protocols for Libraries, Archives and Information Services. ${ }^{27}$ This is the involvement of Indigenous Australians at all levels of practice. Collaboration and cooperation are essential between Indigenous people and LIS professionals in all stages of practice, from the identification of materials, to developing the means for appropriate Indigenous cultural experts to work in institutions to identify materials, to the development of appropriate systems and processes for managing them, for determining the conditions of access or restriction, to determining how to locate, copy or repatriate materials for local access by the relevant communities, to customising the technology to suit particular local specificities, to the development of local LIS activities with an Indigenous knowledge focus of relevance to the specifics of local communities.

In all these, trust, respect, and sharing of practice are critical if custodial authorities from both Indigenous communities and the LIS sector are to feel confident about emerging regimes for practice at these intersections. The experience of the Gupapuyyu Legacy Project at the Galiwin'ku Indigenous Knowledge Centre in the Northern Territory supports this. ${ }^{28}$ Not only were Gupapuyyu elders essential to the process of identifying materials in institutions, the mapping of these materials into Yolyu systems for management to meet local conditions of access could not be achieved without the work of experts in this knowledge system. In local contexts such as this, the development of specific sets of protocols relevant to the particular intersection is necessary to guide future work and build consistency in practice.

This leads to the other critical element to have emerged when dealing with Indigenous knowledge in the LIS sector-the necessity for protocols to guide practice and to assist professionals to deal with unfamiliar issues. Recent research ${ }^{29}$ has indicated that the generic Aboriginal and Torres Strait Islander Protocols for Libraries, Archives and Information Services whilst useful as a first reference, requires more detailed supporting information to meet the needs of a diverse sector.

This is particularly the case with respect to Indigenous knowledge intellectual property intersections and guidelines for digitisation, which is the current technology for repatriation and storage of Indigenous knowledge materials in local contexts or for remote access. Where legal mechanisms to protect Indigenous knowledge have not yet been developed to deal with the intersection between customary laws and Western intellectual property law, protocols are important ways to guide appropriate practice. ${ }^{30}$ With relation to Indigenous knowledge, there is evidence that protocols need to be 
localised to deal with the specific needs and requirements of local groups and that technology needs to be able to support these protection regimes. As well, because Indigenous knowledge is represented in a number of formats, such as text, art, dance, ceremonies, historical photographs, film, audio-recordings and so on, protocols increasingly need to relate to these aspects.

\section{Conclusion}

It is important for professionals used to conceptualising Indigenous knowledge primarily as Indigenous 'material' within 'collections' not only to consider that elements of these materials belong to Indigenous knowledge systems and require differential treatment but also to recognise them as part of the documentary heritage of Australia.

Although we have asserted Indigenous knowledge as an identifiable discrete element of Indigenous materials in the LIS sector, requiring appropriate management practices, it is important to recognise that in its intersection with LIS systems the boundaries between Indigenous knowledge and other materials will not always be neat and tidy. Both repatriation of material in historical collections to local Indigenous databases and ongoing documentation will likely continue the interconnections and overlaps between Indigenous traditional knowledge, Indigenous historical materials, and other materials relevant to Indigenous library and information services. This underlines the need for awareness of Indigenous knowledge within materials and collections as well as deeper understanding of the issues which are emerging as a result of the current trend to document, integrate, innovate and share Indigenous knowledge, as well as consideration of how these activities impact on the provision of services for Indigenous peoples.

Further, we would argue, it is helpful if LIS professionals consider Indigenous heritage from the Indigenous standpoint as expressed by the UN special rapporteur, Erica-Irene Daes and to recognise that at the heart of this intersection are people. In Australia, Indigenous motivation to reconnect with traditional knowledge is varied and complex. But arguably, in many places, individuals, groups and communities will increasingly pursue the re-integration of this knowledge, or innovations based on this knowledge, into the fabric of their personal and community lives and into education and work, in order to develop community capacities and social and economic wellbeing.

Although LIS professionals deal with documented Indigenous heritage and knowledge it is important for the profession to understand this as a derivative form and to continue to conceptualise Indigenous knowledge as an oral tradition, deeply implicated in people's daily practices and attached to local cultural contexts which are, as well, inter-connected via various pathways and networks across the country. In this sense, Indigenous knowledge is more than 'heritage'; it is a dynamic and continuous system of knowledge. Indigenous peoples are the agents of this knowledge and require the means and authority to maintain continuity with their knowledge tradition according to their own understandings. This only increases the need to develop appropriate and, as much as possible, consistent practice in collaboration with Indigenous peoples themselves. 
If these notions are held uppermost in the minds and hearts of the profession, then the development of LIS practice that honours Australia's ancient and modern traditions contemporaneously can prevail. Underpinning the development of best practice, however, is the ongoing need for scholarly conversation and the sharing of practice within the membership. The imperative for the profession to develop the Indigenous professional membership and to develop mutually productive and respectful relationships with members of the Indigenous community at all levels of practice is a strong and continuing one. Resolution of difficulties, tensions and complexities at the intersections of the two systems of knowledge management necessitate no less than this and are destined to fail without it.

\section{Notes}

$1 \quad$ World Intellectual Property Organization, Intellectual Property Needs and Expectations of Traditional Knowledge Holders, report on fact-finding missions on intellectual property and traditional knowledge 1998-1999 WIPO Geneva 2001 p23 at

http://www.wipo.int/tk/en/tk/ffm/report/final/pdf/part1.pdf

2 Working Group on Article 8(j) 2001-2004, Article 8(j): Traditional Knowledge, Innovations and Practice Portal, Secretariat of the Convention on Biological Diversity, Montreal at http://www.biodiv.org/programmes/socio-eco/traditional/default.asp

\section{WIPO $2001 \mathrm{p} 25$}

4 M Battiste and J Youngblood Henderson Protecting Indigenous Knowledge and Heritage: A Global Challenge Purich Saskatoon Saskatchewan 2000

5 A Agrawal 'Indigenous Knowledge and the Politics of Classification, International Social Science Journal vol 54 no 1732002 pp287-297; D Nakashima and P Guchteneire 'Science and Other Systems of Knowledge: A New Impetus for Indigenous Knowledge from the World Conference on Science' Indigenous Knowledge and Development Monitor vol 7 no 31999 pp13 at http://www.nuffic.nl/ciran/ikdm/7-3/nakashima.htm

6 E Mathias-Munday 'Background to the International Symposium on Indigenous Knowledge and Sustainable Development’ Indigenous Knowledge and Development Monitor vol 1 no 21993 at http://www.nuffic.nl/ciran/ikdm/1-2/articles/background.html

$7 \quad$ T Janke Our Culture, Our Future: Report on Australian Indigenous Cultural and Intellectual Property Rights Michael Frankel \& Co Surrey Hills 1998; World Intellectual Property Organization (WIPO), Minding Culture: Case Studies on Intellectual Property and Traditional Cultural Expression prepared by Terri Janke for World Intellectual Property Organization (WIPO) Geneva 2002 at http://www.wipo.int/tk/en/studies/cultural/minding-culture/index.html; J Anderson 'Indigenous Communal Moral Rights: The Utility of an Ineffective Law' Indigenous Law Bulletin vol 5 no 302004 pp8-10; M Davis 'Indigenous Peoples and Intellectual Property Rights' Research Paper no 20 1996-97 Information and Research Services Department of the Parliamentary Library Canberra at http://www.aph.gov.au/library/pubs/rp/1996-97/97rp20.htm; M Davis 'Biological Diversity and Indigenous Knowledge' Research paper no 17 1997-98 Information and Research Services Department of the Parliamentary Library Canberra at http://www.aph.gov.au/library/pubs/rp/1997-98/98rp17.htm; Australian Copyright Council Protecting Indigenous Intellectual Property Redfern 1998

8 Secretariat of the Convention on Biological Diversity, Composite Report on the Status and Trends Regarding the Knowledge, Innovations and Practices of Indigenous and Local Communities, Regional Report: Australia, Asia and the Middle East prepared by M Langton and Z Ma Rhea 2003 at http://www.biodiv.org/doc/meetings/tk/wg8j-03/information/wg8j-03-inf04-en.pdf

9 R Ellen and H Harris 'Concepts of Indigenous Environmental Knowledge in Scientific and Development Studies Literature: A Critical Assessment' paper presented at the East-West Environmental Linkages Network Workshop 3 8-10 May 1996 Canterbury UK at http://www.ukc.ac.uk/rainforest/SML_files/Occpap/indigknow.occpap 1; A Agrawal 'Dismantling the Divide between Indigenous and Western Knowledge' Development and Change vol 26 no 31995 pp413-439 
$10 \quad$ A Agrawal 2002 pp.87-297

11 M Battiste and J Youngblood Henderson 2000

12 A Agrawal 'Indigenous and Scientific Knowledge: Some Critical Comments' Indigenous Knowledge and Development Monitor vol 3 no 3-4 1995 at http://www.nuffic.nl/ciran/ikdm/33/articles/agrawal.html

13 M Langton and Z Ma Rhea $2004 \mathrm{p} 7$

14 Garma Cultural Studies Institute (GCSI) at http://www.Garma.telstra.com/education.html

15 Ibid

16 See http://savanna.ntu.edu.au/research/projects/indigenous.html

17 See http://www.desertknowledge.com.au/PDF/DK-CRCIIP)0204.pdf

18 J Neparrnga Gumbula ch 2 in this volume

19 Ibid

$20 \mathrm{~J}$ Anderson ch 7 in this volume; T Janke ch 8 in this volume

21 Ibid

22 P Veth interview at Australian Institute of Aboriginal and Torres Strait Islander Studies 23 June 2004

23 M Nakata et al. ch 16 in this volume

$24 \quad$ C Richmond ch 3 in this volume

25 R Briggs interview at State Library of New South Wales 7 September 2004

26 United Nations Protection of the Heritage of Indigenous People, Preliminary Report of the Special Rapporteur, Mrs Erica-Irene Daes submitted in conformity with Sub-Commission resolution 1993/44 and decision 1994/105 of the Commission on Human Rights E/CN.4/Sub.2/1994/31 8 July 1994 pp2-3

27 A Byrne, A Garwood, H Moorcroft and A Barnes Aboriginal and Torres Strait Islander Protocols for Libraries, Archives and Information Services ALIA Press Canberra 1995

28 J Anderson ch 7 in this volume

29 M Nakata, A Byrne, G Gardiner and V Nakata 'Mapping the Impact of the 1995 Aboriginal and Torres Strait Islander Protocols for Libraries, Archives and Information services' unpublished report UTS Sydney 2005

T Janke 2004 


\title{
Chapter 2
}

\section{Exploring the Gupapuyna Legacy: Strategies for Developing the Galiwin'ku Indigenous Knowledge Centre}

\author{
Joe Neparrna Gumbula*
}

My job at the Galiwin'ku Indigenous Knowledge Centre is to search for information about old collections that represent local family histories, and to negotiate for digital copies of these materials to be made available for local access. I now spend at least three months of each year travelling interstate to work in state institutions such as Museum Victoria, which holds the Thomson Collection, and to meet with private collectors who often hold large collections of photographs from the mission era.

Galiwin'ku is located in northeast Arnhem Land, which was one of the last regions in Australia to have felt the presence of mission and government authorities. It is populated by Yolnu (people) of some 60 different mala (hereditary groups) whose homelands are spread across this region.

From the 1920s, large collections of artefacts, photos and recordings were gathered in northeast Arnhem Land from people of my parents' and grand-parents' generations. Most of these collections are now held in large state institutions and smaller private collections, and it is only in the past decade that copies of these materials have been returned to our communities with any regularity.

\section{Yolnu Knowledge Management}

In 2002 I created the diagram reproduced here as Figure 1 to demonstrate how Yolyu knowledge systems figure in the management of digital materials at the Galiwin'ku Indigenous Knowledge Centre. The following three figures explain in more detail how I represent the organisation of Yolnu society and the management of Yolnu knowledge. Each adds another layer and reveals the complex relationships that this system manages.

Figure 2 illustrates how Yolyu society is di-constitutional. The super-groups or moieties who possess these two constitutions are called Dhuwa and Yirritja. Each Yolyu group exists under one constitution or the other. My group, Gupapuynu, is Yirritja while my wife's group, Dätiwuy, is Dhuwa, and under Yolyu law we must marry outside our own moieties. This fundamental law ensures cooperation and sociopolitical balance between Dhuwa Yolyu and Yirritja Yolnu.

\footnotetext{
* Joe Neparrnga Gumbula is Community Liaison Officer, Galiwin'ku Indigenous Knowledge Centre \& Senior Research Fellow at University of Melbourne.
} 
Three strata of knowledge, ceremony and law are held by each Yolyu group (see Figure 3). They are yärra' (restricted), dhuni' (peri-restricted) and Garma (public). All Yolyu materials including artefacts, photos and recordings of people, places, ceremonies, language, songs, dances and designs are bound by these principles.

Figure 4 shows knowledge owners, rights and responsibilities. Here:

$0=$ own group

$1=$ sister's child's group

$2=$ sister's daughter's child's group

$3=$ sister's daughter's daughter's child's group

4 = sister's daughter's daughter's daughter's child's group

$5=$ daughter's child's group, and

6 = sister's daughter's husband's group.

In addition to owning its own physical and intellectual property, each Yolnu group also holds secondary rights in the properties of other groups to whom its members are related through gurrutu (kinship). Leaders of each group are responsible for negotiating access to the property of others through these secondary rights. This adds yet another level of complexity to the way that digital materials held by the Galiwin'ku Indigenous Knowledge Centre must be accessible to the community.

\section{Building Collections}

The kinds of materials that I have found in interstate collections include historical photos from the Thomson Collection at Museum Victoria of my father and father's father, Djäwa and Darritjuarritj, from 1937 and my wife's father, Mowarra, who is still with us today, from 1942.

In addition to gathering digital copies of historical materials, the Gupapuynu Yolyu have also embarked on a campaign to record our current cultural initiatives for future generations using the best technologies available to us through partnerships with organisations and institutions including the Australian Institute of Aboriginal and Torres Strait Islander Studies (AIATSIS), Museum Victoria, The University of Melbourne, Ian Potter Museum of Art, ScreenSound Australia, Yothu Yindu Foundation, PARADISEC and the National Recording Project for Indigenous Music in Australia. Since 2002 we have recorded several new performances of major ceremonies for our family history project, the Gupapunu Legacy. 


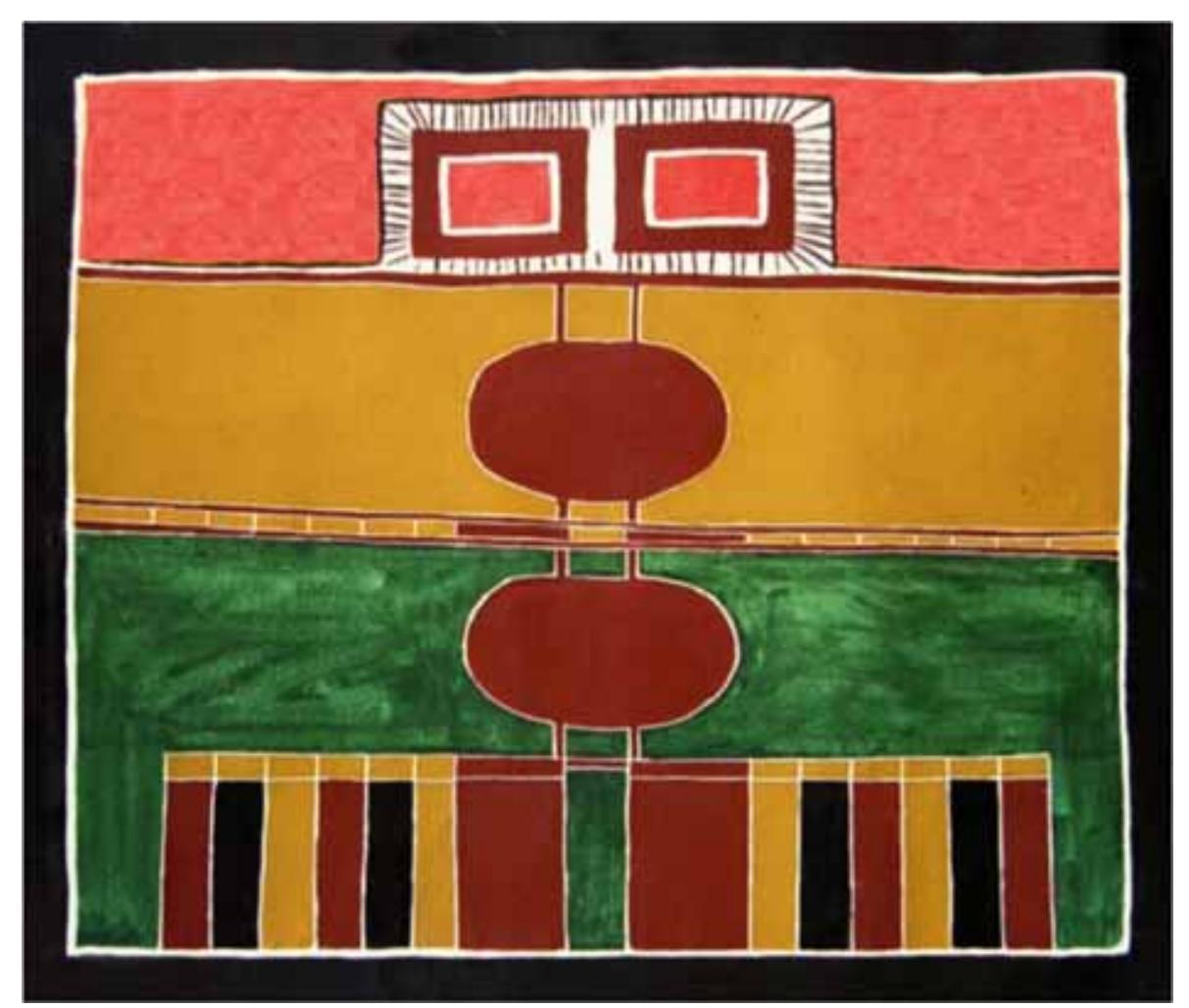

Figure 1: Yolnu knowledge systems

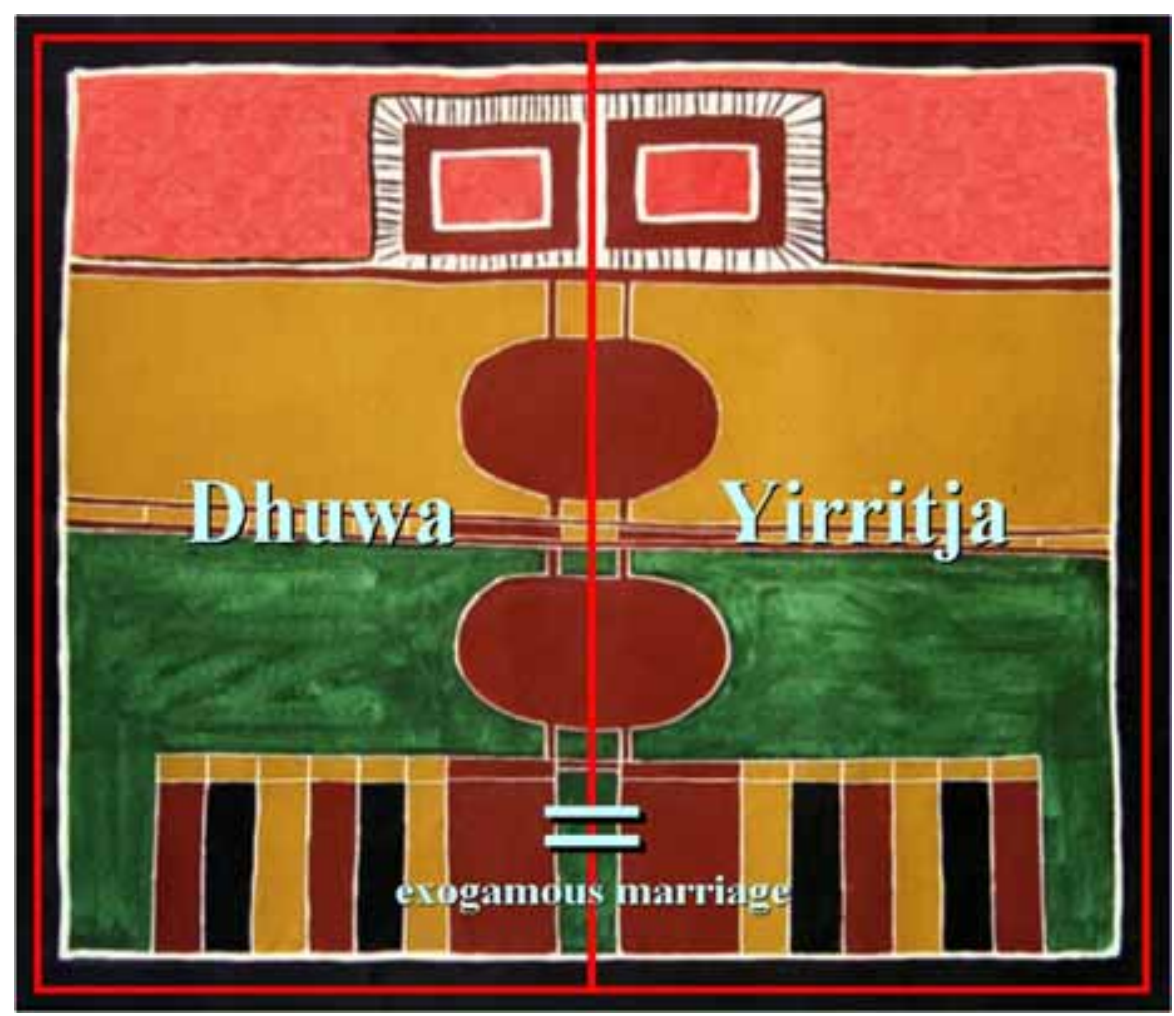

Figure 2: Yolnu society 


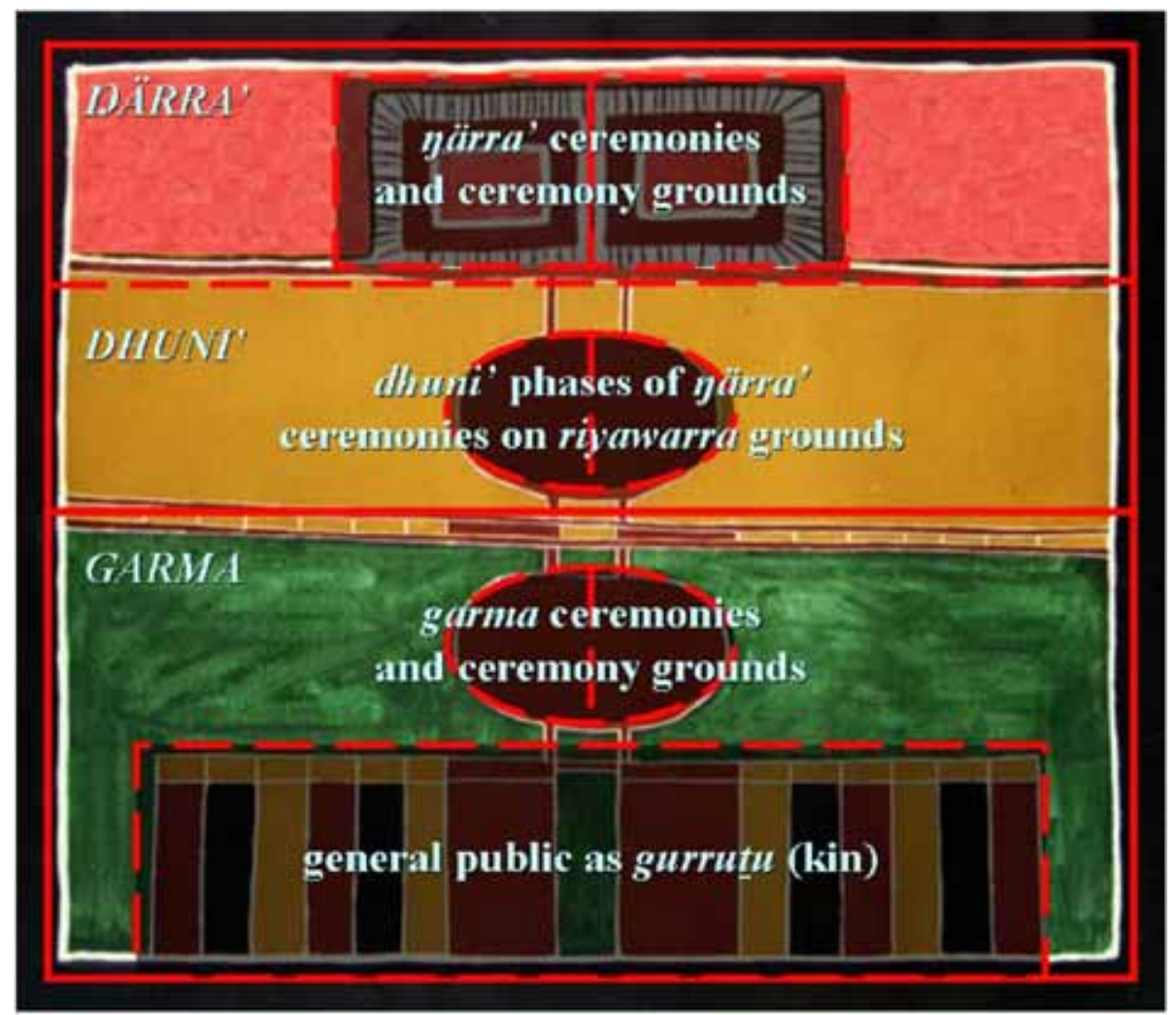

Figure 3: Yolnu strata of knowledge, ceremony and law

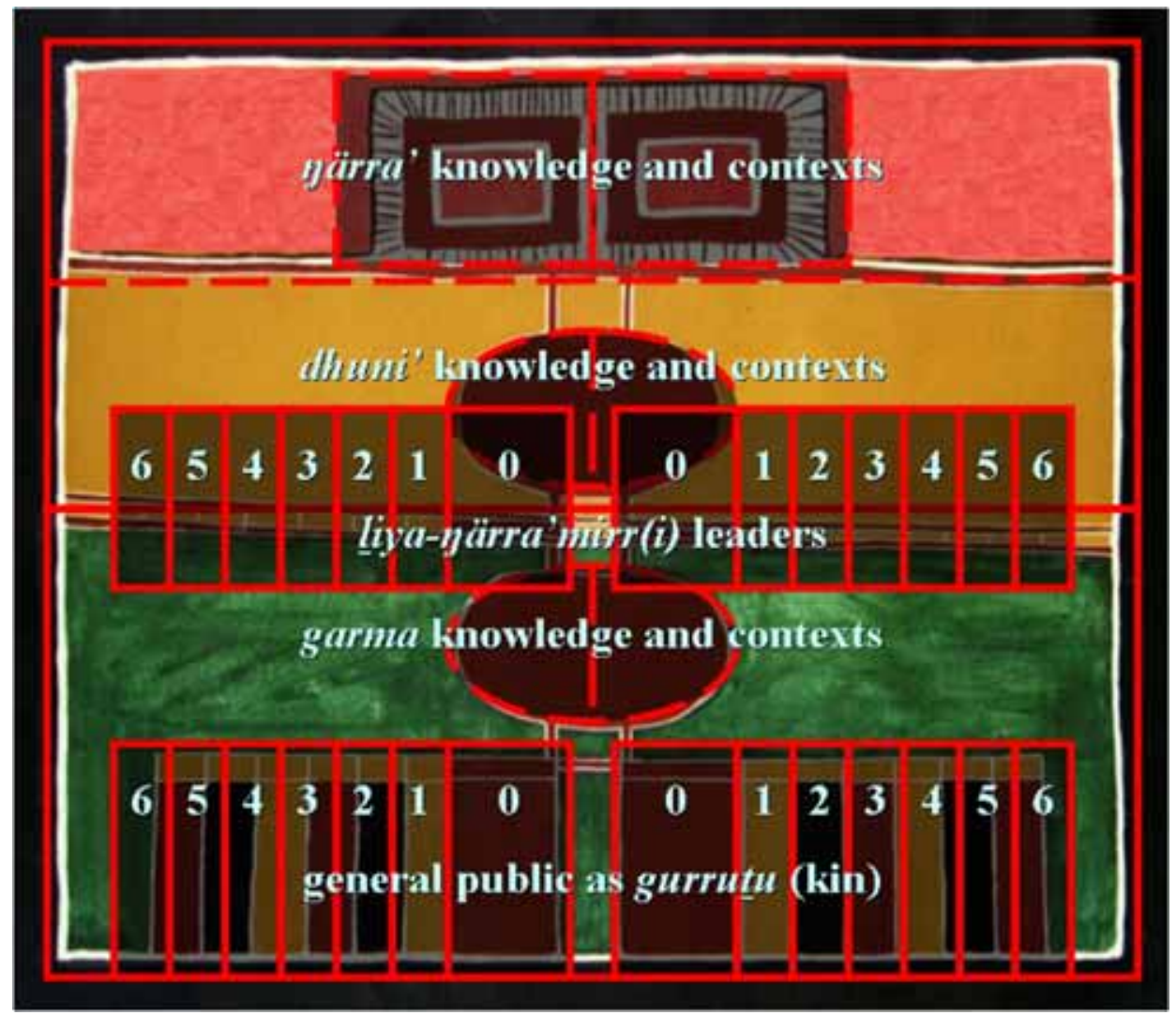

Figure 4: Yolnu knowledge owners, rights and responsibilities 


\title{
Chapter 3
}

\section{Libraries and Knowledge Centres in the Northern Territory}

\author{
Cate Richmond ${ }^{*}$
}

In June 2004, the Northern Territory Library and Information Service (NTLIS) began implementation of a new Libraries and Knowledge Centres' model in eight communities in the Northern Territory. This chapter discusses the NTLIS model for library services in Indigenous communities, explains the implementation process, and explores some of the challenges in providing Indigenous library services in remote locations. Two case studies will be provided to illustrate what we have learned and how the model is being applied in specific communities. This chapter also discusses the database that is being made available to communities to enable them to organise, store and make accessible, digitised material related to their cultural heritage.

\section{Background}

The Northern Territory Library and Information Service is responsible for developing communities by providing access to appropriate library services for all Territorians. The NTLIS has four main goals to:

- develop communities through libraries

- connect people to information

- preserve Northern Territory documentary and cultural heritage, and

- help people learn.

Indigenous people make up $30 \%$ of the Territory's population. While $83 \%$ of Northern Territory residents live in greater Darwin and Alice Springs, $73 \%$ of Indigenous residents live in remote areas.

The Libraries and Knowledge Centres (LKC) unit within NTLIS provides support and training to public libraries, community libraries and school libraries across the Territory. In addition, the LKC Unit is directly responsible for providing library services at two joint-use (school and community) libraries at Taminmin and Nhulunbuy.

There are 22 community libraries, most of which are located in Indigenous communities across the Top End, with several in the southern region of the Territory. These libraries are staffed by Community Library Officers (CLOs) and are usually open from between 10-30 hours per week. NTLIS provides an annual grant to

\footnotetext{
* Cate Richmond is Assistant Director, Libraries and Knowledge Centres, at the Northern Territory Library and Information Service.
} 
Community Government Councils to cover library operating costs and salaries. A separate annual amount is also allocated for the purchase of library resources.

Ongoing training and support is provided to CLOs by NTLIS. This involves site visits and regular telephone and email contact. A CLO website offers further support through procedures and manuals, tips for running programs and activities, recommended web pages, lists of Indigenous resources, etc. A CLO Forum is held in Darwin each year and all CLOs are supported to attend. The forum consists of three days of training and development activities. The theme of this year's forum was 'Building links for reading' with the focus on early childhood learning and library programs to support literacy.

Community libraries contain a range of resources including books, magazines, videos and DVDs. All libraries have at least one computer that is available for public use and most have internet access. Through the internet library clients have access to the IPortal (the combined online catalogue of NT libraries) and to a range of online resources provided by NTLIS including e-books such as TumbleBooks, and the Health and Wellness Resource Centre.

While Indigenous remote clients rarely borrow library resources, Indigenous clients use their community library to access books, magazines, videos and DVDs. Library computers are used for internet access, particularly internet banking sites and Indigenous websites. The most popular material is the Indigenous collection, which is shelved in a specially designated area and is identified by an Aboriginal flag on the spine of each item. The most widely used resources are those that relate to local community and family groups.

\section{LKC model}

The concept of Indigenous Knowledge Centres (IKCs) in the Northern Territory has been discussed for a number of years. Interest and impetus has come from Indigenous communities themselves as a way of preserving their cultural heritage and providing appropriate access to parts of it. Many communities are now focussing on the repatriation of local material and grappling with ways to preserve old photographs, tape and video recordings and documents. There is recognition that these items need to be preserved in a digital format. In communities where digitisation is well advanced, there is further recognition of the need to structure and organise this digital material so that it can easily be retrieved.

Some communities are actively engaged in work to record local languages that are in danger of extinction as elders pass away. There is high demand for access to local material and for the provision of personal copies of family photographs and recordings of songs and stories.

In 2003, NTLIS provided funding for three pilot knowledge centre projects in Galiwin'ku, Wadeye and Anmatjere. The projects were driven by community members and in each case different software and management systems were used. The term 'knowledge centre' has many different interpretations and the challenge for NTLIS was to develop a model which was based on the role of the community library, and which would be sustainable through provision of ongoing support and training. The model provides flexibility to suit individual community needs, and is able to be 
supported by NTLIS. Evaluation of the three pilot centres clearly indicated that NTLIS needed a consistent model for library services in remote communities.

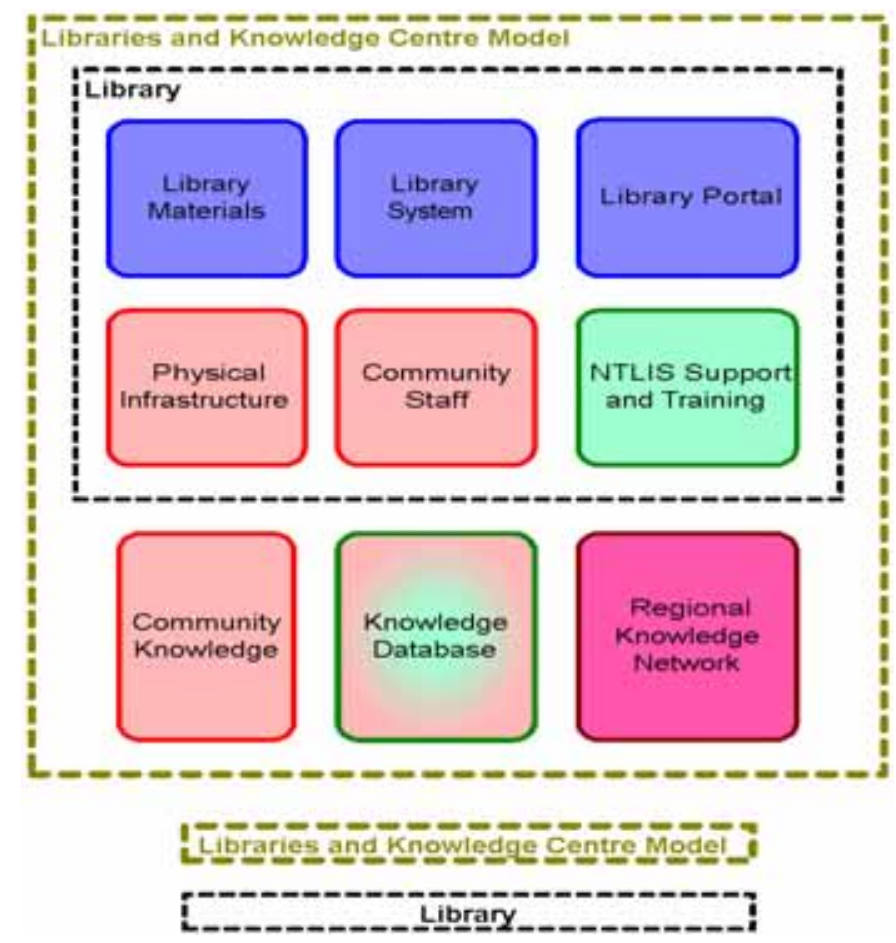

The LKC model is built on the services that NTLIS already provides through community libraries. It is presented as a series of building blocks comprised of traditional library concepts plus Indigenous knowledge concepts. The model outlines the essential components and who is responsible for providing each of these. Components include the library system, community knowledge, a knowledge database and the facility to link local communities through a regional knowledge network. Flexibility is achieved through the community deciding which components suit their needs. Sustainability is achieved through NTLIS support in the areas of library resources, provision of a database and ongoing training and support including maintenance of the software.

The key focus for libraries is on literacy, access to information and preservation of culture. The selected model has the potential to facilitate 'joining up' of other government and non-government services such as Indigenous literacy and language centres, community archiving facilities, and arts and culture centres.

Training in all aspects of managing the Library and Knowledge Centre enables community members to develop or increase their skills.

In short, Libraries and Knowledge Centres:

- provide access to knowledge and information through core library services including English literacy and information literacy programs

- enable the acquisition and preservation of local knowledge 
- provide training and support to community members engaged in acquiring and preserving knowledge, and

- provide access to recreational activities for all groups within the community.

\section{Indigenous Knowledge and Databases}

A key component of the model is the database of digitised local material. NTLIS evaluated several products before selecting the Ara Irititja software that was developed specifically for Pitjantjatjara communities in Central Australia. This database has a simple, user-friendly interface and a proven record of successful implementation and use by Indigenous people. An important feature of the database is the ability to restrict access to individual items to cater for cultural sensitivities.

NTLIS has negotiated a Territory-wide licence for Ara Irititja, which allows it to be installed in all Northern Territory public and community libraries at no cost to local communities. Ongoing licence fees are met by NTLIS. LKC staff are also collaborating on other knowledge database developments, including the software applications developed by the Distributed Systems Technology Centre (DSTC). In time we anticipate that other software products with even more functionality may become available. To ensure communities will take full advantage of new developments, NTLIS has adopted an underlying principle that digitised material and associated metadata is always stored in a logical file structure that would enable the data to be viewed through different software products.

Ara Irititja has been re-branded for Northern Territory library use as Our Story. Each community is encouraged to choose a local name for their database; for example in Wadeye the database is known as Murrinh Nekinigme and in Peppimenarti it is called Ngan'gi Ngagurr. In all cases, the community owns the content in the database and data is stored according to rules set by community leaders.

There is ongoing debate about the concept and validity of Indigenous knowledge databases. Michael Christie, Associate Professor, School of Education, Charles Darwin University, acknowledges that many Indigenous parents and grandparents endorse the use of databases to help teach young people about their culture. However, Christie argues that:

It would be easy to assume that these digital objects actually contain knowledge, but
in fact they are simply information: series of ones and zeros. The digital object is a
re-presentation or an artefact of an earlier act of knowledge
performance/production.

This was reaffirmed by Alfred Wunbaya, Deputy Chair, Galiwin'ku Community Incorporated, when he explained recently that knowledge lives in the head, but it is not made real until it is transferred to the hand, that is, applied through action. ${ }^{2}$

Our experience has taught us that communities and individuals have many different interpretations of both the concept of knowledge and the purpose of a knowledge database. Our role is to work with communities to ensure that their LKC (including the database) meets local needs within the framework of their cultural, legal and social structures. This has led to different implementations in different communities, however all remain based on the LKC model, and are therefore sustainable by NTLIS. 


\section{Implementation}

Implementation of the model began in June 2004. In the first phase of the project, the LKC Unit is focusing on eight communities across three regions:

- Galiwin'ku, Milingimbi and Ramingining (East Arnhem region)

- Wadeye and Peppimenarti (Port Keats/Daly River region)

- Umbakumba, Angurugu and Alyangula (Groote region).

Northern Territory government funding was allocated to commence Phase One, with funds being used to purchase additional IT equipment and to cover salary, travel and software expenses. While the initial implementation is project-based, NTLIS support and training is ongoing. Phase Two will extend the model to other existing community libraries, and Phase Three will seek to extend it to communities that do not currently have a community library. This phase will require significant additional funding, as NTLIS does not currently have the capacity to establish new library services.

Consultation with communities has been continuing since June 2004. It is based on a draft project plan that clearly states the project goals and objectives and the roles and responsibilities of both the Community Council and NTLIS. The plan requires approval from the Community Council and NTLIS, as well as acceptance by CLOs and community leaders.

Our Story has now been installed in four communities. Training of CLOs and other local staff is underway, with LKC staff visiting communities regularly for ongoing consultation and training. The successful implementation of each LKC depends on a number of critical factors, most importantly the involvement of one or more local champions to drive the project from within the community. The next two sections of the chapter will discuss implementation in the communities of Galiwin'ku and Wadeye.

\section{Galiwin'ku Knowledge Centre}

There was strong community vision for the establishment of a knowledge centre in Galiwin'ku. Unlike all other LKC sites, Galiwin'ku does not have a community library, although NTLIS provided initial funding to establish the Knowledge Centre. The Centre is housed in a small building that is not large enough to display library resources or allow access for more than a few people at a time.

Although NTLIS staff had some involvement in the initial planning, the Knowledge Centre had quite different objectives to that envisaged by NTLIS. For the first 18 months of its operation NTLIS had minimal involvement with the Centre.

However, an innovative arrangement was established between the Knowledge Centre, Galiwin'ku Community Inc. and the University of Melbourne, whereby a PhD student undertaking research in Galiwin'ku provides support to the Knowledge Centre for 15 hours a week. This arrangement has facilitated a number of significant local research projects.

When the Centre was established, a knowledge database was selected and purchased, however the software proved to be difficult to access and use, did not meet community needs and therefore failed to engage community members. 
From a library perspective it was difficult for NTLIS to determine how to support this very different Knowledge Centre model. Without ongoing involvement in the Centre NTLIS was not able to provide the building blocks that underpin the model. With the purchase of the Ara Irititja software, NTLIS had something to offer the Galiwin'ku Knowledge Centre by way of a functioning, easy to use database supported by NTLIS.

Consultations with the Council and community members commenced in September last year. Interest in the database has been encouraging, especially from community groups who are actively engaged in research. It soon became clear that local needs and Yolyu cultural and knowledge structures required a different approach. However, the LKC model proved to be robust enough to cater for these needs.

Recently NTLIS put a proposal to Galiwin'ku Council. This involves separate databases being installed at a number of sites in the community (the Yalu Women's Centre, the Literacy Centre at the school and the Arts Centre) as well as at the Knowledge Centre. After initial training of staff at all locations, NTLIS will provide ongoing support and training to Knowledge Centre staff who will then act as coordinators for the other sites. Items added to each database that are identified as Garma or public knowledge will also be uploaded to the Knowledge Centre database, providing the whole community with access to combined, publicly available resources. This also means that sensitive information, which needs to be restricted to a family or clan-based database, can be kept separate and can be maintained by authorised people.

NTLIS is also providing assistance to explore ways to fund an ongoing research position located at the Knowledge Centre and based on the model already established through the partnership between the Knowledge Centre, Galiwin'ku Community Inc. and the University of Melbourne.

\section{Wadeye Library and Knowledge Centre}

Wadeye is the largest Indigenous community in the Northern Territory with almost 2500 residents. This year approximately 100 babies were born in the community. ${ }^{3}$ The LKC is located in the rural transaction centre along with other community services. The room occupied by LKC is small but the facility is very well used. The CLO is a long-time resident of the community, who also operates the museum and assists with a range of other community activities, including research through the local language centre and management of the community radio broadcasting service.

Members of the community have been collecting and creating local material for many years. This has in part been driven by the desire to preserve local languages and culture, which are in danger of being lost as older community members pass away. Prior to commencing the LKC project Wadeye already had a significant amount of digitised material including songs, videos and photographs. The sheer number of digitised files, however, made it difficult to manage the items and it was not possible to easily retrieve specific images or recordings.

In the two months since Our Story was installed, more than 8,000 items have been added to the database. A group of elders is now working with the CLO and LKC team members to determine access levels for each item. In recent weeks, groups such as elders and school children have been providing the content to enrich items in the 
database and to make them searchable and accessible. These sessions are facilitated by an LKC staff member with assistance from community people.

The ability to view items through the database has greatly enhanced the process of adding information (metadata) to each item. Material identified as 'public' is accessible to the entire community through a computer located in the LKC. Back-up processes are now in place to ensure data is not lost due to hardware or power failure.

The LKC team is currently undertaking a pilot training program in Wadeye, with assistance from a project officer who has excellent multimedia skills and significant experience in introducing Indigenous youth to new technologies. The program aims to engage youth and other interested community members through training in a range of skills required for the successful administration and development of the database. NTLIS encourages and supports CLOs to undertake formal qualifications in areas such as library service and administration. The objective is to equip local people with skills that may lead to paid work in the community.

The program will also enable the LKC Team to develop a training model, which can then be used to train people in other communities where the LKC model is being implemented.

The success of the Wadeye LKC has to a large part depended on the enthusiasm and hard work of one individual in the community. He is keen to pass on his skills and knowledge so that the database remains sustainable and young people in Wadeye have an opportunity to learn new skills and to be actively involved in maintaining their cultural heritage.

\section{Challenges}

The implementation of LKCs has brought both challenges and rewards to NTLIS. It is extremely challenging to provide appropriate levels of support to community library staff living in remote locations. Many of them have sole responsibility for the library service, so they face the difficulty of working alone and being professionally isolated. NTLIS needs to develop smarter and more helpful ways of providing remote staff with support and training.

It is sometimes difficult to find and retain library staff. Other challenges include external factors such as changing council staff, unsuitable buildings and unreliable technology and networks. NTLIS tries to create opportunities for more paid employment in communities but the reality is that ongoing funds are often limited. Recently requests for help have come from several communities that do not have a library service. NTLIS would like to help but at this stage we can only offer the general library services that are available to all Territorians through the Northern Territory Library.

The rewards are also numerous. All communities in Phase One of the project have responded very positively to the opportunity for a community-owned software product that will not only preserve some of their cultural heritage but also provide easy access to it. Links between groups in communities are being strengthened as they work together to share resources. In Galiwin'ku for example, the Literacy Centre at the school has a wealth of local material that is used as part of the curriculum. This can now be digitally stored and preserved in Our Story and appropriate material made accessible to the wider community through the Knowledge Centre. In many locations 
community library staff are enthusiastically running school holiday programs and promoting literacy through storytelling sessions and other activities. Most CLOs make the annual trip to Darwin (often accompanied by children and other family members) to attend the CLO Forum. We are overwhelmed that participants are keen enough to attend all sessions over the three days.

\section{Future Directions}

The pilot programs and the first six months of implementation have shown that a consistent model supported by NTLIS and using appropriate software is meeting community needs. In mid-2005 NTLIS plans to implement a research project to evaluate Phase One of the project before embarking on the next phase. We are also working with Northern Territory archives and the Australian Institute of Aboriginal and Torres Strait Islander Studies (AIATSIS) to develop appropriate standards and guidelines for preservation, digitisation and collection management.

\section{Why Libraries?}

Why are libraries involved in this work, which some may see as the preserve of archives or museums? In her keynote speech to the 2004 Australian Library and Information Association (ALIA) Conference, Kay Raseroka, IFLA President and Director, University of Botswana Library Services, reminded librarians of our core value of equitable access to information. She stressed that librarians are leaders in the use of technology and we have the skills and expertise to deliver, organise, access and facilitate engagement with information. She argued that children need to engage with print as well as oral traditions and training in information literacy should begin in the cradle. She reminded us that libraries need to adapt and contextualise information for different groups. ${ }^{4}$

Literacy is a fundamental principle of library service. In August 2004, the Northern Territory Minister for Local Government, Mr John Ah Kit, made a statement to Parliament in which he said:

One of the aims of libraries is to preserve our Indigenous culture and encourage
community development. A vital key to this is to increase opportunities for libraries
in remote areas to assist in the development of information literacy and basic literacy
skills. $^{5}$

The community library is a focal point for access to information, recreation, learning and literacy. At community libraries people have free access to local information and resources and, if required, to resources beyond their community via the library network. Delivery of these services is made possible by the infrastructure provided by community councils and by NTLIS, which provides ongoing training and support. Herein lies our strength. As identified by the Minister for Local Government and Ms Raseroka, NTLIS has the required skills and expertise. These skills are all being utilised through our LKC model. Our work in communities and our commitment to the delivery of library services is ongoing and sustainable: NTLIS is here for the long haul. Unlike many other community projects, our involvement does not end when the project is completed.

In 2005, NTLIS will be implementing a program aimed at encouraging parents to read to their babies and promoting the resources available at community libraries. We have 
already provided access in all community libraries to Tumble Books, an e-book collection for children that is proving to be very popular.

The flexibility of the LKC model means that library services do not always have to be delivered within a designated library space. Library programs and services may better meet local needs if they are delivered elsewhere in the community (e.g. childcare centres, women's centres, museums, art centres etc). Literacy programs and the promotion of reading can occur anywhere, any time. Portable computer equipment enables database access wherever people need it, for example, under a shady tree, or on a bush trip. All of this can be achieved without compromising the key components of the model.

Flexibility, appropriate infrastructure, a user-friendly, robust database and ongoing expert library advice and support are the key elements in the delivery of library services to Indigenous communities in the Northern Territory. Our ongoing commitment to work with communities to develop local skills and to increase literacy through participation in library services ensures that we are contributing to the development of strong, sustainable Indigenous communities.

\section{Notes}

1 M Christie 'Computer Databases and Aboriginal Knowledge: Learning Communities' International Journal of Learning in Social Contexts vol 12003 p4

2 Personal communication with LKC staff 22 October 2004

3 T Bullemor quoted in presentation to the annual general meeting of the Local Government Association of the Northern Territory Darwin 13 October 2004

$4 \quad$ K Raseroka 'An Exciting and Challenging time for IFLA: Opportunities for Transformation' keynote paper presented at the ALIA 2004 Biennial Conference, Gold Coast 21-24 September 2004

$5 \quad$ J Ah Kit Ministerial Statement on Library Services Debates Ninth Assembly First Session 17 August 2004 Parliamentary Record No 212004 


\title{
Chapter 4
}

\section{Developing Indigenous Knowledge Centres}

\author{
Jacob Pilot ${ }^{\star}$
}

This chapter discusses some of the State Library of Queensland's initiatives in relation to the development of library resources and services for Queensland's Indigenous peoples. ${ }^{1}$ As the Chair of our Indigenous Advisory Committee and member of our Library Board, Lilla Watson said:

\begin{abstract}
By showing that respect to the Traditional owners, and Aboriginal protocols, we acknowledge that it was not shown in the past: land was just taken; our women were taken; many of our children were taken; and the bones of our ancestors were taken, often as curios, without any record of their names or country; artefacts and sacred objects were taken and displayed in public here and overseas; stories were taken, and often embellished, modified and published without acknowledgement, and without respect for confidentiality or protocols of their secret status; photos were taken, again, many as curios and often published without any consideration of the feelings of people featured in them. ${ }^{2}$
\end{abstract}

As an introduction to this chapter, in our view, Lilla's words are apt. We believe that for libraries, as custodians of knowledge and charged with ensuring that there is universal access to information, it is important to remind ourselves of the complexities when dealing with Indigenous materials. We believe the work we are doing at the State Library of Queensland is not only helping to provide library and information services to Indigenous peoples but is also challenging libraries to respond to the needs and history of Indigenous peoples, and add to the reconciliation process for all.

The Indigenous Knowledge Centres represent, in a very real example, the two-way learning process between the State Library and Indigenous communities throughout Queensland. Recognising that Indigenous peoples in Australia maintain a strong oral tradition, and working with the most remote communities in Queensland's Cape York and Torres Strait regions, the State Library has over the last two years established nine Indigenous Knowledge Centres at New Mapoon, Lockhart River, Wujal Wujal, Pormpuraaw, Aurukun, Injinoo, Darnley Island, Mabuiag Island and Poruma Island. These Indigenous Knowledge Centres are the first of thirty-one which will be established as a priority of the Indigenous Library Services Strategy. This process has involved challenging traditional library models and developing and exploring the potential for libraries to meet the knowledge needs of Indigenous peoples.

The Indigenous Knowledge Centres are one part of a set of initiatives being implemented by the State Library to improve services for Indigenous Australians and improve the handling of Indigenous materials. Another major initiative is the Indigenous Knowledge Centre Millennium Library Project. Other important initiatives

\footnotetext{
${ }^{*}$ At the time of writing Jacob Pilot was Executive Officer at Indigenous Library Services, State Library of Queensland.
} 
are discussed in the last section of this chapter and range from a pilot project to improve Indigenous services across the public library network, to exhibitions, to Indigenous protocols and policy development.

\title{
The Indigenous Knowledge Centre (IKC) Model
}

The Indigenous Knowledge Centre model that the State Library has developed is a flexible one, shaped by the way a particular community articulates their knowledge needs. It is a partnership between state government and the local Indigenous community council. The whole community can determine what their Indigenous Knowledge Centre will be to them: as special places to look after the songs, language, stories and traditions of their culture and also as a means to reach out to the wider global community.

A pivotal component of the Knowledge Centre model is the recognition that it is essential for the community to determine the way knowledge is created, retrieved, disseminated, utilised and owned. Processes have been described by Sandi Taylor:

\begin{abstract}
IKCs are established in close consultation with the community. When a community decides to proceed, the State Library of Queensland uses community development processes to engage the council and community to work with them to develop plans for their IKC. Local staff are recruited at this stage, so that they are involved in the entire planning and establishment process... ${ }^{3}$

The IKC model enables each community to shape its IKC to meet particular knowledge needs. A partnership between the Queensland Government and the local Community Council, IKCs offer free community wide access to the resources of a traditional library, supplemented with materials to support the oral and visual traditions of Indigenous peoples. The IKCs help capture the rich local history and traditions of communities and provide a repository of knowledge and information for future generations...

Communities often give their IKC a local language name to reflect their aspirations for the IKC. For instance, the Wujal Wujal community has called their IKC the Binal Mungka Bayen Knowledge Centre. Sixty-eight percent of the community is using the centre, and a literacy and numeracy program has commenced. This program is targeted at early school leavers, who are using their centre to develop their adult skills and re-engage with education. ${ }^{5}$
\end{abstract}

\section{Challenges Implementing the IKC Model}

However, establishing these Indigenous Knowledge Centres has not been without challenges. Two major challenges in ongoing sustainability of the Indigenous Knowledge Centres are retention of trained staff, and access to and support for quality technology and communications.

\section{Employment and Training}

As each centre has been developed, we have built upon our experience and developed sustainability strategies for the centres. We understand that critical to the success of Indigenous Knowledge Centres is ownership by the community; and this outcome is more likely if we can staff the centres with local people. However, at the same time we understand the necessity of providing staff with the appropriate skills for the position. 
Strategies to address this issue have included a Community Jobs Plan project in 2003 to run a 33 week Indigenous Knowledge Centre Training and Support Program. The program involved 13 unemployed Indigenous people 'skilling up' to work in local Indigenous Knowledge Centres. It is the first time in Queensland local unemployed Indigenous people have been able to access accredited and culturally appropriate library services training. Nine of the 13 participants successfully completed the Certificate II training, and a number of them are now commencing public sector traineeships together with training for a Certificate III in Library and Information Services.

The State Library has also developed the Librarians in Communities pilot program which involves professional librarians working with local staff in the established Indigenous Knowledge Centres. The Librarians in Communities program is being funded through a partnership between the State Library of Queensland and Indigenous Community Volunteers, an organisation which provides volunteers to support Indigenous community projects all over Australia.

The Librarians in Communities program provides an opportunity for qualified librarians to become mentors to Indigenous staff to guide and support them as they develop the Indigenous Knowledge Centres. Benefits flow two ways from this project as both the mentors and local Indigenous staff have the opportunity to develop cultural awareness in a practical way. Librarians have been placed in a number of communities under this program, and in several cases, librarians are now returning to the same community for a second placement.

This pilot program is a key initiative to improve service delivery and access to information resources for Indigenous Queenslanders. It enables skilled librarians to work alongside staff and community to help develop the organisational capacity of Indigenous Knowledge Centres.

\section{Technology}

When Indigenous Knowledge Centres are established, computers are provided for both staff and public use, and the local council arranges the internet access. Over the past two years there have been continual challenges in keeping computers functioning in Indigenous Knowledge Centres.

Some maintenance can be provided by the State Library's information systems support staff, but when there are major malfunctions equipment must be returned to Cairns or Brisbane, with resulting service limitations in the Indigenous Knowledge Centre. Similarly, where internet access is provided it is usually patchy and slow and there are constant difficulties.

Recognising these challenges, the State Library has sought solutions. One option about to be tested is a trial partnership with Cape York Digital Network. Cape York Digital Network is an organisation established to provide Cape York with advanced information communication and technology (ICT) services. Founded in 2001, the organisation was established with Networking the Nation funding to create a network of managed ICT centres in the Cape. Cape York Digital Network has a commercial focus to market its services, but also has a mandate to support the economic, social and employment development of the Cape York region, its people and the environment. 
Discussions at a workshop in Cairns to explore opportunities for sustainability and capacity building for Indigenous Knowledge Centres identified complementary objectives, and it was agreed that co-location or integration of both facilities might offer some opportunities for partnership in the dual interests of cost efficiency and better services to remote communities. The trial will test co-location of services, sharing of staff, and cooperative staff training programs. It is hoped that the 12 month trial will commence early in 2005, with a six monthly review to keep it on track.

From our perspective, such a partnership will secure better services for the local community through:

- a strong technology infrastructure

- reliable internet access for staff

- free internet access accounts

- access to online training, and

- access to video conferencing facilities

Local communities see their IKCs as critical to their future, as Cygnet Repu from Mabuiag Island has said:

An IKC to me represents a 'hold on time'. It is a place where we can find out about our past in today's presence, preparing us to meet the future. Knowledge must exist in our lives for the present to meet our future. Without the past we cannot know who we are and where we're from. ${ }^{6}$

\section{Indigenous Knowledge Centre at the Millennium Library Project}

On a broader scale, the current redevelopment of the State Library of Queensland will include a flagship Indigenous Knowledge Centre at the Millennium Library Project, due to open in 2006.

The IKC@MLP will act as a focal point for the physical and virtual network of Indigenous Knowledge Centres throughout the rest of Queensland, offering services and support in the same way that the State Library acts as a hub for the Queensland public library network. Plans for physical, virtual and service infrastructure of the IKC@MLP are being developed in consultation with Indigenous communities across the state.

A good example of this has been the Indigenous reference group's advice to the architects, with one of the outcomes being the incorporation of a larger external space suitable to host Aboriginal and Torres Strait Islander social and cultural events.

Some key elements of the Indigenous advisory group's vision for the IKC@MLP are:

- a place to promote, document, support and showcase the vibrancy of Indigenous peoples, their language, experience, knowledge and culture

- a sharing of Indigenous and non-Indigenous knowledge, 'packaged' in a format that gives equal respect to both sets of knowledge, and

- a place where Indigenous peoples feel immediately welcome. 
More than a physical space, the IKC@MLP will be a portal to the Indigenous library services program and service infrastructure. And in a broader sense, the flagship Indigenous Knowledge Centre will represent the Indigenous communities of Queensland in the state capital.

\section{Other Queensland State Library Indigenous Services Initiatives}

Another aim of the Indigenous library services strategy is to collect, preserve and provide access to Indigenous materials for all Queenslanders. To provide an essential framework for accessing Indigenous materials held in the State Library of Queensland's collections, we have embarked on a major project this year to develop protocols and procedures to cover every aspect of access, reproduction, digitisation and repatriation to ensure appropriate access to our collections is balanced against the moral, intellectual and cultural rights of Indigenous peoples as owners of their cultural heritage.

Much of the material in the State Library's collections, with the exception of material which is now in the public domain, remains subject to relevant copyright laws. In many cases the State Library is the owner of copyright, in others copyright is owned by the individuals or entities which created the particular work or material. However, the cultural and intellectual ownership rights of Indigenous peoples are not enshrined in legislation, whereas copyright is well covered. The State Library recognises the lack of a legal underpinning for Indigenous cultural and intellectual rights but acknowledges the importance of these rights for Indigenous peoples.

In the protocols we are developing, the State Library will commit to the following strategies in the collection, preservation and provision of access to relevant Indigenous material and information:

- to maintain and undertake ongoing liaison with Indigenous peoples and communities, the State Library's Indigenous Advisory Committee and the Torres Strait Reference group

- to develop its collections in an equitable manner, taking account of the importance and relevance of material and information by or about Indigenous peoples, and

- to facilitate the ongoing development of Indigenous Knowledge Centres and community keeping places.

In an example of what we are calling 'practical reconciliation', the State Library launched an exhibition in 2001: A Gift of Presence-The Spirit of Reconciliation. This exhibition is a collection of words and images about reconciliation drawn from Queenslanders of diverse backgrounds. ${ }^{7}$

A Gift of Presence speaks volumes, and dares to share personal views that are capable of generating further healing debate. This exhibition is currently showing at the Gab Titui Cultural Centre on Thursday Island, as part of a tour of IKCs in remote communities including Aurukun, Pormpuraaw, Woorabinda and Cherbourg.

The State Library has actively sought to improve access to Indigenous records and to take a leadership role in the improvement of Indigenous library services. We co- 
hosted the Access to Indigenous Records National Forum together with the Community and Personal History Unit at the Department of Aboriginal and Torres Strait Islander Policy. ${ }^{8}$ More recently, we have partnered with Professor Martin Nakata and the University of Technology, Sydney, to undertake the development of a draft policy framework for Indigenous library services for the Council of Australian State Libraries.

The State Library is also undertaking a pilot project called Listen Here! to document strategies within the public library network to improve services to Indigenous people. Whereas our Indigenous Knowledge Centre model is targeted at more remote communities, the Listen Here! project has been developed by the State Library in recognition of the needs of the vast majority of Indigenous Queenslanders living in areas serviced by the public library network. In partnership with selected councils across Queensland, the Listen Here! project will see Indigenous staff members appointed, reference groups established and grants for building collections of material relevant for Indigenous peoples. Each pilot site will then develop and document strategies to engage with and improve services to their local Indigenous communities.

\section{Conclusion}

The significance of Indigenous Knowledge Centres and other initiatives within the Indigenous Library Services represents the efforts of people working together, as recognised by Lilla Watson:

For me this [effort] demonstrates the very important relationship that is being developed between institutions like the State Library and Indigenous people. This is not only relevant to this state, but it is also making an important contribution... in setting benchmarks for the rest of this whole country. ${ }^{9}$

\section{Notes}

1 All sites mentioned in this talk can be found at the Queensland State Library website at http://www.slq.qld.gov.au

2 L Watson Welcome speech presented at the Access to Indigenous Records National Forum State Library of Queensland 19-20 June 2003 unpublished report p2

3 S Taylor 'State Library of Queensland Library Services: Overcoming Barriers and Building Bridges' Australian Academic \& Research Libraries December 2003 vol 34 no 4 pp280-281 Ibid $\mathrm{p} 280$

Ibid $\mathrm{p} 281$

C Repu personal communication 2004

See http://giftofpresence.slq.qld.gov.au/html/exhibit.htm

See www.connectqld.org.au/airnf

L Watson 2003 p2 


\title{
Chapter 5
}

\section{Traditional Indigenous Biodiversity-related Knowledge}

\author{
Marcia Langton and Zane Ma Rhea*
}

Each year since 1997 an Aboriginal festival is held at a place called Gulkula in northeast Arnhem Land in the Northern Territory of Australia. The traditional owners of the land, the Gumatj clan, joined with other Yolnu clans with special affiliations to Gulkula to host a traditional ceremony, the Garma, and, for the first time, to invite others to come to the week long ceremonial gathering to learn about Yolyu culture, religion and philosophy. In 1999 Galarrwuy Yunupingu, a leader of the Gumatj clan, carved a wooden object, called in his language, Maak. ${ }^{1}$ Adroitly carved diamond shapes on the Maak, it was explained, represented the sparks of fire that leapt from the wildfire and spread across the land. 'Like a fire, the truth burns', he explained, 'that's how we know it is the truth'. ${ }^{2}$ It was his intention, he said, to have his invitation to learn Yolyu knowledge of the environment spread across the land 'like a fire'. ${ }^{3}$

The Maak was translated by Merrkiyawuy Stubbs and related to each Yolyu group that had come to the Garma ceremony. The carvings on the Maak each represented a part of a message which Marcia Langton was asked to deliver, along with the Maak, to the vice-chancellors of Australian universities. In the company of local Bundjalung and other clan leaders, the Maak was relayed to Professor Niland at the Australian Vice-Chancellors' Committee (AVCC) meeting at the Southern Cross University in northern New South Wales on 30 August 2000.

As Chairman of the Northern Land Council, Mr Yunupingu, with many other leaders of the clans of this remote part of Australia, was deeply concerned about the fate of traditional Aboriginal knowledge of the environment, as Western-trained government conservation officers encroached onto Aboriginal lands with plans for how the environmental values should be preserved. To do this properly, Mr Yunupingu said, it was important for the federal government to respect and recognise the value of traditional knowledge systems about environmental management, "caring for the country is what we have done for tens of thousands of years and we intend to keep doing that'. ${ }^{4}$ He explained his intentions in this way:

\footnotetext{
...we know that the best, and in fact the only way to do it is to take advantage of both traditional and contemporary knowledge systems. We want to make sure that Aboriginal people learn about contemporary methods and that non-Aboriginal people learn about our knowledge and experience. ${ }^{5}$
}

\footnotetext{
* Dr Marcia Langton is Chair of Australian Indigenous Studies, University of Melbourne.

Dr Zane Ma Rhea is Senior Lecturer, Faculty of Education, Monash University.
} 
In the spirit of the Garma Maak, we discuss here Indigenous Knowledge (IK) systems and some aspects of the value of this knowledge to the peoples who own it and use it. We draw on a study ${ }^{6}$ for the Secretariat of the Convention on Biological Diversity at the United Nations (UN) on the protection and maintenance of traditional biodiversity-related knowledge in Asia, the Middle East and Australia to discuss the potential of Indigenous traditional knowledge as a means of achieving the urgent task of maintaining these ancient systems of human engagement with the environment, and of preserving biodiversity.

\title{
What is Traditional or Indigenous Knowledge and Why is it Important?
}

The Secretariat of the Convention on Biological Diversity ${ }^{7}$ (CBD) defines traditional knowledge in the following way:

\begin{abstract}
Traditional knowledge refers to the knowledge, innovations and practices of Indigenous and local communities around the world. Developed from experience gained over the centuries and adapted to the local culture and environment, traditional knowledge is transmitted orally from generation to generation. It tends to be collectively owned and takes the form of stories, songs, folklore, proverbs, cultural values, beliefs, rituals, community laws, local language, and agricultural practices, including the development of plant species and animal breeds. Traditional knowledge is mainly of a practical nature, particularly in such fields as agriculture, fisheries, health, horticulture, and forestry. ${ }^{8}$
\end{abstract}

Traditional and Indigenous knowledge systems related to biodiversity conservation are fundamental to human life throughout much of Asia, the Middle East and Australia, especially in rural and remote areas, and they play a much larger role in economically developing countries than in developed nations such as, for instance, Australia, Singapore and Japan. This is because of the high dependence of human populations in developing nations in these regions on traditional food production and other activities for providing basic needs. As a result, the value of traditional and Indigenous knowledge systems to the economies of those countries is incalculable. Ferrari suggests that, although limited natural resources are found in urban environments, most biological diversity by far is found in rural areas. Quoting ASEAN (2001) figures, he points out that 'It could be therefore tempting to associate the term "local communities" with people living in rural areas, mostly consisting of farmers and fishers. Southeast Asia has a population of about 526 million, 330 million of whom (about 63\%) live in rural areas'.

Traditional knowledge systems are thus fundamental to the livelihoods of many millions of people. Further, traditional biodiversity-related knowledge used by agriculturalists is of great significance to food security for much of Asia and the Middle East. Traditional methods of irrigation and crop production, and maintenance of seed stock and cultivars, have maintained food and grazing resources, and traditional water management systems have been critical to societies across all ecosystems. Humans have domesticated animals for at least the last 10,000 years, and the coexistence of human and animal populations remains typical of most small-scale, traditional agricultural and herding societies. Hunting, gathering and fishing continue to contribute a substantial part of the diet and basic needs for populations in rural and remote areas of Australia and among coastal groups in Asia that rely on artisanal fisheries. In economically developed nations such as Australia and Japan, Indigenous 
peoples are dependent on traditional knowledge and practices in caring for their traditional estates, for the harvesting of wild food and animals, medicines, water, and other basic needs.

In each of the regions, it is evident that a rich storehouse of traditional biodiversityrelated knowledge exists but is constantly under threat. The position of the Secretariat of the CBD is clear:

\begin{abstract}
There is today a growing appreciation of the value of traditional knowledge. This knowledge is valuable not only to those who depend on it in their daily lives, but to modern industry and agriculture as well. Many widely used products, such as plantbased medicines and cosmetics, are derived from traditional knowledge. Other valuable products based on traditional knowledge include agricultural and non-wood forest products as well as handicraft.

Traditional knowledge can make a significant contribution to sustainable development. Most Indigenous and local communities are situated in areas where the vast majority of the world's plant genetic resources are found. Many of them have cultivated and used biological diversity in a sustainable way for thousands of years. However, the contribution of Indigenous and local communities to the conservation and sustainable use of biological diversity goes far beyond their role as natural resource managers. Their skills and techniques provide valuable information to the global community and a useful model for biodiversity policies. Furthermore, as onsite communities with extensive knowledge of local environments, Indigenous and local communities are most directly involved with conservation and sustainable use. $^{10}$
\end{abstract}

From the study we undertook, our most critical conclusion was that most developing nations of the Asian region do not have the capacity for all of the people who live within their borders to enter the market economy fully. Without attention paid to the protection and preservation of the traditional knowledge and customary natural resource management and tenure systems in the lands and waters of local communities and Indigenous peoples, these nations would be even more vulnerable to food shortages and famines. Some nation states, in acknowledgement of their agreement to the principles of the Convention on Biological Diversity, are seeking ways to conserve rich biospheres whilst balancing a need to ensure that traditional communities can continue to sustain themselves. It is in the interests of nations to engage Indigenous peoples and local communities in the task of protecting the biological diversity in their environment.

In many cases throughout Asia and Australia, the present situation involves a combination of tradition, revival of customary practices, and new approaches. A range of measures to protect biodiversity-related knowledge have been implemented by Indigenous and local communities. Examples include: digital libraries, people's biodiversity registers, inventories, web portals, and in situ management projects that rely, at least in part, on local traditional biodiversity-related knowledge. A growing body of literature has recognised the role of traditional knowledge and practices in preserving biodiversity. ${ }^{11}$ For Indigenous peoples and local communities, concern over the preservation and maintenance of traditional knowledge is not only motivated by the desire to conserve 'biodiversity' as an end in itself, but also by the desire to live on their ancestral lands, to preserve their traditional livelihoods, to safeguard local food security and, to the extent possible, exercise local economic, cultural and political autonomy. ${ }^{12}$ 
As national education systems are extended to rural and remote populations, the documentation of this knowledge will be critical to the capacity of future generations to access that knowledge. ${ }^{13}$ This is a particular concern for the Yolyu people in Australia.

\section{Threats to Traditional Biodiversity-Related Knowledge}

This Maak is a declaration by the Yolnu leaders... The Garma ceremony is an enactment of the meaning of being Yolnu, of being human, as we understand this through our cultural inheritance from our ancestors. Our performance of the ceremony embodies the meanings of our traditions, enshrined in sacred places. To those of us who participate, Garma restores our spirit to a state of harmony and balance in the world, purifying us and bringing us to a deeper understanding of our duty to respect and share the legacy of our knowledge...

The first Maak is to introduce the concept of Yolyu knowledge systems as ancient foundations, ways of comprehending the world that have sustained Yolyu societies. Our traditions provide us with the knowledge and the skills to harvest the bounty of the land and the sea for the satisfaction of our needs, and the opportunity to enjoy life. Through the ideas of Garma we explore our humanity. We, the Yolyu, Aboriginal people of Northeast Arnhem Land, believe that our intellectual traditions are relevant to people of other societies, and are especially important to universities and institutions in which people seek to expand human knowledge. Garma Maak, $1999^{14}$

The observance of respect for the ancestral domain is universal among traditional and Indigenous peoples. The Garma Maak begins with such a declaration and draws our attention to the role of religious and other traditional institutions, leaders and belief systems in preserving the biodiversity-related knowledge of Indigenous and local communities. They have played critical roles in the retention of traditional knowledge of minority groups despite the ubiquitous context of disruption by dominant colonising societies that have brought them under the control of nation states.

Most Indigenous and local communities that retain, at least in part, traditional subsistence economies have also been subject to colonisation in its various forms. A cluster of issues are implicated in the vulnerabilities of traditional knowledge systems: land and sea tenure issues and loss of territory that sustains Indigenous peoples and local communities; cultural absorption of Indigenous peoples and local communities into dominant societies as indicated through language loss; biodiversity loss and its impact on traditional biodiversity-related knowledge; and loss of traditional biodiversity knowledge in conflict and post-conflict areas. Many have been disrupted by the imposition of external regimes and by colonial and postcolonial military and civil conflicts. Such disruptions have caused the collapse of rural economic systems in some cases, and thereby diminished the capacity of these small scale societies to continue their traditional subsistence activities.

In those societies that have high levels of population growth, urbanisation and industrialisation, the consequent threats to biodiversity that result from threats to the viability of traditional biodiversity-related knowledge and practices is profound. The often poor understanding by national governments of inter-relationships between biodiversity and cultural diversity accounts in part for the rapid loss of traditional biodiversity-related knowledge. The rights of Indigenous and local communities are, more often than not, limited by statutes and regulations because of the ideological stance which modern nation states hold towards these subsistence economic systems, 
holding them to be backward ways of life as against the belief in 'progressive' ways of life that the modern global economy is purported to offer. Nation state absorption and assimilation of these groups and assertion of ownership and control of their knowledge systems for commercial and national purposes also poses a great threat to the capacity of these groups to sustain their social and economic systems and, in some cases, to the continued existence of these groups. ${ }^{15}$

Whether nation states recognise, in their biodiversity planning, the intertwined destinies of natural and cultural diversity in the areas where traditional societies continue their economic subsistence practices and related knowledge systems is influenced at the highest political levels by environmental non-government organisations (NGOs). In some cases, the understanding of these issues in the environmental NGOs has lagged behind the urgent demands of the Indigenous and local peoples for protection of their traditional resource rights. ${ }^{16}$

Along with language retention the viability of cultural frameworks, such as religious systems, and traditional medicinal knowledge systems, plays a key role in the state of retention of traditional biodiversity-related knowledge systems. We draw attention to this issue because of the potential for the engagement of religious and other traditional institutions in activities aimed at the maintenance of such knowledge systems. The indications are that this aspect of support for cultural institutions may be more important than generally acknowledged.

\section{Language Diversity and the State of Retention of Biodiversity-Related Knowledge}

Of special relevance to the challenge of maintaining Indigenous life ways is the issue of language loss. The literature highlights language loss as an important indicator of the threat to the retention of traditional biodiversity-related knowledge. Several atlases of languages report worsening levels of language loss in a number of regions. ${ }^{17}$ The Atlas of the World's Languages in Danger of Disappearing ${ }^{18}$ shows the 'crisis areas' where linguistic diversity is most threatened. Scholars generally concur with the Atlas. According to Maffi:

There are an estimated 5,000 to 7,000 languages spoken today on the five continents (Krauss 1992; Grimes 1996). Ethnologue, the best existing catalogue of the world's languages (13th edition, Grimes 1996), gives a total of 6,703 languages, of which $32 \%$ are found in Asia, 30\% in Africa, $19 \%$ in the Pacific, $15 \%$ in the Americas, and $3 \%$ in Europe. Of these languages, statistics put together by conservationist David Harmon (Harmon 1995, based on the 12th edition of the Ethnologue, Grimes 1992) indicate that about half are spoken by communities of 10,000 speakers or less; half of these, in turn, are spoken by communities of 1,000 speakers or less. Overall, languages with 10,000 speakers or under total about 8 million people, less than $0.2 \%$ of an estimated world population of 5.3 billion.

On the other hand, of the remaining half of the world's languages, a small group of less than 300 (such as Chinese, English, Spanish, Arabic, Hindi, and so forth) are spoken by communities of 1 million speakers and above, accounting for a total of over 5 billion speakers, or close to $95 \%$ of the world's population. The top ten of these alone actually comprise almost half of this global population. ${ }^{19}$

Maffi's assessment is that most of the world's linguistic diversity is carried by very small communities of Indigenous and minority people. These are languages, he points out, that have been and continue to be under threat, as a result of: 
...ever-growing assimilation pressures that promote incorporation of their speakers into 'mainstream' society and language shift (the progressive abandonment of a native language in favour of an acquired majority language at the societal level). ${ }^{20}$

Colonisation has been the principal contributing factor in human language loss because of the introduction of settler languages as the dominant, usually official, language of education, instruction and commerce.

Maffi collates statistics that show that currently spoken languages being 'nearly extinct' range between approximately $6 \%$ and $11 \% .{ }^{21}$ In some projections, according to Krauss, as many as $90 \%$ of the world's languages may disappear during the course of the next century. ${ }^{22}$ These figures clearly portray a threat to linguistic and cultural diversity that are an order of magnitude greater than the threat that loss of biological species and ecosystems represents for biodiversity.

Posey, ${ }^{23}$ author of several seminal texts on traditional resource rights, highlighted the phrase 'the inextricable link between cultural and biological diversity' introduced in the 1988 Declaration of Belém. He wrote:

Subsequently that link has been increasingly investigated through studies of ethnobiology, ethnoecology, and linguistics. Clearly the taxonomic systems, emic perceptions, and codified knowledge of overt and covert ethnobiological categories depend on language as a major vehicle for cultural transmission. Together with the understanding that many previously assumed 'natural' ecosystems are in fact 'cultural landscapes', and that many 'wild' plants are indeed human-modified, the role of traditional ecological knowledge and natural resource management strategies have become central to effective conservation of biodiversity. This is formally and legally recognised in the Convention on Biological Diversity. ${ }^{24}$

Maffi argues that that original idea in the Declaration of Belém should be extended to include linguistic diversity as also inextricably linked to biodiversity. ${ }^{25}$ The evidence is compelling: Harmon compared the $\mathrm{IUCN}^{26}$ list of 12 'megadiversity' countries, ${ }^{27}$ to his own list of countries by number of different 'endemic' languages ${ }^{28}$ (that is, languages spoken exclusively within a given country's borders, which means the majority of the smaller languages of the world, accounting for most of the world's linguistic diversity). Ten out of the 12 megadiversity countries (or 83\%)-Australia, Brazil, China, Colombia, India, Indonesia, Malaysia, Mexico, Peru and Zaire-also figure among the top 25 countries for endemic languages. ${ }^{29}$ More than $80 \%$ of countries that have great biological diversity are also places with the greatest number of endemic languages. Countries with large numbers of languages are those with the most forests, are nearer the tropics and with mountain ranges. The same factors affect the number of bird species. Maffi explains further the 'inextricable' link between culture and biodiversity:

At the local level, linguistic and cultural distinctiveness has often developed even
among human groups belonging to the same broadly defined cultural area or whose
languages are considered to be historically related, and within the same bioregion.
As local groups have adapted to life in specific ecological niches, they have
developed specialized knowledge of them, and specialized ways of talking about
them, to convey this vital knowledge and ways of acting upon it for individual and
group survival.

In reference to Australian Aboriginal people the anthropologist, the late Norman Tindale, stated that: '[c]oincidences of tribal boundaries to local ecology are not uncommon and imply that a given group of people may achieve stability by becoming 
the most efficient users of a given area and understanding its potentialities'. ${ }^{31}$ The same could be said in hundreds of other cases of local peoples around the world.

The threats to multilingualism are similar to the threats to biodiversity. The inextricable link between culture and biodiversity is lost 'when external forces begin to undermine traditional cultures, pushing them into the "mainstream". 32 In turn, local languages lose their crucial function of communicating and upholding such knowledge, beliefs and wisdom that are increasingly less significant and intelligible to younger generations. Furthermore, local knowledge does not translate easily into the majority language to which minority language speakers switch; and along with the dominant language usually comes a dominant cultural framework that begins to take over. Because in most cases the knowledge of Indigenous peoples and local communities is only carried by oral tradition, when shifts toward modernisation and dominant languages occur, and oral tradition in the native languages is not retained, local knowledge is lost. Due to its place-specific and subsistence-related nature, local ecological knowledge is at especially high risk of disappearing.

Experts generally consider a community's language to be endangered when at least 30 per cent of its children no longer learn it. Numbers of speakers of languages among Indigenous and local populations may be quite small, compared to the 300 languages spoken by most of the world's population. Many things can lead to people abandoning their native tongues, the Atlas explains. ${ }^{33}$ One is the break-up or transplanting of a community, when individuals or small groups find themselves immersed in a different cultural and linguistic environment, which soon stifles their native language. A tongue can also disappear when its users come into contact with a more aggressive or economically stronger culture. Adults encourage their children to learn the language of the dominant culture, especially as a means to get a job. The situation is worse when the authorities systematically discourage the use of local languages in schools, local government and the media.

But an endangered, moribund or even extinct language can be saved through a determined language policy. In Japan for example, only eight people spoke Ainu on the island of Hokkaido in the late 1980s but today it is being revived after years of ostracism and decline. An Ainu museum has been established and the language is being taught to young people, who are rediscovering its traditional and current use.

\section{The Documentation of Traditional Biodiversity-related Knowledge}

The documentation of traditional and Indigenous knowledge is fundamental to the capacity of traditional knowledge holders to promote, protect and facilitate the proper use of their knowledge. ${ }^{34}$ Accurate documentation also enables nations and other interested parties to enter into agreements and contracts with traditional knowledge holders that will strengthen the capacity of these communities to develop economically sustainable livelihoods. The importance of the literature in these fields cannot be underestimated; the issue of sound documentation lies at the heart of the problem. That problem can be described as the urgent need to recognise, protect and maintain the knowledge, innovations and practices of Indigenous peoples and local communities relevant to the capacity of a community to undertake conservation and 
sustainable use of biodiversity. The threats to traditional knowledge and practices include not only those that threaten subsistence and traditional lifestyles, such as large-scale economic and commercial developments (e.g. militarisation, agroindustrial cropping and forestry, etc) and associated population removals, land dispossession and urbanisation of subject populations, but also biopiracy, misappropriation and unauthorised commercialisation of traditional knowledge, practices and resources. A community cannot build its capacity to mobilise its knowledge if there is no recognition that it is owned by them.

The relevance of traditional knowledge and practice to the vast geographical areas of the regions discussed in our study and the importance of traditional knowledge to the natural resource management, agricultural and pastoral lifestyles, medicinal and other social and economic needs of most rural populations in these regions means that the task of documenting traditional knowledge and practices is unachievable in the short term. Even so, documentation is central to the capacity of Indigenous peoples and local communities to protect their knowledge.

It is at the intersection of intellectual property rights and traditional practices of Indigenous peoples and local communities that the debate about legislative measures to protect traditional knowledge has caused most controversy. Many well documented cases, for example the United States' patent on turmeric which was successfully challenged by the Indian government, ${ }^{35}$ testify to the potential for abuse when monopoly rights are granted over traditional knowledge. In particular, intellectual property regimes of patents and plant breeders' rights have been the subject of much debate. Community-based rights are also the subject of some concern as intellectual property rights are usually granted to individuals and not to collectives, such as groups that hold customary knowledge of plants and the environment as an ancestral legacy.

Posey observed that the nature of traditional knowledge is such that more of it is transmitted orally than written down, and thus there are particular problems when parties not authorised by the holder of that knowledge seek to obtain intellectual property rights (IPRs) over it:

In the absence of any accessible written record, a patent examiner in another country
is unable to access documentation that would challenge the novelty or inventiveness
of an application based on traditional knowledge... it is extremely difficult and
costly for developing countries to monitor and challenge IPRs issued all around the
world. $^{36}$

A range of intellectual property tools have been adopted by a number of countries to promote and protect traditional knowledge and folklore, including specific IPRs. ${ }^{37}$ Some countries have recognised that the existing intellectual property system is not, on its own, adequate to protect traditional knowledge. A number of these have enacted or are in the process of enacting sui generis systems of protection, including the Philippines and Bangladesh. ${ }^{38}$

The range of existing and potential protective measures for traditional knowledge and practice systems, then, depends on sound documentation in order to describe and catalogue the elements of local systems for the purposes of sui generis and other protective measures, as well as for their preservation and protection for the members of those societies in which they originate. Such protective measures, sui generis and otherwise, have particular implications for digital libraries and registers. 
Posey contends that patent applications claiming traditional knowledge already in the public domain should not be granted. However, he acknowledges that:

\begin{abstract}
The problem is that the knowledge tends not to be documented, or if it is, it is unlikely to be easily accessible to a patent examiner. In particular, information on traditional knowledge is not likely to be found in the type of patent-based information that patent offices rely most on when assessing novelty and inventiveness. ${ }^{39}$
\end{abstract}

To address this problem the World Intellectual Property Organisation (WIPO) and a number of developing countries led by India and China are seeking to develop traditional knowledge digital libraries which will detail considerable amounts of traditional knowledge already in the public domain in forms accessible to patent examiners, such as the WIPO International Patent Classification (IPC) system.

\title{
Libraries, Databases, Registers and Inventories
}

Traditional knowledge digital libraries have been the subject of deliberations by a WIPO specialised Task Force, which included representatives from China, India, the United States Patent and Trademark Office (USPTO), and the European Patent Office (EPO), examining how such libraries can be integrated into the existing search tools used by patent offices. ${ }^{40}$ There are three examples being developed by WIPO signatories: traditional Chinese medicine in China, the Traditional Knowledge Digital Library (TKDL) and the People's Biodiversity Registers (PBRs) in India. The government of the Lao People's Democratic Republic has also established the Traditional Medicines Resource Centre.

In its Second National Report on the Convention on Biological Diversity, India addressed the initiatives it has undertaken further to the original Traditional Knowledge Digital Library (TDKL) ${ }^{41}$ initiative. These are well-advanced and represent world best practice both in terms of the extent of documentation and protection provided for traditional knowledge systems:

In the recent past, there have been several cases of biopiracy of traditional knowledge use of biological resources from India. First it was the patent on the wound healing properties of haldi (turmeric); now patents have been obtained in other countries on the hypoglycaemic properties of karela (bitter gourd), and brinjal. These uses have been an integral part of the traditional system of medicine in India. India had challenged the patent on haldi and, because it was proved that this property is documented, it is not novel and is prior art, the patent on turmeric was revoked. Similarly the patent on the fungicidal properties of neem was revoked by the European Union. India has now initiated an exercise to prepare an easily navigable electronic computerised database of documented traditional knowledge relating to use of medicinal and other plants. India's efforts in this regard have been appreciated and, at the meeting of the Committee of Experts of the International Patent Classification (IPC) Union held in February 2001, the IPC Union agreed to set up a Task Force on the Traditional Knowledge Resources Classification.

Documentation of traditional biodiversity-related knowledge on the status, uses and management of biological resources constitutes the People's Biodiversity Registers (PBRs). People, as part of their daily subsistence activities, have acquired knowledge about the use of a variety of biological resources, for example as graziers, as fisherfolk, as basket weavers. The information is almost exclusively orally 
transmitted. People's biodiversity registers are an attempt to document such knowledge. PBRs envisage the creation of decentralised country-wide database on status of biological resources. They also include local knowledge on properties and uses of biodiversity resources, for example, drought resistance of certain varieties, methods of preservation of foods, or the use of certain plants in treating human or livestock diseases. In India, preparation of village-wise PBRs for documenting knowledge, innovations and practices has been undertaken in a few states. For example, the State Plan for Kerala has also actively promoted documentation of local knowledge regarding biodiversity in PBRs. One pilot project on this has been completed in Ernakulam District. Two other projects at Panchayat level have been initiated by the Tropical Botanic Garden and Research Institute and the Kerala Forest Research Institute. There are many other examples.

The Centre for Ecological Sciences, Indian Institute of Science, Bangalore, by mid 1998 had established 75 PBRs. Gene Campaign has undertaken work on documentation of biodiversity and knowledge relating thereto among three tribal populations: the Munnars in South Bihar (in the Chotanagpur region); the Bhils of Madhya Pradesh; and the Tharus of the Terai region. Medicinal plants and knowledge related thereto was sought to be documented with the help of educated tribal youth. Elders in the village, medical practitioners and traditional healers were consulted in the collection and understanding of the information.

The Honey Bee Network is a knowledge centre/network pooling solutions by people from different sectors throughout the country and the world. The network has collected over 10,000 examples of contemporary innovations and outstanding examples of the use of traditional local knowledge in the sustainable management of natural and other resources. These innovations are shared with local communities and individuals within India and in 75 other countries through the Honey Bee newsletter which is published in eight different languages (English, Spanish, Hindi, Gujarati, Tamil, Kannada, Pahari and Telugu). SRISTI, the Society for Research and Initiatives for Sustainable Technologies and Institutions, an NGO based in Ahmedabad, India, was set up in 1993 to essentially sustain the Honey Bee newsletter and associated research and action activities. SRISTI supports the Honey Bee network by linking six 'Es': ethics, equity, excellence, environment, education and efficiency in enterprise.

The Honey Bee network has created new standards of accountability and ethics in dealing with grassroots innovations by strengthening people to people learning. The formal sector cannot use the traditional knowledge in the newsletter without acknowledgement, citation and prior informed consent of the knowledge holder. The Honey Bee supported the principle of prior informed consent much before the Convention on Biological Diversity came into existence. The Honey Bee network approach promotes the concept that for innovations in one part of the world, investments are made in the other. The Honey Bee database with thousands of innovations is being upgraded to multimedia capabilities. This will ensure that barriers of languages, literacy and localism can be overcome to connect innovators, potential entrepreneurs and investors across regions. The idea is that through using electronic, textual and oral media, a multilevel network can be put in place to support the documentation, experimentation and reward, both in material and non-material form, of individual and collective grassroots innovations. 
Another key initiative in this field is the use of inventories compiled to recognise and protect traditional knowledge. Inventories and enumerations of species compiled by governments and scientific bodies form a significant and important category of literature. Within this body of literature are inventories of critical importance to the challenge of recognising and protecting traditional knowledge. For example, in the Convention on Biological Diversity Second National Report of His Majesty's Government of Nepal, among the documents listed to demonstrate progress of the national biodiversity strategy and action plan, reference is made to the "National Register of Medicinal Plants'. ${ }^{42}$

Inventories can serve purposes beyond evidence of innovation for patenting. They can significantly contribute to capacity building measures. They can demonstrate the relationship between traditional knowledge and conservation of biodiversity. Writing for the IUCN Theme on Indigenous/Local Communities, Equity, and Protected Areas (TILCEPA, a working group established jointly by the World Commission on Protected Areas and the Commission on Environmental, Economic and Social Policy), Ferrari ${ }^{43}$ shows a case from North-West Thailand:

\begin{abstract}
The WWF-led Thung Yai Ecology Project in North-West Thailand pointed out great richness and depth of local ecological knowledge of the Karen people in the Thung Yai Wildlife Sanctuary. While the Karen have been threatened with eviction from the sanctuary by the Royal Forestry Department (RFD), this ethnoecological project documented that the local ecological knowledge of the Karen recognises at least 41 different vegetation communities and habitat types (without counting micro-habitats) and interprets the landscape of the sanctuary as one complex and 'interacting mosaic', understanding the importance of this mosaic as an ecological support system for both the people and wildlife populations. ${ }^{44}$
\end{abstract}

Iran has promoted the use of new technologies and techniques relating to combating desertification and better use of Indigenous knowledge and technologies. An inventory of such technologies and knowledge has been prepared and reported to the first Conference of the Parties (COP 1) of the United Nations Convention to Combat Desertification (UNCCD) and reflected in Iran's Reports to the Parties of the Convention of the UNCCD. ${ }^{45}$

Lebanon has developed a Sustainable Use of Dryland Agro-biodiversity project (funded by the United Nations Development Program Global Environment Facility, UNDP/GEF) promoting on-farm conservation management of crops and cultivars and has used eco-botanical surveys, vegetation surveys and Indigenous knowledge surveys.

\title{
Web Portals and Web Libraries
}

Although there is a growing body of information on traditional knowledge on the internet, as WIPO has observed, much of it is not in a form that would make it either searchable or useable by patent examiners. ${ }^{46}$ However, the web portals and libraries allow for accessibility to, and sharing of knowledge and research outcomes among the worldwide community of experts, practitioners and others engaged in the documentation and protection of traditional ecological knowledge.

The international Indigenous Knowledge and Development Network consists of more than 2500 participants in 106 countries worldwide. It aims to facilitate the growing number of formally established Indigenous knowledge resource centres. It acts as a forum for discussing issues associated with Indigenous knowledge systems and 
traditional ecological knowledge. It aims to promote the use of Indigenous knowledge as complementary to the scientific tradition; to expedite the obligations of states to support IKS under provisions contained in Agenda 21, the Biodiversity Convention, and other international agreements and conventions applying to Indigenous peoples; and to work for protection of Indigenous knowledge and just compensation to communities for their knowledge.

Information products include:

- the membership database, which contains information on the expertise of participants and dates from 1993: the Centre for International Research and Advisory Networks (CIRAN/NUFFIC) at http://www.nuffic.nl/ciran/ikdm/

- the Indigenous Knowledge and Development Monitor (IKDM), an electronic journal: some back issues available in full text on the NUFFIC website at http://www.nuffic.nl/, and

- the 'Indknow' discussion list at http://www.nuffic.nl/ik-pages/iknetwork.html.

SciDev.Net is also another significant site. It hosts an Indigenous Knowledge Dossier and is sponsored by Nature and Science in association with the Third World Academy of Sciences. It is published with the financial support of the UK Department for International Development, the Swedish International Development Cooperation Agency, and the International Development Research Centre in Ottawa, Canada, at http://www.scidev.net.

As well, the World Bank hosts an Indigenous Knowledge Gateway as part of its Development Gateway Portals. The gateway, together with numerous others, gathers information from all over the world to facilitate the dissemination of information and best practice examples at http://www.developmentgateway.com.

\section{Indigenous Knowledge and the Fate of Indigenous Peoples in a Globalising World}

The second Maak is to share the vision of Garma. This ceremony reminds us of our duty to pursue knowledge, to discover and teach in co-operation with others, acknowledging the potential of all individuals to contribute equally according to their own capacity. It reminds us to acknowledge our bonds of common humanity, and thus the unity that we celebrate in the Garma ceremony reminds us of the necessity to work with others for the common good. ${ }^{47}$

The challenge of preserving and maintaining traditional knowledge systems strikes deep in the heart of the Western scientific complex of education, research and development. The resistance of Western scientists to accepting the legitimacy of traditional knowledge continues the absurd presumption of Western supremacy over other societies. Many agriculturalists, scientists, botanists, and biologists working in the underdeveloped regions of the world where Indigenous communities predominate have not been so recalcitrant. It is well understood that traditional systems are the primary source of food production knowledge of the world's agricultural, horticultural and subsistence communities. Escobar argues that the biodiversity network constituted by global and national institutional apparatuses promulgates strategies, 
programs, forms of knowledge and types of power based on a techno-scientific idea of biodiversity. ${ }^{48}$ While Article 8(j) of the Convention on Biological Diversity functions to give some attention to local knowledge, Escobar suggests:

\footnotetext{
...this attention is insufficient and often misguided to the extent that local knowledge is rarely understood in its own terms or it is refunctionalised to serve the interest of Western-style conservation. ${ }^{49}$
}

He argues that the plans and strategies put forward by nation states for the conservation of biological diversity 'can be analysed ethnographically as instances of the organisation of knowledge and power'. ${ }^{50}$ Nevertheless, the nation state's ability to control the organisation of knowledge and power is increasingly challenged by the 'appearance of new social actors, including progressive NGOs in many countries and local social movements engaged in the redefinition of cultural and ethnic identities'. 51 These new social actors inscribe themselves within the knowledge-power network of the techno-scientific biodiversity discourse and alternatively resist, subvert or recreate it to serve other ends. ${ }^{52}$ This 'opens up a space for the construction of culturally based forms of development [where what is at issue] is the defense of an entire life project, not only of resources or biodiversity'. 53

The power of such networks is required to challenge the position science assumes in the agricultural, technological and economic spheres, and the many practices that ensue from it which go on to marginalise most of the world's population and their knowledge systems. Science is also deployed in the service of the nation state, and against the interests of Indigenous peoples and others marginalised by the state formation. This need not be the case.

As the Convention on Biological Diversity affirms national sovereignty over biological resources, constitutional recognition of Indigenous peoples and local communities provides a strong basis upon which to enact domestic laws for their benefit. Constitutional acknowledgement of the existence of Indigenous peoples and local communities, in many cases, informs the legislative protection of Indigenous peoples' and local communities' rights. However, even without a constitutional mandate, nations have enacted legislation that recognises the unique position of Indigenous peoples and local communities vis-à-vis the nation state.

In the Philippines, the adoption of the 1987 constitution provided recognition and protection of rights for Indigenous cultural communities (see Article XIV section 17). From this constitutional base, some innovative and progressive legislation to protect traditional knowledge has emerged.

The Constitution of the Peoples' Republic of China vests responsibility with the state to guarantee rights and provide assistance for minority nationalities. Article 4 states:

The state protects the lawful rights and interests of the minority nationalities and upholds and develops a relationship of equality, unity and mutual assistance among all of China's nationalities...

All nationalities have the freedom to use and develop their own spoken and written languages and to preserve or reform their own folkways and customs. ${ }^{54}$

The constitution also provides for the development of both modern and Chinese traditional medicine (Article 21). In the autonomous region of Mongolia, the constitution protects the rights of ethnic groups to practice their native tongues and cultural activities, within a constitutional framework of dominant State ownership. 
India has favoured decentralised forms of government to strengthen local-level control of land and resource use. The Indian constitution provides for the administration of tribal areas in the states of India. Certain regions are declared autonomous states under the constitution, which enables regional customary laws to be recognised and implemented in these states. As Taneja and Kothari explain,

Panchayats, or local institutions of self-governance, have been in existence in India
since before independence, though they were dependent on state governments'
political will to recognise and delegate powers to local level. In 1993 the
Constitution (73rd Amendment) Act was passed, whereby the Panchayati Raj
system-devolving administrative powers to the local village level-was
institutionalised as a third level of governance. In essence, states are mandated to
recognise panchayats as institutions of self-government. The states are responsible
for preparing plans for economic development and social justice for the areas under
panchayat jurisdiction.

The result of this structure is that local level and customary forms of governance are recognised in India.

By contrast, the differential recognition of local groups in the constitution of Malaysia has at times frustrated attempts to coordinate a nationally consistent system. Each of Malaysia's 13 states has its own legislature. While Malaysia's constitutional system ensures local governance for local communities, the fragmentation of legal control in relation to traditional knowledge has resulted in unequal distribution of rights for Indigenous peoples and local communities. State law-making powers in respect of traditional knowledge, local land management and intellectual property are scattered between the various (national, state and municipal) competencies. Furthermore, the states of Sabah and Sarawak have a special constitutional status which guarantees them special rights. As a result, Sabah and Sarawak are excluded from national plans for land use, local government and development.

The Indonesian constitution recognises Indigenous institutions, as well as organisations, mechanisms, laws, rights and obligations within the institutional system of the Indigenous peoples. However, like Malaysia, the multifarious system of government in Indonesia has led to tensions between local and centralised governmental institutions. As Indonesian Indigenous territories are considered special territories, the Indonesian constitution affords special treatment for Indigenous groups whose interests differ from those of the mainstream.

Although the Indonesian constitution recognises the existence of traditional political entities derived from the cultural systems of the Indigenous peoples of Indonesia, Alcorn and Royo argue that laws implemented by the central Indonesian government under President Suharto undermined the constitutional protections afforded to Indigenous people. ${ }^{56}$

In Indonesia, recent reforms to the Forestry Law (1999), the Local Government Law No 22, 1999 (recognising the adat structures and territorial rights of Indigenous peoples), and the Minister of Agrarian Affairs Decree No 5, 1999 (providing for Indigenous land rights) would seem to afford legislative protection to customary governance and land tenure. However, at least in relation to the Forestry Law, ambiguity surrounds the administrative implementation and enforcement arrangements. Baines and Hendro suggest that: 
While national policy now provides for some recognition of adat (customary) law relating to land ownership, use and management, no clear definition of the scope of this policy has emerged. Procedures and mechanisms for customary land and sea rights have not been determined either. Clear and legally supported adat law could greatly improve the prospects for effective community-based management of biodiversity. ${ }^{57}$

Legislative recognition of particular Indigenous populations and local groups by national governments without a constitutional mandate tends to be more selective and provide weaker protective measures. Without rights to traditional estates, the continued existence of Indigenous peoples and local communities is at risk. In the regions covered by our study, the displacement of Indigenous peoples and local communities in the wake of industrialising national projects is well documented. A preliminary step to ensuring the continued existence of traditional knowledge must be that Indigenous people and local communities have secure tenure so that they can maintain, cultivate and continually renew their traditional knowledge.

The social project thrust upon the Australian legislature by the High Court decision in Mabo No 2 (1992) and Wik (1996) is to accommodate Aboriginal land tenure systems alongside the Australian system and, thus, to accommodate the cultural, social and economic differences which arise from the existence of parallel or plural legal systems. The Native Title Act 1993 represented the legislative response to Mabo No 2 (1992). However, the denial of the property rights of Indigenous people, which resulted from amendments to the Act in 1998 has raised concerns about its constitutionality and lack of compliance with international conventions on racial discrimination. ${ }^{58}$ The possibility of using native title as a means of providing protection for traditional biodiversity-related knowledge as intellectual property has not been thoroughly explored in Australia. ${ }^{59}$ Although the Native Title Act 1993 provides for sea rights of Indigenous Australians, in practice the High Court has declined to grant exclusive sea rights to Indigenous sea estates (see Commonwealth $v$ Yarmirr, 2001).

Australia's Environment Protection and Biodiversity Conservation Act 1999 ('EBPC Act') refers to the involvement of Indigenous Australians in biodiversity conservation. Three of the seven objects of the EPBC Act (s3), relate to Indigenous involvement into Australia's biodiversity. These are:

- to promote a co-operative approach to the protection and management of the environment involving governments, the community, landholders and Indigenous peoples

- to recognise the role of Indigenous peoples in the conservation and ecologically sustainable use of Australia's biodiversity, and

- to promote the use of Indigenous peoples' knowledge of biodiversity with the involvement of, and in co-operation with, the owners of the knowledge.

The Act provides for the negotiation of bilateral agreements between the Commonwealth and the states and territories and that the Minister may, under s49A, enter into such an agreement only if he or she has considered the role and interests of Indigenous peoples in promoting the conservation and ecologically sustainable use of 
natural resources in the context of the proposed agreement, taking into account Australia's relevant obligations under the Biodiversity Convention.

Fourmile in her contribution to the Voumard Report argues that while the EPBC Act addresses the important provisions contained in Articles 8(j), 10(c) and 18.4 of the Convention on Biological Diversity, it falls short of providing intellectual propertystyle protection for communally-held traditional knowledge. The formation of contracts and prior informed consent agreements under the Act may provide some legal protection of traditional knowledge. However, the development of a legal regime that recognises traditional knowledge of biological resources as intellectual property under a sui generis system will, as Fourmile advises, provide a higher degree of certainty for all parties and attract greater recognition in court proceedings (see Section 2.6.5).

While biodiversity legislation has often strengthened the participation of Indigenous peoples and local communities in land and resource management, benefits have not always accrued to the participants themselves. For example, the Malaysian Sabah State Biodiversity Enactment 2000 has been criticised as lacking an appropriate regulatory framework to protect the interests of Sabah communities. ${ }^{60}$ It has been used for the purposes of protecting intellectual property rights for commercial purposes, without adequately acknowledging local claims to ownership.

It is evident that India is a world leader in the development of specific legislative mechanisms to protect traditional knowledge. As early as 1994, the Indian Karnataka Community Intellectual Rights Bill proposed a sui generis system in respect of plant varieties in the territory of Kamataka, India, which explicitly recognises community rights. In the same year, the Model Biodiversity-Related Community Intellectual Rights Act was drafted by a group of NGOs. In India's Thematic Report on Access and Benefit-Sharing, sui generis legislation is identified as necessary to protect traditional knowledge because:

\begin{abstract}
Protection of knowledge, innovations and practices associated with biological resources... do not seem to meet the conditions required for grant of patents or other IPRs (e.g. copyrights, trademark etc.) under the prevalent IPR regimes, i.e. novelty, inventiveness and industrial applicability. These conventional forms of IPRs are inadequate to protect Indigenous knowledge essentially because they are based on protection of individual property rights whereas traditional knowledge is by and large collective. Further, the informal knowledge presents other difficulties in being recognised for the purpose of IP protection, such as:
\end{abstract}

- knowledge is developed over a period of time and may either be codified in texts or retained in oral traditions over generations. The conditions of novelty and innovative step necessary for grant of patent are therefore not satisfied, and

- knowledge is quite often held in parallel by communities. ${ }^{61}$

In response to these issues, India has enacted the Biodiversity Act 2002 which provides for the conservation of biological diversity, the sustainable use of its components, and the equitable sharing of the benefits arising out of the use of biological resources. In particular, s 36(iv) of the Act provides for protection of traditional knowledge through knowledge/biodiversity registers, and development of a sui generis system for traditional protection. The National Biodiversity Authority (NBA) is established under the Act to manage equitable benefit-sharing from use of biological resources, and granting of intellectual property rights. Sections 19 and 21 of the Biodiversity Act require prior approval of the NBA before access to resources 
is granted, on terms and conditions which secure equitable sharing of benefits. Section 6 provides that anybody seeking any kind of intellectual property rights on research based upon biological resources or knowledge obtained from India needs to obtain prior approval of the NBA. The NBA will impose benefit sharing conditions. Section 18(iv) stipulates that one of the functions of NBA is to take measures to oppose the grant of intellectual property rights in any country outside India on any biological resource obtained from India or knowledge associated with such biological resource.

The Philippines has also made some remarkable advances in implementing Article $8(\mathrm{j})$ of the Convention on Biological Diversity, and in relation to the protection of the rights of its Indigenous peoples more generally. Article XIV section 17 of the 1987 Constitution, which enshrines the rights of Indigenous cultural communities, has given rise to three notable instruments, namely:

- Executive Order No 247 'Prescribing a Regulatory Framework for the Prospecting of Biological and Genetic Resources, their By-products and Derivatives, for Scientific and Commercial Purposes, and for Other Purposes' (1995)

- The 'Implementing Rules and Regulations' for Executive Order 247 (1996), and

- The Indigenous Peoples Rights Act (1997) and its 'Implementing Rules and Regulations'.

Furthermore, a Community Intellectual Rights Protection Act (1994, updated 2001) is currently in draft form. Although the bill has not been enacted, it represents the Philippines legislature's willingness to consider the special forms of protection that may be necessary for the practical implementation of Article 8(j). This system, which chiefly involves the creation of registers of Indigenous knowledge and local practices, operates separately from the patent system, which is alien to Indigenous philosophy in the Philippines.

There are concerns that the bio-prospecting industry has been damaged by these measures, as only a few agreements have been approved since the implementation of the scheme. The regulatory framework for EO 247 has been criticised as excessively bureaucratic. A respondent to our questionnaire also suggested that information dissemination to local communities is not as good as it could be. Despite these administrative problems, a number of important schemes and registries are being established, in marine environments as well as terrestrial ones.

Despite China's impressive list of legislative measures relating to the protection of traditional knowledge, the Second National Report to the Convention on Biological Diversity acknowledges that the most urgent work for legislation in this field is to formulate the national regulation for access to genetic resources and biosafety management and improving the rule of intellectual property right, in particular the respect and maintenance of traditional knowledge, inventions and practice of local communities. ${ }^{62}$ This suggests that China is also considering a sui generis legislative response to Article 8(j).

In Australia, the report entitled, Our Culture, Our Future: Report on Australian Indigenous Cultural and Intellectual Property Rights, ${ }^{63}$ recommends that such a sui 
generis system be established as a matter of priority for governments in Australia. It states:

\footnotetext{
These measures would enable a more 'holistic' approach to protection and management of Indigenous cultural and intellectual property that includes biodiversity-related traditional knowledge, innovations and practices. ${ }^{64}$
}

The Cusco Declaration advocates the adoption of a sui generis regime, and also promotes international cooperation and information-sharing, and advocating disclosure of the source of genetic material in patent applications. ${ }^{65}$ In the Middle East, a Regional Consultation on the Protection of Expressions of Folklore in the Arab states was organised by WIPO and UNESCO and the government of Tunisia in 1999. This international meeting resulted in a declaration supporting the legal protection of folklore and traditional knowledge through the sui generis approach.

In the Southeast Asian region, ASEAN is working on many levels to address issues relevant to Article 8(j). Firstly, ASEAN is working to harmonise national laws for the protection of plant varieties, in a way which addressed the concerns of developing countries that the UPOV model for the legislative favours commercial entrepreneurs at the expense of local farmers. Secondly, ASEAN's Framework Agreement on Access to Biological and Genetic Resources, which is to be implemented by national legislatures, establishes a regional Clearing House Mechanism to serve as an 'information node' for the reporting of access activities in the region. ${ }^{66}$ The Framework Agreement defines biological resources to include traditional knowledge, but provides that a grant of access to biological and genetic resources shall not automatically mean access to traditional knowledge. The Framework establishes equitable benefit-sharing arrangements with Indigenous peoples, and requires evidence of prior informed consent before access to resources can be granted.

\section{Conclusion}

It is clear that recognition is an important development, for example, of protected and community controlled areas where Indigenous peoples and local communities reside. Where Indigenous peoples and local communities are involved in the management of these areas there have been a number of successes in protecting traditional biodiversity-related knowledge.

A raft of incentive measures is being implemented, most importantly in the development of sui generis negotiations. In addition, poverty reduction strategies, access to benefit sharing strategies, tax exemptions, and collaborative research projects, most successfully linked to sui generis recognition, are providing strong motivation for Indigenous peoples, local communities, governments and corporations to investigate collaborative approaches to conservation and economic development on the basis of the use of traditional biodiversity-related knowledge.

In parallel with the development of incentive measures, a significant investment is being made by international agencies and national governments in capacity building measures to enable Indigenous peoples and local communities to become party to agreements on the use of their traditional biodiversity-related knowledge. Of central importance are documentation projects and adult education programs.

It is apparent that there are strong developments occurring in the legislative and strategic planning arenas regarding the Indigenous peoples and local communities and 
their capacity to own, use, and benefit from their traditional biodiversity-related knowledge. National Biodiversity Plans have mostly now been developed and some nation states are moving to the implementation stage by embedding strategic planning within constitutional and legislative frameworks.

\section{Notes}

1 See http://www.Garma.telstra.com/Maak_st.htm

2 G Yunupingu personal communication with Marcia Langton

3 Ibid

$4 \quad$ Ibid

$5 \quad$ Ibid

6 This paper is based on a study by Marcia Langton and Zane Ma Rhea for the Secretariat of the Convention on Biological Diversity on the protection and maintenance of traditional biodiversity-related knowledge, as this relates to Article 8(j) of the Convention on Biological Diversity: Composite Report on the Status and Trends Regarding the Knowledge, Innovations and Practices of Indigenous and Local Communities. Regional Report: Australia, Asia and the Middle East on the Status and Trends Regarding the Knowledge, Innovations and Practices of Indigenous and Local Communities. CBD Convention on Biological Diversity; Distr. GENERAL; UNEP/CBD/WG8J/3/INF/48; September 2003 ENGLISH ONLY. See http://www.biodiv.org/doc/meeting.aspx?mtg=WG8J-03\&tab=1. In this study we reviewed literature documenting or analysing oral descriptions of knowledge, innovations and practices of Indigenous peoples and local communities relevant to the conservation and sustainable use of biodiversity, in order to assess, and to provide indicators of, the state of retention of such knowledge and practices in the regions.

7 The Secretariat is responsible for servicing meetings held under the Convention, including meetings of the Conference of the Parties, the Subsidiary Body on Scientific, Technical and Technological Advice (SBSTTA), and the Working Group on the Implementation of Article 8(j) and Related Provisions. It is also tasked with preparing documents and draft decisions for these meetings based on information provided by Parties in the form of national reports, case studies, reports of experts, and so on. Indigenous and local communities are particularly invited to contribute to the work of this process. See http://www.biodiv.org/programmes/socioeco/traditional/

8 See http://www.biodiv.org/programmes/socio-eco/traditional/

9 M F Ferrari Protecting Biodiversity and Indigenous Peoples/Local Communities' Rights: The Challenge in Southeast Asia IUCN Theme on Indigenous/Local Communities, Equity and Protected Areas (TILCEPA) 2003 p4

10 See http://www.biodiv.org/programmes/socio-eco/traditional

11 D Ghai (ed) Development \& Environment: Sustaining People and Nature Blackwell Publishers Oxford UK 1994; M F Ferrari 2003; L Maffi (ed) On Biocultural Diversity: Linking Language, Knowledge and the Environment Smithsonian Institution Press Washington DC 2001; E Mathias Indigenous Knowledge and Sustainable Development IIRR Working Paper International Institute of Rural Reconstruction Silang Cavite Philippines 1994; J Matowanyika V Garibaldi \& E Musimwa (eds) Indigenous Knowledge Systems and Natural Resource Management in Southern Africa IUCN Harare Zimbabwe 1995; P Maundu 'Methodology for Collecting and Sharing Indigenous Knowledge: A Case study' Indigenous Knowledge and Development Monitor vol 3 no 21995 http://www.nuffic.nl/ciran/ikdm/3-

2/articles/maundu.html; B Q Nietschmann The Interdependence of Biological and Cultural Diversity Occasional Paper 21 Centre for World Indigenous Studies Kenmore WA 1992; D A Posey 'Intellectual Property Rights and Just Compensation for Indigenous Knowledge' Anthropology Today vol 6 no 41990 pp13-16; D A Posey 'International Agreements and Intellectual Property Right Protection for Indigenous Peoples' in T Greaves (ed) Intellectual Property Rights for Indigenous Peoples: A Sourcebook SFAA Oklahoma City 1994 pp223-251; DA Posey, 'Traditional Resource Rights TRR: de Facto Self-Determination for Indigenous Peoples' in L van der Vlist (ed) Voices of the Earth Centre for Indigenous Peoples \& International Books Amsterdam 1994 pp217-239; D A Posey Indigenous Peoples and 
Traditional Resource Rights: A Basis for Equitable Relationships? Green College Centre for Environmental Policy and Understanding Oxford 1995; S Vertovec \& DA Posey (eds)

Globalization, Globalism, Environments and Environmentalism. Consciousness of Connections, The Linacre Lectures Oxford University Press Oxford 2003

12 See for instance, M L Langton 'The "Wild", the Market, and the Native: Indigenous People face new Forms of Global Colonization' in S Vertovec and D Posey (eds) Globalization, Globalism, Environments and Environmentalism. Consciousness of Connections, The Linacre Lectures Oxford University Press Oxford 2003 pp141-167

13 See footnote 5 in Langton \& Ma Rhea 2003 p12 at http://www.biodiv.org/doc/meeting.aspx?mtg=WG8J-03\&tab=1

14 See Garma Maak at http://www.Garma.telstra.com/Maak st.htm

15 See Langton and Ma Rhea 2003 pp21-24

16 H Magome \& J Murombedzi 'Sharing South African National Parks: Community Land and Conservation in a Democratic South Africa' in W M Adams \& M Mulligan (eds) Decolonising Nature, Strategies for Conservation in a Post-Colonial Era Earthscan London 2003; J Murombedzi 'Devolving the Expropriation of Nature: The "Devolution" of Wildlife Management in Southern Africa' in W M Adams \& M Mulligan (eds) Decolonising Nature, Strategies for Conservation in a Post-Colonial Era Earthscan London 2003

17 The UNESCO Red Book on Endangered Languages (2003) is an extensive listing of endangered languages that provides details of each language listed on a database, see http://www.tooyoo.l.utokyo.ac.jp/Redbook/index.html; see also S A Wurm \& S Tsuchida Endangered Languages in Asia and Pacific 2003 at http://www.tooyoo.l.u-tokyo.ac.jp/Redbook/AsiaPacific/AP index.cgi

18 S Wurm Atlas of the World's Languages in Danger of Disappearing UNESCO 2001

19 See L Maffi Linguistic and Biological Diversity: The Inextricable Link Terralingua Discussion Paper No 31998 at http://www.terralingua.org/DiscPapers/DiscPaper3.html

20 Ibid

21 Ibid; D Harmon 'The Status of the World's Languages as Reported in Ethnologue' Southwest Journal of Linguistics vol 141995 pp1-33

22 M Krauss 'The World's Languages in Crisis' Language vol 68 no 11992 pp4-10

23 D A Posey was, until his untimely death, Director of the Programme for Traditional Resource Rights of the Oxford Centre for the Environment, Ethics and Society, University of Oxford, as well as Visiting Researcher with the Brazilian National Council for Science and Research Professor at the Federal University of Maranhão

24 D A Posey (with contributions by G Dutfield K Plenderleith E da Costa e Silva \& A Argumedo) Traditional Resource Rights: International Instruments for Protection and Compensation for Indigenous Peoples and Local Communities IUCN Gland Switzerland 1996

25 L Maffi 1998

26 Founded on 5 October 1948 as the International Union for the Protection of Nature (IUPN), following an international conference in Fontainebleau, France. The organisation changed its name into the International Union for Conservation of Nature and Natural Resources (IUCN) in 1956. In 1990 it was shortened to IUCN-The World Conservation Union. See http://www.iucn.org/about/index.htm

27 D Harmon 'On the Meaning and Moral Imperative of Diversity' in L Maffi (ed) On Biocultural Diversity: Linking Language, Knowledge and the Environment Smithsonian Institution Press Washington DC 2001

28 J A McNeely K R Miller W V Reid R A Mittermeier \& T B Werner Conserving the World's Biological Diversity IUCN; WRI; WWF-US; World Bank; Conservation International-Gland Switzerland IUCN; Washington DC WRI Conservation International WWF-US World Bank 1990

29 L Maffi 1998

$30 \quad$ Ibid

31 N Tindale Aboriginal Tribes of Australia University of California Press Berkeley Los Angeles 1974 p133

32 L Maffi,1998

33 Wurm 2001

34 Langton \& Ma Rhea 2003 
R V Anuradha 'Biopiracy and Traditional Knowledge' The Hindu Folio Special issue with the Sunday Magazine, from the publishers of THE HINDU 20 May 2001 at http://www.hinduonnet.com/folio/fo0105/01050380.htm. Turmeric is a tropical herb grown in East India, and the powdered product made from the rhizomes of its flowers has several popular uses worldwide. Turmeric powder, which has a distinctive deep yellow colour and bitter taste, is used as a dye, a cooking ingredient, and a litmus in a chemical test, and has medicinal uses as well. In the mid-1990s, this product became the subject of a patent dispute with important ramifications for international trade law. A U.S. patent on turmeric was awarded to the University of Mississippi Medical Center in 1995, specifically for the 'use of turmeric in wound healing'. This patent also granted them the exclusive right to sell and distribute turmeric. Two years later, a complaint was filed by India's Council of Scientific and Industrial Research, which challenged the novelty of the University's 'discovery', and the US patent office investigated the validity of this patent. In India, where turmeric has been used medicinally for thousands of years, concerns grew about the economically and socially damaging impact of this legal 'biopiracy'. In 1997, the patent was revoked. But for two years the patent on turmeric had stood, although the process was non-novel and had in fact been traditionally practiced in India for thousands of years, as was eventually proven by ancient Sanskrit writings that documented turmeric's extensive and varied use throughout India's history. Many developing countries are concerned that the globalisation of intellectual property rights under the WTO's TRIPs agreement, and the negative consequences it has for traditional Indigenous knowledge and biodiversity. See http://www.american.edu/ted/turmeric.htm

36 D A Posey 1996 p81

37 See for example Posey 1996 p70; WIPO Inventory of Existing Online Databases Containing Traditional Knowledge Documentation Data WIPO 2002 Document No WIPO/traditional knowledge F/IC/3/6/-; see WIPO's 'Access and Benefit-Sharing Agreement Between the Lebanese Agricultural Research Institute, Tal Amara, Rayak, Lebanon and The Board of Trustees of the Royal Botanic Gardens, Kew, Richmond, Surrey, TW9 3AE United Kingdom' Traditional Knowledge and Cultural Expressions Contracts Database at http://www.wipo.int/tk/en/ D A Posey 1996 p79

39 Ibid $\mathrm{p} 82$

40 D A Posey \& G Dutfield Beyond Intellectual Property Rights: Towards Traditional Resource Rights for Indigenous and Local Communities IDRC/WWF Ottawa Canada \& Gland Switzerland 1996

41 Government of India India's Second National Report to the Convention on Biological Diversity NBSAP-India Ministry of Environment \& Forests New Delhi 2001

42 His Majesty's Government of Nepal, Biodiversity Profile Project, National Register of Medicinal Plants HMG/IUCN Nepal Kathmandu 2000

$43 \quad$ M F Ferrari 2003 p4c

$44 \quad$ Ibid $\mathrm{p} 7$

45 National Report to the First Conference of the Parties to the Convention to Combat Desertification (UNCCD) 1997, at http://www.unccd.int/cop/menu.php

46 WIPO 2002

47 Garma Maak 1999

48 A Escobar 'Whose Knowledge, Whose Nature? Biodiversity, Conservation, and the Political Ecology of Social Movements' Journal of Political Ecology vol 51998 pp53-80

49 Ibid p61

$50 \quad$ Ibid p59

$51 \quad$ Ibid $\mathrm{p} 56$

$52 \quad$ Ibid $\mathrm{p} 56$

$53 \quad$ Ibid p61

54 Constitution of Peoples' Republic of China 1982, at http://www.chinatoday.com/law/nollaw.htm

55 B Taneja \& A Kothari 'India' in J Carew-Reid (ed) Biodiversity Planning in Asia: A Review of National Biodiversity Strategies and Action Plans (NBSAPs) IUCN 2003 p377, at http://www.rbp-iucn.lk/books/nbsap/india.pdf 2002 
56 J B Alcorn \& A G Royo (eds) Indigenous Social Movements and Ecological Resilience: Lessons from the Dyak of Indonesia World Wildlife Fund Inc Washington DC 2000, at http://www.worldwildlife.org/bsp/publications/asia/resilience/resilience.pdf

57 G Baines \& M Hendro 'Indonesia' in J. Carew-Reid (ed), Biodiversity Planning in Asia: A Review of National Biodiversity Strategies and Action Plans (NBSAPs) IUCN 2003 p138, at http://www.rbp-iucn.lk/books/nbsap/indonesia.pdf 2002

58 M Langton D Epworth \& V Sinnamon 'Indigenous Social, Economic and Cultural Issues in Land, Water and Biodiversity Conservation, A Scoping Study for WWF Australia, Volumes One and Two, Centre for Indigenous Natural and Cultural Resource Management' unpublished report Northern Territory University Darwin 1998. See http://www.biodiv.org/chm/default.aspx

59 See H Fourmile 'Appendix 10: Indigenous Interests in Biological Resources in Commonwealth Areas-Synthesis of Submissions and Related Information' Commonwealth Public Inquiry: Access to Biological Resources in Commonwealth Areas Report commissioned for Environment Australia 2000, at http://www.ea.gov.au/biodiversity/science/access/inquiry/appendix 10.html

60 Biowatch South Africa, 'Biopiracy-Ten Years post-Rio' Proceedings of the South-South Biopiracy Summit August 2002 Johannesburg at http://www.biowatch.org.za/

61 Thematic Report on Access and Benefit Sharing to the Convention on Biological Diversity p3, see http://www.biodiv.org/doc/world/in/in-nr-abs-en.pdf

62 Second National Report on Implementation of the Convention on Biological Diversity, 2001, see http://www.biodiv.org/doc/world/cn/cn-nr-02-en.pdf

63 T Janke Our Culture, Our Future: Report on Australian Indigenous Cultural and Intellectual Property Rights Report commissioned by the Australian Institute of Aboriginal and Torres Strait Islander Studies and the Aboriginal and Torres Strait Islander Commission Michael Frankel \& Co Surrey Hills 1998

64 Ibid

65 See Cusco Declaration, at http://www.comunicadandina.org/ingles/document/cusco29-1102.htm

66 ASEAN 2001. Second ASEAN State of the Environment Report 2000 ASEAN Secretariat Jakarta 


\title{
Chapter 6
}

\section{The Politics of Indigenous Knowledge}

\author{
Arun Agrawal
}

Research on Indigenous knowledge over the past decade has retained a vitality of discussion and generality of interest from both specialists and general audiences in a form that must be truly gratifying to scholars of Indigenous knowledge. Nonetheless, those who think about Indigenous knowledge need to grapple with a curious and continuing lack. Much of the scholarship on this critically important subject remains inattentive to the integral relationship of power with Indigenous knowledge. I do not mean the relationship of the variety that is expressed in common phrases such as 'knowledge is power' or, for that matter, 'power is knowledge'. I refer to a somewhat different set of issues, those that come to the forefront in considering how the nature of the Indigenous is shaped by the workings of power, and what are the ways in which power is a property of that which is classified as Indigenous. This chapter suggests it is important to consider this relationship especially because it can help clarify the viability and nature of political strategies used by both advocates and detractors of Indigenous knowledge.

To illustrate my claim about the limited attention given to the relationship between power and Indigenous knowledge, consider three important works published in the past decade: by James Scott, ${ }^{1}$ James Clifford ${ }^{2}$ and Akhil Gupta. ${ }^{3}$ These all touch upon the question of power explicitly but tangentially, or centrally but implicitly as they discuss ideas about indigeneity and the nature of the Indigenous. But none develops a careful analysis of how one might conceptualise a concern with power and articulate it with a concern with the workings of Indigenous knowledges, what such knowledges are, or what is happening to them.

The issue is both broad and deep enough that my chapter is of necessity a preliminary investigation at best. In a sense, it is a series of ideas in the making, advanced with a view to provoke discussion and debate, rather than as an attempt to settle a dispute.

Descriptions of Indigenous knowledge attempt what might be called a dual redemption. One, they seek to redeem their subject by pointing to how folk knowledges exist in a kin relationship with more formal investigations, their relevance to science, to particular utilitarian ends, and potentially to the interests of those who are not Indigenous. In generating an account of the specific form of knowledge, descriptions of Indigenous knowledges and peoples thus provide an implicit justification for the continuation of the folk lifestyles and livelihoods that gave birth to that form of knowledge. Second, descriptions of the Indigenous seek to prevent its

\footnotetext{
* Dr Arun Agrawal is Associate Professor at the School of Natural Resources and Environment, University of Michigan.
} 
loss in describing it. They serve this second redemptive function thus insofar as the very act of description serves to protect. Even if the peoples with whose knowledge a particular description is concerned were to disappear their knowledge will be preserved. In each of these senses, writings on indigeneity are also what Clifford has called 'allegories of salvage'.

The notion of salvage is central to research on Indigenous knowledge work because of its concern with loss and value. Folk taxonomies, studies of specific people's relations with their plants and animals, and investigations of changing cultural practices are necessary because of the potential loss of information were such studies not carried out, or even were they to be delayed. In common with much work on peasants, pastoralists, and hunter-gatherers, then, scholars of the Indigenous see the subject of their interest as always-already disappearing.

Questions related to loss, value, and salvage are intimately concerned with powerhow power is exercised, who exercises it, and what its role is in social change. I seek to uncover some of these themes by discussing briefly a particular case of mobility and dislocation: one concerning state interventions in the lives of a group of mobile pastoralists. The example raises issues that resonate with other cases of mobility and displacement, other examples of the potential disappearance of ways of Indigenous living and peoples. I use it to open a dialogue of how ideas about power can be reconceptualised in discussions of indigeneity in a way that has not been particularly common to these discussions.

\section{Research on the Indigenous: A Paradox}

Studies of Indigenous knowledge are viewed as necessary because the subjects of this research are seen to be under threat, indeed slowly disappearing. Much research on the subject presents an antagonistic relationship between economic growth or development in its many different guises and the interests of Indigenous peoples. This antagonistic relationship where development processes produce usually harmful changes is seen to be true of market-led changes, as well as situations where nation states initiate programs of development. Social, economic, and ecological deterioration that confronts Indigenous peoples is, in this view, a result of inexorable capitalist market expansion, or externally imposed political, social, legal, and economic structures. ${ }^{5}$ Market expansion can make existing production strategies of Indigenous peoples useless, their cosmologies irrelevant, and their politics marginal. More powerful, better off, and wealthier groups are typically seen as better able to appropriate the opportunities and resources that government interventions create. As Indigenous peoples are isolated from new economic opportunities and as their older livelihood strategies become less viable, their knowledge is threatened with obsolescence and irrelevance.

The necessity of ethnobiological research is coupled with urgency because of the rate at which ethnobiologists perceive their subject of interest to be disappearing. Modernisation, industrialisation, dislocation, economic growth and associated phenomena are not only leading to a decline in the prospects of Indigenous groups, they are bringing it about at an accelerating pace. As the argument goes, social transformations inimical to the interests of Indigenous peoples and their knowledges are hard to arrest; hence if this knowledge is not documented now, it is likely that it 
will be lost forever. It is therefore critical that research into such knowledge be carried out sooner rather than later.

Additionally, research on Indigenous knowledge gains importance because of the potential value of the knowledge that is under threat. Such knowledge can be useful both for Indigenous peoples themselves and for others. It can be useful for the Indigenous peoples if they gained greater, more secure, and more certain access to land and productive resources - they could then deploy their knowledge in conservative and sustainable management practices. It is also useful to others because it can improve the chances of success of development interventions, help in creating more widely available medicines and cures, and facilitate better management of environmental resources.

The necessity, urgency, and importance of conducting ethnobiological research raises a host of philosophical, epistemological, and ontological issues to which scholars of the Indigenous have attended since the founding of their, to coin a somewhat awkward term, inter-discipline. These include whether Indigenous knowledge is really 'old' knowledge, the extent to which it exists in a pure or mixed form, in what ways it might be crucial in development and progressive social change, its relevance to science, its scientific validity, and so forth. These issues are closely tied to the central theme of this chapter: how to enable a way of relating power to Indigenous knowledge that is internally consistent and politically progressive; that is to say, in a way that opens up a space for talking about change through the agency of those presumed to be the victims of modernity.

To illustrate what I have in mind by consistency, let me point to a seeming paradox in writings on Indigenous knowledge. The necessity, urgency, and importance of research on the Indigenous derives from assumptions that such knowledge is disappearing, the rate of disappearance is fast and possibly accelerating, and that such knowledge is valuable. But the value one is talking about is quite specific: it is useful in improving scientific knowledge, it is useful for pursuing development, and so forth. This is somewhat puzzling because it is development that to begin with threatens Indigenous knowledge - it is the progressive spread of science and scientific knowledge that threatens the ways Indigenous cosmologies and knowledge work. So the spread of what threatens Indigenous knowledge is also precisely what many advocates of Indigenous knowledge seek to advance by identifying, documenting, collecting, and systematising Indigenous knowledge. ${ }^{6}$ We seem to be in a catch-22 situation. I suggest that this catch-22 situation can at least be understood better, if not resolved, by paying greater attention to the nature of power, and how quite particular ways of thinking about power implicitly underpin studies of the relationship between Indigenous knowledge and processes related to modernity and change.

\section{The Raikas of India: A Case Description}

To ground the ensuing discussion of power and its relevance of Indigenous knowledge, let me present a case description of displacement and dislocation among the raikas shepherds of India. The raikas inhabit the western states of Rajasthan and Gujarat, and are quite likely the largest group of migrant agro-pastoralists in India. Migrating as collectives over anywhere between three to nine months in the year, they are led by an experienced shepherd called the nambardar. Their mobility allows them 
to enhance levels of agro-pastoral production by taking advantage of variations in production across territorial landscape units, and depends on their ability to enact a series of exchange relationships with farmers, wool shearers, merchants, and petty commodity producers. In this sense, mobility is an adaptation to a hostile social and ecological environment, and one in the absence of which economic production would likely be far lower. However, the mobility of pastoralists is also viewed by many state actors as an irrational response to environmental constraints, modernisation, and market forces.

It is these latter understandings of mobility that led the government of Rajasthan, with the help of funds from the World Bank, to create the Sheep and Pasture Development Program. This program aimed to convert land not used for agriculture into plots of pastures, increase the utilisation of rainwater for pasture development, check soil erosion, maintain fertility, check animal migration, and improve the quality of wool and mutton that reached the market. To meet these objectives, the program officials formed nearly 2500 raika households into 49 cooperative societies, for each of which they fenced one plot of 100 hectares. Members of society contributed capital in the form of ewes. The government hoped that after two or three cycles of rain, the shepherds would witness the greater wool and mutton productivity of sheep on the pasture plots compared to those in migrating flocks, the positive lessons of sedentarised living would compel them to settle down, and the pasture plots could be handed over for local management.

The program produced other effects as well. It created the plots out of the common lands on which village animals grazed; effectively, it reduced the fodder available for grazing. Program officials sowed new grass in the enclosed plots. This grass was only to be grazed by the sheep belonging to the members of the cooperative societies. The flock in each plot included improved varieties of rams to increase the yield of wool and mutton from the sheep.

But after ten years of intensive, expensive efforts at proselytisation, the program had still not managed to persuade any shepherds to settle down. Although each cooperative society earned approximately 2000 rupees annually for their members, salaries of government officials had cost more than a million rupees each year. The overall operating budget surplus from the project was just around 0.5 million. None of the cooperative societies had received any pasture plots to manage.

Shepherds and government officials advanced very different stories as explanations. For officeholders in the program, the fault lay with the shepherds and weather. Rains failed for several consecutive years after the program was launched; but the shepherds had provided unproductive land for the pasture plots, non-member shepherds had broken the fence around the plots, village animals competed with those within the pastures for the available forage, the grasses sown in the enclosed pastures could not establish themselves owing to the high grazing pressure, funding uncertainties had led many shepherds not to join the program; the list went on.

For the shepherds, the program made little sense. It provided access to those who had sheep to spare, others who were denied government largesse did not feel the need to cooperate: their sheep 'encroached' on the enclosed pastures. Many villagers, incensed by the enclosures that sought to overturn perfectly viable existing practices, stole and sold the barbed wire that marked the boundaries of the plot. Some of them 
used the identity papers supplied to them as members of the program to buttress their applications for ration cards as village residents and as voters in elections. Despite the difficulties and failures they encountered, government officials expressed the hope that if the program continued, successful outcomes (from their point of view) would be just around the corner. The program was closed down in 1990.

Different ethnographers have interpreted different sedentarisation programs in radically different ways. One way to describe what happened to the raikas in the Sheep and Pasture Development Program is to point to the imposition by the state, to the dislocation of the lives of some of the shepherds as the program made a large area of grazing resources more difficult to access, took animals out of the migration process, and created new mechanisms of surveillance and state presence in the midst of raikas' lives. The attempt to sedentarise them, to the extent it was successful, made them less able to withstand seasonal and annual variations in rainfall and fodder availability. It constituted what Foucault has called a double repression by institutionalising exclusionary processes and standardising impositions. It included some and excluded others; it imposed certain standards of behaviour on those it included, at the same time promising inclusion to those excluded others who were willing to conform to the new standards.

Another way to represent what happened is to point to the agency of the shepherds and to their success in bringing about the failure of the program. By refusing to cooperate with the processes the program sought to institutionalise, the shepherds defended their lifestyles and showed their power to undermine externally imposed solutions to their problems. They evaded the double repressions of which Foucault speaks by sidestepping or evading the criteria of inclusion, and dodging the standards of conformity. Indeed, one can point to an unintended consequence of the shepherd societies that favoured their overall interests. Members of these societies formed the core of a federation of shepherd societies to lobby politicians. The leader of this federation regularly meets with members of the state legislature and mid-level officials in the state bureaucracy to communicate the complaints and concerns of shepherds. The strength of the federation is at least partly attributable to the ability of the shepherds to promise to cast their votes as a block in local elections.

Indeed, these conflicting interpretations of state interventions can be multiplied by referring to other Indigenous peoples. My intention, however, is neither to provide resonating accounts, nor to lay to rest the differences in interpretations by proving one correct, nor indeed - to seek a resolution - a synthesis that would make different resolutions agree by pointing to a larger truth about the lives of the shepherds. Instead, I want to use the example and its varying interpretations to analyse how power is conceptualised in different interpretations of mobility, indigeneity, and interactions with state forces. To do so, it is necessary to investigate some of the prominent strains of theorization about power in recent social-theoretical literature.

\section{The Faces of Power and Power Without a Face}

Perhaps the most common understandings of power in the social sciences explicate it with reference to the three faces of power. They begin with Bob Dahl's well-known critique of elite theories of community power. Dahl advanced his arguments in distinction to C Wright Mills and sociologists such as Floyd Hunter who argued for a 
concept of power in which the consent of individuals could be managed and manipulated. In contrast, Dahl asked, 'What does it mean to say that A has power over B?' And his answer was, 'To the extent A can get B to do something that B otherwise would not do'. Four features of this idea of power are prominent: it is relational, observable, subjectival, and negative. It is relational because it defines the relationship between two different agents, it can be observed by its effects upon an agent, it is subjectival because the agents are individual subjects, and it is negative because it is a constraint upon the freedom of a subject.

Dahl's arguments were almost immediately contested as constituting only one face of power. First Schattschneider, and then Bacharach and Baratz argued that Dahl's ideas had a critical weakness insofar as they were limited to actual decisions and observed issues. Dahl and his colleagues assumed that non-participation was the result of apathy, indifference or complacency. Instead, non-participation and absence of particular issues on the political landscape could itself be an effect of power. The public face of power and its analysis, for these critics, needed to be complemented by an examination of the hidden face of power-what Bacharach and Baratz called 'the second face of power'. By this they meant that the powerful can influence the powerless by prevailing in manifest conflicts, but also by preventing conflict from arising at all. Politics and effects of power were also about how A got B not to do what A did not want; how did leaders and organisations mobilise bias, and how it included some at the expense of others.

If the second face of power struck many as being difficult to research empirically, their reactions to 'the third face of power', whose importance was argued by Steven Lukes, was simply to call it metaphysical. Lukes argued that power not only had a public and a hidden face, but also had an unperceived face in that it could shape how individuals understand their wants, desires, and interests. A could get B not even to perceive B's real interests. Lukes introduced Marxian conceptions of ideological hegemony into the debate, and other scholars such as Gaventa investigated how methodological obstacles to study power's hidden and unperceived faces could be overcome in empirical research, especially by studying institutional practices, and by focusing on myth, symbols, and rumours.

But ultimately, each of these three ways of understanding power have in common the relational, the subjectival, and the negative aspects of what it means to exercise power. The nature of the subject changes from the first to the third face of power (aware or not aware), but the nature of power does not. Power is exercised by individual agents, and it is a constraint upon the freedom of the self and freedom of actions viz, we know that power is being exercised when subjects and their actions are not free.

Whereas these accounts of power are agent-centered, structural accounts of power in the 1980s and the 1990s engaged the issue of the relationship between human agency and social structure in the exercise of power. The main concerns were about the extent to which the analyses of power relations should be extended beyond the dyadic relationship between A and B, and beyond the specific event in which A affects B's actions.

Structuralists make three distinct claims about the relationship between social power and human freedom, and how the power of agents is shaped by antecedent and 
attendant social conditions. They point to the importance of other agents in shaping the power relationship between the members of a dyad, to the importance of social roles to which individual members of a dyad get assigned, and to the role of values and norms.

Thus, other agents, who are not part of a dyad, can change how a dyadic power relationship works. A's power over B is a result of actions of other agents that may be peripheral to the relationship between $\mathrm{A}$ and $\mathrm{B}$, but who are nonetheless quite crucial to its nature. In the example of the raikas, government officials are able to exercise some kinds of power over the shepherds because of their relationships to other government officials in an administrative hierarchy.

Further, structuralists argue, power is exercised by virtue of one's location in particular roles, participation in social relationships, and capacities that result from these roles; and not just because of the agency of an individual or her personal characteristics. With reference to the raikas, for example, the leader of migrant shepherd camps exercises certain powers of decision making by virtue of his location in that leadership role. All leaders make certain kinds of decisions, shepherds accept them; all leaders assign responsibilities of some types among their followers, shepherds carry out their assigned tasks. These role definitions are assumed by both leaders and shepherds who are members of a migrant collective. Although some shepherds may become leaders by virtue of their personal qualities, their acceptance into a leadership role permits them to exercise powers and make decisions that otherwise would not have been available to them.

It is not just peripheral agents and social roles that influence power relationships between two agents, but also norms and rules. Accepted background beliefs, routines, and norms affect how shepherds will react to their leader's commands. In this sense, background norms and beliefs work to make certain expectations about roles and social positions natural. They strengthen particular kinds of asymmetries in social relationships, or can undermine asymmetries. They are prior to the social roles and peripheral agents who affect A's power over B.

Thus the significant difference between structural and agent-centered conceptions of power lies in the different treatment of peripheral agents, social roles and power, and background norms and expectations. But in both these ways of thinking about power, despite their important differences related to observability, agency, intentionality, and moral responsibility, the basic idea of power as a relationship between agents, and as the antithesis of freedom is common. These frameworks for thinking about power do not help us understand variations in the effectiveness of agency over time or across space; nor do they help us gain much purchase on positive effects of power. They conflate the idea of power with the idea of domination. But power plays a fundamental and foundational role in many social interactions which cannot be understood well by views of power that emphasise its negative workings between individual agents. How do identities of shepherds come into being? What is the relationship between successes of some strategies for shepherds and of others for government officials? If shepherds are structurally weaker than government officials, how do they sometimes gain victories in their interactions with them?

To understand these and related questions, a third set of ideas to inform the nature of power comes from the work of Michel Foucault. This way of thinking about power is 
less interested in what power is, or where it comes from, or whether power is a property of some agents, or something that can be owned or possessed. Rather, the focus is on the effects power produces. It is distinguished from force because it always leaves some element of choice. Power traverses through a body and invests it, thereby helping create what the body does or how it is viewed rather than simply constraining other bodies as its effect.

An important distinction to understand Foucault's arguments is that between power to and power over. Power over is relational and power to is self-directed. But they are a related pair. Power to may be empirically and logically prior to power over, but one can help the other. Power over can thus contribute to power to, and vice versa. Domination, similarly, should not be confused with power over but is a result of a particular effect of some form of actions over other forms. Domination can, thus, in part be explained through the structural aspects of relations of power.

It is important, then, to note three important features of this perspective: a) power does not just constrain but also enables, b) power can be understood not just by investigating institutions of the state, but also by looking at social relationships, and (c) power is exercised upon actions through actions, not by a person over another person. In this approach, power is not antithetical to freedom but its condition. This is because freedom can be seen as realisable in two ways that become as one considers positive and negative constraints to freedom. Positive constraints are internal to a subject. They can prevent self-realisation. Overcoming internal constraints that exist upon an individual's ability to act irrespective of external constraints is an exercise of power and helps constitute the subject more fully. Negative freedom is about external constraints upon the individual's ability to act. Power thus enables particular strategies to come into being, both in the sense of allowing some subjects to overcome constraints to their self-understanding, to realise themselves, and in the sense of allowing particular strategies to influence the enactment of other strategies. In the first sense, power does not constrain a self, but makes the self. Power to achieve something in the personal realm is also freedom in the sense of overcoming positive constraints to action.

In relation to the strategies I have described in the example of the raikas and their interactions with state officials and programs, it is easy to find echoes of the agentcentered and the structural approaches to power. Most such accounts of social struggles as I provided use particular social-categorical classifications as embodiments of particular interests and agencies - the multiplicity of shepherds and state officials denoted by the terms is reduced to a single agent that inhabits the category, with its own interests, preferences, and strategies for all practical analytical purposes. The same is true of my account: government officials (A) tried to get shepherds (B) to do something that shepherds (B) otherwise would not do. They succeeded in some of their goals but not others. The strategies that failed for government officials can be represented as successes for shepherds. Structural relations of the two groups of agents affect the extent to which they are successful. Peripheral actors such as the World Bank, non-participating shepherds, and other villagers left their marks on outcomes as did the respective roles occupied by state officials/shepherds and background expectations associated with these different roles. 
However, these ways of representing what happened ignore two critical aspects of the story: the ways shepherds experienced the strategies enacted by government officials and how they used these strategies, for example, to create their own association or to represent themselves as citizens and residents of a democratic polity; and the radically fractured nature of the different strategies. It is not difficult to see how these different strategies come together in time and place as a common set, instead we see quite different outcomes and little in terms of analytical resources from the agent-centred and structural theories of power to explain how these outcomes can be connected.

Describing these different ways of thinking about power helps move discussions about whether Indigenous knowledge and peoples are being marginalised by economic growth, expansion of political processes, and state interventions to a different plane, one in which it is possible to focus on the underlying concept of power being used rather than the validity or truth claims of the statements comprising the discussion.

I suggest that the two aspects of the working of power that Foucauldian approaches foreground - strategies acting upon strategies, and strategies helping constitute the subject - are crucial to understand the concrete instances of how indigeneity and power articulate. As Foucault argued, individuals are not agents of power; rather, '[o]ne of the prime effects of power [is] that certain bodies, certain gestures, certain discourses, certain desires come to be identified and constituted as individuals'. ${ }^{7}$ To the extent one is interested in processes of production of subjects, and hence in opening up the black box that is often seen to be an individual agent, it is useful to appeal to some aspects of Foucault's later work in thinking about power and indigeneity.

\section{Conclusion: Articulating Power and Indigeneity}

Describing the different varieties of migration, and how movement affects one's sense of place among members of the Kanak in New Caledonia in the south Pacific, Clifford suggests that the example raises three kinds of issues: the relationship between indigeneity and place, that between edge and centre, and finally, between the specificity of particular Indigenous experiences and the generality of the postcolonial discourses and identities. To understand these different relationships better he draws on Stuart Hall to advance claims in favour of a concept of 'Indigenous articulations' that would attend to the diversity and specificity of cultures and histories that go by the name of Indigenous.

The strength of the concept of articulation in relation to Indigenous claims is that it allows one to move away from rigid notions about what constitutes oppositional interests and politics in favour of greater attention to the contingencies involved in crafting a common front. This is a great strength, in that it simultaneously opens up question of authenticity, discusses the need to endow specificity upon generalist criticisms of monolithic categories (such as the Indigenous or the scientific), and focus upon the processes behind the creation of such categories.

Its weakness, as Clifford confesses, is that when pushed to its logical extreme, the idea of articulation flails upon the shoals of radical contingency and fluidity in the creation of coalitions and alliances, ignoring the effects of sedimented histories and localised place experiences. This weakness, to my mind, stems from inadequate 
attention to the strategies of power that different possibilities of articulation signify. Not all articulations are possible. The shepherds in my example did not try to create alliances with government officials in charge of implementing the Sheep and Wool Development Program. Their strategies to win legislative victories did not intersect with their strategies to extract more fodder from the enclosed pasture plots. Locality and history are all very well, but which aspects of local affiliations or historical experiences matter depends upon how power works in the cases under investigation. This is only another way of saying we must attend more closely to the resources involved in any particular power exchange. Without attention to the different ways strategies of power unfold in the articulations that Indigenous peoples attempt, especially those Indigenous peoples undergoing displacement and change, it is neither possible to focus on the agency of the Indigenous, nor on the processes through which agency is produced.

Thus, although I am not interested in a predictive model of strategic alignment of identities, cultural forms, political intentions, disrupting interventions, and so forth, even my more modest desire to focus upon analytical tools to be used to generate a map of experiences of Indigenous articulations requires far greater attention than has been the case to political strategies, resources that make strategies possible, and the actors who are produced in gaining access to resources. It is toward such a goal that new work on Indigenous knowledge needs to move if it is to clarify both the conditions under which Indigenous peoples can gain strategic victories, and the processes through which Indigenous peoples gain a positive sense of their own indigeneity.

\section{Notes}

1 J Scott Seeing like a State: How Certain Schemes to improve the Human Condition have Failed Yale University Press New Haven CT 1998

2 J Clifford 'Indigenous Articulations' The Contemporary Pacific vol 13 no 22001 pp468-90

3 A Gupta Postcolonial Developments: Agriculture in the Making of Modern India Duke University Press Durham NC 1998

4 J Clifford, 'On Ethnographic Allegory' in J Clifford and G Marcus (eds) Writing Culture: The Poetics and Politics of Ethnography University of California Press Berkeley 1986 p115

5 J Clay Indigenous Peoples and Tropical Forests: Models of Land Use and Management from Latin America Cultural Survival Inc Cambridge Mass 1988; G. Massey Subsistence and Change: Lessons of Agropastoralism in Somalia Westview Bouldge 1987

6 For a discussion of these issues in relation to the construction of Indigenous knowledge databases see A Agrawal 'Indigenous Knowledge and the Politics of Classification' in International Social Science Journal vol 54 no 173 September 2002 pp287-297

7 M Foucault 'Body/Power' and 'Truth and Power' in C Gordon (ed.) Michel Foucault: Power/Knowledge Harvester Press 1980 p98 


\title{
Chapter 7
}

\section{Indigenous Knowledge, Intellectual Property, Libraries and Archives: Crises of Access, Control and Future Utility}

\author{
Jane Anderson ${ }^{*}$
}

In Australia, as in other places around the world, Indigenous people are raising important questions about the histories that have been produced from the archive and from libraries. Indigenous people are also seeking greater access to and, in certain cases, control over material that is located within the archive. This not only challenges rationalities of archival management (and I should say that I am using the term archive in a generic way to refer to both libraries and other archives) but also to the conception of the 'public' as well as legal conceptions of authorship and ownership. On one hand these struggles can be understood in the light of post-colonial politics. As the historical subjects of the archive reinterpret and re-inscribe material from within the archive, this affects how the archive is understood, both as a site and its effects on the social.

In this chapter, I discuss some of the reasons why there might be crises of access, control and ownership of Indigenous cultural material, the relationship of these issues to intellectual property law, and how to begin thinking through what the issues mean and how to navigate a pathway through them. I begin with an outline of my work and what I do in this area. From there, I move into some more philosophical questions about the making of archives and libraries - the spaces that they make possible and the relations of power that are inherent to their structure. I do this through the frame of liberal archives and colonial archives. In my view, this perspective is important because the processes of documenting Indigenous knowledge are not isolated to the past but are ongoing activities for a variety of reasons and across a variety of communities and academic disciplines. Whilst Indigenous people and communities are much more involved in these processes than in the past, there are still a number of issues about collecting and documenting Indigenous knowledge and a range of intellectual property implications. I conclude with a discussion about the work I am conducting with the Galiwin'ku Indigenous Knowledge Centre. This involves the development of a very specific community intellectual property agreement that responds to quite specific needs of the Knowledge Centre. The prolific nature of protocols in this area points to their power as a strategic tool. As the Galiwin'ku example will show, they have the potential to forge new relationships between the community and researchers, archives, libraries and other cultural institutions. They

\footnotetext{
* Dr Jane Anderson is Visiting Research Fellow, Australian Institute of Aboriginal and Torres Strait Islander Studies, and Rockefeller Humanities Fellow, Smithsonian Institution.
} 
begin to establish a benchmark for responsible obligations between parties that move around some of the more tedious constraints of copyright law.

\section{Issues of Access and Ownership: The Importance of Intellectual Property}

At the Australian Institute of Aboriginal and Torres Strait Islander Studies (AIATSIS), I work on an intellectual property (IP) and Indigenous knowledge project, which came about because there were serious issues of ownership with the collection at AIATSIS. AIATSIS holds the world's largest collection of Australian Indigenous material. Some of the materials in the collection have issues that generally revolve around authorship and ownership and which have led us to investigate what these mean, how to work through and solve any problems so that AIATSIS can deliver access to that material to Indigenous people and communities. Resolving issues involves wading through a whole historical milieu: what has happened in the past, how material has come to the Institute, who has deposited it, who legally has copyright rights and, significantly, who has had the power to say who does get access. All these questions come to bear on determinations about how and what to do in relation to such materials. So, clearly, intellectual property is a huge kettle of fish, especially in an institution that has such a wide range of Indigenous cultural material. Indeed for AIATSIS and cultural institutions more generally, the road seems to be paved with copyright problems and complications.

The project looks practically at some instances of material that causes difficulty viz, material that has difficult depositors, material that has deceased depositors, and depositors fearful of material that perhaps should never have been collected in the first place. To date these people control access because they are, in most cases, the copyright owners, and if they say, Indigenous people, regardless of whether they are family members or related to the original people in the recordings can be denied access then there is very little power that AIATSIS has over the legal rights of the copyright owners of the material. I should put a caveat here that this is not the majority of material at AIATSIS but because it affects how AIATSIS delivers access now and in the future to the material, these are issues that are in need of attention.

What kind of materials are we talking about? For the most part, the materials that are particularly difficult is photographs, sound recordings and films; or for copyright law, subject matter other than works. ${ }^{1}$ I find this interesting because of the importance of the visual image and aural mediums. They hold an immediacy of representation, for instance, representation of place, of ceremony, of knowledge. That it is this material that raises quite intense questions of authorship and ownership is significant too because in the history of copyright law these have been the types of materials that have posed challenges for copyright law. ${ }^{2}$ For copyright law always has struggled with determining creative endeavour, and hence justifying ownership of this material. ${ }^{3}$ A reflection upon these types of Indigenous cultural material should alert us to the often hidden histories of instability in narratives of the genesis of intellectual property law. ${ }^{4}$

It is significant that intellectual property now features popularly in our society and is much more in the public gaze than it was ten years ago. ${ }^{5}$ However, AIATSIS did recognise, as early as 1972, that copyright was going to be an important issue. ${ }^{6}$ Whilst it was not explicitly written into contracts and agreements of work with people who 
were recording Indigenous cultural material (and this is now certainly a problem), there was an implicit recognition that this was going to be an issue and now in 2004 we are working through what those issues are and how to deal with them both in their historical and contemporary manifestations.

Since Indigenous people have begun to know about IP, they have also started questioning who the legitimate rights holders are and why. ${ }^{7}$ As the recording of Indigenous knowledge and information has predominately been conducted by nonIndigenous people, the making of the material into tangible form, photographs, sound recordings, films etc. means that ownership tends to lie with the non-Indigenous researcher or creator of the work. ${ }^{8}$ The advent of digital technology complicates processes of ownership. ${ }^{9}$ As IP law grapples with the demands of digital technology, so too does it compound some of the problems with Indigenous cultural material. For example, just because some material is in the public domain and even out of copyright protection, doesn't necessarily mean that it is appropriate to circulate freely on the web with little or no restriction or moderation. So ownership of material is an important concern and resolving this issue, with the recognition of Indigenous rights - not just legal rights - lies at the heart of access, control and future utility.

\section{The Role of Archives and Libraries: Some Historical and Philosophical Considerations}

How do archives and libraries begin dealing with this issue? To address this, I want to reflect upon some of the more philosophical questions about what role archives and libraries play in managing knowledge collected over historical periods, and indeed the complexity that this brings to bear on dealing with IP issues in contexts like knowledge centres.

Jacques Derrida begins his influential essay Archive Fever by tracing the etymology or archive of the term. Whilst Derrida's work spurned a rethinking of the archival project which has generated its own wealth of literature, his etymological rendering remains insightful about the extent of power relations involved in the archive as a physical structure as well as those implicated in the processes of governing access.

The meaning of archive, its only meaning, comes to it from the Greek arkeion: initially a house, a domicile, an address, the residence of the superior magistrates, the archons, those who commanded. The citizens who thus held and signified political power were considered to possess the right to make or to represent the law. On account of their publicly recognized authority, it is their home, in that place which is their house (private house, family house or employees house) that official documents are filed. The archons are first of all the documents guardians. They do not only ensure the physical security of what is deposited and of the substrate. They are also accorded the hermeneutic weight and competence. They have the power to interpret the archives. Entrusted to such archons, these documents in effect speak the law: they recall the law and call on or impose the law. To be guarded thus, in the jurisdiction of this speaking the law, they needed at once a guardian and a localization. ${ }^{10}$ 


\section{The Liberal Archive}

Patrick Joyce has developed a cogent argument for the archive as a political technology of liberal governmentality. ${ }^{11}$ By this he means that the archive provides an intrinsic instrument in helping to render readings of social life and social conditionsreadings that are intrinsic to how liberal governments conceptualise subjects and their needs and then develop particular strategies to achieve these ends. It provides a space for the different narratives between the national and the social to be interpreted. Data amassed about a particular subject or experience in daily life, went on to inform the way in which the subject could be managed through targeted governmental and bureaucratic programs.

Of particular interest for Joyce is the emergence of the 'public' archive in Britain. He locates it as the Reading Room in the British Museum in 1753 and the Public Record Office in 1838 some 80 years later as offering a fuller rendering of the 'public'. The Library Act of 1850 instituted the first democratic archive, and we should not discount the role of law - through legislation - in enabling this new free space of interpretation. Indeed, the very idea of the free library was central to the new vocabulary of the social that was engineered through the archive, especially the meanings of 'public'. ${ }^{12}$ Whilst both the British Museum and the Public Record Office were theoretically 'public', access to both was limited, and this was not only in what was accessible, but the extent that freedom of the public was also limited or contained by the very structure and architecture of the buildings.

Joyce highlights the historical development of an archive that, though guarded, is a public space. With the generation of the public space as a relatively recent phenomenon, it is worth reflecting how it is also intrinsically tied to the development of liberalism, and the autonomous liberal subject. I am fascinated by this notion of the archive as a public space and the freedom of the individual to access that space. In particular, I am interested in the range of political powers that are engaged when, for instance, the public space of the archive is disrupted by explicit, as opposed to more subtle, forms of restriction. For the prior consignation of documents to the archives limits what visitors can find in it, and in cases where the archive is tightly constructed to enhance the reputation of an author or to cast an event in a way that supports a partisan cause, the archive can be said to embody an intentional design. Archives are not always coherent, and they may contain a surplus of materials which enable adversary readings. ${ }^{13}$

It is here that the work of Thomas Osborne is useful. Osborne helps us in our understanding of the archive by positioning the archive as a source of both ethical and epistemological credibility. ${ }^{14}$ To understand how such a location for the archive might be conceived he looks to notions of authenticity, identity and evidence and the way that they relate to ideas of representation, interpretation and reason. To think of the archive in such a way allows access to ideal and literal conceptions. That is to say that by tracing the place of the archive, this allows a very particular mode of inquiry for understanding the cultural and historical rationale that made possible its existence. More than this it creates a way of thinking about the archive in differing political systems and drawing resonances in the process of understanding the activities of the archive. This approach gives us a system to understand the political rationales and effects that can be brought to bear on the archive and its contents. 
Using Karl Popper's sense of the term 'objective knowledge', Osborne likens the analytical space created by the very existence of the archive to the space that the laboratory creates for the natural scientist. ${ }^{15}$ This analogy encourages reflection about the extent that the 'things' that are housed, recorded, administrated or even accessed in the archive are also objects that belong to a third world beyond both the physical world of things and the knowing subject or subjective experience. Here Osborne suggests that we may also understand the world of the archives existence as autonomous. That is to say that in this 'third world' what is of particular importance is the possibility of the archive producing its own effects. ${ }^{16}$

Not being completely satisfied with this understanding of the archive as 'autonomous', it is perhaps more usefully conceptualised as a centre for interpretation. ${ }^{17}$ In providing a way of relating to the past, significantly a predominately written past, these places are not innocuous or neutral holders of material but are part of socio-political practices. Although archives continue to be valuable facilities, the practices and struggles associated with composing, assembling and controlling access to documents plays a substantive role in history as well as the scholarly reconstruction of history. ${ }^{18}$

The relationship between the archive and its constituents (the public) raises a range of questions. In thinking about who the public for an archive might be, Osborne notes that 'the archive is there to serve memory, to be useful - but its ultimate ends are necessarily indeterminate. Material is deposited for many purposes, but one of its potentialities is that it waits a constituency or public whose limits are of a necessity unknown. ${ }^{19}$ Just as a text exists because there is a reader to give it meaning so an archive exists because there is a user to give it meaning. ${ }^{20}$

So my interest here turns from the politics of the liberal archive to a more sustained attention how meaning is conveyed to a variety of users. In the changing social and historical contexts of Australia, it seems worthwhile asking what happens to the meaning produced by the archive when the users of the archive shift focus, and what happens when new user groups are constituted, users who have not only been historically excluded from the 'public' space but whose lives and histories informed and consequently formed a corpus of material contained within the walls of the archive?

These questions provide a point of departure to turn to a discussion of the colonial archive and its role in the production of knowledge about colonial subjects.

\section{The Colonial Archive}

We can appreciate that archives are as much products of historical struggle as they are primary sources for writing histories. ${ }^{21}$ Nicholas Dirks explores this nexus in his seminal work on the archival production of caste in India. ${ }^{22}$ For Dirks, the interest in the archive is not what it constitutes as a space, but what meanings have been made and how, in the particular colonial context of India, the interpretation and development of meaning came to hold an immensely influential position in the development of categories of social organisation.

Dirks' work weaves an argument about the ways in which Indian knowledges were recorded and collected and the status they assumed in the management of colonial relations. He makes the observation that early colonial historiographies in British 
India were dependent upon native informants who were later written out of those histories. ${ }^{23}$ Inevitably this draws attention to the relationship between archiving, experts and knowledge production - the role of the collector/author occupying a central locus within this relationship. ${ }^{24}$

Ostensibly Dirks explores the extent that India became an ethnographic state, where anthropology supplanted history as the principal colonial modality of knowledge. For instance anthropology identified as a subject a 'native' population that was to be ruled. 'Colonial history conceded to anthropology the study of a historical subject that has not yet become modern. Anthropology became the history of those without history. It was caste that articulated this legacy of tradition, standing in place of the historical mindedness that was seen to be absent from Indian sensibilities. ${ }^{, 25}$ The colonial archive was about knowledge, and Dirks goes on to argue persuasively that the colonial knowledge that the archive produced was more powerful than the colonial state ever was. This was because it informed social categories that were then acted upon by the colonial state. The colonial documentation project encoded a certain anxiety that rule was always dependent upon knowledge, even as it performed that rule through the gathering and application of knowledge. ${ }^{26}$ In this sense, the colonial archive was a central place for subject making.

Following from Dirks, this leads Stoler - with her own interest in the archival records of the Dutch East Indies Company in rendering readings of colonial desire - to posit that the archive was the supreme technology of the late nineteenth century imperial state; a repository of coded beliefs that clustered (and bore witness to) connections between secrecy, the law and power. ${ }^{27}$ This leaves the question: to what extent can we understand archives as epistemological experiments and colonial archives as crosssections of contested knowledge? For example, what constitutes the archive, what form it takes, and what systems of classification signal at specific times, are the very substance of colonial politics. ${ }^{28}$ 'Colonial archives were both sites of the imaginary and institutions that fashioned histories as they concealed, revealed and reproduced the power of the state. ${ }^{29}$ As Derrida's discussion of the etymology of the word archive illustrates, power and control have been fundamental to the term and its effects within liberal and colonial contexts.

Different cases allow us to recognise that these struggles are not all of one kind, and that they are not the expression of a single 'archic' or 'patriarchic' function. Instead they are local materialisations of history or, rather, historical materialisations of the records from which histories are (re)constructed. Consider, for example, in an Australian context, the particular political moments that might have contributed to a change in the function of the archive. I am specifically thinking about what have been the political influences that have rendered the Australian colonial archive more open to Indigenous people as a different set of users. Has the challenge of land rights and native title and stolen generation played a role in repurposing archives? Have these historical moments provided the catalyst for the development of 'postcolonial' archives?

If, as Stoler and Dirks suggest, archives hold a powerful position as political technologies in how we make meaning of the past, of subjects, of social organisation and representations of relations between ourselves, then are the political shifts that reimagine relationships with the archive relevant to this discussion? Until now this chapter has been sketching a frame for understanding the archive as a place that is 
influenced by and distributes a myriad of relations between knowledge and power. What then might happen as there are shifts in the colonial polity, and the people traditionally subjected to archives, gain a recognised voice and question not only status within the archive but the authority of the archive as a centre of interpretation in contrast to the localised context where the represented knowledge is expected to reside?

If there is a critique to level against these conceptualisations of archives, it is that they are presumed to be quite autonomous and coherent - that they function rationally, and their intended purposes lead to equally predictable outcomes. It is important to remember the disorder and inevitable messiness within archives and libraries. It is fine to construct an image of an archive, including its purpose and function. However, the archive does not function without its internal machinations or without individuals. For when problems arise they are not necessarily easy to identify and isolate, and this returns me to problems of intellectual property. In this sense, problems of IP do not function in isolation to other issues that a library or archive might face. They are intricately wrapped around other issues, historically driven or manifest in the contemporary, and teasing them apart for remedy is often quite difficult. How, for example, are we to deal with problems of intellectual property and Indigenous rights of access, control and ownership of material if, quite simply, the institution does not know what it is that it holds? These questions run seamlessly into problems of cataloguing, of the will to know what is in a collection, and a desire to build new relationships with people who have historically been subjects of the archive through extensive documentation processes.

Unfortunately these questions do not always have easy answers. The archives and libraries privilege a position of authorship, which the archive not only upholds but also distributes more broadly as if also caught in its own 'author-function'. For the archive is sustained within society, not only by what it produces but also through what networks of authority are relied upon.

So legal authority becomes consolidated in the archive through categories of authorship and ownership - categories that are not only socially produced but are authorised by legal narratives that, in turn, strategically deploy such narratives for the purposes of identifying rights of property.

When the colonial archive admitted the new 'Indigenous public', authorship of history and colonial experience began shifting. There was, and remains, a challenge to the authority of the colonial archive to speak for and about Indigenous people. Notwithstanding the ambiguities of colonial relations, it is fair to say that when a majority of material that documents Indigenous people's lives and traditions is owned legally by non-Indigenous people, certain tensions arise. And these tensions find themselves being played out over access and control—authorship and ownership — the key sites that feed into archival authority.

\section{Galiwin'ku Indigenous Knowledge Centre}

I now turn to discuss the development of some practical strategies to engage with these issues in the work being done at the Galiwin'ku Indigenous Knowledge Centre, Northern Territory, where I have been working with Joe Neparrna Gumbula, Richard Gandhuwuy Gurrawurra, Matthew Baltha Gaykamanuguy, Ruth Almakarra 
Garrawurra and Jessica De Largy Healy. ${ }^{30}$ The Galiwin'ku Indigenous Knowledge Centre (GIKC) functions to record and document current cultural practices as well as provide a place for the return of important historical recordings to the community. The kinds of problems of ownership and authorship that we engage with at AIATSIS tend to be replicated in Indigenous Knowledge Centres and other cultural centres that are being developed as cultural material is returned to communities. These problems arise because 'returned material' is still not owned by the community and if communities want to make copies of it or put it on the web, they must engage with all these problems of intellectual property or, to be more precise, copyright and the dilemmas of licensing in the digital environment. For example, the GIKC has hundreds and hundreds of photographs - some old and some more contemporary photographs - and whilst there are some very simple ways of dealing with some of the issues, the way in which they are tied to issues of funding, issues of training, and what the actual purpose of the space is become quite interconnected and complicate the path to resolution.

To work through the ownership problems at GIKC, we needed to develop a particular strategy, quite specific to the community. Whilst the legal questions are simple in many respects about who does own a particular item, they are complicated in the process of returning them to the community for use by the community. Questions arise: how are you allowed to reproduce, for example, a particular photograph, how do you put it into a computer, who then owns it, how do you document these processes, who do you contact if you would like to use it later on, or could you get a transfer of ownership of the photograph so you could use it whenever you wanted to? The problem with older material is that often the copyright owners are unable to be contacted: we have no idea of where they are, or perhaps who they are or what they think about use of their material. This is always a significant problem and points to the responsibility of researchers to maintain a particular ethical standard in how they do document Indigenous knowledge and maintain their continuity with a community they have worked with over a period of time.

We decided at Galiwin'ku that we would develop quite a specific community intellectual property protocol and that this would emanate from Galiwin'ku; it would not emanate from larger organisations and then be imposed on Galiwin'ku. The protocol being developed is quite distinctly a Galiwin'ku document and it incorporates both Yolyu understandings of knowledge management as well as the intellectual property issues. It is starting to be a pathway in terms of dealing with issues that include both these legal strategies and also the Yolyu strategies of knowledge management. It is important to note that we are talking about Garma material; we are not talking about restricted material because the Yolyu system manages that fine and there is no need to mess around with those materials.

We are looking at material that is produced, for example, when researchers come in and take photos of the community. We want to develop something so that researchers have some responsibility and obligation to leave some of those photographs with the GIKC so that the community knows that they have them and they can show their children - the purpose is not complex. In developing the protocol, we are seeking to bridge a gap between Yolyu needs and systems and these quite rational systems of law and ownership and authorship and to re-jig them-dance around copyright, if you will—so that the community does have ownership, does have rights that are 
recognised. When people do come into the community they are under an obligation to respect those rights.

This is creating a space for Galiwin'ku IKC to build different relationships with researchers and institutions. If GIKC has its own document to give to a researcher who comes into the community, the researcher knows that they have an obligation to treat the material that they record in a particular way in accordance with the sitespecific issues. Similarly when Joe Gumbula goes down to deal with different libraries and archives, for example, the Donald Thomson collection at Museum Victoria, or the University of Melbourne, he has something that confirms to them that the GIKC has ideas about intellectual property issues, as well. This is a significant development, as there is reluctance on the part of organisations to hand back materials because of copyright questions. However, if the GIKC is being proactive in how its dealing with these issues, then the institutions can see that there is room for a new and different relationship to be built between institutions and communities. This is a process, not without its flaws, but nevertheless a practical strategy that allows communities to have more rights to material when historically they have had none. The community is strengthened in the process and at the same time it raises the bar in relation to how institutions do deal with Indigenous Knowledge Centres. It is important and timely that these new relationships be recognised and developed through such processes. There is so much cultural material held in institutions. A lot of it is contained in collections that have not been documented. Not only do some institutions not even know what their collections hold but some fear documenting what those collections hold because of the intellectual property implications once they do know what they hold.

The development of a site-specific protocol to assist Galiwin'ku to build on the material that it already has and also know what it can use and how they can use it without always having to go to the copyright owner has actually, given that it is in quite a remote location, put power back into the GIKC as a point of contact. People can go to the GIKC and find out about material rather than relying on an institution like AIATSIS who does not necessarily have that contact information to start with. The development and use of a Galiwin'ku protocol has helped to build these new relationships and push them forward by dancing around intellectual property, which is an incredibly complex field, as the profession knows. Using such a protocol can also contribute to a change in mindsets about what we expect intellectual property to do.

Intellectual property is a tool of control so it can work quite well to recognise rights and to abridge them in many ways. Of course it is about property as well and we have to ask questions about how we are making knowledge into property: Is that useful? Can it provide some sort of leverage to protect knowledge that otherwise wouldn't be protected? And I think in certain instances it can provide a useful tool of leverage. The flipside to intellectual property, of course, is it is restrictive. It restricts and if somebody else has IP rights they restrict others' use of it. These are the fundamental tenets of IP. AIATSIS has some of these problems, as do other institutions in Australia. As well, overseas institutions like the Smithsonian have these issues and nobody is clear on how to deal with them. What the projects at AIATSIS and Galiwin'ku Indigenous Knowledge Centre have highlighted is that the only way to work through the issues is to get them out on the table and make a start. 


\section{Notes}

1 Copyright Act 1968 (Cth) Part IV

2 For instance see the example of photography: B Edelman Ownership of the Image: Elements for a Marxist Theory of Law (trans by E Kingdom) Routledge and Keegan Paul London 1979; J Gaines Contested Culture: The Image, the Voice and the Law The University of North Carolina Press Chapel Hill 1991 p15; K Bowrey 'Copyright, Photography and Computer Works: The Fiction of Original Expression’ UNSW Law Journal vol 18 no 21995 p278. For another discussion of photography as 'difficult' subject matter, see K Garnett 'Copyright in Photographs’ European Intellectual Property Review vol 52000 p229; B Edelman 1979

3 See for instance B Sherman and L Bently The Making of Modern Intellectual Property: The British Experience 1760-1911 Cambridge University Press Cambridge 1999; P Drahos A Philosophy of Intellectual Property Dartmouth Press Sydney 1996; M Rose, 'The Author as Proprietor: Donaldson v Becket and the Genealogy of Modern Authorship' in B Sherman \& A Strowel (eds) Of Authors and Origins: Essays in Copyright Law Clarendon Press London 1994 See J Anderson Law, Knowledge and Culture: The Production of Indigenous Knowledge in Intellectual Property Law Edward Elgar Press (forthcoming 2006)

5 Much of this commentary has involved an evaluation of the role of intellectual property laws in facilitating commodification and the development of new markets. As part of the developing discourse, attention has also been directed to the implicit cultural elements (and hence cultural prejudices) of intellectual property law, wherein cultural products are increasingly circulating as commodities within networks of private property relations. See for instance: P Drahos 'Capitalism, Efficiency and Self-Ownership' Australian Journal of Legal Philosophy vol 28 2003 p215; J Boyle Shamans, Software and Spleens: Law and the Construction of the Information Society Harvard University Press Cambridge MA 1996; L Lessig The Future of Ideas: The Fate of the Commons in an Interconnected World Random House New York 2001; D E Long 'The Impact of Foreign Investment on Indigenous Culture: An Intellectual Property Perspective' NCJ Int'l L \& Com Reg vol 231998 p229; M Ryan Knowledge Diplomacy: Global Competition and the Politics of Intellectual Property Brookings Institution Press Washington DC 1998; S Sell 'Industry Strategies for Intellectual Property and Trade: The Quest for TRIPS and post-TRIPS Strategies' Cardozo Journal of International and Comparative Law vol 10 2002 p79; C May A Global Political Economy of Intellectual Property Rights: The New Enclosure? Routledge London 2000; R Coombe The Cultural Life of Intellectual Properties: Authorship, Appropriation and the Law Duke University Press Durham 1998; K Aoki 'Neocolonialism, Anticommons Property and Biopiracy in the (not-so-brave) New World Order of International Intellectual Property Protection' Indiana Journal of Global Legal Studies vol 6 1998 p 11

6 Early letters between Principals at AIATSIS explicitly mention copyright and recommend the establishment of a copyright committee. Letters on file at AIATSIS and with author

7 The copyright and Aboriginal art cases in Australia increased awareness about these issues in significant ways. See: Yanggarrny Wunungmurra v Peter Stipes 1983 Federal Court, unreported; Bulun Bulun v Nejlam Pty Ltd (unreported Federal Court of Australia Olney J 29 March 1989); Yumbulul v Reserve Bank of Australia 199121 IPR 481; Milpurruru v Indofurn Pty Ltd 199454 FCR 240; Bulun Bulun v R \& T Textiles Pty Ltd 199886 FCR 244; Bulurru Australia Pty Ltd v Oliver 200049 IPR 384. See also C Golvan, Aboriginal Art and Copyright-An Overview and Commentary concerning Recent Developments, 2001, at http://www.golvanarts.com.au/copyright.html

8 See J Anderson and G Koch 'The Politics of Context: Issues for Law, Researchers and the Creation of Databases' in L Barwick A Marett \& J Simpson (eds) Researchers, Communities, Institutions, Sound Recordings University of Sydney Sydney 2004

9 See K Bowrey Law and Internet Cultures Cambridge University Press Cambridge 2005; J Litman Digital Copyright Prometheus Books Amherst NY 2001; J Ginsburg 'Copyright and Control over New Technologies’ Columbia Law Review vol 26 no101 2001 pp1613-1647

10 J Derrida Archive Fever: A Freudian Impression Chicago University Press Chicago 1996

11 P Joyce 'The Politics of the Liberal Archive' History of the Human Sciences vol 12 no 21999 p35

$12 \quad$ Ibid p39 
13 M Lynch 'Archives in Formation: Privileged Spaces, Popular Archives and Paper Trails' History of the Human Sciences vol 12 no 21999 pp65-79

14 T Osborne 'The Ordinariness of the Archive' History of the Human Sciences vol 12 no 2 1999, p51

$15 \quad$ Ibid $\mathrm{p} 52$

$16 \quad$ Ibid $\mathrm{p} 52$

17 Ibid

$18 \quad$ Lynch $\mathrm{p} 67$

19 Osborne p55

20 Ibid

$21 \quad$ Lynch p67

22 N Dirks Castes of Mind: Colonialism and the Making of Modern India Princeton University Press Princeton 2001

23 Ibid p85; see also A Stoler 'Colonial Archives and the Arts of Governance' Archival Science vol 2 no 1-2 p96. For a change in the direction of the narrative see P Chatergee A Princely Imposter: The Kumar of Bhawal and the Secret History of Indian Nationalism Princetown University Press NJ 2002

24 Walter Benjamin's notes on the collector remain ever useful. See W Benjamin The Arcades Project (trans R Tiedermann) Bleknap Press Cambridge MA 1999

25 P Joyce The Rule of Freedom: Liberalism and the Modern City Verso London 2003 p246

26 Dirks p123

$27 \quad$ Stoler p95

$28 \quad$ Ibid $\mathrm{p} 92$

$29 \quad$ Ibid p97

30 I would like to take the opportunity to thank Jessica De Largy Healy for facilitating this contact and for the productive conversations that followed 


\title{
Chapter 8
}

\section{Managing Indigenous Knowledge and Indigenous Cultural and Intellectual Property}

Terri Janke*

\begin{abstract}
Important Notice
This chapter provides general advice only in an effort to encourage constructive debate on the topic. It is not intended to be legal advice. If you have a particular legal issue, we recommend that you seek independent legal advice from a suitably qualified legal practitioner.
\end{abstract}

Indigenous people view the world they live in as an integrated whole. Their traditional knowledge, beliefs, arts, and other forms of cultural expression have been handed down through the generations. This information has been recorded in many forms by non-Indigenous people and Indigenous people. In this way, libraries are important places for Indigenous people. Libraries have inherited a lot of significant Indigenous information about Indigenous people. Indigenous knowledge includes traditional, contemporary, the recorded form, artistic, oral, creative, and written knowledge. Forms include:

- photographs

- stories

- oral histories

- films

- geographic and genealogical information, and

- information about plants and animals.

Some of this knowledge is collectively owned. It might have been written by nonIndigenous people. It might have been taken without the knowledge or consent of Indigenous people.

In recent years, Indigenous people have been successful in calling for greater recognition of their rights to Indigenous knowledge at international forums. Nationally too, there have been many inroads made for greater protection of Indigenous cultural and intellectual property rights by Aboriginal artists taking cases in copyright law. ${ }^{1}$ Studies like Our Culture Our Future: Report on Australian Indigenous Cultural and Intellectual Property Rights ${ }^{2}$ have called for new laws. Given the longterm processes of creating new laws, the main focus of protection in Australia has been the development of protocols within industry and governments. In

\footnotetext{
${ }^{*}$ Terri Janke is a Solicitor \& Principal Lawyer of Terri Janke \& Company Pty Ltd.
} 
December 2003, the government released plans to introduce amendments to the Copyright Act 1968 (Cth) for Indigenous communal moral rights.

Libraries face a new quest about how to manage this Indigenous knowledge material and to whom this material should be made available. In this chapter, I begin with a brief description of Indigenous cultural and intellectual property before setting out some international developments in this area, including activities of the World Intellectual Property Organisation (WIPO), the international agency responsible for administering intellectual property. Then I discuss the role of protocols, with a particular focus on the framework of the Australia Council's Aboriginal and Torres Strait Islander Arts Board artform protocols. Some of the salient issues surrounding the proposed amendments to Australian copyright legislation to deal with Indigenous communal moral rights are then presented. In conclusion, I briefly summarise some key issues for libraries.

\section{Indigenous Cultural and Intellectual Property}

The definition of 'Indigenous cultural and intellectual property' (ICIP) in Our Culture Our Future: Report on Australian Indigenous Cultural and Intellectual Property Rights $^{3}$ follows the international standard developed in 1997 by a global study undertaken by the Chairperson of the United Nations Working Group on Indigenous Populations, Professor Daes. ' ${ }^{4}$ 'Indigenous cultural and intellectual property' is also the term used in the Draft Declaration of the Rights of Indigenous Peoples. ${ }^{5}$ ICIP refers to Indigenous peoples' rights to their heritage. Heritage consists of the intangible and tangible aspects of the whole body of cultural practices, resources and knowledge systems developed, nurtured and refined by Indigenous people and passed on by them as part of expressing their cultural identity. The heritage of an Indigenous people is a living one and includes items that may be created in the future, based on that heritage.

Each Indigenous community asserts ownership of this communally owned heritage material. Whether there are firm cultural rules and expectations will vary from community to community. In many communities, whether consent is necessary may depend on the circumstances of the proposed use, and if the person who wants to use it is part of the relevant cultural group. It is common for Indigenous communities to assert ownership over cultural material in those communities where cultural practices still occur or are being revived.

Copyright law does not cover all the types of rights Indigenous people want to their ICIP. In fact, intellectual property laws actually allow for the plundering of Indigenous knowledge by providing monopoly property rights to those who record or write down knowledge in a material form, or patent it. A communal song or story is not a commodity. Indigenous people view Indigenous knowledge as part of a continuing relationship between people and their heritage. Following this understanding, the definition of heritage affirms that the cultural and intellectual heritage of Indigenous people comprises traditional practices, knowledge and the ways of life that are unique to particular people. Indigenous people are responsible for culture and are the guardians of an Indigenous culture and intellectual property. Their rights and obligations to their heritage are determined by the customs, laws and practices of the community and can be exercised by an individual, a clan, or a people as a whole. 
When Indigenous knowledge is removed from an Indigenous community, the community loses control over the way in which it is represented and used. These systems of knowledge may have evolved over many years and are uniquely bound up with Indigenous peoples' customs, beliefs, traditions, land and resources.

Hence, Indigenous people worldwide have called for greater protection. ICIP rights include the right to:

- own and control Indigenous cultural and intellectual property

- ensure that any means of protecting Indigenous cultural and intellectual property is based on the principle of self-determination

- be recognised as the primary guardians and interpreters of their cultures

- maintain the secrecy of Indigenous knowledge and other cultural practices,

- ensure full and proper attribution, and

- control the recording of cultural customs and expressions, and the particular language, which may be intrinsic to cultural identity, knowledge, skill, and teaching of culture.

A lot of Indigenous knowledge was recorded at a time in our history when Indigenous people could not exercise their prior and informed consent. There is also information that has been recorded by Indigenous people for cultural maintenance purposes. The uses that are now being made of this are often not in accordance with the original intention-commercial and wide publication of material, for instance. Foster $v$ Mountford $^{6}$ represents an example of this. In this case, the recording of cultural information collected by an anthropologist, Mountford, in 1940, was published as Nomads of the Australian Desert and distributed for sale in the Northern Territory in 1976. The Federal Court granted an injunction in favour of members of the Pitjantjatjara Council, who took the action under breach of confidence laws to stop the sale of the book in the Northern Territory. The Pitjantjatjara male elders revealed tribal sites and items of deep cultural and religious significance to the anthropologist and these had been included in the book. It was argued that the wide dissemination of this information could cause serious disruption to Pitjantjatjara culture and society should this material be revealed to women, children and uninitiated men. The information was shown to have been given to Mountford in confidence.

Indigenous people now seek to assert their cultural rights and reclaim their cultures. Access to the information held in libraries assists the continuing maintenance of cultures.

\section{International Developments}

\section{World Intellectual Property Organisation}

In 2000, the World Intellectual Property Organisation (WIPO) established an InterGovernment Committee (IGC) on Intellectual Property and Genetic Resources, Traditional Knowledge and Folklore, to discuss issues relating to access to genetic resources and benefit sharing, the protection of traditional knowledge, innovations and creativity, and the protection of expressions of folklore. 
The IGC extended its mandate in 2003 to accelerate its work and to focus in particular on the international dimension of intellectual property and genetic resources, traditional knowledge and folklore.

The IGC focus for protection of traditional knowledge covers four main areas:

- protection of traditional literary and artistic productions against unauthorised reproduction, adaptation, distribution, performance and other such acts, as well as prevention of insulting, derogatory and/or culturally and spiritually offensive uses

- protection of handicrafts, particularly their style

- prevention of false and misleading claims to authenticity and origin/failure to acknowledge source, and

- defensive protection of traditional signs and symbols. ${ }^{7}$

The IGC supports a comprehensive approach to protection and endorsed the menu of options given to member states for policy and legislative development covering IP type measures: sui-generis systems, customary law, unfair competition, trade practices and administrative measures.

The IGC discussions have focussed on the substantive issues and some points include:

- Who should own and control the rights in traditionally owned material? Should it be communities and/or organisations? Or the state?

- Can traditional cultural expressions be adapted with authority and what processes would need to be given for adaptation?

- Should remuneration be paid to communities for use of traditional cultural expressions?

- How should the communal moral rights of Indigenous and local people be respected?

It might be difficult to ascertain where a traditional cultural expression originated. Another issue arises where a traditional cultural expression is shared by a number of different Indigenous groups.

At its March meeting, the IGC agreed to focus and accelerate the substantive work of the committee on traditional cultural expressions including the preparation of drafts of an overview of policy objectives and core principles for protection of traditional cultural expressions. It is most likely that the outcome will be an international instrument for intellectual property and Indigenous traditional knowledge and expressions of culture (folklore). Most countries supported a choice of policy options and legal mechanisms where the processes allow countries to take into account the needs of Indigenous and traditional communities as well as relevant cultural policy interest issues from the whole of society. Practical tools such as codes, guidelines, checklists, and model clauses for folklorist museums and archives were seen as important tools by many countries. 


\title{
Intellectual Property Laws
}

Intellectual property laws can protect traditional cultural expression in some ways if the requirements for protection are met. For instance, the Minding Culture Case Studies ${ }^{8}$ report on the judgments of the Carpets Case and the Bulun Bulun Case. Although copyright is an incentive-based notion that provides economic benefits rather than cultural protection, copyright does allow the owner of copyright to control the dissemination of that work. This can allow them to manage the rights in ways that are culturally appropriate. There are also moral rights in the Copyright Act 1968 (Cth) and also proposals for Indigenous communal moral rights (in Australia only).

However, a concern of traditional knowledge holders and Indigenous people is that it focuses protection on the material (tangible) expression and not the ideas. Another limitation is the fact that IP laws only protect works for a limited period. For example, in Australia copyright only protects works for 70 years after the death of the creator. Many countries noted that there should be special unlimited protection for items of folklore. This is a controversial point in the application of folklore to intellectual property. Most intellectual property laws have limited time periods given for monopoly rights so that at the end of that time period the subject matter is made available to the public. Other commentators think that to have an unlimited timeframe of protection is against principles of intellectual property and potentially unworkable. ${ }^{9}$

\section{Sui Generis Laws}

Several countries are attempting to use laws within their national law systems to protect folklore. For example, in Panama there is a law to:

\begin{abstract}
protect the collective intellectual property rights and traditional knowledge of indigenous peoples over their creations, such as inventions, models, drawings and designs, innovations contained in the images, figures, symbols, graphics, stone carvings and other details; as well as the cultural elements of their history, music, art and traditional forms of artistic expression susceptible to commercial use, via a special system to register, promote and market their rights, in order to highlight the sociocultural values of indigenous cultures and render social justice unto them. ${ }^{10}$
\end{abstract}

The Chinese Draft Law of the People's Republic of China on the Protection of Ethnic Culture and Folklore, formulated by the Education Science Cultural and Public Health Committee of the National People's Congress in 2003 provides that the state protects ethnic culture and folklore or traditional culture that is in 'imminent danger or of historical value within the territory of China'. ${ }^{11}$ This includes traditional oral literature and folk and written language. It also includes traditional drama (puppet shows), all kinds of folk art forms, music, dance, fine arts (sculpture and paper cutting), acrobatics, and traditional arts and crafts and processing techniques. As well it covers traditional etiquette, festival celebrations and ceremonies, and cultural materials, objects and sites. ${ }^{12}$

\section{Customary Law}

The role of customary law in protecting traditional cultural expression is also a focus at the international level. There were many countries reporting that customary laws were used to deal with controlling uses of traditional cultural expressions. Also, customary law was relevant when negotiating disputes relating to traditional cultural expression. These laws should not be displaced by any state-based laws, or international instruments. 
The government of Nigeria noted that, besides legal frameworks, customary laws of Indigenous people might not be sufficiently developed to cater for the intense and wide uses of folklore that may be used in this time and age. Hence, there is a need for guidance for traditional knowledge holder groups. ${ }^{13}$

This situation may be the same in Australia where new uses for traditional cultural expression are constantly being sought. For example, game boys, film rights and adaptations for stage are some of the varied requests Indigenous Australians receive for use of their traditional cultural expression. Indigenous people need advice on how to develop systems and measures and set their own protocols.

\section{Indigenous Cultural Protocols}

Protocols are appropriate procedures and provide a basis for the way dealings occur within a particular situation, community, culture or industry. Agreeing to comply with the accepted protocols of other cultural groups promotes interaction based on good faith and mutual respect, thus encouraging ethical conduct. The development of protocols for Indigenous cultural material has been the most focussed area of protecting ICIP in the past five years, and I believe will be important in light of the pending Indigenous communal moral rights (ICMR) laws.

Protocols for cultural respect in Indigenous Arts projects guide how to manage the correct cultural use of stories, designs, materials and interpretation of cultural material. Terri Janke and Company produced the guides for the Aboriginal and Torres Strait Islander Arts Board of the Australia Council, with the guidance of leading peers in each relevant industry. These include protocols for producing Indigenous Australian visual arts and crafts, Indigenous Australian literature, Indigenous Australian new media, Indigenous Australian music, and Indigenous Australian performing arts. ${ }^{14}$

\section{Principles of the Australia Council Protocols}

The protocols are based on eight main principles:

(i) Respect: this begins with respecting the right of Indigenous people to own and control their heritage. Respect means following protocols, accepting diversity, and recognising Indigenous cultures as living and continuously evolving.

(ii) Indigenous control: this principle asserts that the right to self-determination should be recognised in Indigenous cultural affairs. This requires involving, consulting and taking advice from appropriate Indigenous people. Some projects attempt to include Indigenous content by referring to text books, copyright art from text books, doing stylised Aboriginal art, or referring to writings by anthropologists. This type of use of cultural material does not recognise Indigenous peoples' right to say whether or not their culture can be used in the project's context.

(iii) Communication, consultation and consent: if traditional and communally owned stories are used, consent may be required from relevant persons such as traditional owners. This is even if copyright has expired. For example, gender issues and sensitivity of content may need to be taken into account. As well, it is important to consult and gain clearance for the particular purpose for which any Indigenous knowledge is to be used, for example, commercial use. In the case of Indigenous knowledge for scientific and commercial purposes, for instance, research and 
pharmaceutical companies are patenting and claiming ownership of traditional medicinal plants.

Electronic databases and digital libraries are gaining popularity in several government initiated projects for documenting traditional knowledge. Putting such knowledge into databases supposedly prevents patents being taken out because the knowledge then becomes part of the prior art base, and therefore does not meet the novelty feature of the patents law regime. Many Indigenous people are concerned that such databases open their knowledge to erosion; others feel that databases and documentation record threatened oral knowledge and prevent further erosion of social processes. Others agree that documentation prevents bio-piracy. Another concern expressed at a global level by Indigenous people and traditional knowledge holders is that centralisation makes information inaccessible to Indigenous communities and alienates them.

However, the main point at issue is that any traditional knowledge database must have the prior informed consent of the communities. In situations where such knowledge is not already in the public domain, governments would need to ensure that disclosure of traditional knowledge by Indigenous people is voluntary. Also, it needs to be recognised that much traditional knowledge that is currently in the public domain may not be there with the consent of the communities concerned.

(iv) Interpretation, integrity and authenticity: this principle refers to how the cultural material is interpreted and presented. It includes perspective given, language used, and the medium in which the material is to be reproduced. Integrity refers to whether a work or story is altered. Authenticity refers to the cultural provenance of an artwork. Protocols in this area can work to overcome established practices that ignore or disrespect Indigenous people whose knowledge is contained within the content of the work.

One example of inappropriate practice is that of using imagery that is not part of a clan associated with where the artist comes from. For instance, rarrk (cross hatching) painting is a traditional technique from a particular area. Likewise, other styles and imagery coming from one region are applied inappropriately to other contexts, for example, wandjinas and mimis. World music recordings often make use of ethnomusicologists' tapes with consent only obtained from them and with no reference to the communities or people who are the subject matter of the recording. The use of stories or texts for artistic works may be similarly problematic. Consideration has to be given to whether it is a 'new' story. It may be a copyright work and therefore require copyright clearance. Use of 'legends' that are out of copyright may also require consultation with Indigenous groups.

(v) Secrecy and confidentiality: personal information or culturally sensitive material should not be widely circulated. In Indigenous communities, there is also genderspecific information that may not be made widely available. Sensitive materials include those relating to family photographs, family trees or any recorded historical information and past histories. This type of material should be treated as sensitive and access to this information should be closely screened. Sacred material refers to material that can only be known to certain initiated persons, or for ceremonial purposes. Generally, this type of information should not be disclosed outside its original context. In many Indigenous communities showing images of deceased people signals the end of the mourning period. In some communities this may be 12 
months, and in others, much longer. I note that the website for the John Oxley Library includes a warning in relation to deceased materials on an online database of photographs. In relation to the issue of sensitive materials, the concern is that copyright only protects works for 70 years after the death of the author. A lot of sensitive material would be out of copyright, held in libraries and publicly accessible without restriction.

(vi) Attribution: this principle is to ensure that the cultural source or origin of the work is properly attributed.

(vii) Proper returns: this principle is to ensure that Indigenous people share in the benefits derived from a work which has made use of traditional knowledge or cultural expression, for example, hosting a workshop to exchange knowledge or providing a share of the royalties.

(viii) Continuing cultures: how will the project maintain a relationship for future generations? This might include making available copies of recordings, films, and photographs to family members at a later date. It might also require consultation at a later date for the further uses of the work that were not envisaged in the initial consultation.

\section{Other Important Protocols}

The Aboriginal and Torres Strait Islander Protocols for Libraries, Archives and Information Services ${ }^{15}$ are a leading guide for libraries on managing information. ScreenSound, the National Film and Sound Archive, has a policy for the management of Indigenous film and sound recordings, which includes terms about how the information is stored and made available.

Protocols are also an important development in the area of Indigenous cultural and intellectual property rights. There are proposed amendments to the Copyright Act 1968 (Cth) which aim to introduce Indigenous communal moral rights to Australian copyright law. In my opinion, protocols will be important in setting the standards for how Indigenous cultural material is dealt with in terms of reasonableness defence for the proposed laws. In this respect, Indigenous communities should examine their own cultural processes to determine how permissions and use can be negotiated, consented to, and monitored.

\section{Indigenous Communal Moral Rights}

In December 2003, the government drafted proposed amendments to the Copyright Act 1968 (Cth) for Indigenous communal moral rights. The draft bill is said to give effect to the Government's 2001 election policy commitment and to a commitment made to Senator Aden Ridgeway in parliament during the passing of the Moral Rights Bill in December 2000.

The Draft Copyright Amendment (Indigenous Communal Moral Rights) Bill 2003 was sent to about 20 Indigenous organisations for comment. There has been no public discussion relating to the proposed amendments. The government has said that they hoped to introduce the new laws in 2004. The bill proposed the following regime: 


\section{Must be a copyright work or film}

For Indigenous communal moral rights to be recognised they must be in a copyright work or a film to which the rights attach. This means that there must be a work as defined under the Copyright Act. The particular cultural item must be an artistic, musical, dramatic or literary work that meets the requirement of the Copyright Act, or a film as defined under the Copyright Act. To be protected under Indigenous communal moral rights, the cultural material item must be one that is:

- in material form and is original,

- created by a living artist or one that has only been deceased for less than 70 years.

Many works of cultural significance will not meet this requirement because they will be oral in form, or older than 70 years after the death of the artist.

\section{Before first dealing requirements}

For there to be Indigenous communal moral rights in a copyright work the following requirements must be met before the first dealing of the work:

- The work must be drawn from the 'particular body of traditions, observances, customs and beliefs held in common by the Indigenous community'. A community is defined loosely and can include an individual, family, clan or community group.

- A voluntary agreement must be entered into between the creator of the work and the Indigenous community. The requirement of a voluntary agreement puts the onus on the Indigenous community. Most Indigenous artists and creators who live and work in their communities would obligingly meet this requirement. It is current practice for them to consult and practice cultural protocols, or observe customary laws and seek consent and permission to use culturally owned material. Outsiders who are not Indigenous or third party users perform the majority of abuses of communal moral rights. For example, in the Milpurrurru $v$ Indofurn (the Carpets Case $)^{16}$ the altered designs were copied images from text books. These types of abuses will not be protected against at all by the proposed amendments. The community would not be able to make third party nonIndigenous users subject to a voluntary agreement, and in many cases may not even know about them until they have occurred.

- There must be acknowledgement of the Indigenous community's association with the work. This requires notice of association to be given by the community and the author. This can be done by the community with respect to works and films it has been consulted on. However, it will not be able to give notice on works and films it has not. These are likely to be the works and films that are infringing communal moral rights.

- Interest holders in the work need to have consented to the Indigenous communal rights in the work. In this respect an Indigenous community has no rights if an interest holder refuses or fails to consent to the Indigenous communal moral rights arising. 
The draft has been criticised as not being effective. According to Jane Anderson, 'the draft bill is highly complicated and legalistic, presenting serious practical hurdles for Indigenous people and communities seeking to protect their knowledge and its use'. ${ }^{17}$ Jane Anderson states that there is a big difference between the government's stated objective and the current draft presented. She states that it is difficult to see where a remedy might arise for infringement.

A more fundamental issue is that there has been limited consultation by the government on the draft bill with Indigenous peoples. The government has failed to engage Indigenous stakeholders in a meaningful debate on the contents of the bill. This seems to be a major oversight if the main impetus for the introduction of the bill was to benefit Indigenous communities.

\section{Conclusion}

Libraries are the holders of important Indigenous knowledge. The recording of Indigenous culture in many artistic, oral, written, and recorded forms provides a wealth of knowledge and assists in the continuation of knowledge.

Libraries have been leaders in their approaches to taking into account Indigenous cultural and intellectual property rights within their management systems. The new international developments, national protocols frameworks and the proposals for an Indigenous communal moral rights (ICMR) law offer an opportunity for libraries to review their own practices. It is important for us to debate these issues and find a balance between the needs of Indigenous and traditional communities as well as relevant cultural policy interest issues from the whole of society.

As the keepers of important Indigenous cultural knowledge materials, both the Indigenous community and the library profession need to recognise that a progressive ICIP policy is an important step to ensuring that the cultural integrity of Indigenous knowledge is maintained, so that future generations of all Australians can benefit.

Some key issues, then, for library management practice are:

- Work with Indigenous communities and develop relationships of partnership and mutual respect.

- Consult and involve Indigenous people on management of Indigenous knowledge in the library collection, especially prior to commercial use or database/electronic use, with the purpose of making information as widely available as possible but with respect for any cultural constraints.

- Keep written records of the relevant people to clear the rights with in future and make sure that explanations are clear on how the library intends to use the material.

- In relation to ICMR issues, proper attribution and acknowledgement of community should also be included, and any integrity issues discussed at the outset. Ask depositors for clear instructions on contents including people, clans, and places, and the nature of material contained therein.

- Increase Indigenous projects on material held and employ Indigenous staff, include Indigenous people as board members, and in reference groups to adopt clear and continuing policy that is reviewed and updated. 


\section{Notes}

1 See Milpurrurru v Indofurn 199530 IPR 209 (Carpets Case); Bulun Bulun v R \& T Textiles 1998157 ALR 193

2 T Janke Our Culture, Our Future: Report on Australian Indigenous Cultural and Intellectual Property Rights Michael Frankel \& Co Surrey Hills 1998 Ibid

4 E I Daes Final Report on the Protection of the Heritage of Indigenous Peoples Report E/CN.4/Sub.2/1995/26 1995, and Supplementary Report: Protection of the Heritage of Indigenous Peoples Report E/CN.4/Sub.2/1996/22 1996

5 UNHCHR Sub-Commission on Prevention of Discrimination and Protection of Minorities, Working Group on Indigenous Populations Draft Declaration on the Rights of Indigenous Peoples 1994/5, at http://www.unhchr.ch/huridocda/huridoca.nsf/(Symbol)/E.CN.4.SUB.2.RES.1994.45.En?Open Document

$6 \quad$ Foster v Mountford (1977) 14 ALR 71

7 Information on WIPO's work can be found at http://www.wipo.int/tk/en/

8 World Intellectual Property Organisation (WIPO) Minding Culture: Case Studies on Intellectual Property and Traditional Cultural Expression prepared by T Janke for World Intellectual Property Organization WIPO Geneva 2002, at http://www.wipo.int/tk/en/studies/cultural/minding-culture/index.html

9 M Rimmer 'Albert Namatjira: Copyright Estates and Traditional Knowledge' InCite vol 24 no 6 2003, at http://www.alia.org.au/publishing/incite/2003/06/albert.namatjira.html

10 Republic of Panama Law Concerning the Special System for Registering the Collective Rights of Indigenous Peoples, for the Protection and Defense of their Cultural Identity and Traditional Knowledge, at

http://www.ichrdd.ca/english/commdoc/publications/indigenous/lawPanama.html

11 World Intellectual Property Organisation, IGC Committee on Intellectual Property and Genetic Resources, Traditional Knowledge and Folklore Report from the Sixth Session, 15 to 19 March 2004 WIPO Geneva Switzerland 2004 p13, at

http://www.wipo.int/documents/en/meetings/2004/igc/pdf/grtkf_ic_6_14.pdf

12 Ibid $\mathrm{p} 13$

13 Ibid $\mathrm{p} 20$

14 T Janke Visual Cultures, Protocols for Producing Indigenous Australian Visual Art and Craft Aboriginal and Torres Strait Islander Arts Board Australia Council Strawberry Hills 2002, at http://www.ozco.gov.au/arts_resources/publications/visual_cultures/; T Janke Writing Cultures, Protocols for Producing Indigenous Australian Literature A Aboriginal and Torres Strait Islander Arts Board Australia Council Strawberry Hills 2002, at http://www.ozco.gov.au/arts_resources/publications/writing_cultures/; T Janke New Media Cultures, Protocols for Producing Indigenous Australian New Media Aboriginal and Torres Strait Islander Arts Board Australia Council Strawberry Hills 2002, at http://www.ozco.gov.au/arts_resources/publications/new_media_cultures/; R Quiggin Song Cultures, Protocols for Producing Indigenous Australian Music Aboriginal and Torres Strait Islander Arts Board Australia Council Strawberry Hills 2002, at http://www.ozco.gov.au/arts_resources/publications/song_cultures/; R Quiggin Performing Cultures, Protocols for Producing Indigenous Australian Performing Arts Aboriginal and Torres Strait Islander Arts Board Australia Council Strawberry Hills 2002, at http://www.ozco.gov.au/arts_resources/publications/performing_cultures/

15 A Byrne, A Garwood, H Moorcroft \& A Barnes Aboriginal and Torres Strait Islander Protocols for Libraries, Archives and Information Services ALIA Press Canberra 1995

16 Milpurrurru v Indofurn 199530 IPR 209 (Carpets Case)

17 J Anderson 'Indigenous Communal Moral Rights: The Utility of an Ineffective Law' Indigenous Law Bulletin vol 5 no 302004 pp8-10 


\title{
Chapter 9
}

\section{The Role of Information Technologies in Indigenous Knowledge Management}

\author{
Jane Hunter
}

More and more communities and organisations around the world are realising the value and significance of Indigenous knowledge and the importance of preserving it for future generations. Indigenous Knowledge Centres (IKCs) are being established globally, but particularly in Australia, Africa, Latin America and Asia. The capture and preservation of Indigenous knowledge is being used to revitalise endangered cultures, improve the economic independence and sustainability of Indigenous communities and to increase community-based involvement in planning and development. In parallel with the increasing recognition of the value and relevance of Indigenous knowledge to today's world and the need to preserve it, is recognition of the role that information technologies (IT) can play in its capture, management and dissemination. This chapter provides an overview of the current state of IT tools, services, and projects relevant to Indigenous knowledge management. In particular it describes information technology tools being developed at DSTC (in consultation with numerous Indigenous and cultural organisations) that have been designed to enable Indigenous communities to capture, control and share their knowledge within local knowledge bases according to their unique, specific local needs. Finally this chapter identifies unresolved issues that will require further collaborative research and development and cooperation between Indigenous communities, researchers and software developers.

\section{Indigenous Knowledge Capture}

Indigenous knowledge, also referred to as traditional or local knowledge, refers to the large body of knowledge and skills that has been developed outside the formal educational system. IK is embedded in culture and is unique to a given location or society. It is the basis for decision-making of communities in food, security, human and animal health, education and natural resource management. ${ }^{1}$

Indigenous knowledge encompasses many forms. It includes cultural heritage in the form of traditional stories, songs, dances and ceremonies that reflect beliefs related to spirituality, family, land and social justice. It includes potentially patentable knowledge about traditional medicines, foods, farm practices, architecture and construction, handicrafts, artwork and folk music. It includes knowledge about people, places, plants, animals, and historical events associated with a particular community.

\footnotetext{
* Dr Jane Hunter is Senior Research Fellow at Distributed Systems Technology CRC (DSTC), University of Queensland, St Lucia, Queensland.
} 
The first steps in many Indigenous knowledge projects involve identifying the material to be preserved and then capturing it in a digital form so that it can be systematically documented, shared, and re-used by permitted groups or individuals. Determining the optimum and most culturally appropriate approach to selecting, eliciting, recording, describing and disseminating this knowledge without insensitivity, intrusion, constraints, degradation or misrepresentation of the content, is a challenge that is often underestimated.

Appropriate consultative processes need to be established to identify and prioritise the material to be captured. Alternative digital technologies and environments for recording and storing the data need to be compared and evaluated. Because of the oral tradition of Indigenous knowledge, audiovisual digital recording devices such as digital video cameras and audio recorders are a primary tool for capturing techniques, practices, stories, language, songs and dances. Scanners are being used to digitise photographs, manuscripts, maps and historic documents. Increasingly 3D scanners are used to generate 3D digital surrogates of physical artifacts in museums and cultural institutions, such as tools, shields, carvings, clothing and baskets.

But there are still many issues which need to be resolved. For example, should audio be saved as WAV or MP3 files? Is QuickTime, MPEG-4 or MPEG-2 the best format for archiving video content? What digital media should be used for storing the content e.g. hard disk, DAT, CD, DVD or FlashRAM? What are the advantages and disadvantages of recording in a controlled environment such as a studio, as opposed to in the field or from a live performance? Should the content be edited to improve or enhance it afterwards? Solutions to many of these questions will depend on a detailed analysis of the specific project and community needs.

Rather than attempt to provide answers to these issues, in the next three subsections I will describe three projects that illustrate the potential of applying innovative technologies to recording, sharing and utilising Indigenous knowledge:

- virtual repatriation at the Smithsonian National Museum of the American Indian (NMAI)

- community mapping, and

- digital libraries of traditional medicine.

\section{Virtual Repatriation}

Many museums, archives, libraries and cultural institutions throughout the world hold large collections of objects that are of cultural or historical significance to Indigenous communities. Because many of these objects were collected without the consent of the traditional owners, the custodial organisations are now facing the challenges of determining ownership, seeking direction from the traditional owners on the future of such objects and either repatriating them, storing them or exhibiting them appropriately as requested. This process is made more difficult because colonisation has caused many Indigenous communities to become dispossessed of their lands and widely dispersed geographically. New, innovative high quality 2D and 3D scanners, collaborative interactive software tools, high-speed networks and emerging grid technologies that facilitate communication and the sharing of resources and knowledge between geographically dispersed groups, are providing an infrastructure 
that is ideally suited to the implementation of such digital and physical repatriation programs.

DSTC is currently working on one such collaborative project with the Smithsonian National Museum of the American Indian (NMAI). In the United States, the Native American Graves Protection and Repatriation Act (NAGPRA) specifies the types of objects and sites to be protected and/or repatriated. Going beyond the requirements of NAGPRA, the NMAI has established a Culturally Sensitive Collections Care Program (CSCCP) to respond to areas of concern of native peoples with regard to the maintenance, presentation, and disposition of sensitive materials and information in the collections of the museum.

The aim of the NMAI's Spiral of Knowledge project is to provide an IT framework which will support its Culturally Sensitive Collections Care Program (although the repatriation of human remains are of particular importance to many communities, they are outside the scope of this project.) Past experience has indicated that many tribal communities would initially like access to the records of all objects in institutional collections associated with their community. After reviewing these, some communities may request that the actual physical artefact be repatriated but many communities will be satisfied with copies of digital surrogates and access to physical objects when requested. Figure 1 illustrates the NMAI's 'spiral of knowledge' workflow that corresponds to the NMAI's virtual repatriation program currently under development.

There are eight stages within the NMAI's virtual repatriation workflow:

1. Generation of a digital information request by community elders

2. Submission and review of a digital information request by the custodial institution (NMAI)

3. Organisation and provision of these resources to the native community - through the transferral of digital objects plus metadata to a local knowledge base

4. Attachment of access rights and sensitive care constraints by community elders

5. Attachment of annotations and metadata corrections by community elders and other community members

6. Disposition of information by the native community. Some subset of the local knowledge base may go back to the cultural institution

7. Review of information by the custodial institution, and

8. Disposition of information by the custodial institution (e.g. in exhibitions, databases, online and educational resources). 
Figure 1

Information Workflow for NMAI's Spiral of Knowledge Project ${ }^{2}$

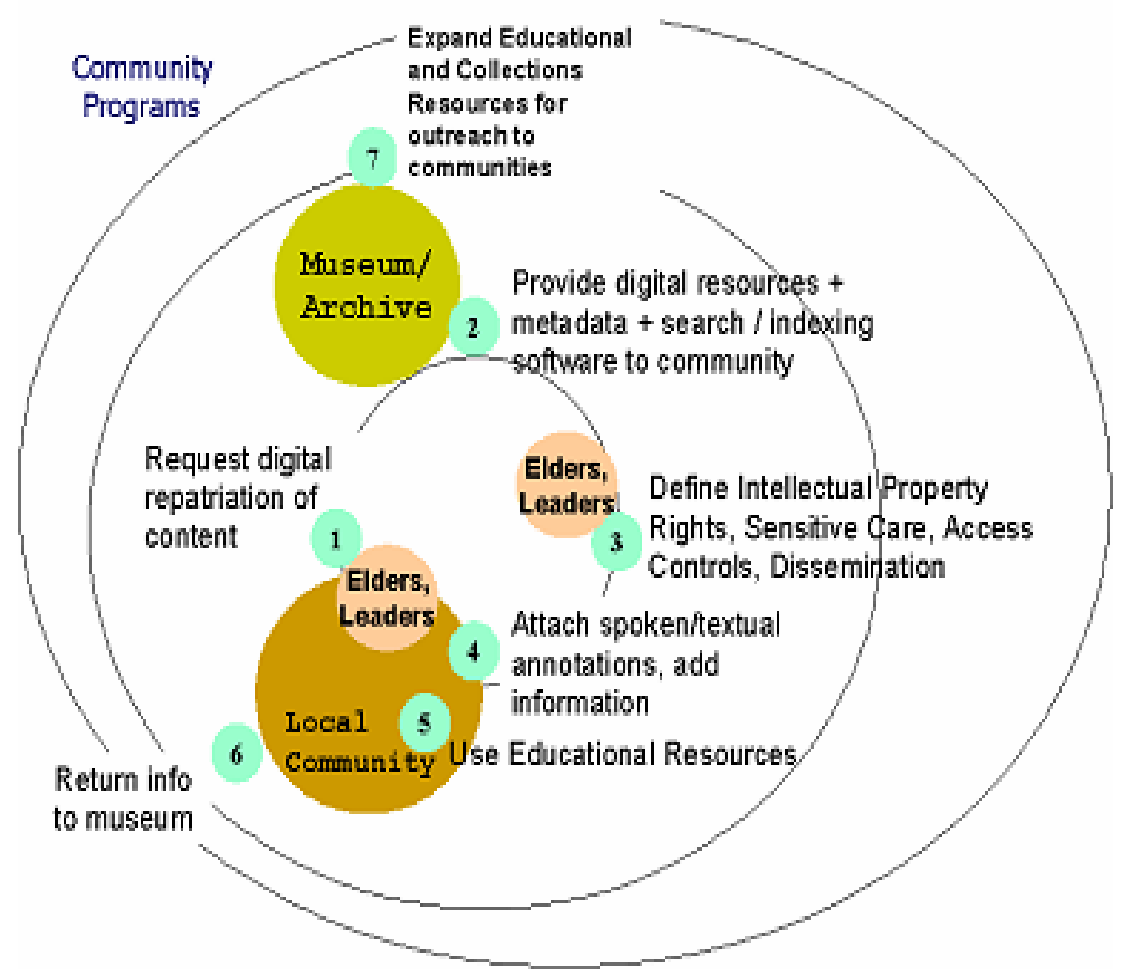

The transfer and exchange of requests, digital objects and associated information is all carried out electronically using XML (extensible markup language) packages that contain structured data which can be understood and uploaded to the databases within the local Indigenous Knowledge Centres or within the custodial institution. Digital objects that have been scanned and indexed within the NMAI are transferred over networks to the local knowledge base within the community.

The IKM software system (described in detail below) is an open-source software system developed at DSTC, in collaboration with the NMAI, that was designed to enable Indigenous communities to develop, support and maintain their local knowledge bases and to define access constraints and rights management in compliance with traditional laws.

\section{Community Mapping Projects}

Indigenous communities have close ties to the land, which is not only seen as a means of production and livelihood e.g. for hunting and gathering, but also as part of Indigenous people's spiritual and cultural traditions. Consequently a significant proportion of Indigenous knowledge is directly related to land. Community-based mapping projects have been established within a number of Indigenous communities to delineate and document the native customary land boundary and thus help preserve the community's traditional knowledge related to their customary land. Once documented, the community map can be used as a tool for negotiation and resolving disputes between the community and outside parties or within the community itself and to strengthen the community's land, fishing and hunting claims. Community maps 
can also be applied as a tool for community-based resource management. To date, they have been used to identify sites or landscape features of cultural significance, to document flora and fauna distribution and Indigenous biodiversity knowledge and to provide input to land, forest and fire management, conservation and planning.

Community mapping projects are being undertaken in Australia, Malaysia, Indonesia, Philippines, Cambodia, Mozambique and Ecuador. ${ }^{3}$ Over the past ten years, community mapping has seen significant transformation. The technologies and methods used by Indigenous communities has advanced from basic compass and tape with hand plotted map to modern sophisticated GPS mapping and the use of portable digital assistants (PDAs), digital cameras and GIS software to produce community maps and related, spatially-indexed knowledge. Additional benefits from such projects include training of Indigenous staff and the production of reference materials on community mapping in the local language.

\section{Digital Libraries of Traditional Medicine}

A number of countries are using information technologies to develop digital libraries of traditional knowledge both to use the knowledge in current community projects and also to prevent misappropriation of the knowledge through commercial patents.

India in particular has developed a Traditional Knowledge Digital Library that contains information on 36,000 formulations used in Ayurveda-India's 5000-yearold system of traditional medicine. The information-presented in English, French, German, Spanish and Japanese - was created in a format accessible by international patent offices to prevent the granting of inappropriate patents.

The Indian system uses a classification system similar to that used by the International Patent Classification (IPC). The IPC has agreed to include the Indian system in its own classification, which will be expanded to include about 200 sub-groups of drugs derived from Indian medicinal plants. This will significantly aid patent offices who can search the databases to ensure that proposed patents are truly novel and have not been previously reported.

Following the success of the Indian system, other South Asian countries (Bangladesh, Bhutan, Maldives, Nepal, Pakistan and Sri Lanka) that are members of the South Asian Association for Regional Cooperation (SAARC), have decided to create a composite digital library that will network the individual Traditional Knowledge Digital Libraries (TKDL) from each country. ${ }^{4}$ The SAARC TKDL will provide a uniform system for organising, disseminating and retrieving traditional knowledge seamlessly across regions or countries. Accessible via the internet, the library will initially contain information on traditional medicine including:

- materials used for treatment, e.g. plants, animal products, minerals

- their generic or specific method of preparations or designs

- their dosage, mode and time of administration, and

- their therapeutic action or application.

The SAARC digital library will be used to fight contentious patent claims by proving the prior existence of knowledge, as well as promoting research on novel drugs, 
enhancing the region's share of the global herbal medicine market and helping set the international agenda on intellectual property rights.

\section{Local Knowledge Bases}

Many Indigenous communities are developing local Indigenous Knowledge Bases either informally or within Indigenous Knowledge and Cultural Centres (IKCs) established specifically for this task. The digital content being assembled and presented within these IKCs is either captured locally, donated or repatriated from external private and public collections belonging to museums, church archives, community members, anthropologists, missionaries, and others. Determining the optimum software solutions to support such knowledge bases requires an analysis of the communities' needs and objectives. Prior to the development of the IKM system, we identified the following set of generic requirements that apply across many Indigenous communities' knowledge bases:

- Security: because of the sacred/secret nature of the content, it is essential that robust, reliable IT security mechanisms are employed. The specific rights management requirements corresponding to customary laws associated with secret or sacred knowledge are described in detail below.

- Simple user interfaces: many of the potential users of this system will have limited computer literacy and poor keyboard skills so simple intuitive user-friendly interfaces are essential.

- Robustness: the system must be able to stand up to the rigours of unexpected input by users with little prior computing experience.

- Low cost: in order to make the software open source and widely accessible to Indigenous and grassroots communities, it must be built as inexpensively as possible, ideally using components that are freely available.

- Interoperability: the software tools should be built on international standards (e.g. Dublin Core, XML) in order to maximise the interoperability between disparate databases.

- Portability: it should be able to run on a range of platforms and operating systems including Windows, Linux and Macintosh. Within the IKM software we employ Java, XML and SMIL (Synchronised Multimedia Integration Language) for the software development environment to ensure transparent portability across platforms.

- Flexibility: the customary laws and intellectual property needs of traditional knowledge holders vary enormously among Indigenous communities throughout the world. Quite often the views within a single clan can vary significantly and they may also vary over time. Our system attempts to support by default the common notions across most Indigenous communities. In addition, we have provided Schema editing tools in order to provide maximum flexibility and to enable easy customisation of the software. 
- Adaptability: both Indigenous knowledge and knowledge management technologies are dynamic and constantly evolving - the corresponding systems and infrastructure must be designed to be flexible and adaptable in order to support these changing needs. As new relevant technology becomes available and affordable (e.g. voice recognition for spoken word interfaces) it should be able to be incorporated with minimum cost or effort.

- Scalability: the size of collections within IKCs can reach hundreds of thousands. The software should be capable of efficiently performing finegrained search and retrieval across very large sets of resources. Attributebased rights management, which involves comparing the user profile of the searcher against the rights metadata for each object, may substantially affect the speed of query retrieval for large data sets.

Although a number of other projects have investigated the application of information technology tools to the protection and management of Indigenous collections according to customary laws, ${ }^{5}$ they have not approached the problem using international metadata standards or developed systems that are capable of easily being customised or modified to support changing local needs. They are also not free or open source and are built on databases such as FileMakerPro which do not scale well and do not support the attachment of spoken annotations. In the next section I describe in detail the IKM system, developed by DSTC in collaboration with the NMAI.

\section{The IKM Software System}

The IKM (Indigenous Knowledge Management) system ${ }^{6}$ was designed as a low-cost, simple robust system to enable Indigenous communities to manage their own digital collections within local Indigenous knowledge bases. It comprises two major components:

1. The XMEG tool: this enables users to describe digital objects (based on an underlying, customisable metadata schema), attach annotations to the objects and define access rights and traditional care constraints. It also enables user profiles to be defined. A Schema Editor allows the underlying metadata schema to be edited - this is reflected in the user interface. Descriptive and rights metadata and annotations can either be saved to a MySQL relational database or flat XML files which can be indexed using an XML database such as Tamino or Xindice or parsed and uploaded to any relational database. In addition to the metadata that is explicitly saved to the database through the user interface, meta-metadata is also recorded - all changes to the metadata, who was responsible and the date/time of the changes are recorded within the database. This represents an important component of the system's built-in security framework.

2. The Search interface: this uses standard web browser technologies (Internet Explorer, Netscape) to enable users to search, browse and retrieve objects from the collection. The advantages of using a standard web browser interface are their familiarity and widespread availability and the lack of re-engineering necessary should collections eventually be disseminated over wider networks. To access the collection, users must have been allocated a login ID and 
password and a user profile. The user profile includes information such as tribal names, native/non-native heritage, tribal/clan membership, gender, status, role, etc. After a user performs a search, the system compares the matching objects' rights constraints with the user's profile to determine whether or not the user is permitted to access this object. If they are, then the object will be retrieved and displayed, along with any rights constraints, which appear as icons. Users can click on individual objects to view/play the high resolution object and to view the metadata details and any annotations. The system also includes software that can automatically aggregate selected mixed-media objects (images, audio clips, video clips, text), and dynamically generate a SMIL (synchronised multimedia integration language) presentation which is presented to the user.

\section{Rights Management}

A significant amount of international effort has been focused on technologies for managing rights associated with digital content e.g. MPEG- $21^{7}$ (multimedia delivery framework) and XrML. ${ }^{8}$ However, because these initiatives are primarily concerned with e-commerce and protecting the commercial rights of content owners, they do not support the specific features needed to protect Indigenous knowledge or to enforce tribal customary laws. They are built on the premise of modern intellectual property law regimes and notions of individual property ownership for a limited duration, which are alien and detrimental to Indigenous cultures.

Figure 2

\section{User Interface for Defining Access Restrictions which depend on the Users' Tribal Affiliation, Gender, Role and Status}

\begin{tabular}{|c|c|c|c|c|c|}
\hline \multicolumn{3}{|c|}{ 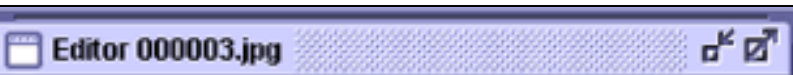 } & \multicolumn{2}{|l|}{$\square$ Editor 000003.jpg } & \multirow[t]{2}{*}{ पर प" } \\
\hline Metadata Annotation Rights Tril & al Care & & Metadata Annotation Rights Tri & bal Care & \\
\hline Gender Role Tribal Unit Status & Ritual & Context & Gender Role Tribal Unit Status & Ritual & Context \\
\hline \multirow{2}{*}{\multicolumn{3}{|c|}{$\begin{array}{l}\text { Restrict access to this resource by. } \\
\square \text { Tribe: }\end{array}$}} & \multirow{9}{*}{\multicolumn{3}{|c|}{$\begin{array}{l}\text { Allow access to this resource to: } \\
\text { Only Males } \\
\text { Only Females } \\
\text { Both Male \& Females }\end{array}$}} \\
\hline & & & & & \\
\hline Enter tribe name & & & & & \\
\hline$\sqrt{V}$ Clan: & & & & & \\
\hline \multicolumn{3}{|l|}{ Nunuccal } & & & \\
\hline \multicolumn{3}{|l|}{$\square$ Band: } & & & \\
\hline \multicolumn{3}{|l|}{ Enter band name } & & & \\
\hline \multicolumn{3}{|l|}{$\square$ Family. } & & & \\
\hline \multicolumn{3}{|l|}{ Enter family name } & & & \\
\hline & Save & Close & & Save & Close \\
\hline
\end{tabular}




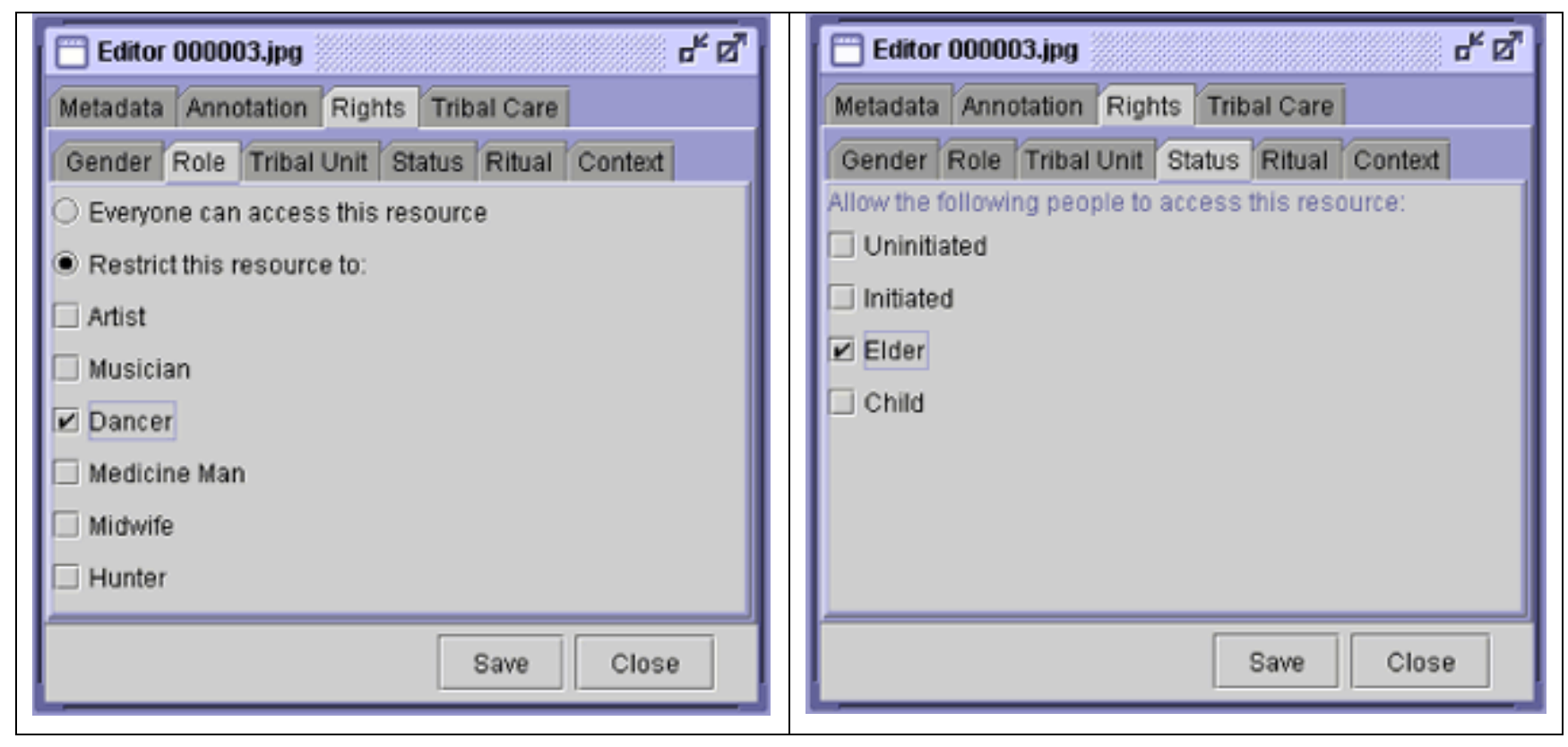

In an earlier paper, ${ }^{9}$ specific extensions to XrML, in the form of customary constraints, were developed to support the description of customary or traditional laws which commonly affect access. An analysis of tribal laws across Aboriginal and Native American communities revealed that there are a number of common restrictions that apply to Indigenous knowledge across communities. Consequently within the IKM system we provided an interface to enable elders or other authorised members of the community to input and edit rights metadata. Support has been provided to enable the definition and application of restrictions based on:

- the user's membership of a particular clan or tribe

- the user's status within the tribe

- the user's role within the tribe

- the user's gender

- the relationship of the user to people, animals or objects depicted in the resource

- the death of people recorded in a resource, and the context in which the resource will be reused or reproduced. 
Figure 3

User Interface for Defining Temporal Access and Warnings

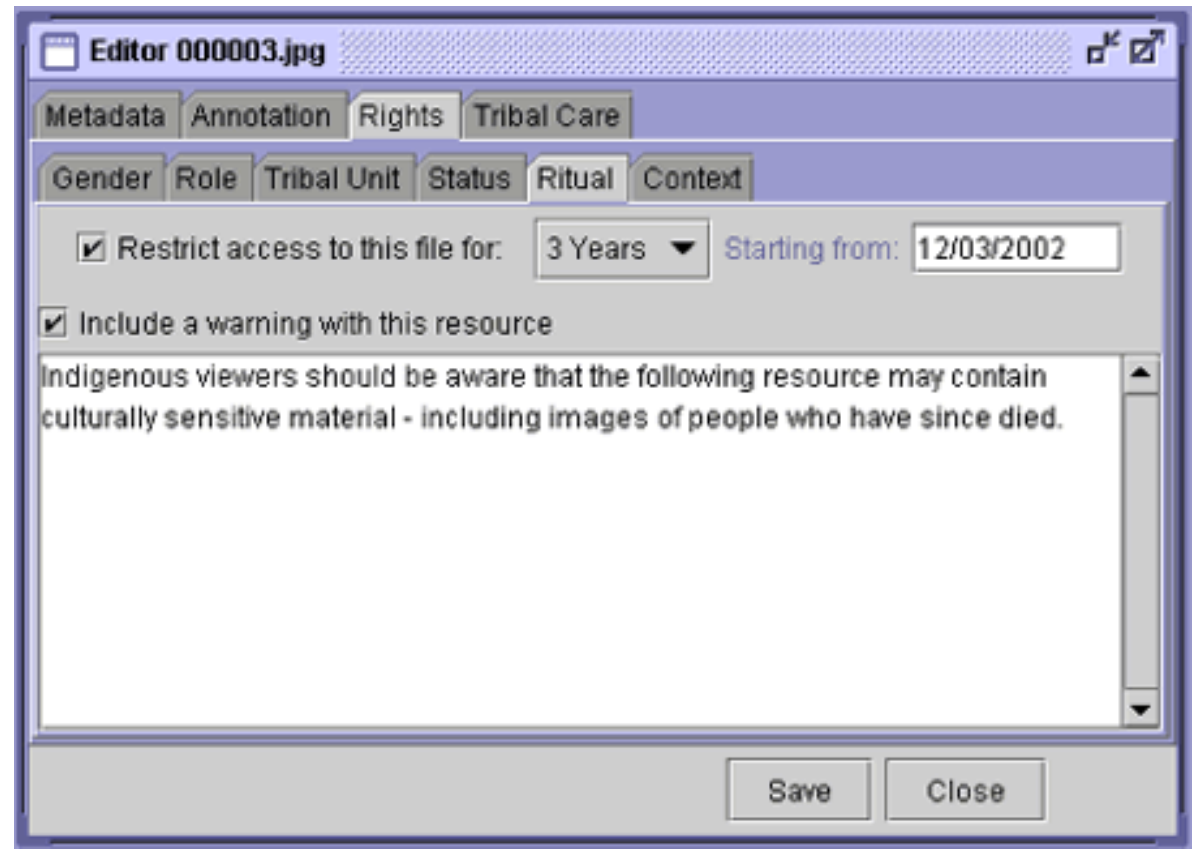

Authorised persons are also able to specify temporal access restrictions, either for a set duration from a start time or recurring (on a monthly or yearly basis). This functionality has been provided to support customs such as sorrow business, in which photographs or video recordings of recently deceased people are inaccessible for a mourning period, or seasonal restrictions (Figure 3).

In addition, we provide a user interface to enable the input and editing of user profiles, for either individuals or user groups (e.g. Nunuccal elder) which record information about the users' tribal affiliations, gender, role, status, family relationships etc. The system compares a user's profile with the rights metadata for objects in the collection to determine access permissions. The major challenges with this approach are not technological but are identifying the authorised elders who can make decisions about access constraints, reaching community agreement on both access constraints and individual's attributes and authority, and building community trust in the system.

\section{Indexing, Search and Retrieval}

Metadata is crucial to the accessibility of the captured knowledge. Within the IKM system, we provide Dublin Core ${ }^{10}$ as the default metadata schema, with extensions for the rights metadata. But we also provide a metadata schema editing tool to enable this to be easily modified. By storing the metadata in XML files, we are not restricted by legacy database structures. The metadata input tools should also be as simple and streamlined as possible. If pre-existing metadata is available (e.g. through the custodial organisation) then it should be re-used. New technologies such as voice recognition and image and video analysis tools are also capable of generating metadata automatically. Controlled vocabularies thesauri (e.g. based on AIATSIS or 
AusAnthrop databases of tribal names, languages and places) and pull-down menus should be used where possible to reduce the effort involved in metadata capture and to control the quality of the metadata. Ontologies also provide a way of defining and inferring richer implicit relationships between objects: in different databases; of different media types; or described using different metadata schemas. They offer significant potential for structuring, integrating and assimilating multimedia information and digital objects drawn from distributed archives, into local Indigenous knowledge bases.

Search interfaces should be designed to support the user-interface needs of the Indigenous communities who want to access the content. The ability to search and browse multimedia collections using techniques other than simple text-based or keyword search will be vital. Within DSTC, we are investigating an array of possible search and browse mechanisms including maps, timelines, genealogies, lexicons and ontologies.

Figure 4

\section{Approaches to Navigating Content in Indigenous Knowledge Bases}

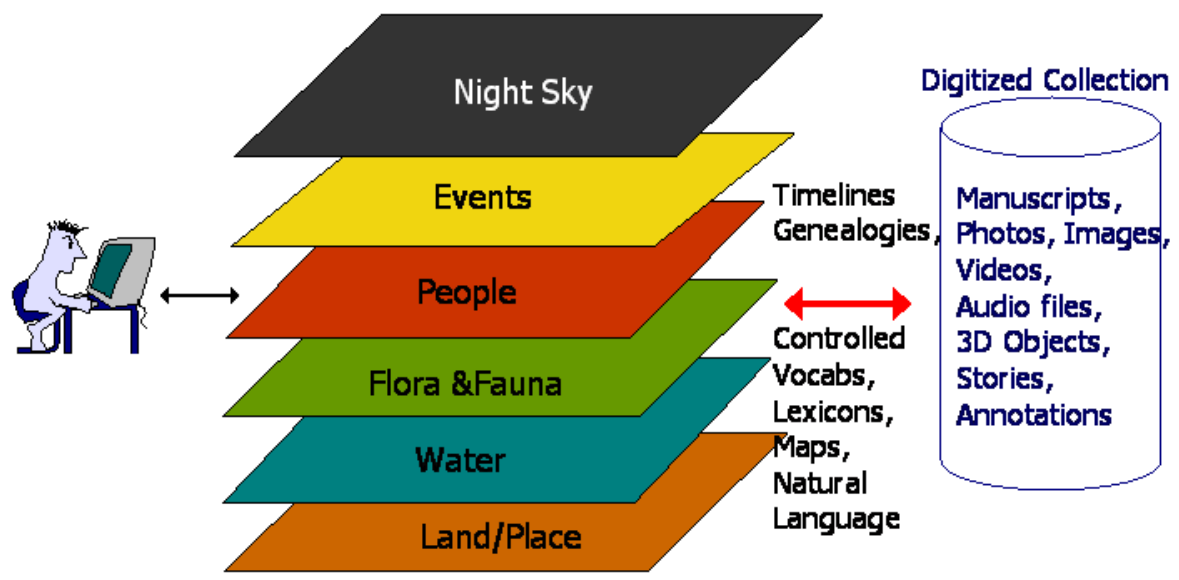

\section{Annotation and Discussion Tools}

Annotation tools enable the traditional owners to describe, contextualise and annotate resources in their own words, their own languages and from their own perspectives. Within the IKM system, authorised users can input, record and attach either textual, spoken annotations or hyperlinks to specific digital objects (photos, videos, 3D models) or regions or segments within those objects.

The ability to enter spoken annotations is an especially powerful feature. It provides a natural user interface which supports the oral tradition and allows users to express their stories in their own words and languages. This is ideal for communities or elderly users with limited computer literacy or poor keyboard skills. They may also generate new language resources and can contribute to the preservation of endangered languages. Figure 5 below, illustrates the annotation interface for the IKM system. Users can also browse the list of previously attached annotations and view/listen to who said what and when about a particular resource. 
This approach supports the unambiguous documentation and attribution of all views/perspectives, even if they are different or contradictory. The software explicitly displays 'who said what and when' rather than displaying only the view of a museum curator which may have been deduced from a number of different sources of varying reliability.

\section{Figure 5}

\section{Annotation Interface for the IKM System}

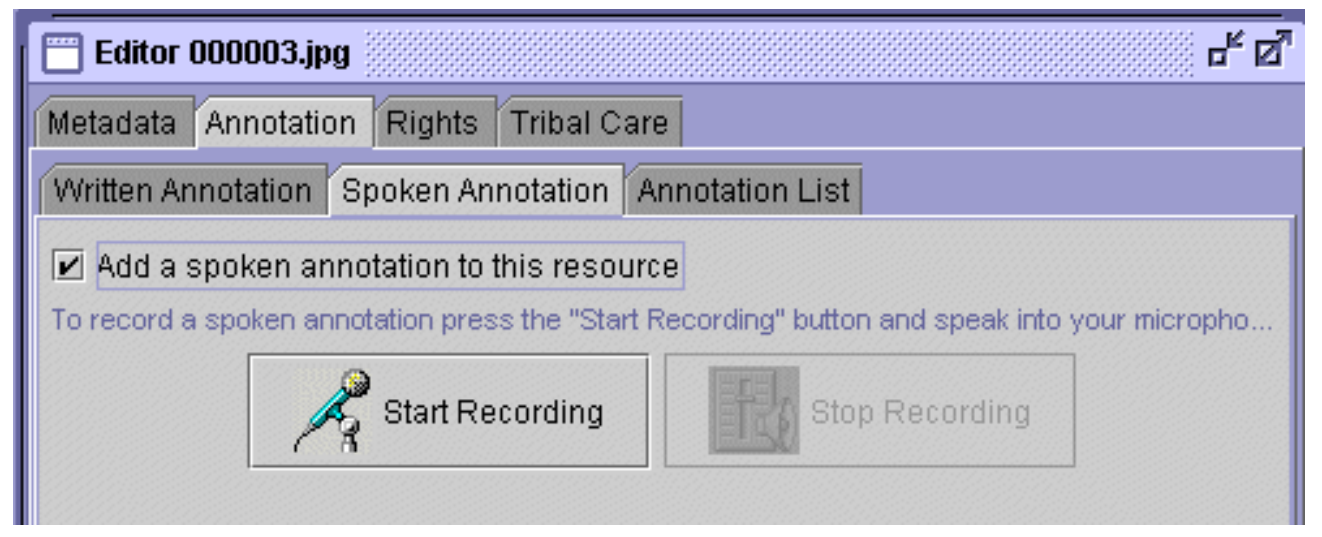

In addition to stand-alone textual and spoken annotation tools, at DSTC we have been developing a system called Vannotea ${ }^{11}$ that uses broadband networks and videoconferencing to enable real-time collaborative annotations of digital content by groups of geographically dispersed users. By sharing an application that allows the search, retrieval and browsing of images, video and 3D objects, geographically distributed users can collaboratively attach annotations to selected regions within images, selected segments, frames or frame regions within videos, or areas within 3D objects. Currently annotations can be either plain text or a URL. Users can view the list of annotations (details of who and when) for an object and also search and browse the annotations. 
Figure 6

Collaborative Annotation of 3D Artefacts using Vannotea
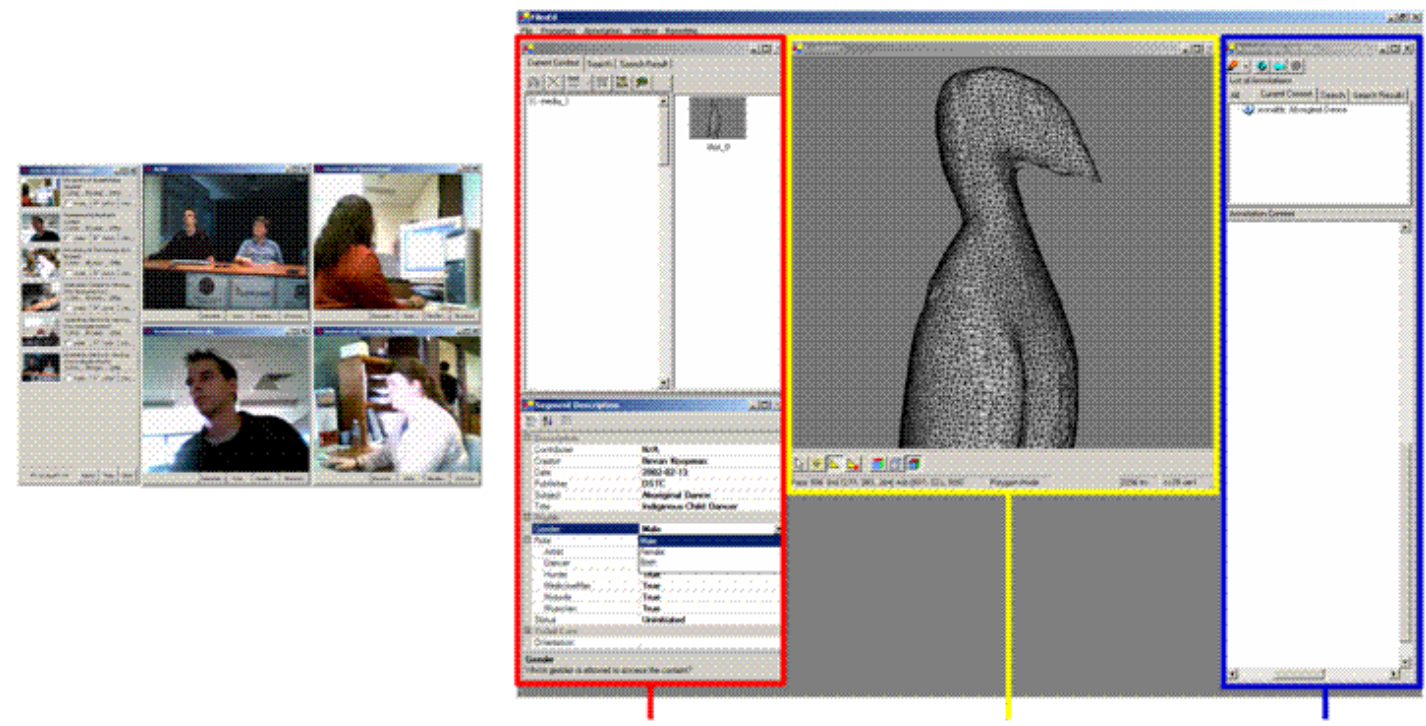

The aim is to deploy and test this software in a collaborative project between the Smithsonian National Museum of the American Indian (NMAI), the American Indian Higher Education Consortium (AIHEC) Tribal Colleges and American Indian communities. This system will enable the groups to discuss the maintenance, presentation, disposition and repatriation of sensitive materials and information in the museum's collections, and the virtual meeting to be recorded.

\section{Evaluation}

As the number of ICT-based Indigenous knowledge projects proliferates, it has become increasingly clear that there is an urgent need to carry out in-depth evaluations of alternative approaches to the implementation of such projects. This is necessary to identify the optimum technologies, procedures and best practices and to prevent scarce funding and resources being wasted on replicating systems that are ineffective, inefficient or unwanted.

The Netherlands Organisation for International Cooperation in Higher Education (NUFFIC's) Indigenous Knowledge Unit in cooperation with UNESCO's Management of Social Transformations Programme (MOST) has identified a number of projects that demonstrate 'Best Practices Using Indigenous Knowledge'. ${ }^{12}$ These are the projects that illustrate the use of IK in developing cost-effective and sustainable survival strategies for poverty alleviation and income generation (e.g. Indigenous land use systems to encourage labour-sharing arrangements among farmers; using IK to increase the fuel-efficiency of local stoves instead of replacing them; using Indigenous institutions by extending credit through existing village loan groups etc.). However the report by NUFFIC and MOST does not specifically evaluate the use of information and communication technologies in capturing, organising, managing or disseminating Indigenous knowledge. 
There is an urgent need to study and evaluate existing IK projects that employ ICTs to determine the optimum procedures and technologies. In particular the following activities and issues should be considered high priority:

- Determining the best process for selecting and prioritising Indigenous knowledge to be recorded. Standard selection criteria for digitisation projects may not apply or have different weightings when applied to Indigenous knowledge. Consultation and input from the community elders is essential.

- Determining qualitative and quantitative metrics for identifying successful technologies or technological approaches-what are the benefits and cost-effectiveness? How should relevance, usage, usability and community benefits be measured? Will the system scale and is it sustainable? What is the best way to acquire users' feedback?

- Evaluating existing systems, projects and IKCs based on the metrics determined above.

- Identifying those practices and system components which are successful, those that appear to have failed and those that could be improved through extensions, modifications or refinements. Identify issues requiring further research and improvement.

- Identifying barriers to success, causes for project failure and how these might be overcome. Are the issues technological, social or economic? Is further training of local staff required? How can the system be made more relevant, useful, cost-effective or sustainable?

- Disseminating best practice guidelines and databases of projects demonstrating best practice for the use of ICT within Indigenous Knowledge Management projects.

It is essential that the costs, benefits and outcomes of IT-based Indigenous knowledge projects are accurately reported and disseminated. Failed projects should not be whitewashed or swept under the carpet. Negative experiences should be shared so that the wider community can learn from past mistakes. It is also essential that additional funding be provided for existing projects or included in new projects, to cover the costs of continual, ongoing evaluation, adaptation and improvement.

\section{Conclusions}

There is no doubt that ICTs hold significant potential for supporting the recording, management, dissemination and long term preservation of Indigenous knowledge. But there remain significant challenges which will need to be overcome to ensure that such projects deliver real benefits to both the Indigenous communities who own the knowledge and the wider community. Although some of the challenges are technological, many of the most difficult issues are social, political or economic and overcoming these will require significant time, patience, funding, resources, support, training and a collaborative effort by Indigenous communities, multidisciplinary researchers, staff from cultural institutions and software engineers and designers to establish mutual trust, respect and a common understanding of what the users want, 
the issues involved, and the possibilities that both current and future technologies hold.

\section{Notes}

1 Indigenous Knowledge Program, World Bank, at http://www.worldbank.org/afr/ik/index.htm

2 NMAI XML Metadata Repository Proof of Concept Functional Specification, Infrastructures for Information Inc August 2004

3 IAPAD Community Mapping PPGIS, PGIS, CiGIS and P3DM Virtual Library, at http://www.iapad.org/bibliography.htm

$4 \quad$ 'SAARC to set up Traditional Knowledge Digital Library' Financial Express 4 January 2005, at http://www.financialexpress.com/fe full story.php? content $\mathrm{id}=78706$

5 See Ara Irititja Archival Project, South Australia, at http://waru.org/arairititja; First Voices Project, at http://www.firstvoices.com; Special Issue on 'Digital Technology and Indigenous Communities' in D-Lib Magazine vol 8 no 3 March 2002, at http://www.dlib.org/dlib/march02/03contents.html

6 J Hunter B Koopman and J Sledge 'Software Tools for Indigenous Knowledge Management' Museums and the Web 2003 Charlotte March 2003

7 ISO/IEC TR 21000-1:2001(E) (MPEG-21) Part 1: Vision, Technologies and Strategy, MPEG, Document: ISO/IEC JTC1/SC29/WG11 N3939, at http://www.cselt.it/mpeg/public/mpeg21 pdtr.zip

8 XrML - The Digital Rights Language for Trusted Content and Services, at http://www.xrml.org/about.asp

9 J Hunter 'Rights Markup Extensions for the Protection of Indigenous Knowledge' in The 11th International World Wide Web Conference-Global Community Track Honolulu 2002

10 Dublin Core Metadata Element Set Version 1.1: Reference Description Dec 2004, at http://dublincore.org/documents/dces/

11 J Hunter R Schroeter B Koopman and M Henderson 'Using the Grid to Build Bridges between Museums and Indigenous Communities' GGF-11, Semantic Grid Applications Workshop Honolulu 10 June 2004

12 Best Practices using Indigenous Knowledge, A Joint Publication by NUFFIC and UNESCO/MOST November 2002, at http://www.unesco.org/most/Bpikpub2.pdf 


\title{
Chapter 10
}

\section{Slouching Towards Australian Public Libraries: The WTO General Agreement on Trade in Services}

\author{
Megan Davis ${ }^{*}$
}

The extensive reach of the liberalisation agenda of the world's primary multilateral trade institution, the World Trade Organization (hereafter WTO) combined with the rapid global proliferation of free trade agreements is contributing to the transformation of the Westphalian notion of state sovereignty and political organisation in liberal democratic states. Many of the WTO trade agreements that member states such as Australia commit to domestically have significant implications for Western liberal democracies whose political organisation have at their genesis the ballot box. At their core, these trade agreements attenuate the capacity of domestic governments to regulate policy, rendering nugatory the political influence of the citizen upon its democratic representatives. One controversial example of the potential transformative power of these global trade agreements is the WTO General Agreement on Trade in Services (hereafter GATS) and the implications of the agreement for public libraries.

Civil society has provided an important critique of the WTO, particularly of the farreaching scope of GATS into areas of policy that have been traditionally the province of domestic governments, such as provision of education, water and health services. A key concern of many civil society ${ }^{1}$ groups with GATS is the existence of an exemption provision that ostensibly precludes services that are provided in the exercise of governmental authority from the operation of the agreement. It is feared by many that the exemption will be read narrowly by the WTO so as to subject services provided in the exercise of governmental authority such as public libraries to liberalisation. To some extent these fears have been realised by a WTO directive that states the exemption will be construed narrowly. ${ }^{2}$ It is the intention of this paper to provide a conspectus of GATS and outline the key concerns of its potential impact upon public libraries. Part I of this paper provides an overview of GATS, in particular, examining the public services exemption in Article 1.3. Part II considers the potential implications of GATS upon public libraries in Australia. In concluding, part III considers the broader human rights implications of GATS and the liberalising of services as has been highlighted by the United Nations High Commissioner for Human Rights and other UN human rights institutions.

\footnotetext{
${ }^{*}$ Megan Davis is Senior Research Fellow, Research Unit, Jumbunna Indigenous House of Learning, University of Technology, Sydney.
} 


\title{
Part I: The GATS: A Brief Overview
}

The WTO GATS is a framework agreement that was adopted during the Uruguay Round in 1994. GATS entered into force on 1 January 1995 and currently there are 140 WTO members that are committed to the agreement. Its drafting was 'largely due to the insistence of the United States that trade in services was placed on the Uruguay Round agenda'. ${ }^{3}$ According to the former director of the WTO Services Division:

\footnotetext{
Without the enormous pressure generated by the American financial services sector, particularly companies like American Express and Citicorp, there would have been no services agreement. ${ }^{4}$
}

Thus from the outset GATS attracted public controversy and initiated 'much controversy and disagreement among other contracting parties [in the WTO], especially developing countries'. 5

The controversy of GATS is foremost informed by its far reaching incursion upon state sovereignty and public policymaking. The WTO is regularly charged with suffering from a democratic deficit. ${ }^{6}$ The perception that 'states are progressively losing their ability to decide for themselves their own policy directions and priorities' is recognised by the WTO. ${ }^{7}$ Yet the WTO poses the question:

\begin{abstract}
Is the notion of 'sovereignty' real? Are countries and governments in a global economy not obliged to subjugate some level of domestic prerogative to international rules and disciplines? If so, is that a gain or loss to the well-being of societies? In short, in the context of the WTO, is complaint over 'sovereignty' a red herring and a cover for justifying annoyance over the rejection of special interest advocacy in the interests of a wider good? ${ }^{8}$
\end{abstract}

Australia is no exception to the charge of democratic deficit when it comes to the negotiation of trade agreements. In Australia, entering into international agreements is an executive power under the Australian constitution. While significant agreements such as GATS are tabled in parliament, ostensibly for transparency reasons, and examined by the Joint Standing Committee on Treaties (JSCOT), public consultation on the text of these agreements and the implications of the agreement for the future of Australian democracy is negligible.

Germane to civil society concern about GATS is that the nature of the agreement targets domestic service markets. GATS is therefore of great importance to multinational corporations, as the significant proportion of trade in services occurs within domestic economies and these businesses generally do not trade across borders. Using Australia as an example, in 2001 Australian service exports were valued as $\$ 31$ billion, an amount which accounts for $20.3 \%$ of total Australian exports. Services accounted for $76 \%$ of Australia's gross domestic product and the service sector employs $81 \%$ of the Australian workforce. ${ }^{9}$

Yet it is difficult for multinational corporations to participate freely in domestic service sector trade across borders because of the number of varying factors preventing their access, such as government ownership of service sectors, government regulation and administration laws in many areas of services. Moreover, often these corporations are prevented from trade in some services because of government restrictions on foreign ownership. Equally relevant to cross border trade in business is that it is difficult to categorise, to calculate, and lacking in transparency: 
There is no easy correspondence between the services that are being traded and existing service sector statistical classifications. Furthermore this trade by its very nature is hard to measure - no customs officials record the passage of a physical product, and keeping track of the associated international financial transactions is difficult. $^{10}$

The built-in agenda of GATS that was concluded at the end of the Uruguay Round is intended to address these hurdles and assist multinational corporations in the pursuit of greater liberalisation of service sectors. It is believed that this is achievable through greater transparency, less 'red tape' and a greatly reduced regulatory environment. The built-in agenda, therefore, is the work program that state members agreed to commit to which is contained in the annexes and related instruments of GATS.

At the 2001 WTO Ministerial Conference in Doha, Qatar, members agreed on a timeframe for their market access commitments. The first phase of negotiations in this timeframe is known as the 'rule-making phase' in which new rules were established with regard to new service areas such as government procurement. The second phase is known as 'request and offer', which means that market access is negotiated on a service by service basis. The request and offer is a essentially a bilateral procedure where members request improved trade commitments from another member and make an offer on the basis of these requests. After the offers have been finalised and tabled, the second phase of negotiation is commenced. The request and offer phase means that member countries have to directly request their trading partners to liberalise the sectors which they listed on their national schedule of commitments.

A request and offer by the European Union (EU) created some controversy in Australia in 2002 when an EU request to Australia was leaked to the Australian media. The leaked document, which revealed the extent to which trade in services may be progressively liberalised in Australia attracted marginal attention in the Australian press. ${ }^{11}$ In the document it revealed that the EU had requested the listing of all public postal services in Australia (namely Australia Post) and the listing of all water services, which some feared would result in the privatisation of public water services. It also requested the removal of limitations on foreign ownership, and the US requested the removal of Australian content rules on television and audio-visual services.

Australia has lodged 35 requests with other member states for market access in the areas of accountancy, architecture, engineering, legal, services related to mining, computer and related services, construction, distribution, private education, environmental services, financial, private health and aged care, maritime transport, pipeline transport, freight logistics, air transport, telecommunications, tourism, sporting services and business services relating to landscape architecture and urban planning. Conversely Australia has received requests from other WTO members in the areas of business services and professional services, transport, recreational, cultural and sporting services, tourism, health services, financial services, environmental services, education, distribution, construction, audiovisual, telecommunications and postal and courier services. There have been 42 offers tabled from other member states of which 21 are relevant to Australia's requests. Four of those offers have been in the recreation, cultural and sporting services sector which the Department of Foreign Affairs and Trade (DFAT) defines as including libraries. ${ }^{12}$ 


\title{
The GATS framework
}

The agreement lists 12 service sectors that must be liberalised under the agreement. ${ }^{13}$ States (i.e. UN member nations) agree to list those service sectors that will be subject to increased market access under the agreement and must specifically list those sectors as commitments. This is known as positive listing. The GATS has six parts to its agreement. The preamble reiterates the importance of global economic development and the importance of establishing:

\begin{abstract}
[a] multilateral framework of principles and rules for trade in services with a view to the expansion of such trade under conditions of transparency and progressive liberalisation and as a means of promoting the economic growth of all trading partners and the development of developing countries.
\end{abstract}

It also reinforces the WTO claim that members will still need to continue regulating the supply of services to achieve their national policy objectives. The preamble also holds that developing countries can improve their capacity to participate in world trade by strengthening efficiency and competitiveness of their national services.

Part I and part II of GATS outline the scope of the agreement and the fundamental rules for the liberalising of trade in services. Part III and part IV contain the rules for negotiations between states for the schedules of commitments they will make with regard to market access. These commitments are bound in the state members' schedule. Part V is the framework for resolution of disputes arising out of the agreement and part VI contains definitions for the agreement.

Part I lists the services that are subject to the GATS agreement. It applies to all levels of government. It identifies the four 'modes of supply' under the agreement. These are significant because of the way in which state obligations to GATS will be managed. For services to be liberalised, states must ensure that foreign suppliers are able to carry out their business in specific countries and this hinges on member government regulations that facilitate different modes of supply. Mode 1 is cross border supply of services which means those services that a supplier in one country provides directly to a consumer in another country. An example of this would be distance education services. Mode 2 is consumption abroad which means a service that a consumer travels internationally to obtain-services such as a consumer studying overseas. Mode 3 is commercial presence which applies to suppliers who establish branches or facilities in a foreign country, such as a bank or a university. Mode 4 is presence of natural persons which refers to those people who travel temporarily between countries to perform services. An example of this would be a supermodel or a consultant.

Part II of GATS provides the framework of obligations and disciplines members must countenance in ensuring access for foreign suppliers in any mode of supply. Part II enshrines two of the most fundamental principles of the WTO system, Most Favoured Nation (MFN) and the principle of transparency. MFN is defined by Article 1 of the General Agreement on Tariffs and Trade ${ }^{14}$ (GATT) and provides that with respect to customs duties and charges of any kind imposed on any member state, any advantage, favour, privilege or immunity shall be accorded immediately and unconditionally to the like product originating in or destined for the territories of all other contracting parties. In summary, under the rule of MFN all state members must give other members the same identical treatment as they would any other country or member. 
The second principle of transparency requires that all member states publish all state measures that have application to any of the services under the agreement. State members are also required to list all the laws and administrative guidelines and regulations that will impact upon the services that are listed in the schedule of commitments.

Part III of GATS is underpinned by two important principles, market access ${ }^{15}$ and national treatment. ${ }^{16}$ The principle of market access allows a country to limit the access of a foreign supplier to its market and this must be listed in the member's national schedule of commitments. The measures that may be taken to limit market access include limitations on the total value of services, limitations on the number of service suppliers, limitations on the number of persons engaged in the supply of the service, and limitations on the total quantity of services, operations or output.

The second important principle mentioned, national treatment, means that foreign suppliers cannot be discriminated against in favour of domestic suppliers and they must be treated the same way. National treatment only applies to where members have made specific commitments. MFN by comparison applies to the services generally and in some circumstances may be exempt (as in free trade agreements) and subject to reservations by members.

\section{Exceptions to GATS}

There are exceptions to the operation of GATS. These may be broad GATT exceptions for measures necessary to protect public morals or maintain public order, or to protect human, animal or plant life or health. However, it is clear from the jurisprudence of the WTO dispute settlement regime that there is complexity and difficulty in proving that these exceptions should be permitted on the basis of, for example, measures necessary to protect human, animal or plant life or health. ${ }^{17}$ Exceptions are also allowed under the agreement for compliance with laws or regulations that are necessary to prevent deceptive or fraudulent practices. The Annex on Financial Services also allows states to take measures for prudential reasons such as for the protection of investors, depositors, policy holders or persons to whom a fiduciary duty is owed by a financial service supplier, or to ensure the integrity and stability of the financial system. It also allows exceptions in the event of members having balance of payments problems.

For the purposes of this paper, the relevant exception to GATS, that has raised civil society concern about the privatising of water, telecommunications, education services and public libraries is Article 1:3 of the agreement. Indeed, civil society has provided excellent legal analysis of the implications of Article $1: 3 .^{18}$

Article 1:3

3. For the purposes of this Agreement:

(a) 'measures by Members' means measures taken by:

(i) central, regional or local governments and authorities; and

(ii) non-governmental bodies in the exercise of powers delegated by central, regional or local governments or authorities;

In fulfilling its obligations and commitments under the Agreement, each Member shall take such reasonable measures as may be available to it to ensure their 
observance by regional and local governments and authorities and non-governmental bodies within its territory;

(b) 'services' includes any service in any sector except services supplied in the exercise of governmental authority;

(c) 'a service supplied in the exercise of governmental authority' means any service which is supplied neither on a commercial basis, nor in competition with one or more service suppliers.

The agreement applies to 'measures' by members 'affecting' trade in services ${ }^{19}$ applying to all levels of government, including non-governmental bodies in the exercise of powers delegated by central, regional or local governments or authorities. $^{20}$ The 'trade in services' includes the four modes elaborated upon above: cross border supply of services, consumption abroad, commercial presence, and presence of natural persons. $^{21}$ 'Measures' are defined as: any measure by a member, whether in the form of a law, regulation, rule, procedure, decision, administrative action or any other form. The agreement does not actually employ the language of public services but rather 'services supplied in the exercise of governmental authority'. Article 1:3 of GATS provides that for the purposes of the agreement, services mean any service 'except services supplied in the exercise of governmental authority'. Such a service that is supplied in the exercise of governmental authority is a service that is supplied neither on a commercial basis, nor in competition with one or more service suppliers.

Therefore the operation of Article 1:3 is predicated upon what is meant by 'service supplied in the exercise of governmental authority'. Clearly there are two elements to this:

1. that the service is not supplied on a commercial basis, and

2. is not in competition with one or more service suppliers.

If a service is provided on a non-commercial basis and that service is not in competition with other suppliers, then it is a service supplied in the exercise of governmental authority. However, if a service is provided on a commercial basis but is without competition then it is not a service supplied in exercise of governmental authority.

The crux of ambiguity may lie in how the Dispute Settlement Understanding (DSU) was to define commercial basis and in competition. If there is a narrow definition of 'commercial basis' and a narrow definition of 'in competition', then the scope of governmental authority is broader and therefore more services are not covered within the GATS agreement. Alternatively if there is a broader reading of 'commercial basis' and 'in competition' then the scope of governmental authority is narrow and all services will effectively be covered by GATS.

The WTO itself is not clear on how the scope of Article 1:3 will be interpreted. However it has provided some clarity on how different services may be viewed in the light of Article 1:3. For example, in the context of health services the secretariat has stated that:

The institutional arrangements governing the provision of health, medical and social services may vary widely, from complete government ownership and control to full market orientation. ${ }^{22}$ 
It would seem that where there is a system that involves a combination of government owned health services and private institutions then it raises ambiguities about the applicability of GATS. ${ }^{23}$ Similarly with respect to postal services; whatever the status of the postal supplier, these would be services covered by GATS as long as they are supplied on a commercial basis. ${ }^{24}$ However, the Secretariat has also stated that:

It is perfectly possible for governmental services to co-exist in the same jurisdiction with private services. In the health and education sectors that is so common as to be virtually the norm... It seems clear that the existence of private health services, for example, in parallel with public services could not be held to invalidate the status of the latter as governmental services. ${ }^{25}$

Much of the controversy around the GATS is from civil society groups who are concerned about commercial basis and in competition being construed narrowly. A WTO Council for Trade in Services meeting has indicated that the interpretation will be narrow:

Members drew attention to the variety of policy objectives governing the provision of health and social services, including basic welfare and equity considerations. Such considerations had led to a very substantial degree of government involvement, both as a direct provider of such services and as a regulator. However, this did not mean that that the whole sector was outside the remit of the GATS; the exception provided for in article 1:3 of the agreement needed to be interpreted narrowly. ${ }^{26}$

Further, according to the WTO Trade in Services Division:

Because no question has been raised by any member about services supplied in the exercise of governmental authority there has been no need for interpretation of this phrase. This issue could only arise if a specific measure which has been challenged in dispute settlement were to be defended on the ground that it applied only to services supplied in the exercise of governmental authority and was therefore outside the scope of GATS. There is no requirement to notify such services. ${ }^{27}$

It is important to note that there are basic rules of interpretation of treaties in public international law. Article 31.1 of the Vienna Convention on the Laws of Treaties in particular is important to predicting how the exception may be interpreted:

A treaty shall be interpreted in good faith in accordance with the ordinary meaning to be given to the terms of the treaty in their context and in the light of its objective and purpose.

How the language of the text will be interpreted is uncertain and it will not be evident how the exception operates until the article is tested under the WTO DSU. Nevertheless, in the WTO Appellate Body decision in Japan-Alcoholic Beverages $I I,{ }^{28}$ the $\mathrm{AB}$ commented that:

The WTO agreement is a treaty - the international equivalent of a contract. It is selfevident that in an exercise of their sovereignty, and in pursuit of their own respective national interests, the members of the WTO have made a bargain. In exchange for the benefits they have agreed to exercise their sovereignty according to the commitments they have made in the WTO agreements. ${ }^{29}$

However, it is interesting to note that the Australian government lists services provided under a governmental authority as a service that falls outside the scope of GATS. According to the DFAT discussion paper on GATS, the following areas lie outside GATS disciplines: immigration, services supplied under governmental authority, fiscal policy and taxation measures, customs systems, certain aspects of investor protection concerning the movement of capital, monetary and exchange rate 
management, and services related to the exercise of air traffic rights. However, Australia has made broad commitments in private secondary education, tertiary education and English language training. ${ }^{30}$

\section{Part II: What Impact upon Public Libraries?}

\section{Civil Society Debate}

The intention of GATS is to remove those domestic regulations of major services that are viewed by corporations as 'constraints' or barriers to trade. Civil society groups view the agreement as, 'designed to facilitate international business constraining democratic governance'. ${ }^{31}$ The WTO defends itself by arguing that:

GATS expressly recognizes the right of members to regulate the supply of services in pursuit of their own policy objectives, and does not seek to influence these objectives. Rather, the agreement establishes a framework of rules to ensure that services regulations are administered in a reasonable, objective and impartial manner and do not constitute unnecessary barriers to trade. ${ }^{32}$

However, cursory examination of civil society concerns over GATS reflects the perceived disingenuous nature of WTO assurances. ${ }^{33}$ They are critical of the way in which GATS curtails governments' regulatory powers and secondly the way in which the agreement may transform the provision of public services that many citizens consider to be the primary role of the state. The Senate Foreign Affairs, Defence and Trade Committees Inquiry into the General Agreement on Trades in Services and the United States Free Trade Agreement found that:

The main argument made by those who are unconvinced about the scope of the exception in Article 1:3 (believing it will be applied narrowly rather than broadly) is that in the economies of most developed countries, a range of public services supplied by governments, such as education and health, are often delivered alongside private sector entities providing similar services or in competition with the government supplier. ${ }^{34}$

The submission to the inquiry from the Monash University Castan Centre for Human Rights has argued that Article 1:3 only applies to government run monopolies that do not run at a profit and do not provide any charge for any service. This is to avoid the operation of 'commercial basis'. The Castan Centre states that this will have a significant impact upon the realisation and enjoyment of human rights in Australia as the agreement would thus affect water and power utilities, sewerage and waste disposal, health services, education, telecommunications, prisons and detention centres and security services. ${ }^{35}$ Further according to the Australian Free Trade and Investment Network:

There is discussion of whether public funding should be treated as unfair subsidies and whether private corporations should have access to public funding through competitive tendering. ${ }^{36}$

The inquiry also found that the use of 'nor' in Article 1.3(b) may indicate that to be exempt from GATS it is required that the service is provided neither on a commercial basis nor in competition with other service providers. The recommendation from the inquiry was that the government clearly defines and makes public its broad interpretation of Article 1:3 of the GATS so that the public is aware of the basis on which future negotiations are undertaken. 
Many argue that the GATS is a renovated form of the equally controversial and ill fated Multilateral Agreement on Investment that was negotiated by the OECD members and aimed at significant liberalisation of investment and services: ${ }^{.37}$

it is a duplication of the Multi-lateral Agreement on Investment in many important respects, there's no question that the hands of government will be tied, that the rights of private sector providers will be massively extended in precisely the way that it was envisaged under the Multilateral Agreement on Investment. ${ }^{38}$

Australia and the EU, however, continue to counter civil society concerns about privatisation of public services. The EU is comparatively proficient in answering to civil society concerns about its commitments under GATS. It has posted a discussion paper similar to Australia, countering the assertion that it seeks to dismantle public services:

The requests do not seek to dismantle public services, nor to privatise state-owned companies. EU requests... in no way undermine or reduce governments' ability to regulate pricing, availability and affordability of water supplies as they choose. ${ }^{39}$

The WTO Secretariat similarly does not shirk from charges that agreements like GATS equate to a loss of policy making capacity in domestic governance. They do not regard GATS as an incursion upon democracy, positing:

Ultimately what counts is whether the balance between some loss of policy space at the national level and the advantages of cooperation and the rule of law at multilateral level is positive or negative. Our view is that it is already a positive for all WTO members and will increasingly be so in the future. ${ }^{40}$

However, such platitudes are little consolation for service providers such as health services or public libraries. The concern for public libraries is that they are operated on the basis of public funds. Public libraries fall under the UN classification Division 96 Recreational, Cultural and Sporting Services. These UN classifications are the way in which members make GATS commitments (libraries, archives, museums and other cultural services). Some libraries may provide services at cost that may include fees for documents, fees for courses, fees for research services, access to databases or links on web pages or use of library name. It is not clear how such services would be considered in the context of Article 1: 3 .

For example, it is difficult to countenance how the services of libraries can be measured against commercial service providers of ostensibly similar services:

Would the GATS consider a for-profit market-research corporation to be in competition with a public library's reference department? Secondly, a public library provides a basic level of access to information to all sectors of society, regardless of income. A fee based information service provider does not. Can the two entities really be considered in competition with each other when their markets and mandates are so different? ? $^{41}$

Recent significant technological developments in libraries also complicate the analysis of the impact of GATS upon public libraries. New technologies in libraries have and will transform the way in which public libraries operate.

Development in technology has brought to the libraries new kind of resources. Digital works such as books, periodicals and other materials are now in libraries' collections. $^{42}$ 
Indeed public libraries have already begun to countenance the implications of these new technologies with the WTO TRIPS agreement and the United States-Australia Free Trade Agreement.

Although traditional library services are not supplied in competition with private suppliers, the picture becomes complicated with regard to the supply of online or digital library services:

\begin{abstract}
the bricks and mortar more traditional library services may be excluded as supplied in the exercise of government authority while on-line and digital information services are not. This coincides of course with the areas of competition with private sector suppliers of e-book and e-library services. ${ }^{43}$
\end{abstract}

Canadian Public Libraries have been particularly organised and active in their concerns regarding the impact of GATS upon their services. Canada has listed as their commitments online information and database retrieval, electronic data interchange, and online information and/or data processing (including transaction processing). Though library services have not been listed per se, the commitments of technology and research and development such as research and experimental development services on social sciences and humanities, mean that GATS is likely to have some impact upon library services. ${ }^{44}$

Similarly, Australian libraries are situated in all levels of educational institutions. They exist in government departments and in judicial institutions such as the High Court, Bar Associations and Supreme Court buildings. Furthermore, public libraries are situated in most Australian cities and towns and are significant community institutions. These public community libraries, for example, provide many services from provision of and free accessibility to information, use of research databases, inter-library borrowing services as well as providing free facilities and resources for community groups and organisations such as the University of the Third Age. It is not inconceivable that future public libraries will involve possibly entry and access fees, or alternatively free entry but a fee-based access to databases and collections. This would transform the nature of public libraries and the role that they play in the Australian community both at the grassroots and in the context of educational institutions. Australia has not made as direct a commitment as Canada on library services, however, from the outset Australia has made broad commitments in private secondary education and tertiary education.

\title{
Part III: Human Rights and Liberalisation of Services
}

\section{The Principle of Non-Discrimination}

Though they developed in isolation from each other, non-discrimination is the cornerstone of the international trade law system as well as a dominant principle of the international human rights law system. The notion of non-discrimination frames the entire GATT. Non-discrimination is encompassed in two key principles, already discussed, known as the MFN principle and the principle of national treatment.

MFN is defined by Article 1 of the GATT and provides that: with respect to customs duties and charges of any kind imposed on any member state, any advantage, favour, privilege or immunity shall be accorded immediately and unconditionally to the like product originating in or destined for the territories of all other contracting parties. ${ }^{45}$ In summary, under the rule of MFN all state members must give other members the 
same treatment as they would any other country or member. Seemingly, this rule on the face of it would preclude the negotiation of free trade agreements, however, GATT provides an exemption of these types of agreements even though they conflict with the MFN principle. ${ }^{46}$ The EU, the Association of South East Asian Nations (ASEAN) and the North America Free Trade Agreement (NAFTA) are examples of free trade agreements that have been successfully negotiated and exempted under the GATT rules. The national treatment principle holds that member states should not discriminate against in favour of domestic corporations and businesses and that preferences and treatment given domestically should also be provided to member states.

The principle of non-discrimination in human rights law is a foundation principle of international law arguably forming part of customary international law or jus cogens. ${ }^{47}$ The Universal Declaration of Human Rights, a defining instrument of the establishment of the United Nations following World War Two, notably included non-discrimination as a core human rights principle that underpins the other elaborated fundamental freedoms and rights of all peoples in the instrument. ${ }^{48}$ Nondiscrimination, 'under human rights is directed towards protecting the weak and vulnerable and removing the structural barriers in achieving greater equality in society'. ${ }^{49}$ It was enshrined in the purposes and principles of the Charter of the United Nations, encouraging states to respect human rights and fundamental freedoms for all 'without distinction as to race, sex, language or religion'. ${ }^{50}$ The principle of nondiscrimination also forms a central principle of two major conventions, the International Convention on the Elimination of All Forms of Racial Discrimination (CERD) and the Convention on the Elimination of All Forms of Discrimination against Women (CEDAW).

There is a clear difference in application of the principle of non-discrimination:

\begin{abstract}
While trade law seeks non-discrimination in the application of laws between nationals and non-nationals and between non-nationals of other WTO member states, the human rights principle of non-discrimination is designed to achieve justice and equality between all individuals whatever their status. ${ }^{51}$
\end{abstract}

Indeed unlike the national treatment rule, human rights allows the differentiation of treatment in certain circumstances. Human rights law permits affirmative action and acknowledges that equal treatment of all people in all cases will not always equate to the achievement of equality. Nevertheless the linkage is a valuable one. The High Commissioner for Human Rights, some trade commentators and human rights advocates are using the principle as a linkage between the two disciplines. According to the High Commissioner, trade law needs to take into account the human rights principle of non-discrimination 'by safeguarding the need to use mechanisms such as cross-subsidization to ensure that the poor, vulnerable and marginalized do not suffer in accessing services in liberalized markets, ${ }^{52}$

The High Commissioner has found that at least 144 members of the WTO have ratified at least one human rights instrument and that at least 112 members have ratified the International Covenant on Economic, Social and Cultural Rights and all members except the United States of America have ratified the Convention of the Rights of the Child. Yet the High Commissioner has raised concern at the operation of GATS, using the example that a government who provides a subsidy to a domestic 
not-for-profit education service provider may have to provide the same subsidy to foreign for-profit service providers.

The question is posed then, if subsidies must be provided to all like service providers then how does this transform the right to education and the realisation of that human right? Furthermore does the principle of non-discrimination in trade, the treatment of all services in a like manner, prevent member governments from using subsidies as a tool with which to realise the human rights of its citizens, namely the principle of nondiscrimination: to make equal that which is unequal.

\begin{abstract}
If the application of trade law, or even trade liberalisation policies generally, threatens 'cross-subsidization' or other policies guaranteed to ensure universal service supply or raises prices of services for the poor, the reduction in quality and quantity of services to the poor, isolated or vulnerable might result in de facto discrimination under human rights law. ${ }^{53}$
\end{abstract}

The High Commissioner cautions member states about the way in which they commit markets for access. In particular, it is interesting to note that the very protections that enabled the development of infant economies of developed nations are being denied or discouraged for developing countries. The World Bank has acknowledged this in its report on Global Economic Prospects, Trade in Service: Using Openness to Grow: ${ }^{54}$

If a country is a relatively inefficient producer of a service, liberalisation and the resultant foreign competition are likely to lead to a decline in domestic prices and improvement in quality. But there is a twist. Frequently, the prices before liberalisation are not determined by the market but set administratively and are kept artificially low for certain categories of end-users and types of service products. Thus rural borrowers may pay lower interest rates than urban borrowers, and prices of local telephone calls and public transport may be kept lower than the cost of provision. This structure of prices is often sustained through cross-subsidization within public monopolies, or through government financial support. Liberalisation threatens these arrangements.

Thus the High Commissioner also argues that there should be flexibility in the way in which states can modify or withdraw commitments and that given economic shifts and social development changes, states should be able to adjust their commitments in the interests of realising their human rights commitments under international law and their human rights obligations to citizens. The High Commissioner recommends in the report on the human rights implications of trade liberalisation in services that there should be equal access to basic services for all, ensuring government's right to and duty to regulate is maintained, that GATS interpretations will be compatible with human rights and that human rights assessments are made of trade policies. ${ }^{55}$

Liberalisation of trade in services has also been subject to a resolution by the SubCommission on the Promotion and Protection of Human Rights of the United Nations that affirmed the importance of state delivery of basic services in education and health. It also acknowledged and emphasised:

the entitlement of Governments to regulate to achieve legitimate policy objectives such as to ensure the availability, accessibility, acceptability and quality of basic services such as medical services, education services and other necessary social services. $^{56}$

The human rights concerns of communities about trade liberalisation have become of significant interest to the United Nations human rights system over the course of the 
past five years. In particular the GATS has come under increasing scrutiny in the UN as a result of pressure from civil society. According to the High Commissioner for Human Rights, the GATS is relevant to the enjoyment of human rights in most of the service sectors that will be committed to liberalisation:

\begin{abstract}
Most directly, any commitments in the health, education or environmental sectors can affect the enjoyment of the right to health, the right to education and the right to development. Further, commitments to liberalisation in other sectors, such as tourism, telecommunications, advertising, or even prison services, can impact on the enjoyment of human rights. ${ }^{57}$
\end{abstract}

Other rights identified by the High Commissioner have been the right to culture which includes access to information and use of libraries and archives. Respect for the right to culture combined with the right to education and the realisation of these rights provide a strong argument for the exclusion of public sector libraries from the operation of the GATS agreement,

\begin{abstract}
The most effective way to guard against the corrosive influence of this regime would be to establish that public sector libraries are entirely exempt from the GATS disciplines as services delivered in the exercise of government authority under Article 1:3 of the text. Should this effort fail it would then be critical to ensure that measures concerning public sector libraries remain free from National Treatment, Market Access and other GATS commitments that would be invoked if commitments are made that affect the services provided by this public sector. ${ }^{58}$
\end{abstract}

The impact of GATS upon services such as public libraries in Australia has not generated community concern to the extent of North America, South America and European civil society. There are some NGO's and civil society groups in Australia who have been examining the agreement, particularly the Australian Free Trade and Investment Network. Nevertheless, community cognisance of the agreement is relatively poor and given the way in which regional, rural and remote communities have reacted to the privatisation of the telecommunications state monopoly, Telstra, it would be expected that the Australian community will object to the possible future privatisation of public sector libraries. This is particularly so, given that such privatisation is dictated by a foreign, unelected body and an agreement to which few Australians were consulted on its ratification and entry into force.

It is true that in minimalist liberal democracies like Australia situated at the ballot box, Australians expect their representatives to make decisions for them on the basis of their democratic mandate and that their representatives have the best interests of their electorate in mind in the course of their political deliberations. However, the Australian political system is dominated by party allegiance, and therefore representatives rarely waiver beyond the dictate of their party policy. The fact that so many Liberal and National party representatives in rural sugar electorates capitulated on the failure of Australia to include the sugar industry in the US-Australia Free Trade Agreement, a decision that benefited the US farmers and not Australian farmers, highlights the failure of the Australian political system in relation to the negotiating of trade agreements. It is conceivable that when the Australian community awakens to this beast slouching toward its public institutions that were once thought the province of the state and the right of all Australians, it will be too late to reverse the General Agreement on Trade in Services. 


\section{Notes}

1 The term 'civil society' is used to define a broad cross section of active political organisations, loosely aligned but concerned with policy issues relating to trade liberalisation and economic globalisation. Civil society is more than non-governmental organisations, it includes local community groups, religious groups, ethnic groups, indigenous groups, anti-poverty groups, human rights organisations, philanthropic organisations, women's groups, environment groups and development groups. M Keck and K Sikkink Activists Beyond Borders: Advocacy Networks in International Politics 1998; J A Scholte Democratizing the Global Economy: The Role of Civil Society Centre for the Study of Globalisation and Regionalisation 2004

2 WTO 18/09/98 S/C/W/50 'Report of the meeting held on 14 October 1998 - Note by the Secretariat' Council for Trade in Services WTO 12/11/98 WTO D Chapter 5 GATS: Implications and Impacts at 5.4

3 M J Trebilcock and R Howse The Regulation of International Trade 2nd ed p278

$4 \quad$ R Sanders 'GATS: The End of Democracy?' Australian Financial Review Sydney 15 June 2001 5 Ibid

6 See generally, J H Jackson 'Sovereignty Modern: An Approach to an Outdated Concept' American Journal of International Law vol 972003 p782

7 World Trade Organization The Future of the WTO: Addressing Institutional Challenges in the New Millennium Report by the Consultative Board to the Director-General Supachai Panitchpakdi, at http://www.wto.org/english/thewto_e/10anniv_e/future_wto.pdf

\section{$8 \quad$ Ibid $\mathrm{p} 29$}

9 World Trade Organization Report by the Australian Government, WTO Trade Policy Reviews: Australia 2002, at http//www.wto.org/english/tratop_e/tpr_e/tp202_e.htm

10 A Mattoo and S Wunsch-Vincent 'Pre-empting Protectionism in Services: The GATS and Outsourcing' Journal of International Economic Law vol 72004 pp765-766

11 See T O'Loughlin 'Europe wants to Muscle in on Post, Water Markets' Sydney Morning Herald 17 April 2002; ABC Radio National Son of MAI Background Briefing 23 June 2002, at http://www.abc.net.au/rn/talks/bbing/stories/s586637.htm

12 Department of Foreign Affairs and Trade WTO's General Agreement on Trade in Services (GATS) - Current State of Play Discussion paper June 2004, at http://www.dfat.gov.au/trade/negotiations/services/downloads/discussion_paper_gats_jan2003.d $\underline{\mathrm{oc}}$

13 Business; Communication; Construction and Engineering; Distribution; Education; Environment; Financial; Health; Recreational; Cultural and Sporting; Tourism and Travel; Transport

14 Final Act Embodying Results of the Uruguay Round of Multilateral Trade Negotiations 15 April 1994 Legal Instruments-Results of the Uruguay Round vol 1199433 ILM 11251144 (1994)

15 Article XVI General Agreement in Trade in Services; for the text of the Agreement, see www.wto.org/english/docs_e/legal_e/26-gats.pdf

16 Article XVII

17 See generally, J J Barcelo III 'Product Standards to protect the Local Environment-The GATT and the Uruguay Round Sanitary and Phytosanitary Agreement' Cornell International Law Journal vol 271994 p755; M A McCrory 'The Sea Turtle Dispute: Implications for Sovereignty, the Environment, and International Trade Law' University of Colorado Law Review vol 712000 p295; World Trade Organization Import Prohibition of Certain Shrimp and Shrimp Products Report of the Appellate Body: United States WT/DS58/AB/R 1998 WL 720123 WTO 12 October 1998

18 This analysis is based on M Krajewski Public Services and the Scope of the General Agreement on Trade in Services Centre for International Environmental Law, at http://www.ciel.org/Publications/PublicServicesScope.pdf; J Pickering GATS, Public Services and Domestic Regulation: Current Issues and Implications for Local Government in Australia Australian Free Trade and Investment Network, at http://piac.asn.au/publications/pubs/gatslocal_20030702.html

19 GATS Article 1:1

20 Article 1:3 (a)

21 Article 1:2 

10

\section{Ibid}

24 Postal and Courier Services Background Note by the Secretariat 12 June $1998 \mathrm{~S} / \mathrm{C} / \mathrm{W} / 39$, at 2

25 WTO Market Access: Unfinished Business Post-Uruguay Round Inventory and Issues Special Study No 6 Geneva April at 123

26 Council for Trade in Services WTO Notes by the Secretariat 12 November 1988 S/C/M/30

27 WTO Trade in Services Division GATS Facts and Fiction 2001 www.wto.org needs checking and fixing

28 Japan-Alcoholic Beverages II Dispute Settlement Reports (1996) WT/DS8/AB/R WT/DS10/AB/R WT/DS11/AB/R

29 Ibid 97 at 108

30 For Australia and other state members Schedule of Commitments see www.wto.org/english/tratop_e/serv_e/serv_commitments_e.htm

31 S Sinclair 'GATS: How the WTO's New Services Negotiations threaten Democracy' Canadian Centre for Policy Alternatives 2000, at http:/www.ratical.org/co-globalize/GATSsummary.pdf World Trade Organization The General Agreement on Trade in Services (GATS): Objectives, Coverage and Disciplines, at http://www.wto.org/english/tratop_e/serv_e/gatsqa e.htm

33 See generally, Foreign Affairs, Defence and Trade References Committee 'Voting on Trade': The General Agreement on Trade in Services and an Australian-US Free Trade Agreement Reference Committee Report 2002, at http://www.aph.gov.au/Senate/committee/fadt_committee/completed_inquiries/200204/gats/report/report.pdf; see also, Submission of Catholic Commission for Justice Development and Peace, Melbourne, at http://www.melbourne.catholic.org.au/ccjdp/articles/pdf/sub\%20200304\%20Submission\%20re \%20Inquiry\%20GATS\%20and\%20Australia-US\%20Free\%20Trade\%20Agreement.pdf

34 Ibid at Chapter 5 'GATS: Implications and Impacts' at 5.4

35 Ibid at 5.14

36 Australian Free Trade and Investment Network The WTO and Trade in Services (GATS): Where to Next? September 2004, at http://www.aftinet.org.au

37 Recommendation 4 above $\mathrm{n} 32$ at xvi

38 See generally, E Neumayer 'Multilateral Agreement on Investment: Lessons for the WTO from the failed OECD Negotiations' Wirtschaftspolitische Bloetter vol 46 1999; J Kurtz 'NGOs, the Internet and International Economic Policy Making: The Failure of the OECD Multilateral Agreement on Investment' Melbourne Journal of International Law vol 32002 pp213-246

39 Kevin Watkins above n11

40 The European Union The EU and Services Negotiations in the WTO: What is the EU Agenda for Services? at http://europa.eu.int/comm/trade/services/index_en.htm

41 Report by the Consultative Board above $\mathrm{n} 7$ at 34

42 F Hunt 'The WTO and the Threat to Libraries' Progressive Librarian vol 18 2001, at http://libr.org/PL/18_Hunt.html; F Hunt 'The GATS' Article 1, paragraph 3...' Information for Social Change vol 15, at http://www.libr.org/ISC/articles/15-Hunt.html

43 B Szczepanska 'Digital is not Different - Copyright in Digital Environment' Library and Information Services Manager, at http://www.iatul.org/conference/proceedings/vol14/fulltexts/Barbara\%20Szczepanzka.pdf

44 S Shrybman 'An Assessment of the Impact of the General Agreement on Trade and Services on Policy, Programs and Law concerning Public Sector Libraries' Legal advice prepared for the Canadian Library Association, Canadian Association of University Teachers, Canadian Association of Research Libraries, Ontario Library Association, Saskatchewan Library Association, Manitoba Library Association, Industry Canada, British Columbia Library Association, Library Association of Alberta, National Library of Canada, at www.cla.ca/resources?gats.pdf Ibid Non-Discrimination in the Context of Globalization Report of the High Commissioner 15 
January 2004 E/CN.4/2004/40, at http://www.unhchr.ch/pdf/chr60/40AV.pdf; Report of the International Law Commission on its Fifty-Third Session Official Records of the General Assembly Fifty-Sixth Session Supplement No 10 (A/56/10) at 208; A Bayefsky 'The Principle of Equality or Non-Discrimination in International Law' Human Rights Journal vol 111990 pp18-24

49 Article 1: All human beings are born free and equal in dignity and rights; Article 2: Everyone is entitled to all the rights and freedoms set forth in the Universal Declaration without distinction of any kind such as race colour sex language religion political or other opinion national or social origin property birth or other status; Article 7: All are equal before the law and are entitled without any discrimination to equal protection of the law

50 Analytical Study of the High Commissioner for Human Rights on the Fundamental Principle of Non-Discrimination in the Context of Globalization

51 United Nations Charter Article 1 (3)

52 Liberalization of Trade in Services and Human Rights Report of the High Commissioner E/CN.4/Sub.2/2002/9 9, at http://daccess-ods.un.org/TMP/4592168.html 9 at para 8

$53 \quad$ Ibid 4 at para c

$54 \quad$ Ibid p27 at para 61

55 World Bank 'Global Economic Prospects' Washington October 200171 at 80

56 UN HCHR report above note 53,29 at para 30

$57 \quad$ Ibid $\mathrm{p} 16$ at para 28

58 Shrybman above note $45 \mathrm{p} 38$ 


\title{
Chapter 11
}

\section{Protocols: Meeting the Challenges of Indigenous Information Needs}

\author{
Alana Garwood-Houng *
}

In 1995, the Aboriginal and Torres Strait Islander Protocols for Libraries, Archives and Information Services ${ }^{1}$ (hereafter the Protocols) were published to guide professional practice in relation to Indigenous Australian people and materials. The library and information context is a diverse and changing one, constantly accommodating technological and information expansion, as well as changing user needs, including changing and diverse Indigenous needs. Protocols can only ever be guidelines and must be broad enough to be interpreted across a range of organisations and circumstances. That is what we endeavoured to provide in the Protocols.

The Protocols have been available for use for a decade. This chapter ${ }^{2}$ restates the importance of Indigenous protocols for the Australian library and information sector. It provides background to the development of the Protocols. From my perspective as an Indigenous librarian who co-authored the Protocols and who has more recently been a member of the reference committee of a research project to gauge its usefulness to the profession, ${ }^{3}$ I discuss some of the ongoing challenges. My concerns focus on the work that still needs to be done in the area of governance, professional development on Indigenous issues, employment, education and training of Indigenous professionals, as well as the role of the Aboriginal and Torres Strait Islander Resource and Information Network (ATSILIRN).

\section{Background to the Protocols}

The Protocols were developed in response to a need by many libraries to know how to deal with their Indigenous collections and how to provide services to their Indigenous clients. It was recognised at the time that libraries, archives and information services had a role to play in the reconciliation process. The vision of the Council for Aboriginal Reconciliation, which was established in 1991, was '[a] united Australia which respects this land of ours; values the Aboriginal and Strait Torres Islander heritage; and provides justice and equity for all. ${ }^{4}$ In the same year, the Royal Commission into Aboriginal Deaths in Custody ${ }^{5}$ recommended in its national report that access to historical archives and records be facilitated to assist Aboriginal people to restore family links. In 1997, the Bringing Them Home report ${ }^{6}$ was published, revealing to other Australians the extent of Indigenous suffering under past government policies. It brought with it further recommendations for increased Indigenous access to archives and other collections and contributed to an increase in

\footnotetext{
* Alana Garwood-Houng is Librarian, Australian Institute of Aboriginal and Torres Strait Islander Studies.
} 
interest in the reconciliation process across the country. This all gave impetus to the Protocols as an important document to assist professionals, and sections of the profession embraced the principles of the Protocols with goodwill and commitment.

The Protocols identified eleven areas that were relevant to Indigenous information issues and broad principles were developed to highlight the issues and guide practice:

\section{Content and perspectives}

This area sought to address issues that related to Indigenous content in collections, the balance in representation of Indigenous perspectives, the inclusion of material about and by Indigenous Australians, promotion of Indigenous collections and access policies for Indigenous content in collections.

\section{Aboriginal and Torres Strait Islander intellectual property issues}

This area sought to draw attention to the rights of Indigenous people as owners and custodians of their cultural knowledge. Copyright only protects the interests of those who publish such materials and not the people who contributed their knowledge. Rights to be considered include legal, moral and communal rights.

\section{Accessibility and use}

This area addressed the historical exclusion and discomfort of Indigenous Australians in libraries and the need for clear strategies for inclusion.

\section{Description and classification of materials}

This area addressed Indigenous concerns about outdated and inappropriate description and classification of Indigenous materials evident in subject headings, indexing terminology and classification systems. To further assist in this area the Aboriginal and Torres Strait Islander Thesaurus was published in $1997 .{ }^{7}$

\section{5. $\quad$ Secret or sacred materials}

This addressed concerns about secret/sacred material which has been published and made publicly available in libraries and archives. Just because material has been published does not mean it is appropriate to allow unrestricted access to it.

\section{Offensive materials}

This area addressed issues surrounding material that was likely to be offensive to Indigenous people. This included outdated, racist, derogatory, sexist, abusive, and inaccurate representations of Indigenous people.

\section{Governance and management}

This section recognised that many Indigenous concerns could be facilitated at governance and policy levels through the inclusion of Indigenous people in advisory roles at this level and through the development of Indigenous policies and operational strategies.

\section{Staffing}

This area drew attention to the need to employ Indigenous people in libraries and archives and to provide appropriate support for them. 


\section{Education and training for professional practice}

This area addressed the appropriate preparation of professionals on Indigenous information and cultural issues.

\section{Awareness of Aboriginal and Torres Islander peoples and issues}

This area encouraged the promotion of Indigenous materials as a way to bring awareness of Indigenous issues to the broader community.

\section{Copying and repatriation of records to Aboriginal and Torres Strait Islander communities}

Libraries and archives hold original records and materials of great interest and importance to Indigenous people and communities. Some of this material was created or collected without consent or through deception. Indigenous communities often do not know what material different collecting institutions hold about them. These communities may also be a long way from collecting institutions making access to any materials difficult. Repatriation is a means of making records and material available in local contexts, usually in the form of copies, and is always a negotiated process.

\section{Reviewing the Protocols}

At the time the Protocols were written it was stated in the introduction that,

Deficiencies in the protocols will be identified by both Aboriginal and Torres Strait Islander people and libraries, archives and information services. They will be addressed in subsequent editions. ${ }^{8}$

In the decade since publication, there have been no subsequent editions. However, in 2004 a project was undertaken to determine whether the Protocols are a useful strategy for highlighting Indigenous information issues and promoting responses to them, to identify any emerging issues which may need to be included, and to collect professional comment on how they could be improved. ${ }^{9}$ The project was conducted by the University of Technology, Sydney, Library and Jumbunna Indigenous House of Learning. Among others from the profession, the reference committee included three Indigenous people: myself, Jackie Huggins, from Reconciliation Australia and a former Board member of the State Library of Queensland, and John Mohi, from the National Library of New Zealand. The project is reported in some detail by Nakata, Byrne, Nakata and Gardiner ${ }^{10}$ in this volume and the final report ${ }^{11}$ has been distributed to key organisations.

From the findings of the project, it was evident that the Protocols formed a most important contribution to the professional literature and advancement of the interests of Indigenous peoples in Australia and that they should be reinvigorated. However, attention was drawn to a number of issues which require addressing.

\section{The Ongoing Challenges from an Indigenous Perspective}

Included in both the report and chapter by Nakata et al is the voice of some Indigenous professionals, although both documents represent these within the general professional responses and concerns, as was set by the brief of the project. However, the researchers have supported the Indigenous voice by strongly advocating the 
Indigenous position in their conclusions. It is important, in my view, that as an Indigenous professional who was involved in both the development of the Protocols and this review of them, I take the opportunity to respond to some of the findings from a distinctly Indigenous professional perspective. I focus on what I consider to be the areas of greatest ongoing concern: governance and policy issues, education and training issues, Indigenous employment, training and staffing issues, the dissemination of the Protocols, and the role of ATSILIRN.

\title{
Governance and management
}

Fifteen years ago, in 1989, Henrietta Fourmile wrote:

\begin{abstract}
There is no requirement for aborigines to be members of the governing boards or councils, no provision for some form of aboriginal management or advisory committee ... Thus we have been legislated out of any effective say over the management of our cultural resources... ${ }^{12}$
\end{abstract}

The Protocols' guidelines in the area of governance and management reflect these concerns. They have been in place for ten years but the question still needs to be put: how many Aboriginal people are on the Board of the National Library, the state libraries, or the Council of the National Archives? Yet this can provide an effective means for organisations to maintain a focus on Indigenous issues within their organisation and, importantly, to build good relationships between institutions and communities. Indigenous people can bring Indigenous perspectives and knowledge that is useful to institutions. They can also take out professional perspectives and concerns into communities and help develop a better understanding of each other's concerns and promote a shared language for communication on the issues. Indigenous library and information practices have to be relevant to Aboriginal communities. The involvement of respected Indigenous people at the management level of institutions assists with this. There need to be mechanisms in place to consult with Indigenous communities, especially elders. Including Indigenous people at governance level can help guide the development of these mechanisms. Fortunately there are some organisations who have achieved this, but they are few. Because many information organisations have overlooked this area, the concerns and needs of Indigenous peoples continue to be perceived as peripheral, from our point of view, and our legal and moral rights over our cultural material remain diminished.

Within governance and management, policy development is another important area. Although $25 \%$ of respondents indicated they used the Protocols to guide policy development, this means that three quarters did not take the opportunity to develop policy positions in relation to Indigenous information issues or did not refer to the Protocols when doing so. Whatever the size or focus of an organisation, policy development is the beginning point of strategy and is an important means for ensuring that goals (however modest) are set, and progress planned and achieved. Without policy development, activity rests on the goodwill and interest of particular individuals in the organisation, making it vulnerable to changes in staff.

\section{Professional Preparation and Development on Indigenous Issues}

The need for education and ongoing professional development on Indigenous issues for the library and information sector is also included in the Protocols but remains an 
area of challenge for the profession. Although professional preparation courses are the starting point for education, ongoing professional development is also required. The extent and complexity of Indigenous information issues varies across sectors and organisations. Sometimes they present an overwhelming demand on organisations with extensive collections, which not only slows progress on the issues but demands considerable depth of knowledge about the issues. Sometimes Indigenous information issues are an insignificant part of an organisation's focus which can result in neglect or oversight. Often, professionals who work in the field are isolated from one another and do not have opportunities to share their concerns or knowledge. As practice in Indigenous information issues becomes more distinct or specialised, and hopefully more standard and consistent, keeping abreast of developments will be essential. This suggests the need for ongoing professional development and support for those who work in the area or who should be more active in the area.

As well, there still exists an identified need for more general cross-cultural awareness training. Some organisations undertake this in line with broader institutional equity policies and find this sufficient. Some deal with it routinely as part of staff induction. Many professionals are sensitive to Indigenous issues and manage cross-cultural interactions well. Those professionals who are unused to interacting with Indigenous people or unfamiliar with Indigenous cultures and issues need to be informed on the issues. Libraries and archives are still intimidating places for many Indigenous people, especially if they are approaching them for the first time. How professionals handle interactions is important, as is a good understanding of the sensitive issues associated with some Indigenous materials, as outlined in the Protocols.

However, if recognising the need for professional development rests on awareness of the Protocols document, then dissemination of the Protocols, in the first instance, is a matter of importance. This was brought home to us during the 2004 research project. The initial survey of the project reached a number of organisations who had never heard of the Protocols. A Catholic school diocese in Victoria contacted the research team requesting some professional development for teacher librarians on the issues, which I subsequently undertook in March 2005. This has led to more requests from different dioceses in that state. It is unlikely this would have occurred without the stimulus provided by the survey. This points to the need for ongoing and/or broader promotion of the issues and of the Protocols document. The role of the Aboriginal and Torres Strait Islander Resource and Information Network (ATSILIRN) is also relevant here but will be discussed separately.

Nevertheless, it is frustrating, from the Indigenous perspective, that those organisations who are aware of the issues cannot take some initiative in the professional development and cultural awareness area. Protocols and guidelines for approaching and communicating with Indigenous peoples can be easily found, especially by the information profession. It is not difficult, in major centres at least, to find Indigenous organisations or people who conduct cultural awareness training sessions. There is also a range of professional literature on Indigenous information issues. Some organisations are fearful of approaching these issues inappropriately and offending Indigenous people. It is appropriate that Indigenous people are involved, but where this is difficult, putting together a reference package for staff that includes some relevant articles and guidelines is a start. Action in this area, however, should 
flow out of policy and strategy development which reinforces the need for attention at that level.

\section{Indigenous Employment and Training}

Employment and training of Indigenous staff was seen as a significant challenge to preventing full implementation of the Protocols for many organisations. There is a small Indigenous professional membership that needs to keep growing. However, finding and recruiting qualified Indigenous people to work in libraries or archives is not easy for organisations who wish to employ Indigenous people. Ensuring Indigenous information workers are professionally qualified should always be a focus, and the roles and strategies of education institutions could be re-examined with the aim of attracting more Indigenous people into the profession.

However, there is also room for the profession, or some sectors of the profession, to consider alternate employment pathways. An Indigenous person with good community standing or with legitimate cultural qualifications can be very valuable and in some situations can achieve more or different things than fully qualified professionals. Indigenous positions that are complementary to professional positions, such as liaison positions, can work effectively to build relationships with Indigenous clients. In remote areas, multi-skilling of Indigenous people in ways that allow employment of a person in, for example, both the local school and the library to make better use of human resources could be considered seriously. Paraprofessional roles and the inclusion of information studies as certificate courses or within other diplomas or degrees (such as community/adult education or Indigenous Studies) could be appropriate and useful in some places.

As well, many very capable Indigenous people have onerous, extended family, financial and community responsibilities which can extend the time it takes to complete qualifications or make it difficult to contemplate full or even part-time study schedules as set down for courses. Ways need to be found to accommodate some of these pressures. Responding to some of these issues requires clearer, long-term but sustainable strategies in the employment area.

The roles of Indigenous staff also need to be considered. One Indigenous staff member is often expected to be the expert on all Indigenous issues. This adds to workloads, can restrict their professional experience and can mean that education on Indigenous issues is not extended across an organisation. All staff who work on reception desks, for example, need to be able to deal with Indigenous people, information and issues. Whilst some issues and clients will need or request referral to an Indigenous staff member, many issues and Indigenous people will not.

\section{The Role of ATSILIRN}

The Aboriginal and Torres Strait Islander Library Resource Network (ATSILRN) came into existence in 1993, after a workshop at the Australian Institute of Aboriginal and Torres Strait Islander Studies (AIATSIS) recognised that Aboriginal and Torres Strait Islander people who work in libraries have very little contact with each other and that libraries servicing Aboriginal and Torres Strait Islander communities needed more information on how to better service this client group. In 1994, the name was changed to Aboriginal and Torres Strait Library and Information Resource Network, to reflect those people not only working in libraries or resource centres but also those 
people working in other information services. The network was involved in the development of the Protocols (and holds the copyright), and the Aboriginal and Torres Strait Islander Thesaurus. ATSILIRN representatives were also included on the steering committee for the Australian Library and Information Association's (ALIA's) Aboriginal and Torres Islander Recruitment and Career Development Strategy. It has also provided advice to a number of libraries on library services to Aboriginal and Torres Strait Islanders.

For a number of years, ATSILIRN ran successful forums for those who worked in the Indigenous information sector and provided a means for the sharing of knowledge and discussion of concerns. These annual forums have not been held in recent times, and findings of the research by Nakata et al indicated that many professionals remembered them as useful. As a result of the stimulus provided by the 2004 review of the Protocols, a forum in August 2005 has been planned and already there is keen interest across the profession to gather and share developments.

ATSILIRN's executive draws from the Indigenous membership and although this is appropriate, it does mean that its operation falls to a few volunteers, with extremely limited resources. ATSILIRN has an important role to play as a way of bringing professionals together regularly for education and support, as a focus for Indigenous information issues, and as the proper home for the Protocols. It may be that there are links between the current lack of awareness of the Protocols by many in the profession and the winding down of ATSILIRN activity. If we want to improve the dissemination of the Protocols and understanding of Indigenous information issues then it would seem, as the research findings concluded, that ATSILIRN requires some re-invigoration. This requires support as discussed by Nakata et al in this book.

The Indigenous professional membership gives ATSILIRN legitimacy across the profession with regard to Indigenous information issues, but the non-Indigenous membership who work in the area are an important source of support for us and for implementing good practice. The respectful interaction between Indigenous and nonIndigenous professionals that characterised early forums must be maintained and extended if Indigenous information issues are to move along as they should. The relationships we build within the profession should be reflected in the relationships we all build between the profession and Indigenous communities, people and our cultural materials. When working in Indigenous contexts, relationship building is one of the most fundamental elements for implementing successful practices.

\section{Conclusion}

Protocols are often defined as 'rules' or 'procedures'. However, those of us who developed the Protocols prefer the term guidelines, which I would define as showing the way for different libraries, archives and information services to better manage their collections and better service their clients, both Indigenous and non-Indigenous. As an Indigenous librarian I consider it time to reinvigorate and promote the Protocols throughout the information sector, so that the needs and concerns of Indigenous people can be addressed as a priority rather than as peripheral to LIS activity. The fact that there remain major challenges reaffirms the importance of Protocols and the need to regularly evaluate their effectiveness. Members of the profession who contributed to the 2004 review of the Protocols have made many suggestions to improve their dissemination and usefulness. My hope is that the means and will to implement these 
suggestions will be found and that the profession will continue to support Indigenous issues in their organisations.

\section{Notes}

1 A Byrne A Garwood H Moorcroft and A Barnes Aboriginal and Torres Strait Islander Protocols for Libraries, Archives and Information Services Canberra ALIA Press 1995

2 I would like to acknowledge Prof Martin Nakata and Ms Vicky Nakata for their advice and assistance with the drafting of this chapter

3 M Nakata A Byrne V Nakata and G Gardiner 'Mapping the Impact of the 1995 Aboriginal and Torres Strait Islander Protocols for Libraries, Archives and Information Services' unpublished report Sydney UTS 2005

4 Council for Aboriginal Reconciliation Towards Social Justice? Compilation report of firstround consultations by the Council of Aboriginal Reconciliation, the Aboriginal and Torres Strait Islander Commission, and the Office of the Aboriginal and Torres Strait Islander Social Justice Commission Canberra AGPS 1994

5 Royal Commission into Deaths in Custody National Report Vol 5 (Elliot Johnston QC, commissioner) Canberra AGPS 1991 p81

6 National Inquiry into the Separation of Aboriginal and Torres Strait Islander Children from their Families Bringing Them Home (Sir Ronald Wilson, President) Sydney Human Rights and Equal Opportunity Commission 1997

7 H Moorcroft and A Garwood The Aboriginal and Torres Strait Islander Thesaurus Canberra National Library of Australia 1997

$8 \quad$ Byrne et al 1995

$9 \quad$ Nakata et al 2005 'Mapping...'

10 M Nakata et al ch 16 in this volume

$11 \quad$ Nakata et al 2005

12 H Fourmile 'Who owns the Past? Aborigines as Captives of the Archives' Aboriginal History vol 13 no 11989 p5 


\title{
Chapter 12
}

\section{Indigenous Archival Records at Risk}

\author{
Ros Kidd ${ }^{*}$
}

It seems as a nation we have grown so used to government dishonesty and injustice that we just shrug our collective shoulders. Our government indefinitely imprisons women and children known to have committed no crime, and it continues to promote an international invasion whose justification has proved to be false. But the bulk of the population don't seem to care, happily sedated by the scandals of people who earn millions role-playing for TV and film, or the scandals of the non-people whose roles they play, or perhaps the latest cricketing crisis about 15 degrees of separation.

There are of course many who are deeply disturbed by the lies and injustices perpetrated by governments in our names. Our voices might not reverse this mendacity but we can proclaim a refusal to play along with the con. We can say, for what it's worth, not in my name. There is always a choice, having learned the facts, not to be duped by the rhetoric.

During the last decade an issue has been slowly emerging out of the archival depths. The media, with its sophisticated sense of the public interest, has flicked it a glance and declared it a non-event, nothing new, old history. Governments, as we shall see, are more than happy with that classification. The issue-which has ramifications far wider than its financial focus - has become known as the Stolen Wages, a term that encompasses Aboriginal wages and other entitlements commandeered by governments during most of the twentieth century. This chapter is about my involvement in the fight for Stolen Wages, the practicalities of research and the implications for action, and how that might relate to archives and records management.

I started university as a mature-age student intending to feed my appetite for knowledge. Griffith University in Queensland was still young in the mid 1980s and there were no courses on Australian history or race relations. But for a number of reasons, mostly centered on my fascination with the forensic inquiries of French philosopher Michel Foucault and his theories of power, I chose as my $\mathrm{PhD}$ project the administration of Aboriginal Queenslanders - a topic I knew nothing about. I wanted to look at the machinery of power: what drove it, what sustained it, who wrote the manuals, who tinkered with it, how did modifications impact on older working parts, did the machinery do what they said it was doing; that sort of thing. I wanted to stand inside the bureaucracy and write about who did what and why, and measure the internal workings against the external rhetoric. To do this, of course, I had to read the records. And so began my 'other' life.

\footnotetext{
* Dr Ros Kidd is an Independent Research and Consultant Historian, and Adjunct Senior Lecturer, Griffith University.
} 
The main problem for an outsider in accessing records is that you have to know what to ask for. And if you're doing a sweeping investigation of a new field this includes just about everything. When I finally got access to restricted government records in February 1991, Queensland State Archives was in a highly nervous state. One year earlier, in sensational circumstances, the state archivist had been party to destruction of official records at the request of the Goss Labor government, records which apparently were also sought in relation to legal claims. ${ }^{1}$ The fall-out was intense, and still festers.

So the prospect of a $\mathrm{PhD}$ student beavering away through dozens of sensitive files triggered alarm bells. Who would know if there was material I shouldn't see? To protect the archivist's professional integrity, someone in authority would have to vet every file before I saw it and his/her costs would not come out of Archives' budget. An additional difficulty for me was the time constraints on Archives' staff producing hundreds of files on request and photocopying where required. On the other hand I had the option of a desk and a photocopier in the department's city office. If my requests for particular files were lodged through the department's records section, then Archives' staff had no responsibility over who accessed them in the department's offices. We had a solution.

I started in the city trawling through a mountain of unsorted boxes in a windowless basement storeroom while I pondered the question of knowing what to ask for. This fell into my hands before long, albeit in an outdated and partial version, and I was soon submitting lists for 20 or so boxes of files, signed off by departmental staff, processed through their records section, and a few weeks later trundled down Charlotte Street on a trolley for off-loading around my rapidly disappearing desk. I soon had one list at archives and a follow-up list already processing through the records section, while I attacked what had just arrived. This was an effective production line that served me well for 15 months.

I had no idea what I was looking for, so I wanted to read everything: what happened to children, working women, rural employment, running the missions, conditions on the settlements, budgeting problems, why federal health professionals impacted on the state's monopoly controls while the anthropologists were frozen out, how effectively a well-wielded pencil in a preliminary report could give just the opposite impression in the official version, bureaucrats versus ministers, premiers versus prime ministers, rhetoric versus reality. This was added to reams of research from church holdings, early archival documents and dozens of secondary texts. Somewhere in mid-1992, with the bench, desk and floor of my room buried under mounds of paper, I realised I had to make a start on the writing.

A major concern for all researchers is accurate identification of sources. For me this concern bordered on fear. I followed archival example and put my bundles in date order with the latest on top and the file number written on that. I put coloured card on the front of every bundle and over several months wrote on that a brief summary of every document in it. I filed these in boxes in broad categories - employment, each mission or settlement, health, education, state-church and state-federal etc-and stacked the boxes chronologically. I never had time - still haven't - to make any sort of digital database, although I dream of it frequently! 
It was in writing the cover cards that I began to get a sense of what had been going on, with particular focus on the twentieth century. My aim was to stand inside the material and reveal its full complexity. Taking time periods of around 30 years, I teased out the mix of concepts, agencies, agendas, legal possibilities etc, which were brought to bear on Aboriginal lives. The finished thesis ${ }^{2}$ ran to just over 700 pages grounded in over 2000 footnotes and took about 18 months to write.

I had uncovered some dynamite material relating to cabinet discussions in the 1970s and 1980s. It revealed the government discussed on several occasions that it was breaking state and federal law in underpaying its Aboriginal employees. Many times I pondered whether or not to include this material, knowing the 30-year embargo on documents used in cabinet. Yet this evidence was crucial to showing how the government wilfully cheated the people, damaged the communities and misled the public since the early 1980s. If I left the stuff out then I was part of the lie and I would know I had compromised my thesis and myself. So in it went. It was several months before the department thought to request a copy of my thesis, a condition of my research access. I took it in, had a cup of coffee and a chat with the head boffin, went home and waited for the fallout, which didn't come.

That summarises the practicalities of research. Now I'd like to look at some of the implications for action. It is my view that twentieth century records controlled by variously-titled Aboriginal Affairs departments are unlike other government archives. They are in a class of their own. I see three reasons for this. First, the departments had power of life and death over thousands of people for many decades purely on the grounds of their race. Second, in some states, Queensland in particular, the departments operated virtually as closed dictatorships outside the purview even of accountable co-departments (I'm thinking here of health, education, housing, policing and justice - all run by Queensland's Aboriginal department for much of the century). Third, the departments jealously guarded the flow of information. Without access to the records, even today, we know only what they choose to tell us.

We know the outcome of this century of total control over Aboriginal lives. We are all shamed by current conditions and statistics. Not only do official files explain how this came about but this evidence is, for thousands of Aboriginal people, the only written record of what was done to themselves and their families. It gives material context to their private narratives. And insomuch as particular files chart matters pertaining to an individual, that evidence charts also official interventions in their lives, labour and finances. And files which reveal internal government machinations impacting on people's lives as individuals should now be available in the interests of those affected by them. Yet governments blockade these records forcefully, as you will see.

The problem for Australian governments today, of course, is that they like the old story of well-meaning bureaucrats, rescued children, benevolent institutions, the guiding hand firm but fair. Not only is this a comforting perspective of national mythology and a gratifying endorsement of white integrity, but it also boycotts the A word. You know the one: A for accountability. Times were tough, we all meant well, and no-one's to blame for continuing wretchedness.

Governments insinuate present dereliction and despair is some unfortunate by-product of a culture clash; whereas the files show it's a consequence of carefully crafted and deliberately implemented policies. Governments imply Aboriginal poverty derives 
from a failure to engage robustly in the wider economy; whereas the files show millions of dollars which belonged to Aboriginal workers and families has never been accounted for by the departments which controlled private finances for most of the twentieth century.

The problem of holding key information is that you are immediately implicated. You have the option to make a difference. Beyond completing the thesis I had no such worthy intention. But I was drawn into action by government denials of what I knew to be the truth as evidenced on their own files. The last eight years have been an alarming lesson in what governments will do to defend their version of the evidence. Here I'll briefly sketch the dynamics.

In 1996 I offered to act as expert witness in a Human Rights and Equal Opportunity Commission inquiry into claims by seven people from Palm Island that the Queensland government had underpaid their wages as employees on a reserve community. This longstanding practice the government knew to be illegal after passage of the federal Racial Discrimination Act in 1975. As I said earlier, cabinet had discussed this several times. Under the protocols of discovery, plaintiff's lawyers should be given all relevant documents by the government for which, from my thesis, it knew every file location. It seems not one of these crucial documents was provided, although I later learned the plaintiffs' solicitor was shown a room full of files and told he could help himself.

When Crown Law saw the document copies I had produced to substantiate my affidavit, they wrote that I could be sued for damages if I submitted them, although such duress contravened the HREOC Act. A huge argument developed around Crown Law's determination to keep key evidence from the Inquiry, an argument it ultimately lost. I wasn't sued, although I was certainly intimidated. And within days of the hearing Crown Law demanded I hand over every document in my possession on any matter relating to Aboriginal administration. This I refused to do. I believed the government would likely withhold vital evidence in future legal actions; this would pervert the course of justice.

The Human Rights and Equal Opportunity Commission (HREOC) found that the government had acted illegally in deliberately under paying its Aboriginal workers. Subsequent compensation to eligible claimants, at $\$ 7,000$ per person (the rate suggested by the Commissioner), has totalled almost $\$ 40$ million. Is this a just outcome? Not in my opinion. First, the government knows this is a fraction of what is owed; I know it holds written advice calculating the average wage debt at $\$ 13,000$, and that's without holiday pay, sick pay, superannuation, overtime, penalty rates etc. Second, the government will not provide all potential claimants with their financial records so most have no idea of their true entitlement. In that context, the government's requirement that claimants must relinquish their legal rights to full reparations is, in my view, a calculated deception which perpetuates financial dispossession. It is a deception grounded in the government's continuing control of all available evidence. And the public remains oblivious to the abuse.

This same pattern of concealment and deception underlies the government's current offer of $\$ 55.6$ million to compensate for past control of the stolen wages. Launched in May 2002, this offer amounts to $\$ 4,000$ per person for those over 50 years old and $\$ 2,000$ for younger claimants, for decades of loss. Again the government demands 
indemnity against legal actions, again it refuses to supply all potential claimants with their records, again most claimants thereby cannot make an informed decision, and again, the government will walk away with millions of dollars owing to those whose interests it was mandated to protect. In fact if you happened to die before the May 2002 date, the government simply keeps your money. Desperate though they are, many spurned the payout as an insult and a pittance; to date under half the expected claimants have responded, almost half those assessed are rejected, and less than $\$ 13$ million has been paid out. ${ }^{3}$ Others are considering pro bono offers of legal support to pursue full redress.

This payout for stolen wages does not 'ease the lasting pain', as the Premier claims. It is a travesty of justice, because this financial management, as I have shown elsewhere, ${ }^{4}$ was blighted by incompetent procedures, negligence, fraudulent dealings, misappropriation by government, and failure to implement recommended safeguards. The government knows this; it holds all the incriminating evidence. But the claimants do not. They could not even know what was happening to their private savings until the 1970s. Because this evidence is suppressed, the Premier can characterise his offer as 'generous' and 'in the spirit of reconciliation', and the largely indifferent media swallows it. Can you imagine the perpetrators of the HIH or James Hardie scandals floating such a scheme without any public accounting?

Concealment of the evidence not only poisons our shared history but it contaminates the course of justice. Concealment underlies government 'spin' that record holdings are so fragmentary that we can't really know what has happened to the funds; it underlies government assertions that people are likely to lose legal action against it to recover their financial entitlements. It is deeply disturbing that governments, whose unfettered powers sustained negligence and misuse of Aboriginal monies, still control the documents upon which accountability and justice depend.

All states and territories, to a greater or lesser extent, took control of private Aboriginal income and finances during much of the twentieth century. Recently the New South Wales government, its hand forced by public exposure of information it had no intention of revealing, is also hiding behind the 'incompleteness' of its holdings. It says it will pay out monies owing, if it can find records to substantiate the claim. Yes, Premier Bob Carr has intimated other testimony might also be considered but my bet is that Crown Law will veto payments lacking official validation. The NSW government, like Queensland, has not made any public accounting of its dealings on Aboriginal monies. The NSW government, like Queensland, says records are so patchy it is all but impossible to chart how much money has gone missing during its decades as banker. For both governments, then, those incomplete records are both a defence against full disclosure and the basis for rejecting claimants. For both governments, the mantra of 'patchy records' is intoned to convince the victims and the public that this is as good as it gets. But is it?

There is no doubt that governments in most states and territories took control of Aboriginal finances. They set and received wages, ran the accounts, dictated when and what withdrawals might be made, invested bulk private monies for interest revenue, intercepted and controlled endowment, pensions, compensation, inheritances. They fulfilled all the roles of trustees. In fact they consistently described themselves as trustees of monies they described as trust funds. 
Trustees have very particular duties. They must keep proper accounts, they must not mix beneficiaries' funds with their own, they must not profit from their financial management, to name the most basic. Where there is a dispute over proper management of another's finances, the trustee must provide a full account of all dealings. Where this cannot be done, where there are gaps in the record, there is no assumption that the money was properly disbursed. In short, patchy records exemplify the failure of a trustee to fulfil his legal duties.

In the United States, for instance, where in 1996 the Blackfeet people of Montana sued the Department of the Interior for missing and mismanaged private funds, the district court has determined the department must account publicly for every cent since it commenced the trust funds in 1887. The department has calculated it might owe US\$40 billion to around half a million claimants, a category that includes every deceased person whose income was taken under control. This order to provide a full historical account is currently under appeal. ${ }^{5}$

Whether or not the fight for justice in Australia is that straightforward, and certainly governments here are urgently canvassing legal opinion to avoid being defined as trustees in this sense, the fact remains that people who suffered under decades of financial controls are entitled to an independent public accounting based on the fullest range of evidence. No financial institution with such a scandalous record would be allowed to deny it. This evidence should not be manipulated by temporary politicians.

Failure to produce available evidence also impacts on a more familiar battle for justice, namely the struggle for Aboriginal Australians to attain title to their land. Here, it seems, the struggle is blighted not so much by wilful concealment of evidence as by wilful withholding of resources, although the effect is much the same. For around two centuries now, governments have amassed evidence of Aboriginal presence and movement. They generated files specific to Aboriginal individuals, they retain all this evidence, they control access to this evidence, they vet what will be available to the bodies who ask to sight it on behalf of claimants. Governments are therefore morally bound to provide resources sufficient for a full appraisal of this evidence. Anything less clearly prejudices claimants' legal rights that judgement of native title be based on the full range of available facts, rather than on a minor portion of evidence. This need not be an onerous task. The provision of all relevant material to claimants within a reasonable time is restricted only by the preparedness of governments to fund staff sufficient for the task. Most 'native title' funding in fact is soaked up by the Native Title Tribunal and by government opposition to claims.

In this increasingly contested field archivists and records managers hold a critical position, a position inextricably linked with the authorities which create the files. Archives receive documents which government departments choose to store with them. Ownership of the documents remains vested in the government which can reclaim them at will or, as was the case in Queensland in 1990, order their destruction. Here the archivist was requested by cabinet to destroy the documents within 24 hours, a requirement condemned as 'political pressure' by the Australian Society of Archivists in 1997. Subsequent legislation ${ }^{6}$ appears not to resolve this dilemma. Ownership of the records remains vested in the department that generated them, and which can demand their return. Destruction depends either on the authority of the archivist or under 'other legal authority, justification or excuse'. This does not sound like professional independence to me. 
And destruction of records is only one of a variety of tactics available to authorities who want to conceal evidence of their practices. The records are extraordinarily vulnerable. They are vulnerable to confiscation by authorities which demand them and may or may not return them to archives. They are vulnerable to tampering. For example, one crucial file I accessed in 1990 held hundreds of letters across a 30-year span; it now is registered as covering only a single insignificant year. Perhaps this is a database glitch. I certainly hope so. Records are also simply excised from their historical context. For instance, the Queensland government only has to declare a file, a box of files or a truckload of files to be of interest to cabinet and they disappear for 30 years during which time, of course, legal actions can be adjudicated without them. In fact Queensland's Information Commissioner was recently highly critical of government misuse of FOI laws to avoid public scrutiny; ${ }^{7}$ he has since been removed and not replaced.

This is why I argue that records generated by variously-titled Aboriginal Affairs departments are in a class of their own. For other sectors of government-health, prisons - there are a range of intersecting authorities and departments whose records reveal multiple perspectives of practices and policies. This is not the case, certainly for Queensland, for the most momentous - and now contested-years of Aboriginal controls. Archivists and record managers certainly have a role to play in preserving this evidence. Is it possible to copy all relevant files before relinquishing them to departments that reclaim them? Or at least summarise the material therein? Destruction of files relating to Aboriginal lives should be a last resort. Even the most banal-work records, travel schedules, ration vouchers - are all grist to the mill of researchers such as myself tracing the footprints of people long gone for native title claims, or footprints of people still waiting to get their money back.

Whether or not archivists can operate as truly independent gatekeepers is a moot point. Certainly there needs to be a person or body to stand between governments and the evidence of their actions, an entity working closely with archivists but perhaps charged more specifically with ensuring that all relevant material is available to both parties in any dispute or litigation over previous government practices.

Better still, with regard to stolen wages, governments should fund an independent accounting of all relevant material. People who still struggle in poverty and despair because of long-term practices which deliberately impoverished their elders are entitled to no less. They are entitled to a re-writing of our national narrative to take account of their labour on which our development was dependent. They are entitled to public acknowledgement that wretched community conditions were pioneered and entrenched by governments fully aware of the dreadful toll on survival, and were recently handed in that state to Aboriginal councils. People are entitled to say, in their thousands, here is evidence to prove that we worked, we earned our pay, but someone else took our money. This is not a story our governments want us to know, but I believe governments should no longer control what can be known. This evidence belongs to us all, it is our heritage, disturbing though it is. If - when - the evidence is public then justice can be done and healing can proceed.

I hope this brief chapter has given you some sense of why our archival records are so significant, and so vulnerable, in this field. Please use your powers and skills to guard their integrity and ensure their availability to all appropriate individuals and agencies. 
We must be ever vigilant against government dishonesty and injustice. We need more people to stand up and say: not in my name.

\section{Notes}

1 See http://www.archivists.org.au/pubs/positionpapers/heiner.html for background and a position paper by the Australian Society of Archivists in March 1999

2 R Kidd Regulating Bodies: Administrations and Aborigines in Queensland 1840-1988 PhD thesis Griffith University 1994

3 See http://www.indigenous.qld.gov.au/datsip/reparations process.cfm for full details. Rejection rate is running at around $40 \%$

$4 \quad$ R Kidd The Way We Civilise: Aboriginal Affairs - the Untold Story St Lucia University of Queensland Press 1997; also see articles at www.linksdisk.com/roskidd

5 See www.indiantrust.com and www.narf.org

6 The Public Records Act 2002

7 See http://www.infocomm.qld.gov.au/indexed/annual/2003-2004_OIdC_annual_report.pdf 


\title{
Chapter 13
}

\section{Indigenous Knowledge and Archives: Accessing Hidden History and Understandings}

\author{
Lynette Russell $^{*}$
}

Over the past decade, I have been involved with numerous archival projects. All of these have had as their primary aim the uncovering of aspects of Indigenous history or culture. In each case, I had assumed that the archival knowledge I would uncover was not Indigenous per se but rather was Western or colonial knowledge about Indigenous people and their cultures. This material was, for the most part, I had understood, the results of the surveillance of Indigenous people and their cultures. In short, these were archival texts within which Indigenous people were the object (and subject) of the gaze of colonial authorities and 'experts,' and from which Indigenous knowledge, perspectives and voice were excluded.

In this chapter, I interrogate this assumption and consider some of the issues that have arisen in using archives for the creation of Indigenous (or hidden) histories. I begin by establishing how I conceptualise Indigenous knowledge for the purposes of my argument. This is followed by an analysis of two case studies, one a project that was both familial and personal and the other an exploration of ethnographical details related to Indigenous people's understandings of weather and climate. I focus on some of the challenges each has presented and discuss how these have led me to develop a set of ideals which would enable archives and libraries to allow additions to the Indigenous records (and knowledge) housed in their collections. In the last part of the chapter, I highlight and discuss an Australian Research Council (ARC) Linkage project I am involved with. My hope is that some of my concerns and the issues I broach below will be dealt with in this project which we entitled Trust and Technology. ${ }^{1}$

\section{Indigenous Knowledge}

It has become increasingly popular to refer to the concept of Indigenous knowledge as distinct and separate from Western knowledge. This separation and what is often perceived as an incompatibility have been discussed at length by educationalists, anthropologists and philosophers and theorists alike. ${ }^{2}$ However, as Donna Haraway reminds us, such perceived differences are perhaps rather arbitrary, as Western knowledge and science in particular 'is above all a story telling practice'. 3 Contemporary interest in Indigenous knowledge is in part a result of global and local political engagements which have situated Indigenous issues and rights as a feature of human rights discourse and also a consequence of renewed interest in Indigenous

\footnotetext{
* Dr Lynette Russell is Chair of Australian Indigenous Studies and Director of the Centre of Australian Indigenous Studies, Monash University.
} 
cultures which stem from the neo-primitivist new age movements. In this context the term Indigenous knowledge is frequently used interchangeably with traditional knowledge. According to Warren, in a definition adopted largely by the United Nations and UNESCO:

\begin{abstract}
Indigenous knowledge (IK) is... local knowledge - knowledge that is unique to a given culture or society. [It] contrasts with the international knowledge system generated by universities, research institutions and private firms. It is the basis for local-level decision making in agriculture, health care, food preparation, education, natural-resource management, and a host of other activities in rural communities. ${ }^{4}$
\end{abstract}

Using this definition, we would not expect archives to house Indigenous knowledge as Indigenous knowledge is ' $[\mathrm{t}$ ]raditional knowledge [that] is generally transmitted orally and experientially and not written'. However, using a definition supplied by Flavier et al, we might consider that information housed in archives can function as Indigenous knowledge, as it 'facilitates communication and decision-making'. ${ }^{6}$ This particular definition depends on and recognises that Indigenous societies and cultures are utterly modern; they are dynamic and adaptive.

For the purposes of this chapter, I will use the term Indigenous knowledge in its broadest sense. Indeed, I am interested in any information, textual or other, that is housed within public, private or state archives, libraries or other institutions, which observes, and records Indigenous activities, and or people. This is not immediately or obviously Indigenous knowledge as it is knowledge not by but rather about Indigenous people. As most historians would agree these archival records are at least as informative for what they reveal about the record makers as they are for any 'knowledge' contained within them. Therefore, while I do not believe that the material housed in archives and libraries in general is Indigenous knowledge per se, such material can become Indigenous through reclamation processes which can be facilitated by libraries and archives and which, I believe, will bring the two parties closer together.

\title{
Case Study One: Looking for, Finding and Reclaiming Emily
}

\section{Accessing Private and Confidential Knowledge}

There is an inextricable link between identity and culture and access to knowledge. As the colonial process has effectively fragmented many Indigenous families and they have, on occasion, been denied access to their cultural knowledge, many have turned to the materials housed in archives and libraries relevant to their own histories and such. For a number of years, I worked with elders assisting them to retrieve some of the fragments of their heritage housed in various archives. It was with this experience behind me that I began to search in earnest for any records pertaining to my Aboriginal great-grandmother, Emily. Like many family historians (even those of us who are also professionally trained), I had a few leads, the most important of which was the essential clue that she had been committed to a mental asylum at some time in the $1920 \mathrm{~s}$ or $30 \mathrm{~s}$. I was able to locate and extract from numerous archives, medical records, police records, welfare records and even school records. Most of these records were housed in government archives, the Public Record Office of Victoria, the mental health archives, police and welfare agency records. The result of this work 
was the book A Little Bird Told $\mathrm{Me}^{7}$ and much more importantly a deeper and more nuanced understanding of the Indigenous heritage and knowledge of my family. I learnt first hand that inextricable link between identity and culture, and that access to knowledge presented very particular problems and created a very specific and often times conflicted relationship between me and the archival materials.

The raw material I drew on for developing Emily's biographical narrative consisted of boxes of hospital records, a photograph of Emily in hospital garb and a series of psychiatric evaluation sheets. Added to this were the weekly letters that Emily's husband wrote to the asylum authorities, the requests for visits.

My grandmother also kept a small private archive, which consisted of birth, death and marriage certificates, some of which had been altered, and a short abstracted memoir. In her memoir, Nana focused on her childhood, providing very little detail that could help me in my quest. As a supplement to the hospital records and my grandmother's sanitised memoir, I conducted a series of interviews with those who could remember Emily, including my own parents, my aunt and several of my grandmother's distant cousins. This was my introduction to working in the perilous world of memory and oral history.

\section{Archival Resources}

Medical records tend to be poorly written, barely legible and highly cryptic. They are, however, remarkable sources of information and the archives are often a rich and untapped source of material. Dashed off notes, hurriedly scribbled instructions and scarcely decipherable observations indicate that the medical staff were extremely overworked. On some occasions patients had to be kept indoors or restrained simply for lack of staff. Sedation was frequently used and it would appear that for many a patient the first few weeks of their stay was spent in a near unconscious state. Despite my professional training as an historian, I was deeply affected by this material. As the great-granddaughter of the subject of these records, I was often visibly and palpably distressed.

After hundreds of hours reading doctors' notebooks, diaries and case histories, I developed a sense of the mental health system in the early part of last century. The mental health archives are housed on the grounds of the Royal Park Psychiatric Institution. The archives hold published and unpublished materials. I was able to locate doctors' notebooks and attendants' ward records. The medical records revealed that Emily was institutionalised for what the medical authorities described as 'auditory hallucinations'. Emily herself, according to the doctor's notes, called these the voices of the spirits. Therefore, while we cannot really call the patient and welfare records Indigenous as such, it is clear that Indigenous knowledge can be found within them. This material has been subsequently reclaimed and is now presumed to be Indigenous by family members.

Access to this material varied. Individual patient records cannot be enabled unless the patient was a family member, or was born more than 100 years ago. On this latter point I was deeply concerned. For many Aboriginal families, 100 years is not a long time - four, maybe five, generations - and I am certain that many (maybe most) would not want this material on open access for anyone to read. Even in 500 years, I do not want just anyone to be able to read the 'treatments' to which members of my family were subjected. 
The records on inmates, be these asylum or jail records, along with protector's records, mission records, welfare records and so on are records of surveillance. The Oxford English Dictionary defines surveillance as:

\footnotetext{
Watch or guard kept over a person, etc., esp over a suspected person, a prisoner, or the like; often, spying, supervision; less commonly, supervision for the purpose of direction or control, superintendence [my emphasis]. ${ }^{8}$
}

The status I am ascribing this material, that is, 'surveillance' records is very important. Over a number of years I have accompanied Aboriginal elders to archives, public records offices and the like, and have often seen firsthand the sort of trauma these records can produce. People are confused as to why their families who were sometimes living perfectly 'normal', even suburban, lives were subjected to the shadowy observation of police and welfare agencies alike.

According to the definitions presented earlier, these records cannot be routinely described as Indigenous knowledge. However, as this information is incorporated into a community or family's worldview it becomes Indigenous knowledge and is factored into decisions made and choices exerted. Emily, once thought of by family members as troubled and possibly mentally ill, is now reconfigured as an Aboriginal woman who talked to her spirits and her Wotjabaluk ancestors, who had practised, and now through archival research had passed on (some) of her Indigenous cultural knowledge.

\section{Implications for Libraries and Archives}

Clearly, there are policy and practical implications for libraries and archives and, in most archives where I have worked, attempts are made to meet these challenges. Most archives and repositories have an Aboriginal policy document (usually developed with considerable community input) and, in general, most staff are sensitive to the issues. Although policy or protocols make a difference and help provide guidelines for practice, it is clear that there are no blanket solutions that will meet all circumstances.

In some locations, Indigenous people have been employed as liaison officers or facilitators. This is not necessarily the answer for everyone, as I have been in situations where particularly private elders have expressly requested that they do not deal with an Aboriginal person, even an archivist or librarian, as they felt 'shamed' and preferred to deal with a complete stranger. Although I would not suggest censorship, I have at times needed to proceed with great caution, warning people that there could be extremely unpleasant information that they may choose not to see. I have encountered records where the forced sterilisation of Aboriginal women is described and documented, and for some particularly elderly individuals this was not something they wished to see. In these cases I have found it is always better to take more than one person/family member to the repository so that these issues can be discussed and no one person feels pressured to view distressing material.

Finally, once families become aware that material is available, there is often a strong desire for that material to be destroyed - a desire that is clearly at odds with the charter of the archive or library. This is a very sensitive issue and one which I believe needs to be fully discussed and mechanisms developed for either restricting access to the material or alternatively enabling Indigenous people the right of reply. Recently, I discovered a police welfare report relating to my grandmother and her capacity as a parent. Some of the information was wrong and other aspects of it were at least in need of modification. At a minimum I wanted a right of reply. On this latter point, 
which I will develop further in my next case study, I suggest that archives and libraries embrace the new digital technologies and provide the opportunity for interactive and performative interventions.

\section{Case Study Two: The Preliminary Indigenous Weather Knowledge Project}

\section{Accessing Ethnographic Knowledge in the Public Domain}

In 2000 I began a project, along with the Bureau of Meteorology (Victoria) and Professor Nigel Tapper of Monash University's School of Geography and Environmental Science, on Indigenous Understandings of Weather and Climate. As a preliminary to a large ARC Linkage application, we developed a pilot desktop study to ascertain the viability of the project. The Bureau of Meteorology was particularly keen to develop a series of seasonal calendars for their website. In order to ensure we achieved a comprehensive pilot study, which would outline the possibilities of a largescale continent-wide project, we needed to ensure that we limited ourselves to publicly available materials.

Several issues arose in the preliminary project and now two years into the larger project we continue to confront these. Firstly, and perhaps most importantly, it has become abundantly clear that just because material is in the public domain its status as 'public' and therefore open to use is not certain. To their great credit, the bureau staff were keen to fully and adequately acknowledge the communities whose knowledge was to be placed on their website. ${ }^{9}$ This meant that we needed to check with those communities from which the information or knowledge had come. This ensured that we had community consent to allow us to publish images or information. Interestingly, in many cases the Indigenous community concerned did not even know that the material existed in the public arena, as it had been secured by external people (anthropologists, ethnographers and other visitors) often without the knowledge or contemporary memory of the elders. Thus the intellectual property rights of the community, which we were concerned to protect, had already been violated.

The next key concern that we encountered and continue to grapple with concerns the irreconcilable nature of Indigenous knowledge vis-à-vis Western knowledge. We faced what we now recognise and label 'irreconcilable ontologies', following the conceptual work of Turnbull. ${ }^{10}$ At a crude level, Western science and climatological studies are based on recognition of certain cycles of certain lengths, certain numbers of seasons and so on. Indigenous weather and climate knowledge is then collected and placed in juxtaposition to- or more often subordinate to-Western knowledge. These two knowledge systems, rather than having equal value, are made hierarchal. This is necessary in order to produce the seasonal calendars, which the Bureau wanted for their webpage. Such calendars are, on reflection, incommensurate with traditional understandings of the environment.

A Bureau of Meteorology webpage which relates to Wantangka season of the Walabunnba people of central Australia provides an example for discussion. ${ }^{11}$ After consultation with the knowledgeable Aboriginal women, Lana, Rachel, Pansy, Trisha and Lindy, all family members of the Walya Altjerre Aboriginal Corporation, the decision was made to share cultural knowledge. In this case, the community was not asked to develop a new seasonal calendar but rather to verify and give permission to 
use the Walabunnba seasonal calendar as developed by the Bureau of Meteorology. The substance of the calendar was already preconfigured and constructed out of archival materials located in the public domain. The community is described as having two seasons. The first of which is Wantangka or as the webpage describes it 'hot weather'. The webpage lists the following:

October to March

The hot weather (summer) called Wantangka gradually gets hotter so we know to be ready for high temperatures, bush fires and rains. A variety of different bush foods become available and certain animals are ready to eat.

The Bush Plum is found around Central Australia in the hot weather (summer). The Bush Plum is not a traditional Dreaming unlike Bush Banana or Bush Potato. We eat the plum straight off the bush when it is dark. It is sweet to taste.

... We share a ceremony which is held during the hot weather.

The grass is burnt after the rains which is the end of the hot weather. The burning helps the bush foods to grow again.

There are several interventions in the text of this that suggest the incommensurable nature of the different knowledge systems. One is the use of the terms October to March as markers of the beginning and end of the 'season'. This is an imposition, a Western intervention that undermines the value of the Indigenous knowledge. In fact Wantangka begins when it begins, and ends when it ends, at different times every cycle. The insertion of the word 'summer' in parenthesis further demonstrates how the Indigenous knowledge is being made to be subservient to and simultaneously subsumed within the Western knowledge system.

Whilst my concerns here are easily trivialised by the argument that we are never able to overcome these problems, I think that such an argument is perhaps unnecessarily pessimistic and simplistic. Two issues which emerged in this project and which could not be put aside were Indigenous cultural and intellectual property rights over material in the public domain and 'incommensurable ontologies'.

\section{Implications for Libraries and Archives}

It has become increasingly clear that some communities do not know (or perhaps no longer remember) that there is material in the public domain relevant to their culture, history and region, and that some of this knowledge is traditional Indigenous knowledge. The preliminary Indigenous weather knowledge (desktop) project highlighted this very clearly. Firstly, the information in the public domain was probably collected a long time ago and, secondly, as is often the case, there was little or no follow up so that the communities involved did not know what had been produced out of the sharing of their cultural knowledge. As far as the various archives were concerned, the copyright rested with the creators of the records and not the Indigenous knowledge holders. Institutional-based researchers bound by ethics committees and ethical practice policies are frequently reminded that they need to liaise with the relevant communities and so forth, however, this is not a usual requirement if the material is deemed to be in the public domain. Indeed, many researchers assume that public domain material is open for all and as such there is no need to consider the copyright (apart from adequate acknowledgement). As a result of this attitude, the moral rights of the material's owners are rarely even considered. 
Libraries and archives as holders of, or repositories for, material with significant Indigenous content need to be cognisant of these issues and I suggest a simple document or webpage that indicates that if archival material which might be deemed to be Indigenous knowledge is to be published, in electronic or other formats, that every attempt be made to consult with and obtain permission of the relevant community. Anything less is simply bad manners.

The other aspect of this project that I would like to consider in terms of its implications for libraries and archives is that of competing knowledge systems or, as I labelled these before, 'incommensurate ontologies'. This is also relevant to my previous discussion about the need for Aboriginal people to be able to add to records, correct information and in general offer alternate interpretations or context.

As noted above, drawing on the work of Flavier and others, Indigenous knowledge is often oral knowledge or at least knowledge that is often delivered in oral form. The Indigenous weather knowledge project has highlighted for me that the creation and passing on of Indigenous knowledge is something that happens within a culture and therefore is both performative and interactive. Converting this knowledge into text or some other inactive medium basically and perhaps even fundamentally changes the information. As Walter Ong reflects:

\begin{abstract}
Without writing, human consciousness cannot achieve its fuller potentials, cannot produce other beautiful and powerful creations. In this sense, orality needs to produce and is destined to produce writing.... There is hardly an oral culture or a predominantly oral culture left in the world today that is not somehow aware of the vast complex of powers forever inaccessible without literacy. This awareness is agony for persons rooted in primary orality, who know very well that moving into the exciting world of literacy means leaving behind much that is exciting and deeply loved in the earlier oral world. We have to die to continue living. ${ }^{12}$
\end{abstract}

I am not as pessimistic as Ong. Given the proliferation of digital technologies, it is increasingly likely that archives and libraries will be able to offer the opportunity to incorporate oral material into their collections in new and clever ways. How then do we incorporate oral culture without contributing to its death, to use Ong's terms, and all the while keeping in mind that Indigenous heritage is fragile but living heritage.

\title{
Trust and Technology: Building Archival Systems for Indigenous Oral Memory ${ }^{13}$
}

\section{The Background to the Project}

This project has three broad and interrelated phases. We are at present in the primary data-gathering phase or the 'user needs analysis' and about to begin phase two. We began by recognising that traditionally in pre-contact times Aboriginal Australia was mainly an oral culture. We also noted the passing of information from one generation to the next was achieved by harnessing memories and the storytelling associated with them. This ensured that cultural knowledge was transmitted and younger generations knew what was important to know. Finally, we noted that the importance of oral tradition continues to underwrite much Aboriginal culture. For the purposes of the ARC linkage application we used the term 'oral memory' as a short-hand reference to historical knowledge that has been transmitted orally across the generations. As a consequence of colonisation, dispossession, removal and the relentless surveillance to 
which Indigenous people were subjected, many significant records about Indigenous communities reside in institutions such as libraries, public record offices and other archives. These are virtually all written records and not oral memory.

One of the key motivations in the trust and technology project was to offer Aboriginal people the opportunity to incorporate their oral memories into archival institutions. Importantly we are not collecting oral traditions, stories, memories or any other form of Indigenous knowledge. Instead, we are in the first instance asking Indigenous people how and if they would like their material represented and delivered. This forms our user needs analysis and, based on the outcomes of this phase, we will explore a range of archival techniques and technology to build an archival system that provides access to oral memory. We certainly hope that such a system will also enable Aboriginal people to add to records already housed in archives and libraries and thus value add to existing records.

Whilst we are focusing on oral material, stories and the like, we anticipate that the project's outcomes will play a fundamental role in building trust and understanding between archival institutions and Indigenous communities. This is something that my experience to date would suggest is lacking, notwithstanding the goodwill that exists on both sides of the divide. The key aims of the project were developed by bringing together a multidisciplinary group consisting of historian, archival specialists, Aboriginal scholars and a community liaison and expert in community protocols.

Although it is undoubtedly early days for this research, we anticipate a number of significant outcomes and benefits for archives and libraries, Aboriginal communities, and the relationships between the two. A key benefit will be an increased enabling of access to oral materials that have been previously unavailable. Such access we hope will aid the process of recovery for Indigenous people affected by past and ongoing government decisions and policies. This will hopefully promote the healing of family and community ties and make an important contribution to national efforts of reconciliation.

The trust aspect of the project will be developed and attempted through a consistent and sincere effort to consult, cooperate and collaborate with Indigenous communities. It is essential for relationship building that the Indigenous community is a crucial and inalienable part of the decision-making process with regard to how their oral traditions and memories should be handled. The comprehensive exploration of the needs of Indigenous users of archival services will develop understandings on both sides and enable models for archival strategies and services for Indigenous communities that are driven by their needs. There will also be significant benefit for industry partners who have all striven to work ethically and respectfully with the relevant Aboriginal community groups. All anticipate improved service delivery which we hope will filter through to the archival community in general.

First peoples in Aotearoa/New Zealand, Canada and the United States of America along with many other Indigenous peoples face similar issues relating to access to, and control of, information about their cultures and communities. One of the main benefits of this project will be the provision of a model for archives around the world to engage in a meaningful dialogue with Indigenous owners and custodians. Other benefits of the project as we see it are: 
- Aboriginal people in regional and rural Victoria will have increased access to oral materials relevant to their communities, and communities will be supported to develop collections housed locally if they so desire;

- archives, libraries and other record-holding agencies will develop culturally appropriate access to their collections for Indigenous people. This will extend and go vastly beyond existing procedures and policies;

- new collections of oral materials may (if communities so desire) be developed through the systematic capture and preservation of representations of Indigenous stories and memories which will lead to an accumulation of valued heritage;

- trust will be built between the Indigenous communities of Victoria and archival service providers. This trust will both be the foundation for and ensure the security, authenticity and integrity of memory and knowledge captured in physical form; and

- the best methods of capturing and preserving representations of oral memory for long periods of time will be investigated. This will involve innovative deployment of culturally sensitive metadata schema, and the development of customised and user friendly interfaces.

The trust and technology project builds on the experiences of the chief and partner investigators. For my part, I hope that my involvement might enable the production of solutions to some of the issues I have encountered as an archival historian undertaking a range of projects which have included those outlined above. My key concern, as I have observed, is to create archival systems to which Indigenous people and Indigenous knowledge can be interactively added. Perhaps we might even develop systems that not merely acknowledge the inherently different nature of Indigenous knowledge but celebrate the ontological incommensurability of various knowledge systems and work towards making the two systems at least comprehensible and of equal value.

\section{Notes}

1 Industry partners include: the Public Records Office of Victoria, the Koorie Heritage Trust, the Australian Society of Archivists Indigenous Issues Special Interest Group and the Victorian Koorie Records Taskforce. Academic partners include: School of Information Management Systems and the Centre for Australian Indigenous Studies, Monash University

2 W W Cobern and C C Loving 'Defining "Science" in a Multicultural World: Implications for Science Education' Science Education vol 852001 pp50-67

3 D Haraway Primate Visions: Gender, Race and Nature in the World of Modern Science New York Routledge 1989 p4

4 D M Warren Using Indigenous Knowledge in Agricultural Development World Bank Discussion Paper No 1271991

5 J C Capp and C Jorgensen 'Traditional Knowledge: Don't Leave Home Without It' paper presented at the 62nd North American Wildlife and Natural Resources Conference 1997 Washington DC cited in S Forrest, 'Indigenous Knowledge and its Representation within Western Australia's New Curriculum Framework' refereed paper presented at the Australian Indigenous Education Conference Fremantle 3-7 April 2000 p7 at http://www.ecu.edu.au/csess/kk/aeic/ 
6 J M Flavier et al 'The Regional Program for the Promotion of Indigenous Knowledge in Asia' in D M Warren L J Slikkerveer and D Brokensha (eds) The Cultural Dimension of Development: Indigenous Knowledge Systems Intermediate Technology Publications 1995 p479 L Russell A Little Bird Told Me: Family Secrets Necessary Lies Allen and Unwin 2002 Oxford English Dictionary Online, at http://www.oed.com

9 Bureau of Meteorology Indigenous Knowledge Page, at http://www.bom.gov.au/iwk/

10 D Turnbull 'Performing and Narrating Knowledge and Space: William Dawes and the First Australian Meteorological and Astronomical Observatory' seminar paper presented at Monash University 26 May 2004; D Turnbull Locating, Negotiating, and Crossing Boundaries: A Western Desert Land Claim, the Tordesillas Line and the West Australian Border (in press); D Turnbull Masons, Tricksters and Cartographers: Comparative Studies in the Sociology of Scientific and Indigenous Knowledge Reading Harwood Academic Publishers 2000

11 Bureau of Meteorology Walabunnba Calendar, at http://www.bom.gov.au/iwk/walabunnba/index.shtml

12 W Ong Orality and Literacy: The Technologizing of the Word London Methuen 1982 p15

13 I would like to acknowledge and thank my fellow researchers for agreeing to my discussing this project particularly as we have yet to release any findings. I am grateful to fellow Chief Investigators Graeme Johanson, Sue McKemmish and Don Schauder and thanks also to former CI Kirsty Williamson. Others involved in the project to whom I offer appreciation are Shannon Faulkhead, Justine Heazlewood, Carol Jackway, Fiona Ross, Jen Sullivan, Diane Singh, Emma Toon and Andrew Waugh 


\title{
Chapter 14
}

\section{Accessing State Records on Aboriginal People}

\author{
Andrew Wilson ${ }^{*}$
}

\begin{abstract}
The challenge in devising policies for research, museum, library or archive collections lies in finding the best way to provide a high curatorial standard, so that the heritage values are preserved, and at the same time to meet other needs. We ought to be able to avoid repressive policies which restrict the freedom of researchers and yet at the same time preserve the integrity of Aboriginal culture, history, religion and ceremonial life. This is particularly important given the demand by Aboriginal and Torres Strait Islander people themselves to have aspects of their culture recorded for posterity. We can and ought to demand restricted access to some records. But in respect of any particular item, it must be the Indigenous people with the authority in the particular group who own the information who advise on research and curatorial practices. ${ }^{1}$
\end{abstract}

Over the last decade, archives and records offices in Australia have been developing initiatives to provide Indigenous Australians access to records that relate to them. These records are also of interest to researchers of Aboriginal history and cultures and other related areas. The challenge Marcia Langton refers to in the quote above has been taken up generally in a climate of goodwill, though progress overall is slow. This chapter outlines a number of issues that are important in meeting these challenges, from my perspective as the Senior Aboriginal Project Officer, State Records, South Australia. These include: the importance of indexing, including Aboriginal people in advisory capacities, outreach activities, and the production of useful resources.

\section{The Value of Indexing}

There is no issue more important than the indexing of records relating to Aboriginal people. The importance of indexing has been highlighted over the last decade and a half following a number of national inquiries which recommended facilitating Indigenous access to government records relating to the administration of Aboriginal and Torres Strait Islanders. ${ }^{2}$ Christopher Anderson, a former director of the South Australian Museum, speaking in relation to the increased use of the Norman Tindale Aboriginal family history records, which are of Australia-wide importance to Aboriginal people, once stated that restricting access can actually increase access. As well as increasing access, indexing importantly also provides more appropriate access by helping to maintain the privacy of Aboriginal people mentioned in records, particularly with reference to personally sensitive information about them.

As an example of how restricting access to increase it works in practice, and at the same time looking at how this increases privacy, I refer to one of the more significant record series of the former Department of Aboriginal Affairs, South Australia - the Aborigines Protection Board minutes, 1940-1963.

\footnotetext{
${ }^{*}$ Andrew Wilson is Senior Aboriginal Project Officer, State Records, South Australia.
} 
Before indexing of the minutes began, once researchers had received approval from the Department of State Aboriginal Affairs to access these records, there was no alternative other than to allow them to handle the minutes to search them. This was difficult to avoid because the four volume Aborigines Protection Board minutes consisted of hundreds of pages and this meant that there was too much material for an archivist to search through on behalf of each researcher. There were three significant problems with this situation. Firstly, without an index, there was no way of knowing if any relevant information even existed and much time was wasted by researchers. Secondly, unavoidably these researchers encountered a lot of personal information, including sensitive personal information, about many people that was not relevant to their research. Thirdly, this situation led to excessive and unproductive handling of these precious records, which was detrimental to their long-term survival as this process was repeated by many individual researchers.

However, since indexing the minutes about ten years ago, a member of the State Records Aboriginal Access Team or an archivist can now search for personal information on behalf of researchers by the name of a person on the Aboriginal Name Index without them needing to go through the minutes themselves as they did in the past. This example clearly highlights the value of indexing in relation to saving time and preserving the records. Furthermore, indexing by name, via the Aboriginal Name Index, enables more appropriate access. This is particularly important as access to records relating to Aboriginal people is at times fraught with sensitivities and difficulties.

The Aboriginal Name Index has perhaps been our most important initiative and was undertaken by South Australian State records in response to recommendations of the Aboriginal Deaths in Custody and Bringing Them Home reports. ${ }^{3}$ To date the index, which is an ongoing project, contains in excess of 70,000 entries listing the names of Aboriginal people and related information about them. At State Records, we are finding that the Aboriginal Name Index is increasingly showing its worth as a vital indexing project.

Furthermore, this indexing encourages the provision of access to those Aboriginal people to whom the information relates while assisting to protect it from the scrutiny of those to whom it does not. It is important to note that where I am using the term 'sensitive' in relation to records relating to Aboriginal people that are in the custody of State Records, I am largely referring to personal information and not information that might be classified as 'secret and sacred'. Most importantly, the Aboriginal Name Index alerts Aboriginal people to the existence of information in public records about them.

Indexing also helps to deal more effectively with government concerns about the content of their historical records. Such concerns generally relate to the use of these records as evidence in inquiries or investigations of government policies and practice that may have legal and compensation implications or political consequences. Government concern over the release of records has occurred and continues to occur in association with a range of circumstances including:

- government inquiries or royal commissions such as the Inquiry into Aboriginal Deaths in Custody (1987) or the Separation of Aboriginal and Torres Strait Islander Children from their Families (1996) ${ }^{4}$ 
- court cases related to a native title claim or other issues relating to Aboriginal people, and

- ministerial enquiries especially where questions in parliament or media focus have raised issues that may be reflected in the records relating to Aboriginal people.

These situations can put pressure on government, which may result in the government increasing restrictions on public access to sensitive records, including records relating to Aboriginal people. My experience in South Australia has led me to believe that the less that governments know about the contents of their records, the more likely they are to impose excessive or blanket restrictions because they fear what might emerge. Indexing, not only at the item level (record by record), but also at the document (folio) level is therefore helpful because it allows governments to assess more accurately what their records contain or do not contain, leading to less restriction. Government practice in this area might be politically motivated and not desirable from the public interest point of view, but the fact is governments do place restrictions on access to their records. In a practical sense, indexing can actually decrease government restriction, in my experience.

All of the above points illustrate the value of indexing records relating to Aboriginal people and the underlying urgency for indexing projects to be initiated and progressed. Despite the need for some restrictions, our main priority in archives is to create easier access to records, not to restrict it unnecessarily. At State Records, the question of how we might increase indexing of Aboriginal records is a perennial topic during business planning, so important is this matter to us.

\section{Aboriginal Advisory Mechanisms}

Another issue that is important in archives is the inclusion of Aboriginal people into advisory roles. Anemaat argues that '[a]ccess and restrictions need to be discussed and revised after consultation with the relevant groups'. ${ }^{5}$ Anemaat further elaborates:

\footnotetext{
In the case of officially produced records, such as photographs, genealogies and organisational records, the donor is not usually the subject of records. The information they record may be secret/sacred in nature, insensitively handled, or offensive to the people concerned. Consultation about access to these records should take place with the Aboriginal groups concerned and not with the relevant government department, researcher, only. Such steps are necessary in the interest of all parties. ${ }^{6}$
}

The Aboriginal Access Team at State Records is once again examining the question of whether some form of Aboriginal advisory body or, more informally, a Reference Group comprising some of our stakeholders would be useful or viable in the South Australian context. A successful venture of this nature could result in the following:

- opportunities to work not only with current State Records stakeholders but potentially with some very valuable new ones

- provision of a significant forum for the Aboriginal people of South Australia through which they can gain an awareness of the services State Records offers that are of direct benefit to them, including the better provision of access to records important to meet personal and family needs, and 
- the opportunity for the Aboriginal peoples of South Australia, with the involvement of relevant Aboriginal organisations, including the SA LinkUp program, to have input into how State Records and its Aboriginal Access Team deal with issues confronting Aboriginal people trying to access records and the opportunity to provide advice on how State Records can provide better reference and access services to records relating to Aboriginal people.

\section{Outreach}

An important part of improving Aboriginal people's access to records is outreach work. In addition to other initiatives, the State Records Aboriginal Access team does engage in outreach work. This includes visits to Aboriginal communities around South Australia to enable Aboriginal people to become more familiar with our records and to assist them to locate those of interest to them or their community. It is important that Aboriginal people in regional areas who might find it difficult to come to our Adelaide archives and who may also find it too daunting to make a telephone enquiry or to write a letter, can have an opportunity to speak to an Aboriginal Access Team member from State Records. Our experience confirms that the more familiar Aboriginal people become with the officers of the Access team, the more confident they become in taking the required steps to access records.

\section{Resources}

Earlier in this chapter, I referred to resources as another important way to improve and enhance access to records. To this end, the State Records Aboriginal Access Team has developed a number of resources, including publications.

One of the most important is entitled A Little Flour and a Few Blankets-An Administrative History of Aboriginal Affairs in South Australia 1834-2000. ${ }^{7}$ This work has three main components:

- an administrative history largely constructed from primary sources identified from the records of our Aboriginal Affairs Correspondence Files (letters received) 1866-1968

- a series listing reflecting many series of records across a number of South Australian government agencies that are either about Aboriginal people or contain records relating to Aboriginal people, and

- a summary of legislation used to govern Aboriginal people in South Australia.

In short, A Little Flour and a Few Blankets is an extremely valuable resource as it provides administrative, historical and legislative context for the records in our collection by providing details of the legislative and administrative framework that governed the lives of Aboriginal people over many decades, the results of which we can still see today.

Our State Records Aboriginal Resource Kit-An Introduction to Primary Source Records relating to Aboriginal People ${ }^{8}$ is another important work which contains a number of transcribed primary source records to provide researchers with awareness about the records we hold relating to Aboriginal people. One other feature of the 
Aboriginal resource kit is its detailed description of some of the more significant series relating to Aboriginal people.

Lastly, we have produced a video entitled Distant Voices-Using the Archives of State Records to Unlock our Indigenous Past. ${ }^{9}$ This is both an educational and entertaining resource. It features a number of Aboriginal people who each volunteered their stories and how they benefited from using primary sources held by State Records. Together with A Little Flour and a Few Blankets, these two resources were distributed to all Aboriginal communities throughout South Australia.

\section{Conclusion}

In developing appropriate services for Aboriginal Australians, the challenge for archives is how to provide increased access to records and at the same time appropriate access that takes into account individual privacy issues and other issues of sensitivity. In the South Australian context, indexing the names of Aboriginal people in government administration records has greatly facilitated both these aspects. At the same time it has reduced excessive handling of records and has lessened the impact of other restrictions to records that result from government concerns.

However, the best indexing practices are not effective if Aboriginal people remain unaware of just what records are held that relate to them and therefore do not access them. Our experience in South Australia emphasises the value of outreach into Aboriginal communities by archival institutions holding relevant records. It also affirms the value of developing resources in the form of guides and electronic indexes and sharing that knowledge with the people of those communities. Such contact often leads to those individuals we assist finding their way into our archival research centres, reading rooms and reference libraries in Adelaide.

Despite this progress, one area still to be addressed has been one of the issues raised by Marcia Langton in the opening quote of this chapter viz, that Indigenous people with authority must advise on practices. Anemaat's words should also be heeded - the importance of including Aboriginal people in advisory roles to ensure that activities and processes for managing access to Aboriginal records progress according to Aboriginal interest, needs and concerns. To this, I would add the importance of Indigenous people occupying decision-making roles in organisations. Indigenous staff members, such as the Aboriginal Access team, are important but cannot always represent or influence decisions effectively at higher levels, especially if they work alone or form a very small part of the staff. These issues remain a challenge for archives.

\section{Notes}

1 M Langton 'Echoes of History: Archives and Library Collections: Our Heritage and Custodial Responsibility' Safekeeping Women's Business Australian Indigenous Women and Museums National Conference Adelaide 7-9 March 1993 Canberra AGPS 1993 p33 Royal Commission into Aboriginal Deaths in Custody National Report vol 5 (Elliot Johnston QC Commissioner) Canberra AGPS 1991; National Inquiry into the Separation of Aboriginal and Torres Strait Islander Children from their Families Bringing Them Home (Sir Ronald Wilson President) Sydney Human Rights and Equal Opportunity Commission 1997 
5 L Anemaat 'Documenting Aboriginal History' The Information Environment — Towards 2000 Proceedings of the 8th National Convention Darwin September 1991 Records Management Association of Australia 1991 p184.

$6 \quad$ Ibid $\mathrm{p} 185$

7 Department for Administrative and Information Services State Records 'A Little Flour and a Few Blankets': An Administrative History of Aboriginal Affairs in South Australia 1834-2000 Gepps Cross State Records of South Australia 2002

8 Department for Administrative and Information Services State Records Aboriginal Resource Kit: An Introduction to Primary Sources held by State Records Relating to Aboriginal People Gepps Cross State Records of South Australia 2002

9 Distant Voices: Using the Archives of State Records to unlock our Indigenous Past, video recording Department of Administrative Services and Information State Records of South Australia 2002 


\title{
Chapter 15
}

\section{Indigenous Knowledge and Archives}

\author{
Kirsten Thorpe ${ }^{1}$
}

I have been employed at State Records New South Wales, based at the Sydney Records Centre, The Rocks, for six years. I began work as a cadet Aboriginal Archivist in early 1999 and as part of the cadetship undertook external studies to obtain a Postgraduate Diploma in Science (Archives and Records), Edith Cowan University, Perth. At the time, there were Aboriginal people working in archives and libraries but there were not many who had completed the relevant professional qualifications.

The cadetship was created by New South Wales State Records in December 1998 in collaboration with the Australian Library and Information Association (ALIA), the then Department of Employment, Education, Training and Youth Affairs (DEETYA) and the Australian Society of Archivists (ASA), and aimed to increase the number of Indigenous people working in the library/archives sector. The position was created largely as a response to the release of the Bringing Them Home Report ${ }^{1}$ as awareness developed in the archival profession of the need for more Indigenous people to enter it.

In this chapter, I outline the key outcomes for NSW State Records of this cadetship, including the ongoing and proposed activities to address Indigenous issues in State Records. I then outline the nationally focussed activities of the Indigenous Issues Special Interest Group (IISIG) of the Australian Society for Archivists. I conclude by setting out what I consider to be the key future issues that the profession has to engage with to meet Indigenous people's needs in archives.

\section{Key Outcomes of the Aboriginal Archivist Cadetship}

\section{Archivist-Aboriginal Liaison Position}

The initial outcome of the cadetship has been the creation of a permanent position of Archivist-Aboriginal Liaison at State Records. The primary role of the position has been to liaise in the development and provision of services for Indigenous people seeking access to the state's archives. The position covers those areas of activities that impact on Indigenous people and records and does appear overwhelming for one person. The core responsibility of the Archivist-Aboriginal Liaison is to establish open and trusting relationships with Aboriginal communities that reflect an understanding of cultural issues. More detailed responsibilities include:

\footnotetext{
${ }^{1}$ Kirsten Thorpe is Archivist-Aboriginal Liaison, State Records, Sydney, New South Wales.
} 
- providing assistance to Indigenous people visiting the reading room or making enquiries to State Records, including providing advice on records closed to public access, especially sensitive records of the Aborigines Welfare Board

- undertaking consultation with Aboriginal communities on an ongoing basis to identify services that best meet the needs of the community

- liaising with public offices and other external organisations to facilitate access to records relating to Indigenous people to ensure they are handling these materials appropriately

- promoting State Records and its holdings to Aboriginal communities

- developing extension activities for Indigenous people-seminars, workshops, talks, and tours and information sessions, and

- contributing to publications, exhibitions and displays.

The most important priority in Indigenous archives services at this point in time is providing assistance to clients to access records of the former Aborigines Welfare Board held at NSW State Archives and working in partnership with the NSW Department of Aboriginal Affairs to assist access for clients to closed records. The creation of the role of Archivist-Aboriginal Liaison enabled a number of subsequent initiatives to be developed to support and improve these services.

\section{Indigenous Consultancy Project 2001}

When the role was first established, it was immediately apparent that there was no clear view of what Aboriginal people or communities wanted from State Records. To establish this, in 2001 we undertook a project to consult with Aboriginal communities throughout NSW to identify services which could best meet the needs of Indigenous people.

The consultation involved visits to communities with meetings held in Sydney, Newcastle, Wollongong, Inverell, Dubbo and Broken Hill. A survey was also distributed and made available on the website to assess our current products and services. The meetings provided an opportunity for State Records to make contact with Aboriginal communities and discuss what kinds of improvements could be made in the future. Some of these meetings developed into seminars and information sessions about State Records as we found that many Aboriginal people did not know what we held, what we did, or what services we provided.

As a result of this consultation, a number of strategies were identified. These strategies represented, in my mind, a vision, a 'grand plan' through which to improve services for Indigenous people. However, their implementation depends on resources so implementation requires planning for the short and long term.

Strategies identified included:

- A whole-of-organisation approach to providing products and services to Indigenous people. Key points include the establishment of Indigenous protocols for staff use, the establishment of Indigenous advisory committees, Indigenous representation on all established committees at State Records, and cross-cultural training for staff. 
- Employment and training of Indigenous people. The goal is to develop an Indigenous employment strategy to improve the employment of Indigenous people in archives. We have also promoted a volunteers program and currently have one volunteer who not only makes a substantial contribution but had increased her skills and education also. We also encourage youth to come to us for work experience as a way to raise awareness of archives and the profession.

- Community awareness, raising State Records profile in Indigenous communities. This includes creating tools such as information kits and brochures to promote and develop awareness of archive services.

- Creation of resources that improve access to records for Indigenous people. We aim to produce guides to records and other publications that will suit Aboriginal people and assist them to locate what they need. The guides that we have are mainly for archivists and are not easy to use. An Indigenous section on our website is currently being developed to assist entry and access to records. As well, we plan an exhibition program at State Records to highlight Indigenous records.

- Outreach work to increase contact with Indigenous people in regional and rural areas. There are two aspects to outreach activity. The first is making copies, where possible, of relevant Indigenous records for our regional repositories at Broken Hill, Wagga Wagga, Newcastle, Armidale and Wollongong to improve local access. The second is undertaking at least one annual extension activity beyond the metropolitan area by going to regional centres or communities in response to identified local needs.

- Creating partnerships and building on-going relationships. This refers to our interactions with public sector agencies, Indigenous organisations and professional associations.

These strategies have been incorporated into an Indigenous services action plan, which supports short and long-term planning of Indigenous services at State Records.

\section{Corporate Goal with Focus on Indigenous Services}

An important outcome of the consultation report is that State Records NSW has acknowledged the importance of Indigenous service as a corporate goal. The Key Result Area: Services and Guidance, includes a statement on Indigenous services (6. Improve services for Aboriginal people by implementing the strategies identified in the 2001 Indigenous Consultancy Project). The implication of this is that we are required to report against the statement and this helps to maintain the focus. Even in a constrained funding environment, we hope progressively to achieve something each year.

\section{Indigenous Protocols for State Records}

Currently in second draft form, the Indigenous Protocols for State Records are intended to assist and guide State Records on best practice in interacting with Indigenous people and in handling state archives with Indigenous content. They ensure products and services are delivered in a respectful and culturally appropriate 
manner. The protocols are dynamic and subject to review. As necessary, they will incorporate change and address new issues.

The document is divided into three sections: principles, protocols, and guidelines. The guidelines are being designed as a working tool for staff and set out what their responsibilities are when working with cultural materials. Projects that alerted us to the importance of protocols were the digitisation of the Myall Creek massacre depositions and the Threkheld Journals.

These protocols are consistent with the Aboriginal and Torres Strait Islander Library and Information Resource Network (ATSILIRN) Aboriginal and Torres Strait Islander Protocols for Libraries, Archives and Information Services. ${ }^{2}$

\section{Exhibition on Photographs of the Aborigines Welfare Board}

Work has also begun on the development of a new exhibition in the State Records Gallery for 2005, based on 1000 personal and official photographs held in the files of the former Aborigines Welfare Board (AWB). The photographs taken between 1924 and 1961 are a key resource for Aboriginal people affected by state policies and those who are researching their family and community history.

Susan Charlton, Creative Producer, State Records and I will develop the exhibition along with the guidance of an Indigenous Advisory Group and wider consultative network. Consultation is the key to the entire exhibition process, which depends on the consent, advice and support of the Department of Aboriginal Affairs and the wider Indigenous community.

The exhibition will address the photographs as living records, which have both compelling histories and powerful connections to the present. The development team proposes to move beyond the anonymity of the board's photographic record to honour individuals and communities with personal histories, before and after the Board's intervention in their lives. We hope to identify people in the photographs, add their names and where possible the stories attached to them.

\section{The Role of the Indigenous Issues Special Interest Group}

In May 1996, the Australian Society of Archivists adopted a Policy Statement relating to Archival Services and Aboriginal and Torres Strait Islander Peoples. The statement recognised that archives have the opportunity and responsibility to assist Aboriginal and Torres Strait Islander people to make maximum use of archival holdings and services and to facilitate Aboriginal access to records of their own cultural heritage and historical experience. ${ }^{3}$

The Indigenous Issues Special Interest Group (IISIG) was formed following the annual conference in Alice Springs in 1996. It holds regular meetings at the ASA annual conference. A newsletter is produced bi-annually to disseminate information about current initiatives and projects that are occurring with archives and Indigenous people around Australia. It is a vibrant network of professionals - both Indigenous and non-Indigenous - working in this field. The current IISIG Executive Committee includes Convenor Loris Williams, Secretary Anne Wright and Newsletter Editor Emma Toon.

The Australian Society of Archivists has provided financial support to the Indigenous Issues SIG to create a brochure to attract more Indigenous people to the archives and 
records management profession. The brochure, which was launched at the group's annual general meeting in 2004, will be an important information tool to provide to Aboriginal people who may be interested in a career working in archives.

As well, the Indigenous Issues Special Interest Group has provided input into archives and records education stakeholders, presenting a paper at the Melbourne 2003 forum on Indigenous issues for archive professional preparation courses. The IISIG hopes to include working with educational institutions as part of its role.

\section{Future Issues for Archives}

To conclude, I believe there are three key areas which need to be explored further in relation to issues in archives: employment, education and resource issues.

The profession needs to continue to be active in creating employment opportunities for Indigenous people in record-holding institutions throughout Australia. There needs to more of us assisting Indigenous people and improving access to records. Indigenous people also need to be in leadership roles and occupy decision-making positions.

Education to increase awareness of Aboriginal history and culture within the archives profession needs to improve. This includes increasing the Indigenous content and perspectives in archives training courses so that future archivists are aware of their responsibilities when dealing with Indigenous cultural materials held in archives. When I began my study, there was not one article included that related to Indigenous issues.

Increasing awareness of Indigenous issues also involves creating meaningful partnerships with communities and taking appropriate care of cultural material in relation to access and storage, as well as working towards the return of cultural material to the communities to which they belong.

Finally, most plans to improve services for Indigenous people rest on the provision of adequate resources to achieve goals. Funding support needs to be increased. As well, the future will demand Indigenous communities keep and store good records and support for such activity will also be required.

\section{Notes}

1 National Inquiry into the Separation of Aboriginal and Torres Strait Islander Children from their Families Bringing Them Home (Sir Ronald Wilson President) Sydney Human Rights and Equal Opportunity Commission 1997

2 A Byrne A Garwood H Moorcroft and A Barnes Aboriginal and Torres Strait Islander Protocols for Libraries, Archives and Information Services Canberra ALIA Press 1995

3 Australian Society of Archivists Policy Statement on Archival Services and Aboriginal and Torres Strait Islander People 1996, at

http://www.archivists.org.au/pubs/positionpapers/atsi.html 


\title{
Chapter 16
}

\section{Libraries, Indigenous Australians and a Developing Protocols Strategy for the Library and Information Sector}

\author{
Martin Nakata, Alex Byrne, Vicky Nakata and Gabrielle Gardiner ${ }^{*}$
}

The Aboriginal and Torres Strait Islander Protocols for Libraries, Archives and Information Services (hereafter the Protocols) were published in $1995^{1}$ in conjunction with the Aboriginal and Torres Strait Islander Library and Information Resource Network (ATSILIRN), the association for professionals who work in Indigenous library, archive and information services. In 2004, researchers from the University of Technology, Sydney, Library and Jumbunna Indigenous House of Learning surveyed and interviewed professionals from organisations across Australia with a view to using the data to assist in a revision and updated version of the Protocols. ${ }^{2}$ This chapter describes and discusses this research and its implications for firstly, a revision of the Protocols, and secondly, for the reinvigoration of a cross-sector strategy to carry Indigenous information issues progressively forward and more widely across the library and information sector (LIS).

The 1995 Protocols were a key outcome of both Indigenous and professional concern about the state of Indigenous relationships with libraries, archives and information services. In Australia, these relationships became a point of professional focus throughout the 1990s.

The concerns of Indigenous people ${ }^{3}$ had been on the record for some time ${ }^{4}$ and they were amplified in the 1990s as the profession accelerated its activity in response. In brief, Indigenous concerns included issues such as: historical exclusion from libraries; the offensive nature of much of the material about Indigenous people in library collections and archives; subject headings that described Indigenous peoples and cultures in ways that had little to do with how Indigenous peoples described themselves, and which demeaned Indigenous peoples and cultures; access issues for Indigenous peoples and materials; and general Indigenous service issues. ${ }^{5}$

\footnotetext{
* Dr Martin Nakata is Chair of Australian Indigenous Education, and Director of Jumbunna Indigenous House of Learning, University of Technology Sydney.

Dr Alex Byrne is Pro-Vice Chancellor (Teaching \& Learning) and Vice-President (Alumni \& Development) at the University of Technology Sydney, and President of IFLA.

Vicky Nakata is Research Assistant at Jumbunna Indigenous House of Learning, University of Technology Sydney.

Gabrielle Gardiner is Research and Policy Officer at UTS Library, University of Technology Sydney.
} 
A number of LIS professionals contributed to professional scholarship on some of these issues. ${ }^{6}$ However, professional activity was also stimulated by or occurred in conjunction with other events. These included:

- recommendation no 53 of the Royal Commission into Aboriginal Deaths in Custody in $1991^{7}$

- the establishment, also in 1991, of the Council for Aboriginal Reconciliation to promote a process of reconciliation between Indigenous Australians and the wider Australian community ${ }^{8}$

- resolutions addressing the documentary heritage of Indigenous people that emerged from the National Library of Australia project, 'Towards Federation 2001: Linking Australians and their heritage', which commenced in $1992^{9}$

- the 1995 National Library of Australia's Biennial Round Table meetings on library and archive collections and services for Indigenous Australians $^{10}$

- the formation of the Aboriginal and Torres Strait Islander Library and Information Resource Network (ATSILIRN) ${ }^{11}$ and the Indigenous Issues Special Interest Group within the Australian Society of Archivists $(\mathrm{ASA})^{12}$

- the 1995 development by the Australian Library and Information Association (ALIA) of policy for Aboriginal and Torres Strait Islander peoples and services, ${ }^{13}$ the Aboriginal and Torres Strait Islander Recruitment and Career Development Strategy, and endorsement of the Protocols as the profession's guide to appropriate practice in the area, and

- recommendations (nos 21-29; nos 38-39) of the 1997 Bringing Them Home Report that further enforced the need for improved access to Indigenous records ${ }^{14}$ and the resultant funding of special projects at the National Library of Australia and the National Archives of Australia.

The focus that these events brought to the previously neglected area of Indigenous information issues provided the stimulus for a range of projects and activities across the sector, from national to local organisations, in archives and libraries, as well as other specialist collections such as museums. The Protocols were the primary guide available to assist individuals and organisations to establish appropriate practices.

\section{LIS Responses}

It is useful to draw attention to some examples of LIS activity gathered in the course of our research. These are but examples of shifts in LIS practice that have helped to constitute an information context more relevant to Indigenous Australian needs and interests; they do not represent a comprehensive account of all innovations in practice.

A large part of practical activity has focussed on identifying and providing better access to Indigenous materials - historical and cultural - that are held in collections across the nation. The National Library of Australia, for example, produced Mura Gadi, an online annotated guide to information relating to Indigenous Australians within the library's manuscript collection, oral history collection and pictures 
collection. It described, annotated and indexed previously unidentified Indigenous material within these collections, based on the Thesaurus, ${ }^{15}$ to facilitate better access.

The National Archives of Australia (NAA) likewise produced guides to Indigenous records, to make them more accessible to Indigenous peoples. One guide, to give an example, is a name index that lists the names of Indigenous peoples identified in the records. The issues associated with setting conditions of access centre on facilitating Indigenous access to records that normally would not be open and conversely restricting sensitive records of a personal nature that might be open to access by others. Identifying material and setting access conditions for records is a major part of building guides and indexes for Indigenous records and requires extensive consultations with the appropriate Indigenous peoples and negotiations with the owners of records. The NAA has also developed memoranda of understanding (MOUs) with organisations in the states of Victoria, South Australia and the Northern Territory, to assist people in these states to access their records.

The Australian Institute of Aboriginal and Torres Strait Islander Studies (AIATSIS), which houses the largest collection of Australian Indigenous studies research materials in the world, has developed appropriate processes for handling and assisting Indigenous and researchers' access to these materials. Whilst these processes are continually being refined, many precede the 1990s. For example, what is now the Aboriginal Family History Unit, established as a recommendation of the Bringing Them Home Report in 1997, was preceded by the Aboriginal Biographical Index, which has been indexing Aboriginal and Torres Strait names in its collection since 1979 (now in excess of 50,000 entries).

AIATSIS leads on many issues and is a reference source for other institutions; the Protocols confirmed rather than guided their practice. As an organisation whose entire collection is devoted to Aboriginal and Torres Strait Islander peoples, cultures and languages, AIATSIS' LIS focus has been on managing access issues in regard to sensitive materials in an increasingly complex legal and ethical environment as knowledge ownership and rights to access over research material gathered from Indigenous people become more contested issues. For example, deposit forms have been developed to deal with access issues on incoming material, and processes exist for clearing material for digitisation or uplift onto the web. In consultation with the appropriate Indigenous peoples, ways for dealing with sensitive materials range from identification of and processes for access/restriction on secret/sacred knowledge, include warnings and disclaimers for offensive historical material and for deceased people, or blacking out content or captions, and establishing conditions of use.

Examples of activities in state libraries include the State Library of New South Wales' InfoKoori, which is a web based index to the Koori Mail (1991+), a national fortnightly newspaper for Aboriginal and Torres Strait Islander peoples. This index also includes biographical information on Aboriginal and Torres Strait Islander peoples from the magazines Our Aim (1907-1961), Dawn (1952-1969), New Dawn (1970-1975) and Identity (1971-1982). As well, Indigenous librarians assist in the provision of access to Indigenous materials held in collections.

The State Library of Queensland appointed its first Indigenous Board Member in 1994 and since has established an Indigenous Services Section, providing guides to resources in its collections and assistance to Indigenous peoples. Initiatives have 
included family history services and the development of protocols and procedures for access, reproduction, digitisation and repatriation of materials in a way that takes into account the intellectual, moral and cultural rights of Indigenous peoples as owners of their knowledge and custodians of their heritage. As well, it has established nine of a proposed 31 Indigenous Knowledge Centres in areas across the state, which previously have not had libraries, using a flexible model that provides the means for free access to library services supplemented by resources to deal with traditional knowledge and materials. Essential aspects include: the community determining their needs and ways to collect, store, retrieve, utilise and control their knowledge; and the recruitment of local staff who are involved in both the planning and implementation of the centres.

A similar concept (Libraries and Knowledge Centres) has also been explored and implemented by the Northern Territory Library and Information Service (NTLIS) as a way to improve services to Indigenous communities. Using a flexible and sustainable model, which includes traditional library concepts and Indigenous knowledge concepts, the community decides on the mix of components that suit their needs and NTLIS provides the necessary support for implementation and sustainability. The LKC model includes a digital database component included for documentation of and community access to local Indigenous knowledge.

State records offices have also produced guides or provided better access to their records for Indigenous peoples. For example, during this period the South Australian State Records Aboriginal Access Team initiated an (ongoing) Aboriginal Name Index project which to date contains 70,000 entries listing the names of Aboriginal people and related information about them. As well, a number of guides list various government administrative records of interest to Indigenous Australians. Another example is NSW State Records which in 1997 (following the tabling of the Bringing Them Home Report) established first a cadetship and then a permanent position of Aboriginal Liaison Archivist to develop and assist the provision of services for Indigenous Australians. In Queensland, the Department of Aboriginal and Torres Strait Islander Policy employs an Indigenous archivist to facilitate Indigenous access to their records held by Queensland State Archives. Central to these strategies is the employment of Indigenous professionals. Indigenous professionals have the advantage of already having extensive relationships in their communities which help establish trust and which also help in the identification of relevant records. Other states and territories have also responded in similar ways.

Other special collections exist in university libraries and sometimes in local history collections in public libraries and there is evidence of growing awareness of the importance of some of these to particular Indigenous groups and communities and the need to facilitate access to them. In universities, attention also focuses on collection development as the Indigenous studies field and specialist degrees or strands in health, education, law, social sciences and the arts demand materials with a focus on the relevant Indigenous issues and scholarship. In some public libraries, collections also grow in line with increasing interest in Indigenous issues from non-Indigenous Australians, Indigenous use of libraries, and increasing Indigenous authorship of publications.

A range of strategies is being used in university and public libraries to develop access, though our research can only conclude that practice is patchy rather than standard. 
Guides to Indigenous collections exist in some university libraries, as do liaison librarians for Indigenous Studies and/or Indigenous students in some places. Some libraries have developed special meeting or study areas for Indigenous students or provide targeted orientation programs.

Some public libraries identify Aboriginal and Torres Strait Islander materials with flag stickers; others shelve their Indigenous material as a separate collection to assist access for Indigenous users. Other public libraries employ outreach strategies to build pathways for Indigenous clients into the library, for example, story telling sessions, visits by Aboriginal identities (e.g. Palmerston, NT), sessions to involve the community in book selection (e.g. Marrickville, NSW), multiple-strategy projects such as the Cool-In-Lib project (Cooloola, Qld), ${ }^{16}$ and establishing Indigenous liaison positions or projects to encourage documentation of local Indigenous history and Indigenous use of the library (e.g. Moree, NSW).

Although our research elicited very few responses from schools, proportionate to their numbers, there was evidence of the issues permeating this level, particularly in areas that service Indigenous students and/or where there is a high level of awareness of Indigenous issues, such as the Northern Territory and parts of Queensland. There was evidence of culling of outdated or inappropriate materials and collection building to enhance relevant curriculum areas and general reading. Once again, separate shelving or identification of Indigenous materials by stickers was used in some cases and, in Queensland, specialist libraries existed within the four Aboriginal and Torres Strait Islander Learning and Engagement Centres to assist teachers' access to Indigenous resources. In the Northern Territory, issues of sensitivity, awareness of the need for proper attribution and acknowledgement of Indigenous-owned knowledge, and consultation with Indigenous staff were largely standard practice in the schools we visited, even where a school was unaware of the existence of the Protocols. This sector of LIS activity arguably intersects more with the Indigenous education sector and the Aboriginal Studies Association, which has done much to promote Aboriginal Studies curriculum and resource issues in the schooling sector.

\section{Effectiveness of Protocols}

We turn now to describe professional comment on the Protocols as a strategy to address Indigenous information issues and guide practice. The aim of our research was to assess how useful the Protocols were as a strategy to address Indigenous information issues, to identify emerging issues that should be included in a revised version, and to gather views from the profession on how the document could be improved to assist practice more effectively. ${ }^{17}$

Over 220 organisations responded to the survey and/or were interviewed. Very few organisations ( $8 \%$ ) had formally adopted the Protocols, only $21 \%$ had used them at some time to guide policy development, and just over a third (34\%) had used them in some way. Some of those who had not used them had not seen them or did not know of their existence. Of those who had used them $84 \%$ indicated that they were useful or very useful with $7 \%$ indicating they were informative and $1 \%$ useless. The sections of the Protocols considered to be the most relevant were: content and perspectives; accessibility and use; subject headings/classification of materials; offensive materials; and awareness of Aboriginal and Torres Strait Islander people and issues. The least relevant were considered to be: governance and management; staffing; copying and 
repatriation. Further probing indicated that this was generally because these are the hardest areas to implement.

Responses from both the survey and interviews indicated a general consensus that the Protocols provide a very useful starting point for addressing Indigenous issues in libraries and archives - a first and general reference. They are useful for raising awareness and were used by some in induction of new staff. They also provide an external authority for professionals and organisations that want to respond to the issues or submit for special grants.

However, the diversity of the LIS sector means that different organisations have different charters or priorities, serve different communities of clients, and have varying levels of understanding and intersection with Indigenous peoples, communities, history and issues. The diversity of the Indigenous community means that Indigenous information needs and interests cannot be assumed, are not always easy to determine or provide, can be perceived to conflict with traditional notions of library/archive practice and service provision, and are not easily generalised across contexts.

In the light of this, strong consensus also emerged that although a useful starting point, the Protocols did not provide enough depth or breadth of information to assist many organisations to apply them. The need for supporting information was not only expressed by organisations that hold significant collections of Indigenous materials that might require identification and determinations to set appropriate access conditions or those that delivered services in areas with significant Indigenous populations. It was also expressed by organisations that did not have a strong Indigenous focus either in their collections or in the community they serviced. Both groups of organisations articulated the need for information to support implementation of the principles most relevant to their needs.

So, for example, some of the former category expressed a need for quicker referral assistance or guidance on how to proceed on case-by-case issues, or more substantive information on Indigenous intellectual property issues, or strategies to promote their collections to communities, or strategies to encourage Indigenous use of their library, and so forth. The latter category more often sought more focussed information such as reduced and more practical sets of guidelines dealing only with the aspects of the Protocols that applied to their context and/or explanations of how and why aspects of the Protocols related to their professional practice.

But in both cases, it was evident that organisations were looking for quicker access to information that would save them time in determining 'what' to do and 'how' to do it. Many comments were directed towards this end and a range of suggestions provided on the types and ways to organise supporting information for these varied needs.

As well, many suggestions were offered about modes for presentation, dissemination and sharing of this information. In discussions about improving the presentation of the Protocols all respondents agreed that a website that could link to layers of supporting information for a range of diverse organisational needs would be an effective model for dissemination. Suggestions of types of information included: practical information to assist the implementation of the eleven principles of the Protocols; practical and more focussed sector-specific information directed at schools, public libraries, universities, etc; and more scholarly information on the underlying issues, for 
example, intellectual property. A range of formats for practical information was suggested: case studies and examples of practice from similar organisations, fact sheets, common question and answer sheets, discussion lists, contact lists, lists of new Indigenous publications, lists of relevant Indigenous people/organisations, and templates for warnings for sensitive materials. For more scholarly information, links to useful resources such as selected articles and relevant websites were suggested.

However, a website was not thought to be sufficient or the only way to disseminate the Protocols and relevant supporting information. Some argued for the retention of a printed version and the production of printed supplementary material. Others argued for telephone referral services.

The above suggestions all point to ways to provide professionals and organisations with better access to relevant information to support the Protocols document.

\section{New Issues}

There was also consensus that the Protocols needed an additional section to guide digitisation and electronic access issues which had emerged in the decade since publication. The uplift of information to the WWW provides easier and wider access to Indigenous materials but at the same time it amplifies the risk of inappropriate access. Extreme care is required in relation to sensitive cultural and historical materials, copyright clearance, and consent issues; resolving such issues is often challenging and time-consuming. These concerns also related to the public display of materials in non-electronic form, for example, the use of photographs in exhibitions or promotional displays, brochures and leaflets.

The challenges associated with digitisation of materials for easier access are particularly complex when dealing with Indigenous knowledge. Since the early 1990s, Indigenous knowledge systems - what professionals generally refer to as cultural material - have become increasingly recognised globally as legitimate and valuable systems of knowledge, with their own associated systems for management and with their own inherent intellectual property rights. ${ }^{18}$ In Australia, historical collections contain significant amounts of traditional cultural knowledge and significant amounts of information that can assist Indigenous people to recover, reclaim and establish continuity with former knowledge traditions. The historical destruction and ongoing intergenerational loss of this knowledge has increased the urgency to document it in order to preserve it and, as well, to protect it as a valuable source of cultural and knowledge capital with potential for future utility and innovation. ${ }^{19}$ This documentation is occurring through the digital retrieval of material held in historical collections and in local documentation projects in a number of sites and fields, including scientific, academic and legal research.

Indigenous peoples are questioning and contesting ownership and access issues with respect to material that documents their lives but is legally owned by others, including those materials produced in contemporary research in Indigenous communities. The recognition of Indigenous concepts of intellectual and cultural property rights has brought increased complexity to the area of Intellectual Property. Protocols are therefore critically important in the absence of satisfactory legal mechanisms to resolve these issues and manage these rights. ${ }^{20}$ The LIS sector increasingly intersects with these complex issues but cannot resolve them without following protocols and 
working collaboratively with Indigenous peoples. The Gupapuynu Legacy Project at the Galiwin'ku Knowledge Centre in the Northern Territory provides a good example of this complexity and the importance of a mutually respectful engagement between communities and collecting institutions. ${ }^{21}$ However, these issues are not relevant to remote areas of service only. Our research confirmed that wherever materials are located that contain evidence of traditional Indigenous peoples' knowledge, cultures, and history, professionals are increasingly required to engage with Indigenous peoples, families, clans and communities to resolve similar complex issues and tensions. Some professionals venture that reaching high and consistent standards of practice in this area will be a major future challenge to the sector.

In addition to guidelines for digital and electronic issues, some organisations suggested the need for guidelines for interaction with Indigenous clients and others for guidelines for approaching and consulting with Indigenous communities. There was no consensus on these as either necessary or as additions to the Protocols, with some emphasising very strongly that there should not be any general characterisation of communication styles of Indigenous clients as a group. However, some who disagreed with their addition to the Protocols did acknowledge that supporting information about some of the issues to be cognisant of might be helpful to those who are unfamiliar with interacting with Indigenous peoples. One Indigenous professional emphasised that it did not automatically occur to some professionals that five minutes of helpful and friendly attention to an Indigenous client could be the difference between that person using a library or archive for a lifetime or not ever entering one again. The quality of interaction is obviously important but what is implicitly understood as appropriate practice by some professionals sometimes needs to be made explicit to others. Whilst these issues might not warrant a section in the Protocols, some guidance towards useful information might be indicated in any future website. Certainly these issues have a place within cultural awareness programs.

\section{Cross-Sector Co-operation}

Some of the arguments for more active dissemination of information related to concern that the Protocols would not be more widely implemented unless they were promoted more actively. Indigenous professionals, though they were not alone in this view, felt strongly that it was not enough to just 'present' the Protocols: there had to be outreach and face-to-face professional development in organisations to ensure that the underlying issues were understood and to assist interpretation of the principles into appropriate practice. Further, the Protocols were thought to need a home, 'a face', and perhaps a recognisable brand or logo that organisations using them could display to promote their further use. As well, the more traditional dissemination avenues, such as regular forums, conferences, seminars and special interest groups were also suggested as more active ways to share knowledge and practice, with many citing the early ATSILIRN conferences as useful.

In addition to this, it was further emphasised by those who remembered the activity and impetus generated when the Protocols were first distributed and who had observed it falling away over time, that broader and more effective promotion of the issues and implementation of some aspects of the Protocols across the LIS sector required the development or renewal of a concerted 'across the profession' strategy. 
This was argued particularly in relation to a number of issues addressed by the Protocols that often could not be dealt with satisfactorily by organisations acting in isolation. They included Indigenous employment issues, professional preparation and professional development about Indigenous information issues, the reinvigoration of mechanisms for sharing practice, and general concerns about the challenges that resource constraints, such as project-based or short-term funding, posed for the implementation of some aspects of the Protocols. These were areas that had proved to be particularly challenging to the sector but were highly implicated in ensuring the development of appropriate Indigenous LIS practice in the long term. Once again comments on the importance of these issues and frustration about the lack of progress on some of them, included a strong voice from Indigenous professionals. As well, Indigenous professionals were concerned that governance and management issues as outlined in the Protocols were still to be addressed by many organisations. This added to arguments that a sustained agenda and leadership at the national level was required to maintain the focus and devise more effective strategy to address these issues. This was especially in view of the fact that the ALIA Recruitment and Career Development Strategy had fallen away, that the national position on the extent of inclusion of Indigenous information issues into professional preparation programs was not clear, and that dissemination of the Protocols had faltered and lost its initial impetus.

Discussion about leadership, sustained agendas, and faltering dissemination of the Protocols, invariably led to discussion of the role of ATSILIRN. A range of respondents mentioned the importance of ATSILIRN's role, particularly the role that its annual conferences had played in maintaining a focus on Indigenous issues and the sharing of practice. Regret was expressed that it had recently been less active in the area and comments made by a range of professionals and organisations that it needed reinvigoration.

However, a number of professionals suggested that reinvigoration of Indigenous issues by the relevant professional associations may still not be sufficient and that other mechanisms are required. For example, although ATSILIRN has provided an authoritative reference point in the development of appropriate Indigenous LIS practices by bringing together professionals from across the sector to discuss, share and report on practice, it is not invested with any authority for devising strategy or overseeing the implementation of appropriate practice. ALIA, which was also initially active in the area of professional policy and employment, has also had difficulty in maintaining the necessary focus and momentum.

These observations and concerns were closely aligned to suggestions by a number of professionals that the Protocols required more teeth to encourage compliance but how this could be achieved was not clear. We would agree, as some professionals intimated, that in a professional sector characterised by goodwill, big sticks and playing on guilt are not just inappropriate and likely to be ineffective but should not be necessary. As in other contexts and organisations, implementing changes in practice can be driven by policy from the top, and the measurement of policy objectives can be built in through internal reporting mechanisms. As well, as in all professional contexts, change in practice is informed by the connections between intellectual inquiry, problem solving in practice, and professional and scholarly communication. As argued by more than one Indigenous professional, there is a lot of scope for these two ingredients for facilitating changes to practice to be brought 
together more effectively. That is, change needs to driven from two directions: systemically through governance and policy mechanisms; and via problem solving and scholarship developed in the course of practice. In addition to this we would add the need for a mechanism to measure progress in the area on a sector-wide basis, because Indigenous information issues although a relatively small proportion of LIS activity are well dispersed across the country and sectors.

We turn therefore to the role that could be played by other peak bodies in concert with professional associations and their memberships to identify a way forward that requires only minimal augmentation and refinement to present arrangements.

\section{Future Possibilities}

All peak LIS organisations have a legislative mandate to preserve the documentary heritage of the nation and to provide LIS services for all Australians. In an inclusive society such as ours, this heritage and these services incorporate documented Indigenous heritage and services for Indigenous Australians. Whilst the issues surrounding the documentary heritage of Indigenous Australia and the provision of relevant services are complex, distinct, and now require a hitherto unprecedented intersection with the management principles of quite different traditional Indigenous knowledge systems, this should not relegate Indigenous LIS issues to the margins. Rather, we would argue, Indigenous heritage can and should be seen at the core of what is accepted as Australian heritage and the provision of relevant and current services for Indigenous peoples as part of 'core business' for the LIS sector.

Indigenous heritage is used over and over in the promotion of Australia to the world. It is valuable, complex, helps to define the modern nation, and is a source of future utility and potential benefits for Indigenous peoples and all Australians. It needs to take its place and be treated with respect and with deference to the tradition from which it originates. Without this, its preservation and intersection in LIS systems is a meaningless exercise to Indigenous peoples. To relegate this heritage (and services) to the peripheries is to be complicit in keeping Indigenous peoples themselves at the peripheries of national life and the national story and to constrain their possible futures.

Three things can be argued as important in any approach to fulfil mandates in respect of Indigenous heritage and service provision. Strategies developed by the sector need to have: legitimacy with the Indigenous community; relevance to Indigenous interests; and currency in terms of Indigenous needs and issues (that is, they need to keep abreast of changes and developments in Indigenous thought, priorities, and realities). Unlike past inclusive agendas and patronage of Indigenous peoples in the decisionmaking process, which have largely rested on goodwill, the task of pushing forward on Indigenous LIS services that have legitimacy, relevance and currency with the Indigenous community requires a more clearly defined agenda, including a more coordinated plan that can function effectively across the sector. In recognition of this, the Council of Australian State Libraries (CASL) has taken steps toward a national policy framework for the development of Indigenous library services. Indigenous LIS policy developed at the national level, and which satisfies these criteria, can be filtered down into local policies that sit within and across organisations alongside other policies. Progress can be measured internally by organisations according to their own processes. 
At the professional level ATSILIRN can regenerate its function in terms of what it is good at - bringing professionals together from across the sector to discuss practice and contribute to developing scholarship in the area, which circulates amongst practitioners and feeds into the education institutions that service the LIS sector. If CASL and the other relevant peak bodies were to provide appropriate support to ATSILIRN to continue this engagement with changing practice, they would also achieve an effective means to gather information from the profession about performance and progress toward Indigenous policy objectives should they wish to gather evidence for quality assurance or other purposes.

In all this, the Protocols remain at centre of play. The Protocols guide and provide a measure of external authority for appropriate practice. They can continue to be 'owned' by ATSILIRN but with sufficient support for ATSILIRN to maintain them as a dynamic and more useful document with currency in regard to the shifting and developing Indigenous information context. Through this, and through support for the governance and management principles of the Protocols, the peak bodies gain legitimacy in the area of Indigenous LIS policy development and through their systemic processes help to drive policy through to local levels. Currency depends on dialogue with Indigenous peoples and professionals and the sharing of practice across the profession in a way that also feeds into the ongoing scholarship and educational programs; this helps to ensure high standards of practice at local levels. It also encourages the development of practice in local contexts as well as the means to push more systemic reform and progress on the issues across the whole sector. Legitimacy, relevance and currency at all levels rest on the involvement of Indigenous peoples. In this sense the employment and inclusion of Aboriginal and Torres Strait Islander peoples at all levels is not just about adequate representation but also fundamentally about Indigenous input into the development of appropriate practice and relevant services. Without this involvement, legitimacy, relevance and currency will be impossible to achieve.

\section{Conclusion}

In sum, it must be acknowledged that in places there is still no clear priority for Indigenous information issues or uptake of the Protocols. As well, any conclusions about the effectiveness of the Protocols as a strategy to address Indigenous information issues must be prefaced by evidence that a proportion of respondents had not seen the Protocols and that more active promotion and dissemination of the issues is required in the first instance if they are to be more widely implemented across the sector. Despite this, it was clear that the uptake of Indigenous information issues across the sector, which had occurred over the decade, was indicative of enormous goodwill and interest and a desire by the profession to do the right thing.

After little more than a decade of attention to the Indigenous LIS intersection there is evidence of an emerging area of distinct practice and a dynamic and changing Indigenous information context. This is evident across a range of aspects of LIS and archive practice but is nowhere clearer than in the complex intersections between Indigenous knowledge and LIS systems of knowledge and information management. Indigenous traditional, cultural and historical materials, including contemporary forms of production and documentation, are a significant part of the documentary heritage of the nation, which the LIS sector is mandated to preserve. Increasingly, the Indigenous 
LIS intersection is not simply a site for liberal intervention in the interests of equality or inclusion but a site for recognition of and, to some extent, reconciliation of different traditions. Effective Protocols are one central element to guide practice in this area. Another is the development of more effective mechanisms to ensure Indigenous information issues are driven more systemically and with less dependence on goodwill. At the heart of the issues are Indigenous peoples, the preservation of their heritage, and the development of better futures. If Indigenous peoples are to invest in LIS services then the LIS sector must invest in Indigenous knowledge and peoples.

\section{Notes}

1 A Byrne A Garwood H Moorcroft and A Barnes Aboriginal and Torres Strait Islander Protocols for Libraries, Archives and Information Services ALIA Press Canberra 1995

2 This project was supported by a research grant from the Faculty of Humanities and Social Sciences, University of Technology, Sydney. We are particularly grateful to Professor Joyce Kirk and Dr Paul Ashton

3 We use the identifier Indigenous in this chapter interchangeably with the identifier Aboriginal and Torres Strait Islander peoples

$4 \quad$ M Wilson 'The Original Culture: Aborigines in Libraries? - The Aboriginal Viewpoint' in Libraries in a Multicultural Society, Papers presented at Special Study no16 Canberra 27-29 August 1979 as part of 20th Biennial Conference of the Library Association of Australia Public Libraries Division State Library of NSW 1979; G Yunupingu 'Misinformation and Aboriginal Culture' in A J Walker (ed) Lifestyles and Libraries, Proceedings of the 24th LAA Conference Darwin 1986 Library Association of Australia Sydney 1987 pp121-27; H Fourmile 'Who owns the Past? Aborigines as Captives of the Archives' Aboriginal History vol 13 no 11989 p3 $H$ Fourmile 'The Need for an Independent National Inquiry into State Collections of Aboriginal and Torres Strait Islander Cultural Heritage' Aboriginal Law Bulletin vol 2 no 561992 pp3-4; G Agius 'The Aboriginal and Islander Library Network Committee' in A Hazell (ed) Access and Equity: Challenges in Public Librarianship Blackwood SA Auslib Press 1992 pp162-172; M Langton 'Echoes of History: Archives and Library Collections: Our Heritage and Custodial Responsibility' Safekeeping Women's Business: Australian Indigenous Women and Museums National Conference Adelaide 7-9 March 1993 Canberra AGPS 1993; M Dodson 'Cultural Issues and Library Services' in M Maynard (ed) Infobridges: Linking Australia and Asia, Proceedings of the Second National Reference and Information Service Section Conference Darwin 9-11 July 1993 Darwin RAISS 1993 pp1-5; H Fourmile 'Aborigines as Captives of the Archives: A Prison Revisited' in Archives in the Tropics, Proceedings of the Australian Society of Archivists Conference Townsville 9-11 May 1994 O'Connor ACT Australian Society of Archivists 1994 pp117-121; A Garwood 'Indigenous Library Deeds' paper presented at He wake eke noa=Embarking together NZLIA-ALIA Joint Conference Wellington 1994; A Garwood 'Aboriginal and Torres Strait Islander Recruitment and Career Development Strategy for the Library and Information Sector' in Reading the Future Proceedings of the Biennial Conference of the Australian Library and Information Association Melbourne 6-11 October 1996 Canberra ALIA Press 1996 pp237-242; A Garwood 'Opening doors: the Aboriginal and Torres Strait Islander Library, Information and Resource Network (ATSILIRN) and its Role in the Library and Information Sector' in On the edge, Proceedings of the Seventh Asian Pacific Specials, Health and Law Librarians' Conference, Perth 12-17 October 1997 Australian Library and Information Association Special Libraries Section and Health Libraries Section Australian Law Librarians Group 1997 pp97-105

6 H Moorcroft 'Ethnocentrism in Subject Headings’ Australian Library Journal vol 41 no 11992 pp40-45; H Moorcroft 'The Construction of Silence' Australian Library Journal vol 42 no 1 1993 pp27-32; P Williams F Williams and H Moorcroft 'Providing Library Services for Aboriginal and Torres Strait Islander People' in M Maynard (ed) Infobridges: Linking Australia and Asia Proceedings of the Second National Reference and Information Service Section Conference Darwin 9-11 July 1993 Darwin RAISS 1993 pp76-84; H Moorcroft and A Byrne 
'Secret and Sacred: How should Libraries and Archives handle Aboriginal and Islander Information Resources? Limited Edition no 4 Dec 1994 pp3-8; H Moorcroft 'Reflections on Constructing an Aboriginal and Torres Strait Islander Thesaurus' Cataloguing Australia vol 20 no 41994 pp108-111; G Martin 'Possible Subject Headings for the Aboriginal Peoples of Australia' Cataloguing Australia vol 20 no 41994 pp95-107; H Moorcroft and A Byrne 'Intellectual Property and Indigenous Peoples' Information' Australian Academic \& Research Libraries vol 27 no 21996 pp87-94; H Moorcroft 'Libraries as Sites for Contested Knowledges: Collection Development in the Area of Aboriginal Studies' Collection Building vol 16 no 3 1997 pp108-13

7 Royal Commission into Aboriginal Deaths in Custody National Report Vol 5 (Elliot Johnston QC Commissioner) Canberra AGPS 1991 p81

8 Reconciliation Australia 2004 The History of Reconciliation Canberra Reconciliation Australia, at http://www.reconciliationaustralia.org/aboutus/whatis.html

9 National Library of Australia 'Towards Federation 2001: Linking Australians and Their Heritage' A National Conference on Access to Australia's Recorded Documentary Heritage 2326 March 1992 working papers Canberra National Library of Australia 1992

10 National Library of Australia 1995-2004 'The Aboriginal Thesaurus' First Roundtable on Library and Archives Collections and Services of Relevance to Aboriginal and Torres Strait Islander People State Library of South Australia Adelaide May 41995 Canberra NLA, at http://www.nla.gov.au/niac/libs/thesaurus.html; M Giles 'Library of Congress Subject Headings (LCSH) for Aboriginal and Torres Strait Islander People' First Roundtable on Library and Archives Collections and Services of Relevance to Aboriginal and Torres Strait Islander People State Library of South Australia Adelaide May 41995 Canberra NLA, at http://www.nla.gov.au/niac/libs/martin.html; A Byrne 'Responsibilities and Responses: Aboriginal and Torres Strait Islander Protocols for Libraries, Archives and Information Services' First Roundtable on Library and Archives Collections and Services of Relevance to Aboriginal and Torres Strait Islander People State Library of South Australia Adelaide May 4 1995 Canberra NLA, at http://www.nla.gov.au/niac/libs/byrne.html

11 T Lane-Hudson 'Providing Support and Education' InCite vol. 22 no 6, p17, at http://alia.org.au/publishing/incite/2001/06/atsilirn.html

12 Australian Society of Archivists Indigenous Issues Special Interest Group, Canberra, 2004, at http://www.archivists.org.au/structure.html\#indig

13 Australian Library and Information Association (ALIA) Library and Information Services and Aboriginal and Torres Strait Islander Peoples Canberra 1995, at http://alia.org.au/policies/aboriginal.html

14 National Inquiry into the Separation of Aboriginal and Torres Strait Islander Children from their Families Bringing Them Home (Sir Ronald Wilson President) Sydney Human Rights and Equal Opportunity Commission 1997

15 H Moorcroft and A Garwood The Aboriginal and Torres Strait Islander Thesaurus Canberra National Library of Australia 1997

16 See http://www.cooloola.qld.gov.au/documents/Indigenous\%20Collections\%20article.pdf

17 M Nakata A Byrne G Gardiner and V Nakata 'Mapping the Impact of the 1995 Aboriginal and Torres Strait Islander Protocols for Libraries, Archives and Information Services' unpublished report Sydney UTS 2005

18 T Janke Our Culture, Our Future: Report on Australian Indigenous Cultural and Intellectual Property Rights Surrey Hills Michael Frankel \& Co 1998; M Nakata 'Indigenous Knowledge and the Cultural Interface: Underlying Issues at the Intersections of Knowledge and Information Systems' IFLA Journal vol 28 no 5/6 pp281-91

19 Secretariat of the Convention on Biological Diversity Composite Report on the Status and Trends regarding the Knowledge, Innovations and Practices of Indigenous and Local Communities, Regional Report: Australia, Asia and the Middle East prepared by M Langton and Z Ma Rhea 2003, at http:/www.biodiv.org/doc/meetings/tk/wg8j-03/information/wg8j-03-inf04-en.pdf

20 T Janke ch 8 in this volume

21 J Neparrnga Gumbula ch 2 in this volume 


\title{
Afterword
}

\section{Indigenous Knowledge and Libraries}

\author{
Alex Byrne*
}

Indigenous peoples and those who create, manage and value libraries and archives share a commitment to the preservation and transmission of knowledge. This superficial generalisation belies many complexities of culture and context. But it is crucial and consequently bears repetition: Indigenous peoples and those who create, manage and value libraries and archives share a commitment to the preservation and transmission of knowledge.

As has been illustrated in this collection, notably by Joe Neparrna Gumbula in his enthralling and engaging exploration of the Gupapuyna legacy, knowledge is at the core of being for Indigenous peoples. It locates individuals precisely and inextricably in their communities and interrelates individuals and communities with their natural and spiritual environments. It is conveyed through language and culture as traditional knowledge which is privileged and required to be used appropriately by those authorised within the knowledge system. It has a coherence and orthodoxy which must be maintained to preserve its integrity and passed on to provide meaning for future generations. But it is not static or frozen, not 'carbon dated', it is alive and in responsive dialogue with vibrant cultural life.

For library, archives and information professionals, knowledge is the stuff in which we deal. We have a responsibility to curate it and ensure its transmission through good times and bad to those who may need or appreciate it in other periods and places. Our responsibility goes beyond the artefact-be it clay tablet, manuscript, codex, photograph or dataset - to preserve and make available the knowledge it carries. This is a deeply felt commitment which goes to the core of our being as professionals. It is a commitment which has emboldened many to protect collections and to promote the transmission of knowledge in the face of repression and sometimes acute personal danger. The commitment defines a professional identity which determines the attitudes and behaviours of information professionals. It guides our professional practice and the ways in which we respond to the duties of preservation and transmission of knowledge and the needs of our clients. It is expressed through our body of professional knowledge and demonstrated through our methods and skills. In the dominant professional modality, it derives its primary warrant from Article 19 of the Universal Declaration of Human Rights:

Everyone has the right to freedom of expression; this right includes freedom to hold opinions without interference and to seek, receive and impart information and ideas through any media and regardless of frontiers.

\footnotetext{
* Dr Alex Byrne is Pro-Vice Chancellor (Teaching \& Learning), Vice-President (Alumni \& Development) at the University of Technology Sydney, and President of IFLA.
} 
This commitment is in the tradition of the Enlightenment: it founds information practice on a principled defence of intellectual freedom which entails a rejection of privilege and knowledge control except in terms of maintaining integrity and authenticity. It holds that knowledge should be open to all and contestable because all have a right to both knowledge and opinions. Of information professionals, it demands an unbiased application of their skills to the preservation, transmission and provision of knowledge including that which the professionals may consider unacceptable. It is a non-judgemental stance which places the professional outside the knowledge as the facilitator of a system which aims to transmit knowledge without distortion to those who seek it. In doing this, the information professionals - when operating as professionals though not, of course, within their civil lives-suspend their own rights to express opinions on the knowledge except within the ambits of professional practice in favour of respecting the rights of their clients.

This is far from being a practice without values since it is based on firm principles including the key principles which recognise the universality of knowledge and the right of all to access it, Article 19's universal human right to know. In locating their practice on a warrant based in human rights, information professionals must also accept the other rights which demand respect for the dignity and autonomy of all. This follows from the explicit and implicit interdependence of human rights. They are interdependent both in their presentation through the Universal Declaration and other instruments and because to obtain one's right to know and to express opinions 'without interference' implies respecting the same rights for others.

This professional orthodoxy conflicts with the privilege inherent in Indigenous knowledge, its highly contextualised relevance and application, its conditional accessibility. In placing the curator outside the knowledge, the non-judgemental approach to professional transmission of knowledge claims to transmit without distortion and to present knowledge without commentary, leaving it to users to consider and debate. But, in spite of the worthy aims, the actualisation of that approach changes the way in which knowledge is seen. It is objectified, transmuted from identity with being to a 'resource' to be managed and made available. Further, in describing the records of knowledge, the materials held by libraries and archives, they are not only rendered manageable and accessible but the descriptive terminology applied to them itself becomes commentary. Those metadata place the materials and the knowledge they record in an ontological context which relocates the knowledge from its original embeddedness to a relatedness to other knowledge and other knowledge systems. Among other examples, these processes of objectification and description demonstrate the contradictions which arise when the practice and traditions of library, archive and information professionals seek to engage with other knowledge systems and especially Indigenous knowledge and Indigenous peoples. However well intentioned the engagement may be, the process unavoidably juxtaposes different knowledge systems. Their epistemologies challenge and sometimes contradict each other as their rules of access challenge and contradict as well. It is thereby impossible to transmit without changing-which raises serious difficulties but also exciting possibilities. Instances of both have been presented in this collection; their intellectual vigour and practical potentialities make them important subjects for professional concern, for interrogation and for attempting to develop mutually beneficial partnerships. 
In historical context, the development of modern libraries and their methods from the seventeenth century paralleled the expansion of European colonialism and the confrontations with Indigenous peoples that punctuated and permeated that process. ${ }^{1}$ In an intellectual sense, leaving aside the emerging nation-states' desires for geopolitical and economic dominance, both had similar philosophical roots in a shared desire for hegemony. For the colonial powers this was demonstrated through their extraordinarily successful attempt to subjugate, at least at a surface level, the entire habitable world both to their political control and to the hegemony of their languages, laws, religions and customs - to their knowledge systems. In asserting the dominance of their systems they denigrated both consciously and unconsciously the Indigenous knowledge systems and marginalised the Indigenous peoples with consequences felt to this day. For libraries, the hegemony was expressed in terms of universalism, of the encyclopaedic capture of all knowledge both through the construction of collections which aspired to Alexandrian comprehensiveness and via the development of avowedly holistic systems of classification and description. Because the processes of selection and evaluation applied to these tasks were based in Western cultural norms they incorporated Western cultural assumptions which are evident in their organisation and use of language.

As Martin Nakata and Marcia Langton note in the Introduction to this collection, these considerations go to the heart of the question. They challenge the practice of library, archives and information professionals. They take libraries beyond their project of inclusion expressed through such documents as the IFLA/Unesco Public Library Manifesto. ${ }^{2}$ They require both the practitioners and the institutions in which they work and which they shape to engage with different knowledge systems in a respectful dialogue which will advance the project of inclusion but will also improve professional practice by demanding a reconsideration of many tenets of the profession.

The issues presented in the Aboriginal and Torres Strait Islander Protocols for Libraries, Archives and Information Services ${ }^{3}$ extend across the spectrum of professional practice. They reflect and challenge the purposes for which the libraries, archives and information services have been established and the means by which they are administered. Far from rejecting the practices and principles of the fields, they celebrate their importance but challenge them to engage with the issues raised in the Protocols. In doing this, they recognise that the library and archives professions like law, as Geertz ${ }^{4}$ argued, are cultural systems. To accept this is not to reject the professions' modalities and attitudes by adopting a relativistic perspective but, rather, to recognise both their strengths and achievements and their need to be interrogated. Alana Garwood-Houng has explored this in her reflection on a decade's experience with the Protocols which emphasises the need for an ongoing program of promotion and dissemination of them but also challenges the institutions to take some initiative in engaging with the issues. As she notes, the review conducted by Martin Nakata et al, reported in this collection, confirmed that the compilation and publication of the Protocols did represent a useful strategy for raising and beginning to address issues relating to Indigenous peoples and libraries and archives but there was a major failure in implementation. The Protocols were inadequately promulgated and insufficient resources were devoted to their promotion, application and support. At least in regard to the situation in Australia, and perhaps in other countries, the Protocols remain valid with fairly minor revision and some necessary extension to address issues which have 
arisen during the last decade. But if they are to be effective, they need to be applied across the diversity of archival, library and information contexts. Achievement of this project demands willing supporters, an implementation plan, sufficient resources and sustained commitment from the institutions.

The necessary interrogation of professional norms must be conducted both in terms of the professions' own projects of preservation and access and by considering the dimensions of power inherent in these clashes of knowledge systems. In his paper, Arun Agrawal highlights the importance of exploring power, extending from his case of sedentarisation of shepherds in India to the articulating power and indigeneity. As he states, "we must attend more closely to the resources involved in any particular power exchange'. Archives and libraries in their role, along with museums, as the key memory institutions have considerable power. The resources they hold are vital to the processes of salvage but can also contribute to the processes to which Agrawal points 'through which Indigenous peoples gain a positive sense of their own indigeneity' and 'gain strategic victories'.

But it must be recognised, as the Protocols note, that unlike museums the resources that archives and libraries hold consist largely of depictions of Indigenous peoples rather than their own descriptions of themselves. These ethnographical studies, travellers' tales and official reports present Indigenous peoples through others' eyes and demonstrate the power of reportage. They are valued for their descriptions, particularly the more objective, but they are not neutral. Fictional accounts can also be valuable in exciting interest and some understanding but generally they romanticise, portraying Indigenous peoples as exotic and 'savage'-noble or otherwise. The novelist Ion Idriess, for example, introduced many readers to the peoples of Australia, the Torres Strait, New Guinea and elsewhere but his writings displayed the power to awaken interest but misled perhaps more than they informed. Even the works which purport to compile and present traditions without comment have almost always been compiled by writers and researchers from outside the Indigenous communities and knowledge systems. Deliberately or not, those reporters introduce their own perspectives by exercising the power implicit in recording, selection, editing and translation. Their work is nevertheless valuable, especially when they have recorded the languages and cultures of Indigenous peoples who have suffered severe cultural disruption or utter destruction, but it should not be accepted as authentic views of the peoples themselves.

Further, the application of archival, library and of course museological practices to the selection, description and presentation of the resources introduces another power dimension, the power exercised by professional authority which inserts a prism through which what is presented is perceived and understood. The very grouping of resources, their cataloguing and classification impose a knowledge order which is different from that in which they would have been understood within their own cultural context. This is not necessarily harmful, except when labels incorporate pejorative descriptions, but it is not neutral. The professional principles which guide the disciplines provide the solution here by encouraging professionals to seek balance in collections, integrity in arrangement, objectivity in description, equity in access. By interrogating practices in the light of the issues relating to Indigenous peoples in dialogue with Indigenous authority, professional librarians and archivists will identify deficiencies, rectification of which will improve practice. 
The professionals do not, however, have the capacity to do this alone. It can only be done in consultation with Indigenous peoples, by generating a productive dialogue between different knowledge systems, between professional principles and practice and Indigenous perspective and authority. This is where the aspects of the Protocols to which Alana Garwood-Houng draws particular attention are of greatest importance. Without the involvement of Indigenous peoples in governance, management, policy development and day-to-day employment, it is very difficult to engage productively with these complex issues in sufficient depth to address them properly in a continuing dialogue. Far from viewing this as an imposition, librarians and archivists should welcome these challenges which go to the heart of their practice, demanding a rigorous intellectual interrogation which will both strengthen their methods and return real benefits for Indigenous peoples. In so doing, it will contribute mightily to the process of rapprochement which is so vital to communities composed of Indigenous and non-Indigenous peoples.

\section{Notes}

1 See, for example, Clendinnen's account of the early contacts around the British settlement in I Clendinnen Sydney: Dancing with Strangers Melbourne Text 2003

$2 \quad$ IFLA and UNESCO Public Library Manifesto The Hague IFLA 1994

3 A Byrne A Garwood H Moorcroft and A Barnes, Aboriginal and Torres Strait Islander Protocols for Libraries, Archives and Information Services Canberra Australian Library and Information Association for ATSILIRN 1994

$4 \quad$ C Geertz Local Knowledge New York Basic Books 1983 p167 